\title{
Facilities Management for Students and Practitioners
}

\author{
Jensen, Per Anker
}

Publication date:

2008

Document Version

Publisher's PDF, also known as Version of record

Link back to DTU Orbit

Citation (APA):

Jensen, P. A. (2008). Facilities Management for Students and Practitioners. (1 ed.) Centre for Facilities Management - Realdania Research.

\section{General rights}

Copyright and moral rights for the publications made accessible in the public portal are retained by the authors and/or other copyright owners and it is a condition of accessing publications that users recognise and abide by the legal requirements associated with these rights.

- Users may download and print one copy of any publication from the public portal for the purpose of private study or research.

- You may not further distribute the material or use it for any profit-making activity or commercial gain

- You may freely distribute the URL identifying the publication in the public portal

If you believe that this document breaches copyright please contact us providing details, and we will remove access to the work immediately and investigate your claim. 


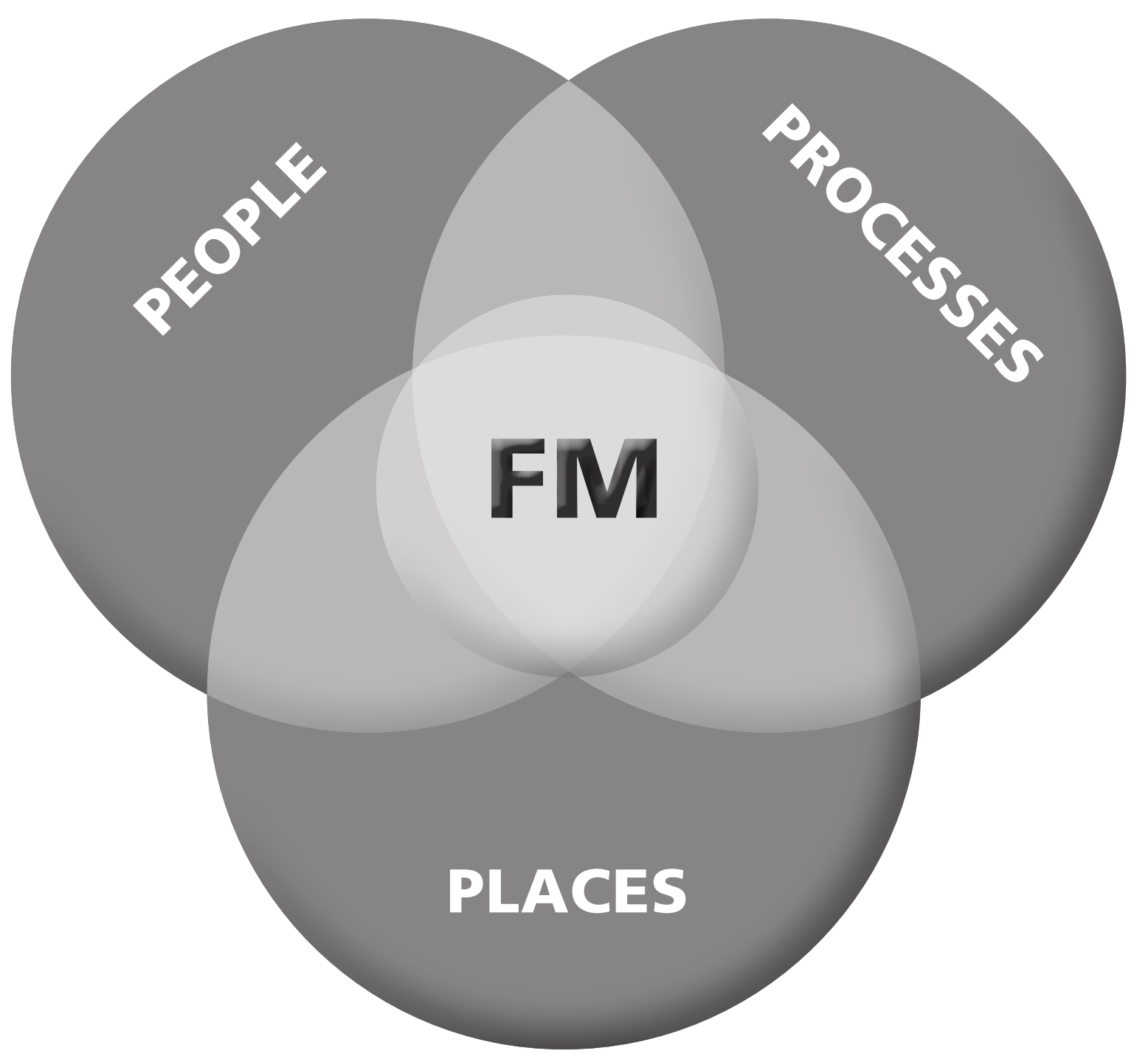

\section{FACILITIES MANAGEMENT FOR STUDENTS AND PRACTITIONERS}


Facilities Management for Students and Practitioners

C Per Anker Jensen

$1^{\text {st }}$ edition

Published

2008

Language

English

Translation

Lena Boye, www.boylenvikar.dk

ISBN

978-87-90855-14-7

\section{Layout}

Prinfoparitas A/S

Tryk

Prinfoparitas A/S

\section{Publisher}

Centre for Facilities Management - Realdania Research

DTU Management Engineering, Technical University of Denmark

Reprint

Permitted in extract, but only with the source reference:

Per Anker Jensen: Facilities Management for Students and Practitioners.

Centre for Facilities Management - Realdania Research.

DTU Management Engineering,Technical University of Denmark.

2008 


\section{List of content}

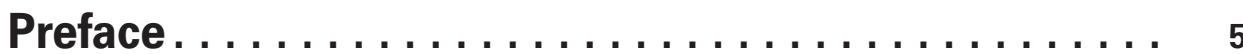

Introduction $\ldots \ldots \ldots \ldots \ldots \ldots \ldots \ldots \ldots \ldots \ldots$

1. Introduction to $\mathrm{FM} \ldots \ldots \ldots \ldots \ldots \ldots \ldots \ldots \ldots$. 9

Definition of FM $\bullet$ The Development of FM as Field of Work

The Development of FM as a Discipline • Characteristic FM Tools • The FM Market

Aspects of FM of Significance in the Nordic Countries

2. Management and Organisation

FM and the Company Organisation • Outsourcing $\bullet$ Quality Management of Services

Qualifications and Development of the FM Function

3. Financial Management

FM in the Company's General Financial System • Internal Rent

Financial Management in the FM Function • Benchmarking and Key Indicators

4. Strategic Planning

Property Strategies $\bullet$ Adaptation of the Property Portfolio for the Organisation Investment Analysis and Life Cycle Cost $\bullet$ The Building Client Function Maintenance Strategies • Building Investment and Maintenance Planning Building Assessment and Classification • Risk Management

5. Space Management

Spaces $\bullet$ Adaptation between the Physical Frames and the Organisation Workplace Design

6. Property Operation.

Maintenance $\bullet$ Utilities $\bullet$ Cleaning $\bullet$ General Operation

Fixed Property Expensess

7. Services.

Guarding and Security $\bullet$ Reception and Telephone Exchange • Post Service

Data Infrastructure $\bullet$ Catering $\bullet$ Other Services

8. IT and Telecommunication.

ICT as a Field within FM • IT based FM Tools Intelligent Buildings

9. Environment and Health \& Safety

Construction and Environment $\bullet$ Environmental and Energy Management

Indoor Climate $\bullet$ Work Involving Computer Screens

10. FM in Denmark and Internationally

FM in Denmark • FM Internationally $\bullet$ Research in FM $\bullet$ FM in the Future

Terms and Definitions . . . . . . . . . . . . 195

Index ............................ 207 


\section{Preface}

This book is intended as a textbook for students and a reference book for practitioners within the field of Facilities Management (FM). The ambition with the book is to provide a coherent and comprehensive introduction to FM. The book provides a status of best practice in FM with particular focus on the situation in Denmark and the other Nordic countries - Norway, Sweden, Finland and Iceland. It defines the terminology in FM based on the new European standards, presents relevant theory, methods and tools, and covers all the main disciplines in FM like organisation, financial management, strategic planning, space management, property operation, services, ICT and sustainability with the main focus on strategic and tactical levels of management.

I - the author - am associate professor at the Technical University of Denmark (DTU). The book is based on my many years of practical experience, active participation in the development in FM, and since 2005 on my research and teaching at DTU. The practical experience included 14 years in Danish Broadcasting Corporation (DR) as project manager, facilities manager and deputy director in the client organisation of a huge building project for a new media centre. The participation in the development of FM includes activities in the Danish Facilities Management Association (DFM), the Danish FM Benchmarking Association (DFM-benchmarking), the Nordic FM network (NordicFM), the European FM network (EuroFM) and the European FM standardisation (CEN/TC348). The research has included a number of projects in Denmark, chairman of EuroFM's Research Network Group with participation in several international projects as well as preparing and from 2008 managing the Centre for Facilities Management - Realdania Research at DTU established with financial support from the private Danish foundation Realdania. The teaching has included courses for engineering students at bachelor and master level as well as postgraduate master student at DTU and various continuing education courses.

The book will be used in DTU's teaching of students in civil engineering and other building related engineering students at bachelor and master levels, but it can also be used for teaching students at other institutions and of candidates and practitioners participating in continuing education. The practical orientation together with detailed lists of content for each chapter and the index also make it suitable as a reference book for practitioners.

In 2007 all courses for engineering students at DTU started to be taught in English in stead of Danish. This created the need for a textbook in English. The former Danish textbook - "Handbook in Facilities Management" (translation of the Danish title) - was written by me and originally published by DFM at the association's 10 years anniversary in 2001 with a second edition in 2006. The present book is a translated and updated version of the Danish book. The translation and publication of the book is supported by Realdania via the Centre for Faciltities Management - Realdania Research.

I would like to thank all the people who have helped to make the publication of the book possible.

Comments on the book and information about eventual mistakes are very welcome. Please send by e-mail to pje@byg.dtu.dk. Thereby the book can be improved to the benefit of new readers if new editions are produced.

Per Anker Jensen 


\section{Introduction}

This book in Facilities Management has been prepared to give an introduction to this relatively new professional subject and field of work. The term Facilities Management - in the following abbreviated by $\boldsymbol{F} \boldsymbol{M}$ - began to be used in Denmark around 1990 as a general concept covering the management of estate operation and service functions in corporations, see the figure below. The concept was first introduced i USA in the 1970's, and from then on FM was gradually disseminated as a term for a specific field of work. Via multinational companies the concept was introduced in Europe - first in Great Britain and the Netherlands - and the rest of the world.

Facilities Management and the Company

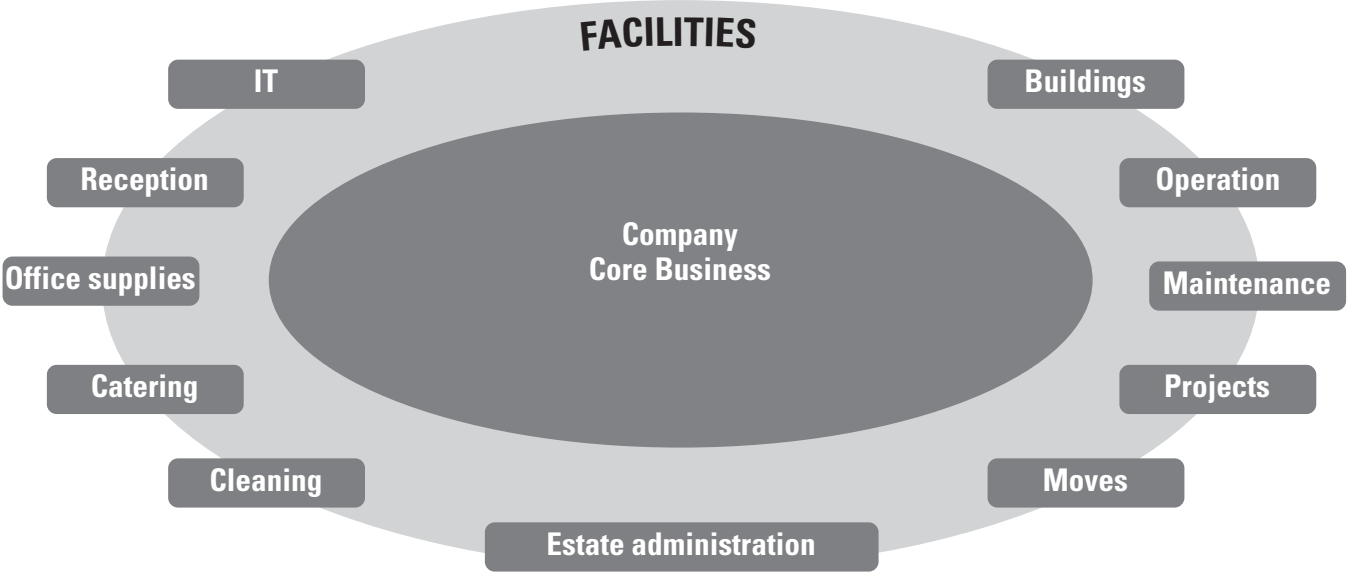

Danish Facilities Management Association (DFM) was founded in 1991 on the initiative of a number of persons from some of the largest private and public property owners in Denmark. DFM is still today the only forum for FM professionals in Denmark. The association had in 2007 almost 200 members, out of which 132 were companies and the remaining were personal members and students. The purpose of DFM is:

- to develop the professional subject Facilities Management

- to make the subject widely known by disseminating knowledge

- to improve the interrelations between practice, education and research

- to be the connection to Facilities Management internationally.

One of DFM's most ambitious and successful activities concerns key figures for estate operation. This activity was started as a project in 1992 and one result was the publication: "Key Indicators for Estate Operation - as a tool for Benchmarking" (translation of Danish title) in 1995. The publication presented the first key indicators concerning the year 1992 together with descriptions of the purpose, definitions and methods for collecting the data and using the key indicators in benchmarking. The activities with key indicators and benchmarking continued in a separate association, DFM-benchmarking, which since 1996 has carried out annual collections and analyses of key indicators on estate operation and services to the benefit of the members of DFM-benchmarking.

The above mentioned publication also included the first coherent introduction to FM in Danish and has had great importance in making FM known and widely accepted in Denmark. It was followed up by the publication of a "Handbook in Facilities Management" in 2001 - also in Danish but with a broader and more thorough introduction to FM. The present book is a translated and updated version of the handbook in Danish. 
There are off course already a number of textbooks on FM in English. However, the experiences with the Danish handbook have been very positive. It has been sold and used for teaching not only in Denmark but also in other Nordic countries, and the second edition from 2006 is nearly out of stock. There seems to be a need for a textbook in English written from a Scandinavian perspective. The reason for this is that the development and understanding of FM varies from country to country due to differences in company structures, culture, education etc. This book put special emphasis on aspects of FM of particular importance in Denmark and the other Nordic countries.

The book is not only intended as a textbook to give the reader an introduction to FM once and for all, but it also aims to be used as a reference book - a daily tool for Facilities Managers to be used recurrently. In order to fulfill this, the individual chapters have been prepared to be read independently of each other.

The book is structured with Introduction to FM in chapter 1. Following this the general managerial aspects of FM are described, respectively Management and Organisation in chapter 2 and Financial Management in chapter 3.

The more specific professional aspects of FM at strategic level are dealt with under the headline Strategic Planning in chapter 4, while similar professional aspects on tactical level are dealt with under the headline Space Management in chapter 5. The professional aspects on operational level are described in two chapters, Property Operation in chapter 6 and Services in chapter 7.

The following two chapters deal with general issues, that are not specific to FM but still of immense importance for FM. That is IT and Communication Technology in chapter 8 and Environment and Health and Safety in chapter 9. The last chapter deals with the development of professional associations in FM in Denmark and Internationally in chapter 10, and the chapter finishes with some suggestions on the future of FM.

At the front page of each chapter a detailed list of content can be found and each chapter finishes with references to literature and web-sites with recommendations of the most important. Concerning web-sites the situation is very dynamic with rapid changes in the selection, but those included can give access to useful information and links to other web-sites.

Towards the end of the book a list of terms with definitions is included as well as an extensive index.

The book includes a considerable number of short cases. Besides one anonymous case on benchmarking all cases are described with the name of the respective company or source. Due to professional background of the author several cases stems from DR (Danish Broadcasting Corporation) and are to a great extent based on my personal experiences. The intention has been to make the cases appear more authentic and thereby more interesting not being anonymous. It has not been the intention that the cases should express any particularities with the respective companies. A collection with 36 more comprehensive cases of best practice in FM in the Nordic countries has been published by Centre for Facilities Management, DTU in 2008 - both in Danish and English, and these cases are recommended as a supplement to this text- and reference book 


\section{Introduction to FM}

\footnotetext{
Figures:

1.1 The meaning of Facility and Facilities in dictionaries from different years . . . . . 11

1.2 FM and the core business ..........11

1.3 FM in relation to the main elements of the company.

1.4 FM function, FM provisions and the core business

1.5 The partners of the FM function. . . . . . 13

1.6 The FM tasks in a larger company ......13

1.7 Factors which stimulate FM . . . . . . . . 14

1.8 The share of the FM costs in a typical office based company ......... 15

1.9 The office workplace...............16

Cases:

1.a Outsourcing of FM in IBM $\ldots \ldots \ldots \ldots 12$

1.b IFMA's Code of Ethics ............. 18
}

Definition of FM . . . . . . . . . . . . . . . . . . . . 10

The Development of FM as Field of Work . . . . . . 14

- The transition from industrial society to information society. . 14

- The office as a mass workplace . . . . . . . . . . . . . . . . . . 14

- Industrialisation of the building industry. . . . . . . . . . . . . . 14

- The energy crisis and the green wave . . . . . . . . . . . . . 15

- Global competition ... . . . . . . . . . . . . . . . . . . . . . . 15

- The information technology . . . . . . . . . . . . . . . . . . 15

- The increasing economical importance of FM functions . . . . . 16

- Increased demands to the office environment ........... 16

The Development of FM as a Discipline . . . . . . 16

Characteristic FM Tools ..................... 17

- Organisational tools, cf. chapter $2 \ldots . . . \ldots . . . . . . .20$

- Financial management tools, cf. chapter 3. . . . . . . . . . . . . 20

- Strategic planning tools, cf. chapter 4 . . . . . . . . . . . . . . 20

- Space Management tools, cf. chapter 5. . . . . . . . . . . . . 20

- IT tools, cf. chapter 8 . . . . . . . . . . . . . . . . . . . . . . . . 21

- Environmental and health \& safety, cf. chapter 9. . . . . . . . 21

The FM Market . . . . . . . . . . . . . . . . . . 21

Aspects of FM of Significance in the

Nordic Countries .................... 22

References. . . . . . . . . . . . . . . . 24 
$F M=$

Facilities Manage-

ment or Facility

Management
Primary and secondary production

\section{Facilities Management or Facility Manage-} ment - two different things or the same. The first term is mainly used in England and some other countries in Europe, including Denmark, and the second term is mainly used in USA. However, there does not seem to be any intended differences as regards to content of the two terms. In the European FM standard on terms and definition is it specified, that the terms are synonyms (EN15221-1, 2006). FM is used as common international abbreviation regardless of spelling.

The term FM is used internationally even in many non-English speaking countries. A direct translation is difficult in many languages, and no national term has found common use, for instance in Denmark. In the other Nordic countries they also use the Anglo-Saxon terms for FM, although they often unlike in Denmark insert new linguistic terms as match for new international terms. The same concerns the German language area, in Japan and even in France!

A complication as to the term $\mathbf{F M}$ is that it is used with various meanings. Hence there are many examples that service providers try to limit the term to some services, which the company in question delivers. In particular it is emphasized that FM in the IT industry is used as external operation of a company's IT-systems referred to as IT FM in chapter 8. As you will realise from the following FM has in this book a far wider meaning.

This chapter provides a general introduction to FM. The term FM is defined in section 1.1. A main view in this book is that FM includes a field of work, a discipline and a market. In section 1.2 the basis for development of FM as a field of work is described. Similar to this FM is described as a discipline in section 1.3, whereas some important FM tools are referred to in section 1.4. The market for FM in Denmark is shown in section 1.5, and FM conditions of special importance in Denmark are described in section 1.6. The chapter is completed with references.

\subsection{Definition of FM}

There are various formulations of FM definitions. In the European standard FM is defined as:
"Facilities Management is the integration of processes in an organisation to maintain and develop the agreed services, which support and improve the effectiveness of the primary processes"(EN15221-1, 2006).

This definition has been adopted by most European FM associations.

The meaning of the terms Facility and Facilities in various dictionaries from different years are shown in figure 1.1. It shows that the singular form used to mostly had to do with human abilities, while the plural form mostly had to do with physical artefacts. The common feature was that they serve a purpose and make things easier. In the recent dictionary from 2002 the difference in meaning between singular and plural has disappeared but the duality with a combination of human abilities and physical artefacts prevails.

These meanings of the terms facility and facilities are in accordance with the definition of FM being related to delivering services to an organisation. The distinction between primary processes and support processes is central to FM. A conceptual management model is included in annex A to the standard, which explains that FM is supply of facility services to support the demand of the primary activities in an organisation. The services can be provided internal and/or external. The interaction between FM and the organisation responsible for the primary processes takes place on strategic, tactical and operational level. The representative of the organisation on strategic level is called the client, while the representative on the tactical level is called the customer, and the end users receives the services on operational level.

Hence it is characteristic that FM is based on a certain way of considering a company, in which there are differentiated between primary production or core business and secondary production or support business, cf. figure 1.2.

Hence FM is evidently defined as secondary production or support business which cannot be considered in isolation, but must be considered in connection with the primary business or the core functions which are supported. 


\begin{tabular}{|l|l|l|l|}
\hline & $\begin{array}{l}\text { Webster's New World Dic- } \\
\text { tionary Compact Edition, } \\
\text { New York 1972 }\end{array}$ & $\begin{array}{l}\text { The Concise Oxford Dic- } \\
\text { tionary } \\
\text { 9th edition, } \\
\text { London, 1996 }\end{array}$ & $\begin{array}{l}\text { The Concise Oxford Dic- } \\
\text { tionary } \\
\text { 10th edition, } \\
\text { London, 2002 }\end{array}$ \\
\hline Facility & $\begin{array}{l}\text { Absence of difficulty } \\
\text { A ready ability, skill }\end{array}$ & $\begin{array}{l}\text { Ease, absence of difficulty } \\
\text { Dexterity, aptitude (of } \\
\text { expression) } \\
\text { A plant, installation or estab- } \\
\text { lishment }\end{array}$ & $\begin{array}{l}\text { A building, a service, or a } \\
\text { piece of equipment provided } \\
\text { for a particular purpose } \\
\text { Absence of difficulty or } \\
\text { effort }\end{array}$ \\
\hline $\begin{array}{l}\text { Facili- } \\
\text { ties }\end{array}$ & $\begin{array}{l}\text { The means by which some- } \\
\text { thing can be easily done } \\
\text { Conveniences }\end{array}$ & $\begin{array}{l}\text { An opportunity, the equip- } \\
\text { ment, the resources to do } \\
\text { something }\end{array}$ & (Plural of facility) \\
\hline
\end{tabular}

Figure 1.1

The meaning of Facility and Facilities in dictionaries from different years

The American based International Facility Management Association (IFMA) has the following definition of FM:

"Facility management is a profession that encompasses multiple disciplines to ensure functionality of the built environment by integrating people, place, process and technology."

Based on this definition FM can be seen as an integration of the three P's: People, Places and Processes as shown in figure 1.3.

The tasks of FM on strategic, tactical and operational levels can be described as follows:

- Strategic tasks have a long-term nature and relate to policies and strategies for development of the property portfolio and support functions in relation to the overall strategies and objectives of a corporation and structural changes in the surroundings.

- Tactical tasks include planning of specific changes in the property portfolio and support functions, partly to meet the long-term policies and strategies, partly with a view to adaptation to other changes within the corporation, for instance related to the current state of the market.

- Operational tasks include the daily operation of properties and support functions with a view to fulfil the needs of the corporation in the best way according to agreed service levels.

In spite of the fact that FM in principle concerns all functions outside the core business, the corporation's property portfolio is of such essential importance, both as to cost and to the function of the corporation, that is has an inherent strategic position.

Concurrently with the increasing use of external providers to manage FM services there is a need

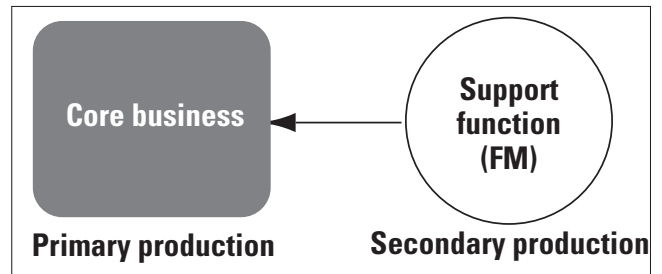

Figure 1.2

FM and the core business

to make a distinction between on one hand the FM function which must ensure the continuous coordination and adaptation of the FM services in relation to the development of the corporation, and on the other hand provision of FM services. This distinction is shown in figure 1.4.

It is mainly the company's operational tasks which are the target of so-called outsourcing.

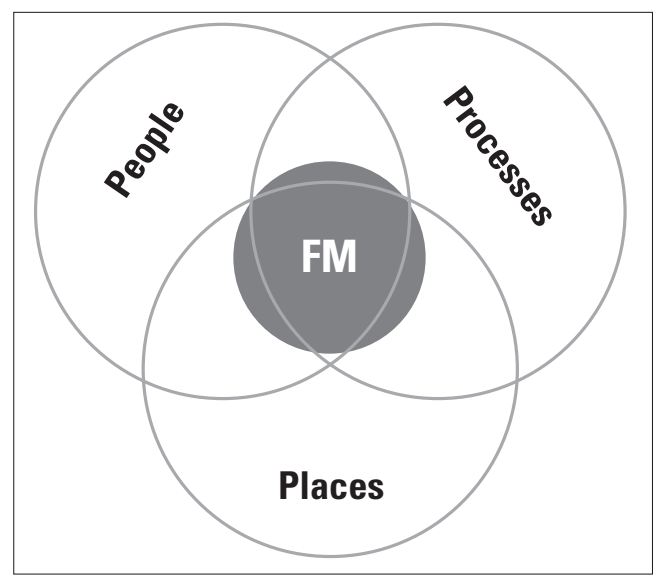

Figure 1.3

$F M$ in relation to the main elements of the company

Figure 1.4

FM function, FM probusiness (source: Andreas van Wagenberg, CFM Netherlands)

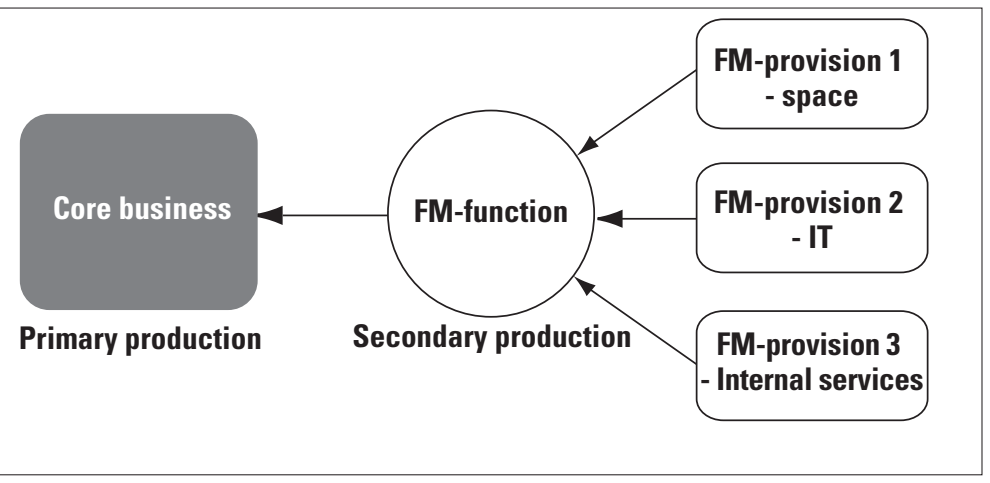
visions and the core 


\section{Case 1.a: Outsourcing of FM in IBM}

Source: Jørgen K. Jakobsen, former Nordic Facility Manager in IBM Danmark A/S

In 1996 IBM Denmark carried out a rather comprehensive outsourcing of FM to the company Johnson Controls. This was part of a worldwide strategy to IBM, which for instance included establishment of an international line organisation, cooperation with pan-European providers and outsourcing of non-core business.

At the outsourcing Johnson Controls took over $100 \%$ of the following services:

- Building maintenance

- Cleaning

- Gardening

- Receptions

- Post

- Telephone exchange (later on transferred by the IBM centre in Ireland covering all Europe)

- Printing

- Conference rooms and tele-conference centre

- Office supplies

- Energy programme

- Administration af internal computer equipment (later on transferred to IBM for handling through a common European data system situated in Germany)

- Shared activities

As to the following areas Johnson Controls took over the daily operation while the ownership of contracts stayed with IBM:

- Canteens

- Photocopiers

- Security

The following services were continuously handled by IBM:

- Overall space strategy

- General space allocation for departments (later on transferred to Johnson Controls)

- Rent administration and payments

- Energy payments

IBM's expectations in connection with the outsourcing were the following:

- A reduction of the total costs for FM

- A reduction of general administration

- Handling and payment of invoices

- $\quad$ Staff administration

- Administration and negotiation of provider contracts

- More knowhow because FM is now part of an organisation which has FM a the core function

- A more obviously defined communication between each IBM employee and FM

The economic goals of the outsourcing were a cost reduction of $20 \%$ to the services in question. In spite of the size of the outsourcing it only included $35 \%$ of the total budget in IBM Danmark's FM-function. The contract between IBM and Johnson Controls is described in Case 2.b in chapter 2. 
These tasks include mainly routine operational functions which have a relatively static nature. The strategic and tactical tasks are to a greater extent dependent on the actual development within the company; hence they are more difficult to define precisely. An example of outsourcing is shown in Case 1.a.

Compared to outsourcing it is not unusual to consider FM as an area where the main focus is on cost minimisation. This may in specific situations, in which large savings are achieved through outsourcing, be correct on a short term. As a consequence of the relatively new nature of the area there may be gained large profits. Seen in a larger perspective this must to a great extent be considered as circumstances determined by the state of the economy.

Many companies have in the 1980'ies and the 1990 'ies been squeezed, and in which large changes and cost savings have been necessary to ensure survival. This especially concerns former public owned businesses which have been privatised and companies involved in global competition. In other situations FM will play a more important role as to creating qualitative improvements in the companies - for instance to attract and sustain employees during situations with lack of manpower.

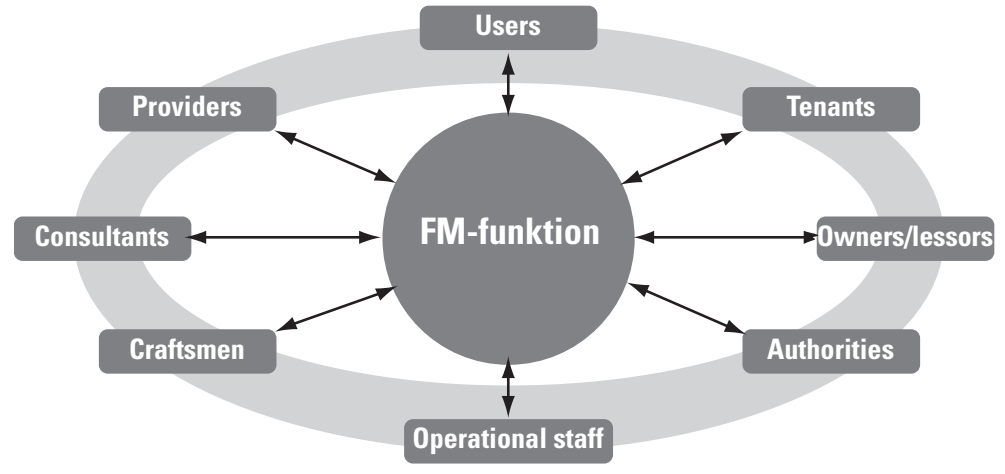

Figure 1.5

Regardless of the amount of outsourcing it is however characteristic that the FM-function has many partners, both internal in the company and external. In many ways the FM-function acts as a mediator between on one hand the company's general management and the staff, and on the other hand external parties such as authorities, lessors, consultants, craftsmen and providers. This is shown in figure 1.5 .

The partners of the FM function

The tasks included in FM are extensive, but they vary depending on size and type of company. In figure 1.6 is shown an example of the range of the FM-tasks in a larger company.

In some companies some of these tasks will have no importance or will not exist. Accordingly the organisation of the tasks will vary much
Figure 1.6

The FM tasks in a larger company

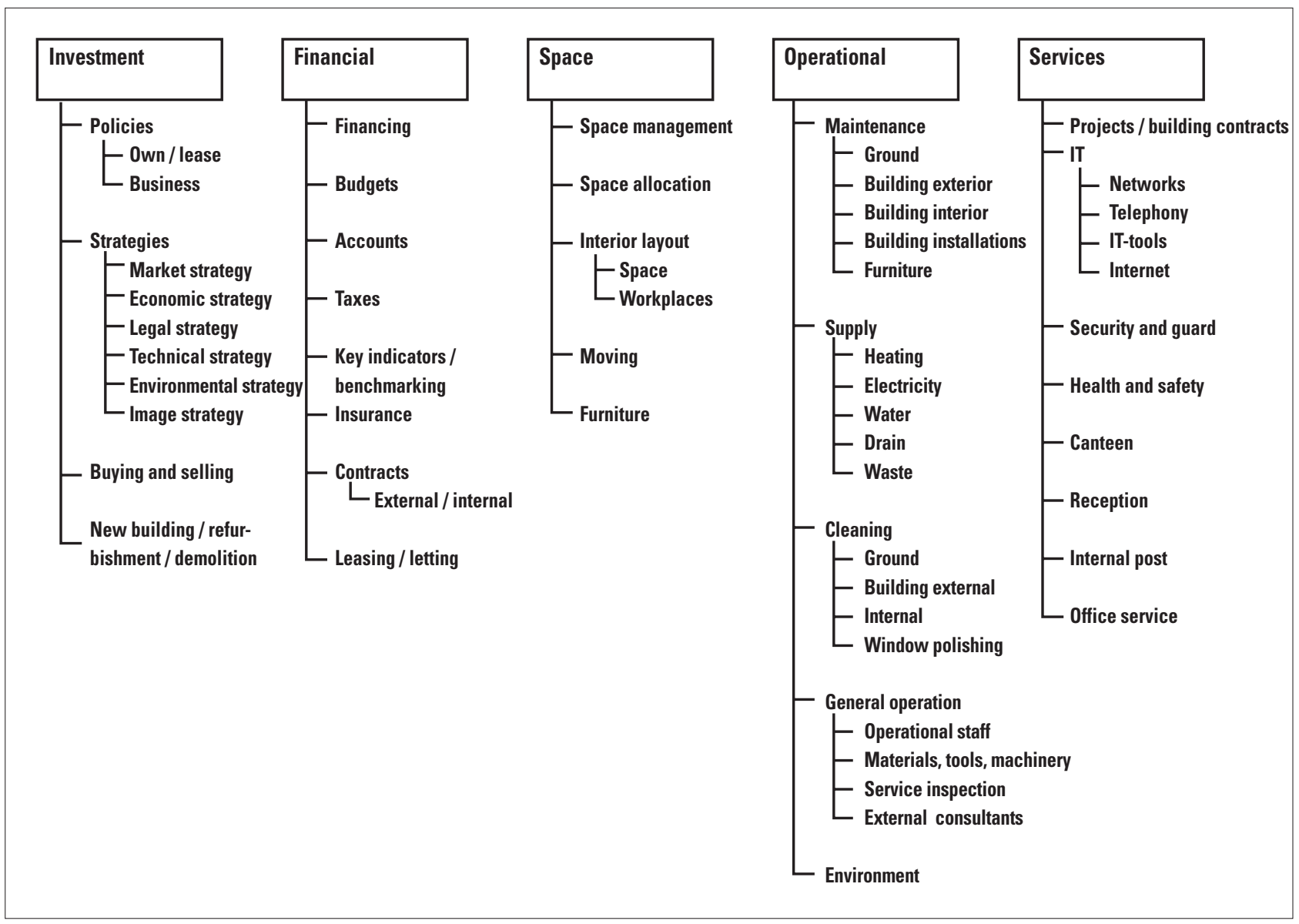


Companies with

defined core functions from company to company. It is mainly companies in which an internal process of defining and limiting the core functions of the company has taken place that the FM tasks are considered and organised consistently.

\subsection{The Development of FM as a Field of Work}

A series of various factors have influenced that FM has emerged as a specific field of work and that this field of work has become increasingly important. Some of these factors are shown in figure 1.7. In the following these and other factors will be described in a wider context.

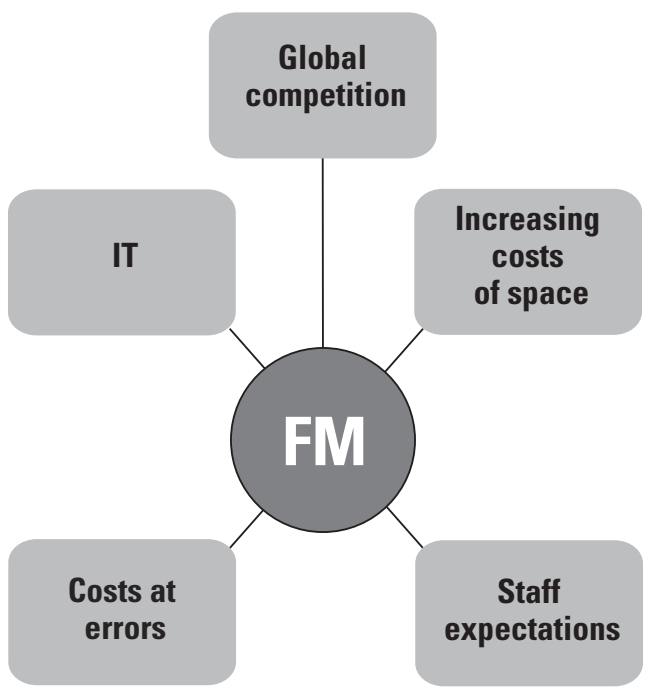

\section{The transition from industrial society to information society}

In the industrial society the factory building was the setting of the main activities. The operation of the factory buildings were closely connected to the demands which the production activities made, and it was often managed by the same persons who handled the production management. Concurrently with the increasing automation of the industrial production the number of employees in the physical production process was gradually reduced. In return a gradual increase in the number of employees in for instance development, sales and economy departments took place with office workplaces in administration buildings et cetera. Concurrently a large number of new service companies emerged, for instance within finance, marketing, consulting, media et cetera, where the work mainly was office based.

\section{The office as a mass workplace}

With the transition to the information society, office work changed from including a few trusted employees to include mass workplaces. With the increase of the office work the need for internal support functions also increased, such as reception, telephone exchange, mail distribution, printing, cleaning and supply of equipment and office supply. The property operation became more independent in relation to the activities in the building than at the industrial production.

\section{The growth and stagnation of the wel- fare society}

Concurrently with the above mentioned development, which in Denmark mainly occurred in the $1960^{\prime}$ ies and the 1970'ies, an increase in the public administration took place concurrently with the development of the welfare society, just as the areas of education, the social sector and the health sector also expanded heavily. In all areas the development entailed a heavy growth of the number of buildings to accommodate all new functions and workplaces.

With the many new administration and institution buildings followed costs for property operation and support functions. After the 1970'ies the growth has changed into stagnation and pressure on the budgets to keep the tax burden down. Hence there is an increased focus on the possibilities to cut down on property operation and support functions to continuously be able to meet the demands to the core functions. Outsourcing of support functions has been one of the most frequently used means, and this development has been increased by the legislation, both in the EU and in Denmark.

\section{Industrialisation of the building industry} Throughout the 1960'ies the building industry became partly industrialised with the implementation of new ways of construction and a great variety of new materials. This development focused on quantity more than quality, and the long-term operational considerations were mostly ignored. The high growth of the number of buildings in itself implied that more people were involved into the property operation. The increased problems with many buildings due to construction errors and bad quality implied increased demands to the qualifications of the persons who were involved in the property management. 
The energy crisis and the green wave With the energy crisis in the 1970'ies a rude awakening took place in connection with the galloping growth of production and consumption. The demands to the construction industry as to the heat insulation were much tightened up, and the awareness of the use of resources in connection with production, new building and building operation were slowly increased. At first this involved the energy area, but for instance the Brundtland report's emphasis on the need of a sustainable development has pushed the "green wave" with a more wide environmental perspective.

With implementation of an environmentally friendly design in connection with new building and environmental management, energy management and green accounts within many companies, environmental considerations have become part of everyday life in many companies, and today it represents a significant element of FM.

\section{Global competition}

The increasing globalisation, which for instance is driven by new world trade agreements, strongly increased and fast international capital movements supported by new communication technologies and larger size and distribution of multinational companies, has implied that many companies witness a higher level of competition.

In Europe the disintegration of the borders between Eastern and Western Europe, and also implementation of EU's internal market has increased this development. The answer to this challenge has from many management gurus and company managers been to concentrate on the core business of the companies, and to reduce or outsource the secondary functions.

\section{The development of the information technology}

The most important thing in connection with the changes in office work and the development of FM is undoubtedly the information technology (IT). Even if the IT development has a long story - the first punched card machines was for instance introduced in the 1950' ies - it is during the last 20-25 years that IT really has led to heavy and fundamental changes of the office work. Today the computer is taken as granted as a tool for everybody, but only 25 years back it was in most offices primarily secretaries and a few other employees who worked at computer terminals.
Initially the computer was mostly a replacement for the typewriter for text processing and was also used to search for data on a few central databases, but after the introduction of the internet the computer has become a highly efficient work and communication tool in practically all office based workplaces, and the home office has become a common alternative, or perhaps rather a supplement to many. And with the constant improvements of the mobile systems the fixation of the information work to the office as a physical workplace has been significantly reduced.

The consequences of the IT development are many-sided and of crucial importance to most companies. Under the headline Business Process Reengineering (BPR), c.f. chapter 2, many companies have reorganised their work processes, and this has to a great extent occured on the basis of the new possibilities which the IT development implies. A central part of BPR is definition of the company core business, hence also the FM functions.

In relation to the office work, introduction of new ways of working, c.f. chapter 5, has accordingly been based on the possibilities which the IT development offers. Economically the IT development implies that the investments in establishment of office workplaces are higher than before, but IT also gives great possibilities to streamline and rationalise the office work. In both cases it gives FM an important role as to the development of the company. Furthermore the IT development offers a series of useful tools to FM.

\section{The increased economical importance of FM functions}

Most of the conditions which are described above have helped to give the FM functions an
The Brundtland report about sustainable development

Business Process Reengineering (BPR)

Introduction of new ways of working

\section{口}

The companies increasingly concentrate on the core functions.

Figure 1.8

The share of the FM costs in a typical office based company

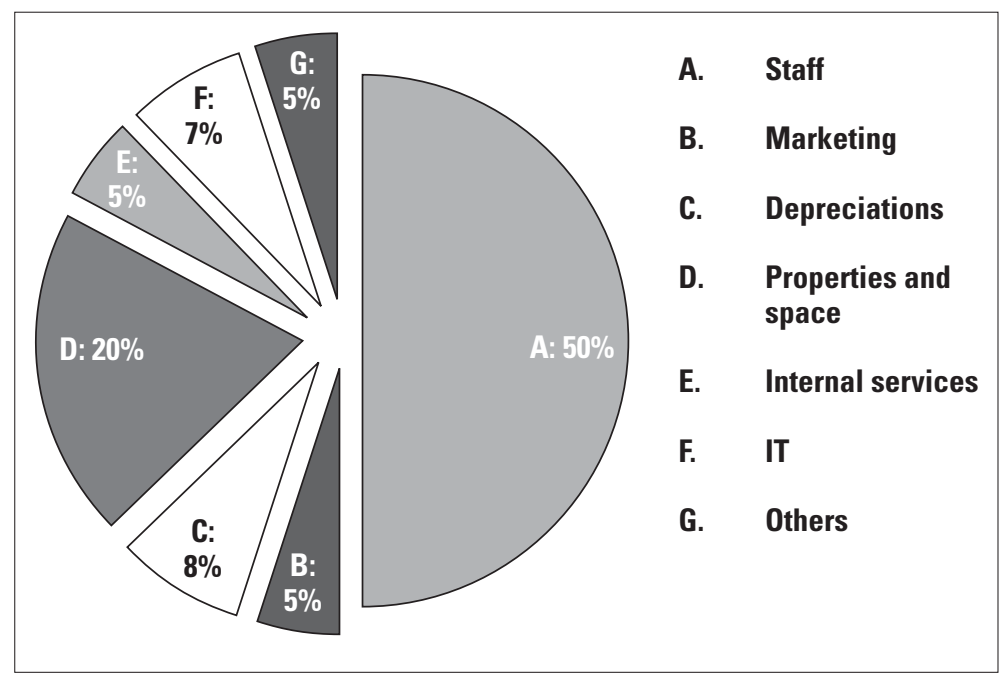


increased importance as to work and economy. Next to staff salary the FM costs are the highest expenditure in many companies. The FM costs are normally $15-30 \%$ of the companies' total costs. An example of the cost division in a typical office company is shown in figure 1.8 .

\section{Increased demands to the office environment}

As the office has become a mass workplace and the increased attention in general on health and safety, the office environment has become an object to increased demands. This especially concerns indoor climate and ergonomics, where the increased introduction of IT has caused increased heat strain, screen radiation and FM as a management discipline

Figure 1.9

The office workplace changed work postures. But also not specific work related conditions such as sport facilities and child care centre connected to the workplace has become of increased importance. In the companies' fight in attracting and maintaining highly qualified manpower such aspects of the FM function are important to the development of the company. In figure 1.9 a number of important conditions in relation to the office workplace are shown. ised by a shared domain. To many disciplines, it is mostly the community as to educational background which along with shared work field define the professional community. However this is not today the case to FM.

In section 1.1 about the definition of FM it was emphasised that the word "facilities" is important to the work field of FM. It was also pointed out in the definition that FM includes integration of facilities services in relation to the company's goals. Hence the management aspect in FM is accentuated. If one considers FM as a discipline, the managerial part has a special importance. Hence FM is often regarded as $\boldsymbol{a}$ management discipline.

\begin{tabular}{|c|c|c|}
\hline $\begin{array}{l}\text { - Furniture } \\
\text { - IT equipment } \\
\text { - Telephony } \\
\text { - Wiring, LAN } \\
\text { - Heating } \\
\text { - Ventilation } \\
\text { - Acoustics } \\
\text { - Lighting } \\
\text { - Windows } \\
\text { - Sun shade }\end{array}$ & $\begin{array}{l}\text { Staff facilities } \\
\begin{array}{r}\text { Type of office } \\
\text { Employee } \\
\text { Wensios }\end{array} \\
\text { Space standards } \\
\text { Planning } \\
\text { Performance } \\
\text { Moving } \\
\text { Refurbishment }\end{array}$ & $\begin{array}{l}\text { - Cleaning } \\
\text { - Maintenance } \\
\text { - Plants } \\
\text { - Art } \\
\text { - Internal post } \\
\text { - Office accessories } \\
\text { - Meeting facilities } \\
\text { - Canteen } \\
\text { - Reception } \\
\text { - Parking et cetera }\end{array}$ \\
\hline
\end{tabular}

\subsection{Development of FM as a Discipline}

In the previous section a number of factors are described, which are important to the fact that FM has developed as a separate work field. It still is a work field which is managed by persons with varied backgrounds as to education

Education can institutionalise a discipline and a profession
In many managerial fields the work is handled by persons with different backgrounds as to officers and personnel officers may have very different backgrounds. The same goes for technical managers, even if it takes a certain amount of technical background, but this can be achieved in various ways. However within these fields of management there are no distinct discipline, even if there within each area is a kind of uniformity in the work field, and also in the knowledge and the methods which are used.

In fact one may on basis of this conclude, that it is rather remarkable that FM has become a discipline, when a community regarding work field, knowledge and methods are not sufficient to constitute a discipline, and FM is not characterised in having a uniform educational background.

The basis for this apparently paradox is that the term from which one may view a discipline is the sociological point of view. A discipline arises when persons within a work field create a community to define the discipline and ensure its development through a kind of institutionalisation of the discipline. Disciplines do not emerge from technological and structural changes in society. Such changes may create the basis for a discipline, but human acting is required to create and develop a discipline.

The establishment of a shared education is an important way of institutionalisation of a discipline. If the education also may be used to monopolise the entrance the discipline through authorisation and/or professional agreements the discipline in question is really strengthened and future-proof. education and occupation. Corporate finance and occupation. However there are obvious indications that FM increasingly also has become a separate discipline. In this chapter a number of characteristics at FM are mentioned, which entitle it to be called a discipline.

What is the difference between a work field and a discipline? A work field is above all character- 
In the FM field there are only limited educations in Denmark, but in spite of this there is, both in Denmark and even more in some other countries a number of tendencies to institutionalise the discipline.

Institutionalisation must be understood broadly as establishment of social structures for the discipline, i.e. apart from actual institutions as for instance education and research institutions, and also associations, networks, knowledge sharing, shared rules, shared events and shared projects. The purpose to the institutionalisation is in general to professionalise the discipline to the benefit for the practitioners in the work field.

The first part of the institutionalisation of FM has been to establish associations. In USA IFMA (International Facility Management Association) was established in 1980 in order to organise personal members from all over the world, and today IFMA has more than 19.000 members in 60 countries. In Europe the first national associations were established in the 1980 'ies in Great Britain and the Netherlands. DFM (Danish Facilities Management Assocation) was established in 1991 and organise both companies and personal members. The common European network EuroFM was established by some national associations - among these DFM - in 1992.

The first European institute to FM was Centre for Facilities Management (CFM) at the University of Strathclyde in Glasgow, also established in 1992.

Since then CFM has been working with both education and research, as the majority of the research tasks are ordered and paid by private companies. In the summer 2000 the British CMF moved to The University of Salford at Manchester. During the 1990 'ies similar institutions was established in other countries, and a number of universities and educational institutions have started up education and research in FM. In Denmark, however, it has had a rather modest extent so far. The recent development has been to establish the research centre CFM (Centre for Facilities Management) at DTU (Technical University of Denmark) with financial support from the private Danish foundation Realdania from 2008-2012.

In order to define and limit the subject area for instance IFMA and the British FM-association BIFM (British Institute of Facilities Management) has drawn up detailed job profiles for FM. Such job profiles may for instance be used to define content of educations and to determine requirements at exams and at certification of members. EuroFM has defined a shared European job profile based on BIFM's job profile. The main elements of this are described in case 2.e in connection with the discussion of FMqualifications in chapter 2 .

Within sociology certain fields are called professions. This especially concerns professions based on higher educations and with relation to liberal professions, where it is emphasised that the professional behaviour is according to specific ethical rules, and with an internal discipline within the profession. The most known example of such ethical rules is the Hippocratic oath, where the compliance in Denmark is supervised by the Medical Council.

At present DFM has not drawn up ethical rules for FM, and it has not been much debated in Denmark. However, IFMA has determined ethical rules, which the members of the association are expected to keep. In case of complaints about a member, IFMA's ethical committee investigate the case, and the committee is able to order sanctions to members who have broken the rules.

The text of IFMA's ethical rules is shown in case 1.b. It is emphasised that the ethical rules, besides demands of common decent behaviour and of being worthy representatives of the FMprofession, also emphasises that the members do not unintended exploit IFMA to promote own commercial interests.

In chapter 10 the Danish and the international development of FM is described more thoroughly along with some suggestions to the future of FM. Further information about international events, periodicals and other publications can be seen on the international homepages, please see the references. In the next section some of the tools which are of special importance to FM will be introduced.

\subsection{Characteristic FM Tools}

Most of the tools used in FM are also used within other work fields. The only unique FMtools are computer based systems targeted to FM-functions with Computer Aided Facilities Management (CAFM) as the most fundamental tool. In this section the most characteristic tools of FM are discussed as part of the general introduction to FM, which is the purpose of this chapter.
Job profile for FM

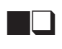

Professionalisation by means of institutionalisation

\section{口}

International

FM-associations

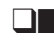

Ethical rules

for professions

\section{FM institutes}

\section{CAFM}




\section{Case 1.b: IFMA's Code of Ethics}

The following presents IFMA's "Code of Ethics", which can be found on IFMA's homepage (http://www.ifma.org/about_ifma/code_ethics.cfm)

\section{Code of Ethics}

Description: Statements concerning behaviors, perceptions, and actions of all members that relate to ethical compliance while acting within all areas of IFMA. This document is a guideline and does not represent the entire breadth of what constitutes good conduct and ethical behavior.

Purpose: To clearly set expectations so individuals will know how to act ethically at all times. The code is designed to foster trust and mutual respect among those working in IFMA and the facility management profession.

Governing Authorities: IFMA's Constitution and Bylaws

Scope:

- This policy covers all volunteer leaders within IFMA. It also covers individual member's behaviors when acting in any capacity of IFMA membership. Individuals applying for and being accepted for membership in IFMA implicitly agree to abide by the rules and regulations that govern the Association, which include these Code of Ethics statements.

- Members are expected to comply with any and all similar standards and ethical guidelines that are prescribed by their employer.

- These statements work in concert with the IFMA Standards of Business Conduct that are focused on the business operation functions within IFMA.

- Member expulsion from IFMA is only approved by the Board of Directors.

Purpose: All IFMA members are expected to comply with the IFMA Code of Ethics. When in doubt, members have the responsibility to seek clarification from IFMA.

\section{Professionalism}

- IFMA members shall treat each other with respect when dealing with matters that could affect their professional reputations. All members shall recognize that the profession will be judged by the conduct of individual members.

- IFMA members shall use IFMA membership as a means of professional development for themselves and not personal aggrandizement.

\section{Confidentiality}

- IFMA members shall not disclose, directly or indirectly, any confidential information relating to IFMA business, staff, or other IFMA members.

- IFMA members shall be encouraged to share (within bounds of confidentiality and proprietary) educational and professional development information to the membership.

- IFMA members shall maintain the highest professional standards and ethical behavior in their Association relationships. This includes, but is not limited to, the use of mail lists, membership information and membership resources, or any calls, contacts or working relationships outside of IFMA. 


\section{Conflicts of Interest}

- Promptly disclose any known conflict of interest to related parties, and use any reasonable means to resolve such conflicts.

- IFMA members shall not buy or sell products or services at IFMA functions, except at trade shows or displays established for that purpose.

\section{Compliance with Laws}

- IFMA members shall not discriminate because of race, sex, creed, age, disability or national origin as it relates to their Association relationships.

- Recognize and discharge my responsibility and that of my Association to uphold all laws and regulations relating to IFMA activities.

\section{Responsibility to the Profession}

- IFMA members shall abide by the Constitution and Bylaws of the Association and shall support the objectives of its strategic plan and show respect in interactions with the interests of the Association.

- IFMA members shall not engage in professional malfeasance, nor shall they make any misrepresentation concerning professional designations authorized by IFMA, nor shall any member misrepresent their educational qualifications, credentials, or working experience.

\section{Protection of Assets}

- Individuals who oversee Association assets shall apply the best available knowledge and techniques to preserve asset value and integrity.

\section{Fair Dealing}

- IFMA members shall endeavor to deal fairly with other members, competitors, vendors, and employees. No member shall take unfair advantage of anyone through manipulation, concealment, misrepresentation or material facts, or any other unfair dealing practice.

\section{Reporting of any Illegal or Unethical Behavior}

- IFMA members are responsible to report the actions of individuals or companies considered contrary to the Code of Ethics to IFMA.

- IFMA shall follow standard procedures for the enforcement of this Code as approved by the IFMA Board of Directors. 


\section{口}

Service Management.

D田

Life Cycle Costing.

Key indicators and benchmarking.
For further descriptions of the various tools, see the subsequent chapters. Hence the tools will be presented in connection with the topics and chapters in which they are described more closely.

\section{Organisational tools, c.f. chapter 2}

As a management discipline FM is under influence of the management philosophy which is called Service Management. This implies for instance a high prioritisation of customer orientation. The personal contact between the service provider's employee and the customer is crucial to the customer's experienced quality of the service. Hence, delegation is a significant organisational tool in FM as in others service trades. This can be shown in many ways, for instance as "learning organisations" and "self managed groups"

Another organisational tool is naturally outsourcing, where the service is moved from being handled by in-house employees to be handled by an external service provider. The employment of the staff is often transferred to the new service provider, cf. case 1.a. As well known outsourcing is not just used in relation to FM, but is also much used and discussed in relation to public services within for instance transportation, education, social services and health services. Outsourcing has emphasized the needs to define the quality of services and Service Level Agreements (SLA) are often used to define the required quality level by the demand side, while Key Performance Indicators (KPI) is often used to measure the quality of the service deliveries from the supply side.

Financial management tools cf. chapter 3 As the FM-functions do not include the core functions of the companies, the general financial systems in the companies are often insufficient to make an efficient financial management. This concerns both private and public companies. Hence it is necessary to establish a supplemental system for financial management of FM. The fundamentally part of such supplemental financial systems is activity based costing. With this as the basis it is possible on a suitable level of detail to use the financial system as an active management tool.

If the financial system is appropriately designed it is furthermore possible to use it to calculate economical FM key indicators, which can be used for benchmarking with other FM-functions. By means of such key indicators it is possible to document the results of the FM-function in a precise way, and a more precise target management of the activities can be made. Members of DFM-benchmarking each year report data about the operation of their properties and have reports with average key indicators of all members spread on properties of different categories, for instance use and age.

A widely used financial management tool in larger companies is establishment of an internal market with settlement of services among the various units of the company. A rather interesting variant in relation to FM is internal rent. This implies that each department pays rent for the spaces, which the department has at its disposal, and for the services attached, for instance cleaning, lighting, heat, ventilation, internal post, telephone and ICT.

\section{Strategic planning tools, cf. chapter 4}

The strategic planning tools in relation to FM mainly concerns preparation of proposals to the development of the property portfolio in relation to the long-term goals and strategies of the company, and also analyses of advantages and disadvantages at such proposals. A significant tool at such tasks is investment analyses.

In such analyses are not only capital investments and capital conditions such as amortization, repayment and interest included. Also the consequences of the running cost for FM-functions, especially including the building operation, are important factors. In order to make a realistic analysis life cycle costing can be used, where current and expected future costs and earnings are placed on a shared form with the capital cost by discounting the expected future costs and earnings.

Furthermore, risk analyses are an important tool within many areas of FM. This is especially important in relation to a proper risk management, but also in connection with larger construction projects risk analyses may be useful.

\section{Space Management tools, cf. chapter $\mathbf{5}$} Space Management includes tasks in relation to space allocation, rebuilding and redeployment in order to adapt buildings for a changed organisation or the like. The basis for such tasks is the needs of the organisation, the present space utilisation and the possibilities to reorganise in relation to the building. For recording of the present space utilisation and preparation of suggestions for changes in the space allocation $\boldsymbol{C A F M}$-systems are commonly used and indispensable tools. 
Furthermore space standards and space key indicators are used in connection with Space Management, for instance in relation to space utilisation like number of $\mathrm{m}^{2}$ per employee and gross/net ratio.

\section{IT-tools, cf. chapter 8}

As mentioned previously $\boldsymbol{C A F M}$-systems are basic IT-tools for FM. There are a number of other systems to be used with FM, and it is difficult to obtain a clear picture of them as the development is very fast, and there are many different systems.

As a compile term to a number of systems, the term Facilities Management Information systems (FMIS) is used. Where CAFM-systems have a main focus on graphical data, other systems are more broadly oriented with emphasis on management of information, for instance economics, internal settlement, staff, buying and providers. Such systems can be integrated with a CAFM-system and others systems, for instance help desk systems and building maintenance systems.

Environmental and health \& safety tools, cf. chapter 9

Concerning both environment and health \& safety, the activities are heavily influenced by the legislation and other political approaches.

In relation to environment energy labelling is a mandatory tool for the management of the use of energy in all buildings above a certain size. Correlated to this is green accounts mandatory in certain particular environmental hazardous companies, but these tools are also implemented in several other companies, for instance in relation to image, as part of management of the use of resources and the exposure of the surroundings.

In relation to health \& safety, the mandatory work in the safety organisation is at the centre of the efforts. During the recent years the mandatory workplace assessments have to larger companies been an important tool to record and process problems at each type of workplace.

\subsection{The FM Market}

A special aspect of FM is the fact, that the development within work field happens concurrently with a market development, in which, due to the growth of the work field and the increased outsourcing, a number of new provider companies are established. FM professionals are engaged both by the to demand side, i.e. companies with internal FM-functions, and by the supply side, i.e. provider companies and various consultants. The commercial roles are different to the employees depending on the type of company, but the professional content of the work is to a great extent convergent.

The players on the FM-market are very different. There are a number of smaller service companies, which are specialised within a specific field of service with cleaning as the most common. Other service companies have, with the basis of cleaning, developed themselves to handle a wide range of services. ISS is a significant example to this, and it is also the only multinational FM-provider based in Denmark.

Another typical FM-provider is contractors and building companies, who with basis in rebuilding work and building maintenance enter as FM-providers. Correspondingly are installation companies with basis in installation work and installation maintenance. Among such companies there are also tendencies that the companies try to expand there field of work to other parts of FM.

A third kind of FM-providers are property administrators, who traditionally primarily have administered rental properties, but out of which some also have entered the market as FM-providers for other companies.

Along with the increased importance of FM a number of consulting engineering companies and other consultant companies have also focused on getting tasks as consultants for FM. This has to a great extent happened as an expansion of consultant services in relation to building operation and maintenance. IT-systems for the use at FM are offered by many consultants and software companies.

In total the FM providers can be divided into the following 5 types, cf. figure 1.10.

- Providers of single services

- Providers of multi services

- Providers of total FM concepts
FM functions

on demand and

supply side

The players on the FM-market

FM providers 
Figure 1.10

Types of FM-providers

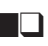

The potential and actual market

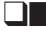

Benchmarking in USA and Europe

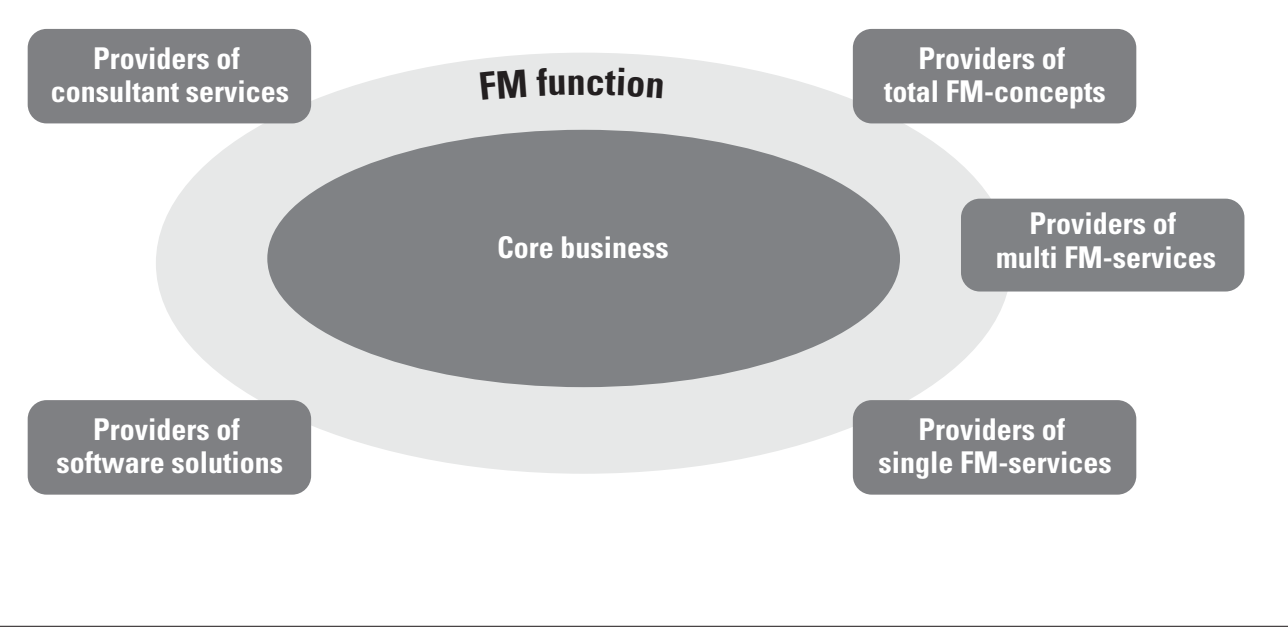

- Providers of software solutions

- Providers of consultant services

The FM market in Denmark and the other Nordic countries has not been researched very much. The most comprehensive investigation was made in 2004 and 2005 (Capgemini, 2005). The results are presented in the book on FM Best Practice in the Nordic Countries (Jensen et al, 2008). The main results are that the potential market in the five Nordic countries was approx. $€ 53$ million in 2004. The market in Sweden was by far the largest with $€ 23$ million followed by $€ 12$ million in Finland, $€ 9$ million in Norway, $€ 8$ million in Denmark and $€ 1$ million in Iceland. The actual outsourced market was $25 \%$ of the potential market. The annual increase in the actual market was estimated as $8 \%$. Compared to some other indications the results about the size of the market in the Nordic countries from Capgemini tend to be conservative.

\subsection{Aspects of FM of Significance in the Nordic Countries}

In the following a number of areas in which FM in Denmark is different from FM abroad are emphasised, and it concerns nuances and relative differences. It also concerns differences of various kind depending on which foreign areas we discuss. Hence there are differences between USA and Europe. Internal in Europe there are differences between Northern Europe and Southern Europe. The most trendsetting countries in Europe are Great Britain and the Netherlands, and there are differences among these countries in relation to the Nordic countries. Among the Nordic countries there are of course also differences, but FM in Denmark is close to FM in the other Nordic countries.
In relation to USA the differences to a great extent have basis in some general cultural differences. The most significant differences are related to the American society's very competitive nature. FM is primarily seen in USA in connection with private companies with one-sided goals of profit maximisation, and of being the best. In Europe public companies have a greater importance within FM, and within private companies the goals are in general more wide, for instance emphasising that the companies are good workplaces and contribute to a positive development of the society.

In relation to benchmarking this difference is very conspicuous. In the American way of FM the main purpose with benchmarking is to measure yourself with "the best in class" to be the best yourselves. In Europe and even more in the Nordic countries the main purpose at benchmarking is more to introduce learning processes, so you can improve your performances, both qualitative and quantitative in relation to the company needs.

Another reason to the differences is that FM in the Nordic countries to a great extent is influenced by persons with backgrounds as architect and engineers, whereas FM in many other countries to a greater extent is influences by persons with background from business schools et cetera. This is due to the fact that many large Danish companies, especially among the public and semi-public companies, have had large building units/administrations/ services which increasingly have got the responsibility to other FM-functions. Another reason is probably the cold and damp climate in Scandinavia, which demands specific technical design and operation of the built facilities, and the engineering profession has in 
general a stronger position in Scandinavia than in many other countries.

This difference has implied that building operation and not at least the technical aspects are of considerable importance within the FM area in Denmark. Hence, it is characteristic that DFM benhcmarking till now primarily have gathered key figures for building operation. The same circumstances have contributed to the rather great importance in Denmark of the energy area and environmental area.

In relation to workplace design the importance of daylight at workplaces has a much greater importance in Scandinavia than in many other countries. This is also shown by the mandatory demands in the building codes and health \& safety regulations. The ergonomic conditions in relation to the workplace design have apparently also a much greater importance in Nordic coun- tries than in many other countries. Although the fundamental EU regulations to design of workplaces with computer screens are alike in all EU countries, there apparently are many differences in how the regulations are put into practice and observed.

Such differences as to workplace design have probably basis in a greater tradition to staff involvement in the Nordic countries. This is correlated to the special democratic tradition in Nordic countries, which also appears from a strong association culture. Hence it is characteristic that the professional development of FM in Denmark to a greater extent is association related than in most other countries. Even if there are FM associations in other countries they are to a greater extent dependent on company sponsors, and development projects are to a greater extent executed by means of consultant companies or by means of institutes.
Strong association culture in Scandinavia 


\section{References}

Below is under literature mentioned some general in introductions to FM, research on FM and other references. The book by Barrett \& Baldry can be recommended as further reading on issues like user needs evaluation, outsourcing, decision making, and change management. The books edited by Nutt \& McLennan and Alexander, Atkin, Bröchner \& Haugen give introductions to research in FM. The book by Jensen et al. is recommended as a practice oriented supplement with 36 cases from the Nordic countries. Under standards you will find the two first European FM standards. The websites include the websites of the FM associations and the Danish research centre mentioned in chapter 1.

\section{Litterature}

Keith Alexander (ed.): Facilities Management - Theory and Practice. E \& FN Spon, London \& New York, 1996.

Keith Alexander, Brian Atkin, Jan Bröchner \& Tore Haugen (ed.): Facilities Management - Innovation and Performance. Spon Press, 2004.

Brian Atkin \& Adrian Brooks: Total Facilities Management. Blackwell Publishing, Second Edition, 2005.

Peter Barrett \& David Baldry: Facilities Management - Towards Best Practice. Blackwell Publishing, Second Edition, 2003.

Franklin Becker: The Total Workplace - Facilities Management and the Elastic Organization. Van Nostrand Reinhold, New York, 1990.

CapGemini: More for less - A Nordic Facilities Management Study 2004/2005. CapGemini, Sweden, 2005

Per Anker Jensen, Kjeld Nielsen \& Susanne Balslev Nielsen: Facilities Management Best Practice in the Nordic Countries - 36 cases. Centre for Facilities Management - Realdania Research, DTU Management, Technical University of Denmark, 2008.

Wes McGregor \& Daanny Shiem-Shin Then: Facilities Management and the Business of Space. Butterworth Heinemann, 2001.

Bev Nutt \& Peter McLennan (ed.): Facilities Management - Risks \& Opportunities. Blackwell Science, 2000.

Alan Park: Facilities Management - An Explanation. Van Nostrand Reinhold, New York, 1990.

\section{European FM standards}

EN15221-1: Facility Management - Part 1: Terms and definitions. CEN, 2006.

EN15221-2: Facility Management - Part 2: Guidance on how to prepare Facility Management agreements. CEN, 2006.

\section{Websites}

CFM (Centre for FM, Technical University of Denmark) ... . www.cfm.dtu.dk

CFM (Centre for FM, University of Salford) . . . . . . . . www.scpm.salford.ac.uk/cfm

DFM (Danish FM Association). . . . . . . . . . . . . www.dfm-net.dk

EuroFM ...........................

IFMA $\ldots \ldots \ldots \ldots \ldots \ldots \ldots \ldots \ldots \ldots \ldots \ldots \ldots \ldots \ldots \ldots \ldots \ldots \ldots \ldots$.ifma.org 


\begin{tabular}{|c|c|}
\hline \multicolumn{2}{|c|}{ Figures } \\
\hline 2.1 & $\begin{array}{l}\text { Advantages and disadvantages of } \\
\text { various organisational solutions ... }\end{array}$ \\
\hline 2.2 & $\begin{array}{l}\text { The FM organisation with } \\
\text { outsourcing of a number of services . . . } 29\end{array}$ \\
\hline 2.3 & $\begin{array}{l}\text { The FM organisation with contracting-out } \\
\text { on a commercial contract ...........31 }\end{array}$ \\
\hline 2.4 & $\begin{array}{l}\text { The FM organisation with contracting-out } \\
\text { on a management agreement. . . . . . . } 31\end{array}$ \\
\hline 2.5 & Comparison of methods . . . . . . . \\
\hline 2.6 & $\begin{array}{l}\text { The development in } \\
\text { customer/provider relations. .........33 }\end{array}$ \\
\hline 2.7 & $\begin{array}{l}\text { The difference between service } \\
\text { and physical products .......... }\end{array}$ \\
\hline 2.8 & $\begin{array}{l}\text { The value creation through the } \\
\text { TQM process. .............. }\end{array}$ \\
\hline \multicolumn{2}{|c|}{ Cases } \\
\hline 2.a & $\begin{array}{l}\text { Organising of FM Functions in Danish } \\
\text { Broadcasting Corporation (DR) ....... } 28\end{array}$ \\
\hline 2.b & $\begin{array}{l}\text { The Contract between IBM and Johnson } \\
\text { Controls about Outsourcing ......... } 30\end{array}$ \\
\hline 2.c & $\begin{array}{l}\text { Partnership Contract between } \\
\text { Rover Group and Drake \& Scull . . . . . } 32\end{array}$ \\
\hline 2.d & EU Procurement of Cleaning in DR ... 36 \\
\hline 2.e & Competence Profile for FM. . \\
\hline $2 . f$ & $\begin{array}{l}\text { Self Managed Groups at Gardening } \\
\text { in Novo Nordic.............. } 42\end{array}$ \\
\hline
\end{tabular}

FM and the Company Organisation ....................... 26

Outsourcing 27

- The legal basis to outsourcing .............................................. 33

- Advantages and disadvantages of

in-house / outsourcing............................................................ 34

- Preconditions to a successful outsourcing ............................... 35

Quality Management of Services............................. 36

Qualifications and Development

of the FM Function................................................... 38

- Job profile and qualifications.............................................. 38

- Service Management.......................................................... 39

- Development of the FM function ........................................... 43

- FM and the value creation in the company ............................ 45

References........................................................ 47 
Position on a high level and impact are important

From cost reduction to value creation
The definition of FM as covering property and service functions, which support the core business of a company, cf. section 1.1, is based on the concept of a typical production or service company. This chapter has the same basis.

However, it is important to notice that there are a number of companies in which FM is the core business of the company. This concerns typically the various types of FM-providers, who were discussed in section 1.5.

To the companies who have specialised in being providers of FM services, FM is obviously the core business of the company. This is the fact no matter it is providers of single services, providers of multi services or providers of total FM concepts. Such companies often use the fact that FM is their core business as an important element in their marketing.

For the providers of software solutions and consultant services these fields are in principle part of the companies' core business. Yet, in many cases FM related services are a smaller special field among a number of various software solutions or consultant services.

In companies in which FM is the core business, FM will often be represented in the very top management of the company. Such a basis gives FM a higher status, and frequently also a position at a higher level in the company's organisation than in other companies, in which FM is a support function. In section 2.1 the position of FM in the company's organisation will be further discussed.

An important organisational tool to FM is outsourcing of services. Outsourcing is the theme of section 2.2, in which a number of terms and organisational models related to outsourcing is shown as well as the legal basis for outsourcing. Advantages and disadvantages in connection with outsourcing are discussed, and concluding the preconditions to a successful outsourcing is described.

There is no doubt that the development with increased outsourcing has contributed to an increased professionalisation of FM - both in FM functions internal in companies, and with FM providers. An element of this professionalisation is increased focus on quality control of FM services. This is discussed in section 2.3.
Others elements of the professionalisation of the FM function are discussed in section 2.4 about qualifications and development of the FM function. It is preceded with a description of job profile and qualifications. Subsequently the management philosophy Service Management is discussed, which with focus on customer orientation and delegation of responsibility has been of great importance to FM. This is succeeded by mention of a number of tools for development of the FM function, and finally the relation between FM and the value creation in the company is discussed.

The chapter is concluded with references.

\subsection{FM and the Company Organisation}

As to other functions within a company it is important to the FM function to have the best possible representation at the highest level in the company. Like other functions the FM function is dependent on the impact of the function on the top management of the company. Each function has some special considerations and arguments, which must be included in a overall company prioritisation, and the more impact the representative of a function has, the more influence the function will have on its own circumstances and on the entire development of the company.

In general the FM function has been rather weakly represented in the top management of most companies. But with the increased importance and the increasing professionalisation of the FM function there is a tendency to a more significant position of FM in the management hierarchy.

If the FM function will be able to develop from primarily to focus on cost reduction and to contribute to a value creation in the company in a convincing way, the FM function will be able to strengthen its position in the company management.

In the traditional functional organised line organisation with chief executives to production, development, sales, technique, economy and staff, FM functions have often been placed or spread under the technical chief executive, the economy chief executive and/or the staff chief executive. To none of these chief execu- 
tives FM is their primary work area, and the FM function has often been seen as a necessary cost, and perhaps even as a necessary evil. On basis of this it is not surprising that FM as a new management discipline primarily has been met with expectations of in itself being able to produce cost reductions.

It is very much the FM function itself who must convince the company management that FM has other things and much more to offer in connection to the development of the company. These possibilities will be present - and in connection with the more frequent reorganisations of companies, such possibilities sometimes will be good - depending on the, at any time, predominant management philosophies in the top of the company. As FM is born from the new generation of management philosophies, FM will have good possibilities to strengthen its position in the management of the companies when some of these management philosophies are observed.

In case 2.a is shown an example of the development of the FM function's organisational conditions in a company.

In connection with relocalisation of a company the strategic FM function will have an exceptional possibility to hold an important role in the development of the company. It can to a certain extent also be the case in connection with Business Process Reengineering - especially when this involves introduction of new ways of working, cf. section 2.4 and 5.3. In these situations there are also obvious possibilities to reorganise the FM function to match the changes of the company's facilities and overall organisation and along with the central role of the FM function in such situations, the possibility to strengthen the FM function's position in the management structure may occur.

To companies with various geographically distributed locations, special conditions exist in relation to the position of FM in the company's organisation. First of all the question is if and to what extent the FM function must be placed centrally or de-centrally. At a mainly de-central position one must consider how to ensure a total overview of the FM function. At a mainly central situation one must consider how to ensure the necessary user contact. A typical solution will be a centrally situated FM function which primarily handle the strategic tasks, and the main part of the tactical tasks, and de-central
FM functions, who primarily handle the operational tasks.

To larger companies there is a similar basis to consider whether the FM function must be situated as a line organisation in the company, or whether the FM function must be separated in an independent organisation - as a profit centre or a separate company. Furthermore, the companies must consider possible outsourcing/outtasking of FM functions. Advantages and disadvantages of these organisational solutions are shown in figure 2.1. Outsourcing/outtasking is further discussed in the next section.

\subsection{Outsourcing}

\section{Terms related to outsourcing}

Outsourcing is without doubt the most discussed and contentious topic with relation to FM. This is not at least related to the public field, where the debate can be highly politicised. At the same time outsourcing is obviously the tool which has led to the highest and fastest direct economically savings. To the creation of a market for FM
FM in line organisation or in independent organisation

The FM function must prove is value
Figure 2.1

Advantages and disadvantages of various organisational solutions

\begin{tabular}{|c|c|}
\hline Advantages & Disadvantages \\
\hline \multicolumn{2}{|l|}{ FM as line organisation } \\
\hline $\begin{array}{l}\text { Profiling of image } \\
\text { Crosswise cooperation } \\
\text { Simple cost distribution } \\
\text { Easy communication lines } \\
\text { Easy management } \\
\text { Thorough knowledge of the } \\
\text { organisation/the production }\end{array}$ & $\begin{array}{l}\text { Not suitable to larger groups } \\
\text { Large staff organisation } \\
\text { Lack of cost awareness }\end{array}$ \\
\hline \multicolumn{2}{|l|}{ FM in independent organisation } \\
\hline $\begin{array}{l}\text { Suitable to larger groups } \\
\text { Economical management of the capital } \\
\text { Cost awareness } \\
\text { Possibilities to administer for other } \\
\text { companies } \\
\text { Economies of scale } \\
\text { Possibility to efficient organisation }\end{array}$ & $\begin{array}{l}\text { More administration } \\
\text { Resources needed for internal invoicing } \\
\text { Control function is needed } \\
\text { Longer communication lines } \\
\text { Reduced internal knowledge }\end{array}$ \\
\hline \multicolumn{2}{|l|}{ Outsourcing/outtasking } \\
\hline $\begin{array}{l}\text { Price competition } \\
\text { Less fixed costs } \\
\text { Easy adaptation of resources } \\
\text { Easy administration }\end{array}$ & $\begin{array}{l}\text { Resources to manage external provider } \\
\text { Necessary to have a control function } \\
\text { Not direct communication with } \\
\text { users/tenants } \\
\text { Profiling of image }\end{array}$ \\
\hline
\end{tabular}




\section{Case 2.a: Organising FM Functions in Danish Broadcasting Corporation (DR)}

Until 1994 the FM functions in DR were placed under a corporate finance officer and organisationally divided into a building administration, a service administration and a procurement department. As part of a larger reorganisation of DR emphasising to strengthen the chief executives of radio and television, the directorates for economy, staff and technique were closed, and a number of former shared functions in the technical and administrative areas were de-centralised into radio and television respectively.

The FM functions became part of $\boldsymbol{D} \boldsymbol{R}$ Service under a new service manager referring to a deputy director with responsibility to the remaining shared functions. The organisation in DR Service was divided in DR Property Administration, DR Procurement, DR Printing Office and three decentral service areas in each headquarters of DR: TV City and, Radio House in the Copenhagen area and R/TV House in Århus. Subsequently it should be evaluated which functions of DR Service were going be tested in outsourcing.

Hence it was an obvious restructuring of the company with strengthening of the core business in the radio and television production, but also a partly politically decided development towards media sharing.

Shortly after a change of director general in 1994 a strategic planning process was initiated, in which DR was defined as being a customer focussed broadcasting company with less emphasis on programme production. Simultaneously a rationalisation scheme was completed, partly under the name of Business Process Reengineering, which resulted in a reduction of the staff with approx. $10 \%$. Furthermore the canteens in the TV City and Radio House were outsourced. During the years that followed the organisation went through continuous adjustments, by which the previous tendency towards decentralisation and media sharing was changed to a tendency towards centralisation.

In the shared areas the organisation was divided into a strategic part and an operational part. To DR Service this implied a change of the DR Property Administration to a small strategic function called DR Properties, whereas building maintenance and smaller reconstructions were transferred to the decentral service areas. DR Procurement was also divided in a contract oriented function and a store function. Among other things this division of the organisation took place in order to be able to outsource the operational functions.

The organisation was in 1998 changed with establishment of DR News managed by a news chief executive, and gathering the news functions from radio and television. The change of organisation was carried on in 1999 with establishment of $\boldsymbol{D} \boldsymbol{R}$ Resources managed by a resource chief executive, who has the responsibility to all former shared functions and also all technical support functions for the programme production. The FM functions were situated in DR Resources with the main part in a division to Internal Service.

In 1999 DR decided to move all functions in the Copenhagen region to a new headquarters called DR City. As preparation to this relocation, DR completed a new strategic planning, which implied an extensive Business Process Reengineering of DR's activities with digital technology and integration of radio, television and on-line into a multimedia production. Furthermore, a staff function to the resource chief executive was established to act as building client for the establishment of the new media centre. DR City was occupied in 2006-2007. 
services and establishment and development of provider companies, outsourcing has had a crucial importance.

The reason for the importance of outsourcing must among other things be seen in the general liberalisation wave, which has occurred in the 1980 'ies and the 1990'ies, and which also has resulted in the internal market of the EU. Economical crisis during the period and the constant pressure of the public expenses has strengthened the incentive to take advantage of the possibilities of cost reduction, which outsourcing makes possible. Correspondingly the increased international competition has led to the fact that many companies to a greater extent have focused on developing their core functions, and with an eye to this they have tried to gain savings at support functions through outsourcing.

Outsourcing is in this book used as a common term to various terms, which all concern external provision of services. Outsourcing is a term of the process through which services are changed from being carried out in-house into being provided by an external provider. Outsourcing is furthermore considered being an organisational tool in relation to management of FM functions.

An example of organising of FM with outsourcing of a number of services is shown in figure 2.2.

The English term "outsourcing" is used in Denmark as well as in some other non-English speaking countries, but in Denmark the term "tendering-out" (udlicitering) is also used. This in particular concerns the public sector, where specific EU procurement rules are established, which has to be observed. In this context outsourcing is a formalised procurement process where a number of providers compete through submission of tenders. Similar to construction works a competitive bidding is arranged.

In English the terms outtasking, rightsizing/ downsizing, contracting-out, TFM, insourcing/ resourcing and cosourcing/partnering are used.

Outtasking means the same as outsourcing except from the fact, that outtasking implies a single service, for instance cleaning, whereas outsourcing may also relate to a group of services.

Rightsizing and downsizing are practically synonymous and represent organisational adaptation processes where companies go through work processes and functions in order to clarify the functions they want to be kept in-house, and which to be outsourced. This often takes place in connection with Business Process Reengineering.

Contracting-out means a bundled outsourcing of services - all often operationel FM functions - in a contract with one provider. Contractingout can either be executed by means of a commercial contract where all services are provided at a fixed price or as a management contract where the provider works in accordance with an agreed budget - with possible incentive agreements et cetera. The contract mentioned in case 2.b between IBM and Johnson Controls is an example of a management contract. The principle of organising FM at contracting-out with a commercial contract is shown in figure 2.3 and with a management contract in figure 2.4.

TFM represents Total Facilities Management and is used in connection with contracting-out in cases where not only the operational FM

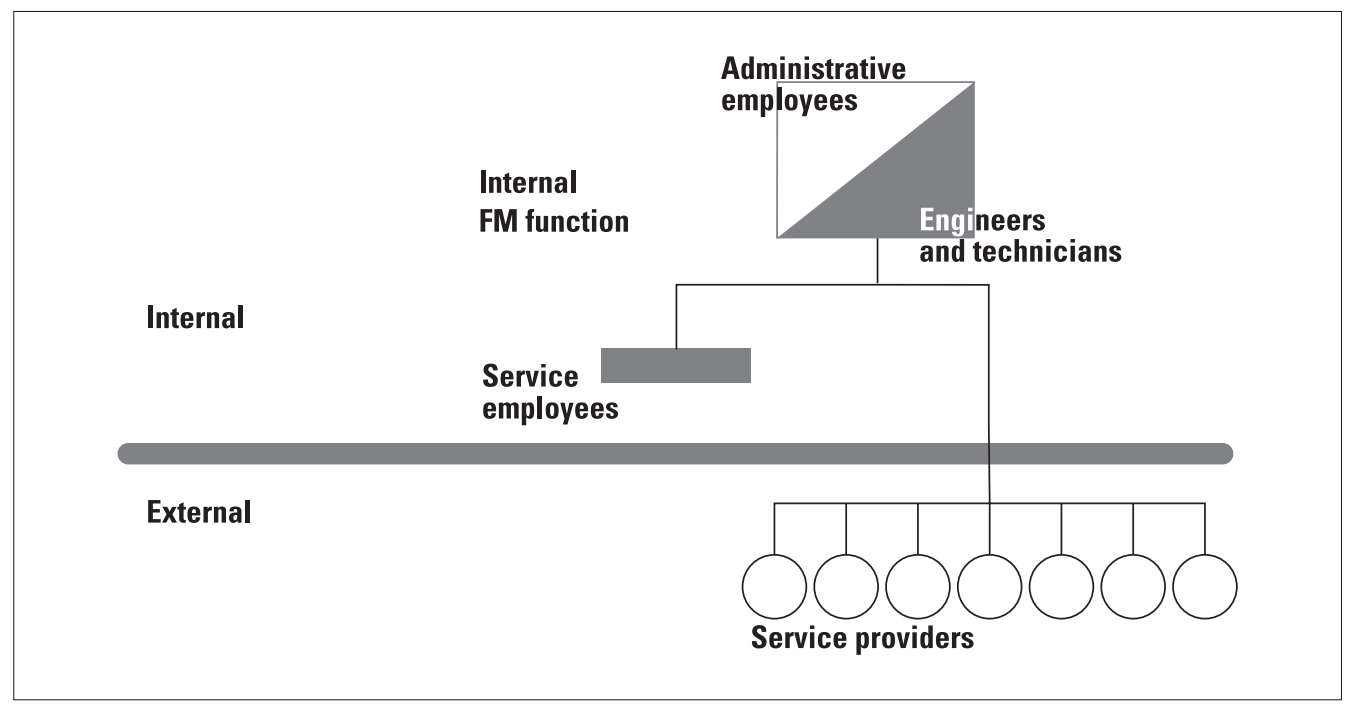

Figure 2.2

FM organisation with outsourcing of a number of services (source: Williams, 1996)

Definition of outsourcing

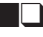

Tendering-out 


\section{Case 2.b: The Contract between IBM and Johnson Controls about Outsourcing}

(Source: Jakobsen, 1997)

The completed outsourcing in 1996 by FM services in IBM Denmark to Johnson Controls, which is presented in case 1.a, was made in accordance with a basic agreement between IBM in Europe and Johnson Controls.

The main contents of the contract between IBM Denmark and Johnson Controls was as follows:

- Buildings which are included by the contract

- Services which are included in the contract

- Employees who are transferred to Johnson Controls

- Conditions to employees who are transferred to Johnson Controls

- Existing contracts which Johnson Controls must take over

- 5 year budget

- Way of settlement

- Provisional Service Level Agreements (SLA)

- Duration

- Obligation to measurements of performance

- Form of cooperation

- Planned changes to obtain savings

- Changes which are not wanted to be implemented

The form of cooperation can be illustrated as shown below:

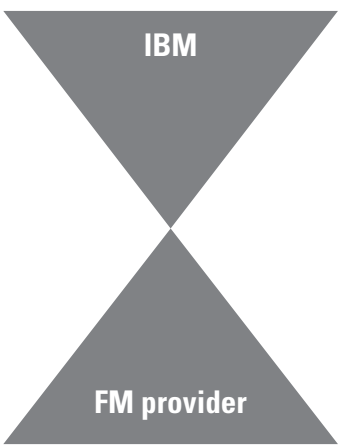

Establish strategies

Plan projects

Approve

Supervise the operation

Deliver the service

Keep SLA

State-of-the-Art provision

Customer satisfaction

Each employee communicates directly with Johnson Control's staff in the daily work, so that just exceptional situations are passed on to IBM's person in charge for the contract. 


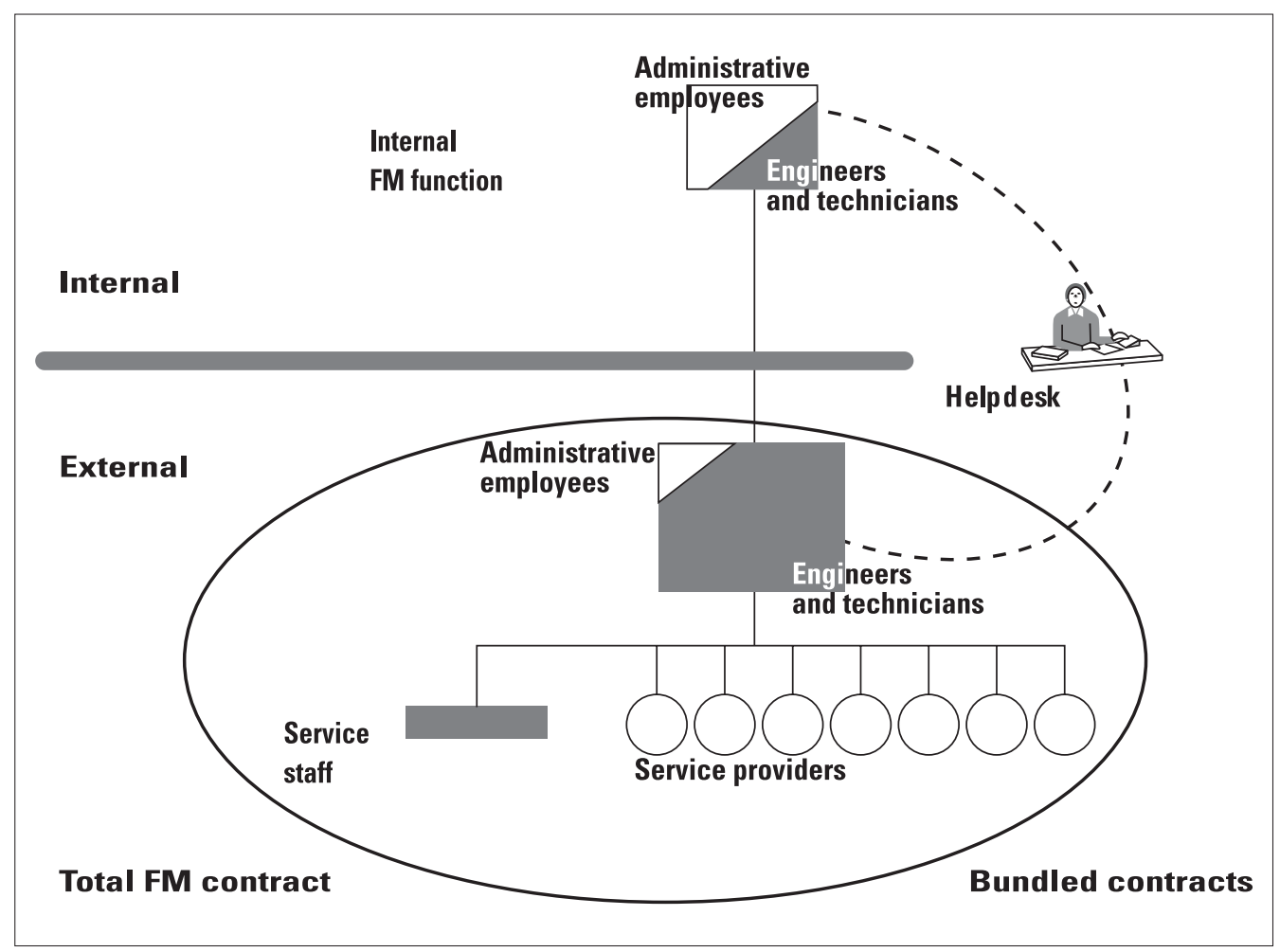

Figure 2.3

FM organisation with contracting-out on a commercial contract

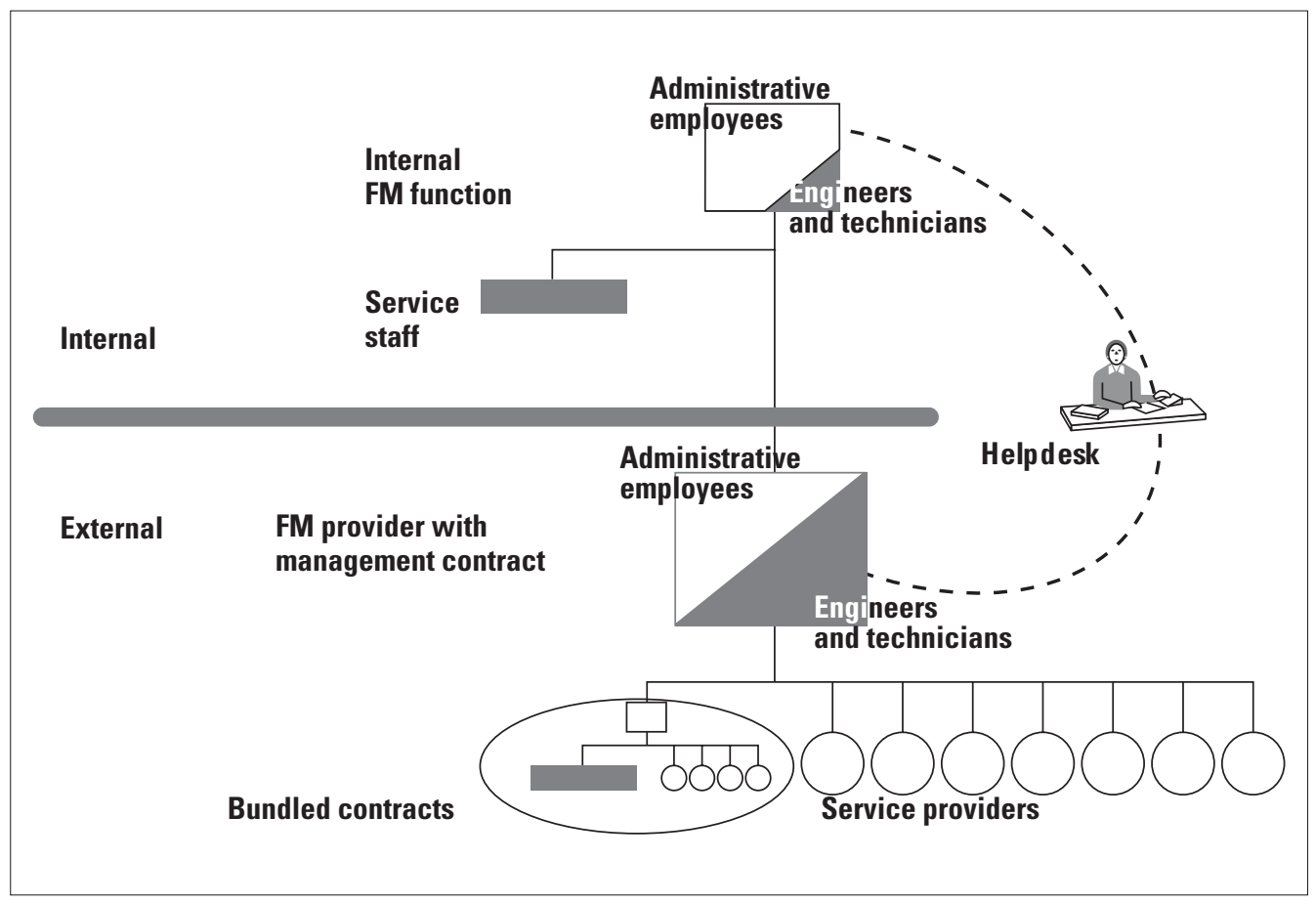
(source: Williams, 1996)

Figure 2.4

FM organisation with contracting-out on a management agreement (source: Williams, 1996)

functions, but also the tactical and strategic FM functions to some extend are included. A TFM contract can be made as a commercial contract or as a management contract. In case of TFM outsourcing there is only the client function left in the company who make the outsourcing.

Insourcing and resourcing are concepts which cover internal reorganisations and rationalisations of services with basis on the company's own staff. At insourcing there is usually a process where external consultants implement an analysis of the functions in question and con- tribute as process consultants in the implementation of changes in-house. At resourcing it is normally included in the change process that the internal services become more or less economically independent units which act as providers to an internal marked with attached internal invoicing, and in case of establishment of a separate company there might be possibilities to deliver to the external market.

Cosourcing and partnering are expressions of cooperation forms where a sort of strategic alliance is made in relation to provision and deve- 


\title{
Case 2.c: Partnership Contract between Rover Group and Drake \& Scull Technical Services Ltd.
}

\author{
(Source: Carey \& Clarke, 1996)
}

The Rover Group (RG) was in the beginning of the 1980'ies a nationalised and state subsidised company with survival problems and labour disputes. Later the company was owned by BMW and yielded a profit. A flexible work organisation was achieved, and the staff had employment security as a result of a new collective agreement. Furthermore the purchasing department changed from focus on short-term economical gains to focus on long-term strategic alliances with providers. Hence it was natural to RG as well to find a strategic partner in the FM area. They focused on finding a company which had a company culture and development potential to match RG - also in relation to staff conditions and education et cetera.

Drake \& Scull (D\&S) has its roots in the construction industry where the company acts as subcontractor. This area is described as totally based on specifications, very price centred, single trade oriented, short-term and tactically characterised, and always with a third party between the company and the end user. The company experiences the first change as it moved into maintenance business. Here there are possibilities to build longterm relations and contact with the end user, although the work also here is based on specifications, price centred and single trade oriented. The next change occurred as the company started activities within FM. Here there were possibilities to long-term relations, and the area is not just price centred, but there are also possibilities to add value to the customer. The work is also to some extent based on specifications, but they use increasingly contracts based on service levels in stead of specifications. Furthermore there are more possibilities to work cross-functional and in direct cooperation with the end user in a long-term perspective with shared goals.

RG began the process in finding a partner by making a benchmarking of relevant provider companies. On basis of this D\&S was selected as a potential provider, and RG started a long-term informal dialogue with leading employees at D\&S to test opinions, theories and ideas. At that time prices and other conditions as to the contract were not discussed. In D\&S they were in the beginning rather sceptical and uncertain if RG just wanted good ideas to use for themselves. However, D\&S decided to take a stake, and during the process a confidential relation emerged between key persons from both companies.

The first formal document was the letter of intent stating that RG would enter into a contract with $D \& S$ if $R G$ decided to outsource FM functions. After that D\&S was asked to establish an office at one of RG's factories and make tenders for various tasks. D\&S somewhat reluctantly worked with open calculations and accounts. Subsequently RG finished their usual provider audit for strategic providers, and after formal approval they entered into a contract which includes a number of various services, for instance cleaning, maintenance of forklifts and test of laboratory equipment.

Both companies admit that it involves many resources - not at the least managerial - to prepare and implement a partnering contract. In return there are considerable long-term benefits to both parties. RG states that they commercially gain a higher service level at the same price as before, and they have possibilities to involve the provider at an earlier stage of the development plans. To D\&S the partnering contract provide better possibilities to plan the development of the organisation. 


\begin{tabular}{|l|l|l|l|}
\hline & Insourcing & Outsourcing & Cosourcing \\
\hline Owners control & High and direct & High but indirect & Divided \\
$\begin{array}{l}\text { Speed of change } \\
\text { Owner keeps the } \\
\text { competence }\end{array}$ & Moderate & Fastest & Fast \\
$\begin{array}{l}\text { Company relation } \\
\text { Effect }\end{array}$ & No & Maybe \\
\hline
\end{tabular}

lopment of services. The responsibility to the services is maintained within the company, but the execution of the operational functions is handled by service providers at agreed ways of settlement and development goals. With such cooperation forms a larger flexibility of the services may be achieved, and the partners will be able to work with more long-term perspectives to the cooperation. An example of partnering is described in case 2.c.

In figure 2.5 is shown a comparison of the methods insourcing, outsourcing and cosourcing.

A survey including 4.000 North American companies made by IFMA in 1999 showed that outsourcing is part of the strategic plans in $70 \%$ of the companies, and outsourcing is expected to be increased during the 5 years to come. Outtasking of a few service areas also show to be more used than total outsourcing of a group of services. The survey also shows that some services are more suitable for outsourcing / outtasking than others. The 10 services which are frequently outtasked were (IFMA, 1999):

1. Architect design

2. Waste disposal

3. Housekeeping

4. Facility systems

5. Garden maintenance

6. Property valuation

7. Larger moves

8. Disposal of hazardous material

9. Larger refurbishments

10. Moving of furniture

Regardless that outtasking according to the above mentioned survey is much used, there seems to be general tendencies towards more total procurements and towards more close collaboration between providers and customer. The development of the customer / provider relation can be illustrated as shown in figure 2.6.

\section{The legal basis to outsourcing}

It is emphasised that the aim of this paragraph is to provide an overview of the legal basis of outsourcing. In connection with outsourcing an inexperienced facilities manager must always seek for expert support, and regardless of involving of consultants with experience in outsourcing, it must also be recommended to involved qualified legal counselling - at the least when EU procurements must be implemented.

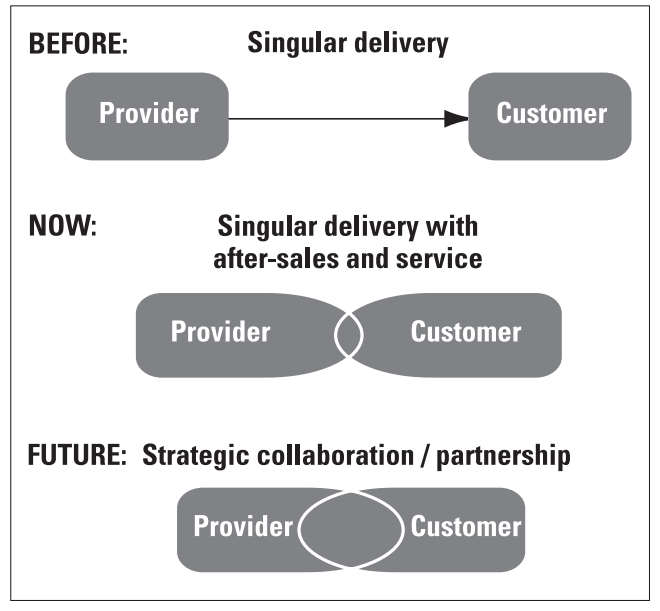

One of the most important and oldest legal regulations for outsourcing concerns the protection of employment in the transfer of employees from one company to another. This is in legal terms labelled Transfer of undertakings and in UK the regulation was implemented in 1981 and abbreviated TUBE. In Denmark a similar act is from 1979 (Lov om virksomhedsoverdragelse). It is based on an EU directive, so there is a similar legislation in other EU countries. In accordance with the transfer of undertakings regulation, a provider who takes ownership of a company - or a part of a company must enter the rights and duties which were present at the time of the takeover. This also implies, that employees who are employed within a work field in a company which is subject to outsourcing must be offered employment in the company which in the future will manage the work field in question. The employees must in fair time before the transfer be told of the reason to the transfer. Furthermore, the employees are
Figure 2.5:

Comparison of methods

(Source: Facility

Management Journal, 1995)

Figure 2.6:

The development of customer / provider relations

\section{Transfer of} undertakings 
The EU's directive on public procurement

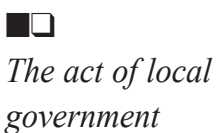
government

\section{口a}

The circular letter of outsourcing of state operating and construction tasks

Internal services as a kind of monopoly for a period ensured the same terms of employment and salary as before the outsourcing. The conditions for pensions are often a very important issue in relation to outsourcing and transfer of employment.

In the public sector there are a number of rules which are of importance in relation to outsourcing. In general the regulation is based on an EU directive from 2006 (The Community Directive 2004/18/EC on procurement of public works, supplies and services). The directive is implemented into national legislation in all the member countries. Besides there can be other national legislation that regulates aspects of outsourcing in each countries.

In Denmark the municipalities must in accordance with the act of local government decide whether the municipal tasks must be solved through own production or external provider, for instance a private company, another public authority or a shared municipal company. Authority tasks cannot without a specific legal authority be transferred to an external provider, and this has importance to for instance rescue service and elderly care. The act of local government furthermore includes regulations that each municipality at least every second year must account for the operations which after procurement must be made by others than the municipality itself.

In the Danish state area The Ministry of Finance's circular letter about outsourcing state operation and construction from 1992 is applied. In accordance to this circular letter it applies as an ordinary rule for disposition of state authorisations, that tasks which can be performed by external providers, with suitable intervals must be exposed to a round of procurement. Provided tasks must be outsourced if it through the procurement is proved that it is the most profitable to the state. As in the municipal area authority tasks are excluded unless there is a specific legal basis. In connection with the circular letter the so-called council of outsourcing was appointed to counsel about outsourcing of public operation and construction tasks.

To all public areas, and areas subject to public control, for instance social housing, EU's regulations of public procurement is used. The basis to these regulations is the EU treaty's rules of competition and regulations about free movement to goods, workers, services and capital. The regulation is based on principles of equal treatment, non-discrimination, transparency, proportionality and mutual recognition. Before 2004 there were separate directives for public works, supplies and services. Outsourcing was regulated by a service directive from 1993.

EU's procurement regulations must be obeyed when the total value of the service is expected to surpass a certain threshold value. The threshold values vary from states, regions and municipalities, and the limits are adjusted every second year. If the value of the service surpasses the limit in question, EU's procurement directive must be obeyed. They include for instance requirements of advertising in the EU news, certain time limits in connection with prequalification and tendering, determination of selection criteria and publication of the result of the bidding round. Equal treatment of the tenderers is a crucial principle, and there are very limited possibilities to negotiation with the tenderers. A new element in the directive from 2004 was the introduction of a new form of tendering called competitive dialogue. Regular services must be procured at least every 5 th year.

\section{Advantages and disadvantages of in-house / outsourcing}

The most used argument to outsourcing is that it provides the possibilities for economical savings. There are many examples to support this argument, but there are also examples that apparent savings were not fulfilled because the provider did not live up to his bid. In principle it ought to be possible to manage services inhouse as efficiently and economically as external providers. In fact the external provider must have a profit to his provision, and this profit can stay in the company by keeping the tasks inhouse.

It is in fact a matter of managing the services with a competent management and skilled and motivated employees, no matter the tasks are solved in-house or outsourced. However there are conditions which in various situations and various companies speak in favour of one or another solution. These conditions may change over time. Hence there is no right solution. Each company must find its own solution in each situation, and the solution may vary for different services.

Internal service functions often have a position as a kind of monopoly, where the internal customers have no choice among various providers, and the cost is fixed and cannot be discussed. 
Another risk in connection with internal service functions is that they provide a better service than the company needs and really wants to pay for. Hence it is reasonable to look into the cost level through a market test. Thus the company is forced to define the necessary or desired service level. Other possibilities are to make a benchmarking process to document the cost level and establishment of an internal market will make the cost level visible.

In some cases the wage and work conditions to employees in internal services has been raised similar to the conditions for the employees in the company's core business, whereas the level of the wage and work conditions is lower in the provider industry. This implies higher costs to the internal services. Even if the transfer of undertakings regulation in principle ensure the employees' wage and work conditions at outsourcing, it is only applies to the initial outsourcing and not at succeeding bidding rounds.

Hence there may be a competition of wages and work conditions, which naturally contribute to the rather politically based debate.

The market situation at the time on the price retrieval has a great influence on the bidding prices. Hence one sees rather large variations in the prices to services, and this is naturally connected to the "hunger" of the provider companies. This is quite equal to biddings in the area of construction and civil engineering. Through outsourcing a company hence may obtain a very favourable bid. However there is a risk of having a frivolous underbid, and this may backfire as to the provider's lack of ability and will to live up to the bid, cf. case 2.d. The next time the company invites tenders the price may be considerably higher and may exceed the cost of inhouse provision.

Among the arguments for outsourcing from the larger service providers are that they have a large and wide qualified support base, and they are able to create better development and career possibilities to the employees. This is primarily relevant in connection with internal services in smaller companies, where it may be impossible to employ many specialists, but this problem can be solved in using external consultants. It may particularly be difficult to middle managers in internal services to achieve the necessary professional development.
Against outsourcing speaks that the employees in internal services know the company and its culture from inside. Hence they have better knowledge of internal customers and background to understand their needs and wishes. Often a very strong loyalty to the company is built up among the employees, and this implies for instance that they want to make extra performances when the company requires it. As opposed to this, employees in a provider company have a primary interest in ensuring their own earnings and the requirements of the provider company.

The company with internal services has also a greater flexibility to be able to adapt to the changed demands by transferring the employees. At the use of external providers formal contracts about payment are needed in order to be able to make changes of the services. Security reasons are in some companies decisive to use own service staff, for instance for cleaning in specific areas.

In connection with outsourcing of services it is necessary that the company establish or develop an Intelligent or Informed Client Function (IFC). If the company does not set aside professionally qualified resources to observe that the outsourced services fulfil the demands drawn up, outsourcing will be like buying a pig in a poke.

\section{Preconditions to a successful outsourcing}

In connection with implementation of outsourcing it is important to make a thorough preparation in an open process involving the affected employees.

Initially one must decide a goal to the process.

- Is it already decided to outsource, or is the target to find the best and cheapest solution to the company?

- If procurement is finished, will the employees have possibilities to make bids themselves?

- What other factors are involved in the decision besides the economically aspect?

After that one must make a feasibility study of the areas in question to investigate how suitable they are for outsourcing. For instance the internal customer / provider conditions must be clarified, and it must be ensured that the area organisationally and in relation to tasks is clearly defined.
Benchmarking as an alternative to market testing

Intelligent Client Function

Goal for the process 
Service level must be defined

Service Level Agreement (SLA)
Before a market test one must finish a rationalisation process (insourcing / resourcing) in the area in question for instance by the use of external process experts. The former and the necessary future service level must be specified, and also the former cost level, so a benchmark can be made in relation to the expected market level. Hence one can draw up an economical target to the rationalisation process.

If the economical target is reached you may consider whether the market test must be accomplished. If the economic target is not reached, it will clearly indicate to the employees involved that outsourcing is of interest to the company. Through the rationalisation process the employees will also be prepared as to work and mind to be transferred to a provider company.

In connection with procurement it is crucial to define the necessary service level as precise and measurable as possible, $\mathrm{cf}$. the following section. It is furthermore in connection with EU procurement important to determine precise criteria to the most important things in connection with evaluation of the bids. The tenderers who are deselected at EU procurement have the right to a written explanation to this. If a complaint is brought up in connection with an EU procurement it is crucial to be able to show written documentation to the selection procedure which prove that the tenderers has been treated equally and that only the stipulated criteria has been the basis for the selection.

\subsection{Quality Management of Services}

A central task to the FM function is setting of service levels to various services adapted to the company's needs, and continuously to ensure adherence and adjustment of these service levels. In connection with contracts with service providers the service levels are made in a socalled Service Level Agreement (SLA), cf. case 2.b.

\section{Case 2.d: EU Procurement of Cleaning in Danish Broadcasting Corporation (DR)}

External handling of FM functions is not a new phenomenon. This is for instance shown by the fact that DR's contract with ISS about cleaning of the Radio House reached its $50^{\text {th }}$ anniversary. As far as it is known the contract was not tested in a competition with other providers during these 50 years.

In 1995 DR for the first time implemented EU procurement of cleaning. The procurement was related to all DR's 29 locations in Denmark, and it was accomplished with the Danish Technical Cleaning Institute as consultant. It was a demand that the companies were able to document that they only use organised labour, that they use quality assurance in the work process, and that they have environmental policy for the cleaning products they use. The quality of the cleaning was defined on the same level as previous.

The result of the procurement was remarkable. From a total cost for cleaning and window polishing of approx. $€ 2.2$ million, the cheapest bids had a total cost of approx. $€ 1.6$ million, i.e. savings of $€ 660.000$ equivalent to $30 \%$. The cheapest bids were divided between 5 companies from 5 different geographical areas.

The large savings on cleaning was by the service manager at DR explained as consequences of the tough competition within the cleaning industry. It became subsequently obvious, that the tough competition had led to unrealistic low prices. The lowest tenderer of cleaning TV City, which was the largest contract, had to realise after the tendering that the price was too low, and had to be replaced by the second lowest before the contract was signed. The winner of the cleaning of Radio House, which was the second largest contract, was deprived from work after 6 months due to lack of compliance to the quality demands.

Afterwards DR has finished a new EU procurement of cleaning. The cost level is still much lower than the level before 1995, but not as low as at the first procurement. 
It is easy to provide a good service as long as the money is there but the purpose to the FM function is at any time to deliver the proper service at the lowest possible price. Determination of the service level is finally a political matter. However it can be difficult to make the top management make up their mind as to the wanted service level, unless this is expressed as obvious options with attached economical consequences. In most cases the FM function itself must determine a service level, which they think is suitable for the company.

A starting point to determination of a service level to a certain service is to define a minimum level. This might for instance be based on regulatory requirements to the area in question.

Based on such a service level it will be estimated which risk factors they involve compared to a higher service level. Among possible risk factors may be:

- Bad image

- Lower productivity

- Technical breakdown

- Higher sick absence

If the service level is estimated to involve unacceptable risks one can increase the service level step by step until an acceptable risk level has been reached. In doing this, one will achieve a service level which with the least cost is acceptable. If one by further increase may expect positive effects to the company, it may be a fine alternative in a proposal.

Another possibility is to take the former service level as the starting point and make a similar estimation of risk factors or positive effects through a step by step decrease or increase of the service level.

Such estimations are of course difficult to make and implies considerable experience. The first problem is how to define a service level, so it is precise and measurable. To do this one must define specific performance indicators, which in the European FM standard are called Key Performance Indicators (KPI). It may be relevant to define performance indicators both in relation to input and in relation to output - respectively KIPI and KOPI.

Performance indicators for input can be separated into 3 main elements:

1. The work process, for instance frequency, time of the day, time of response
2. Resources, for instance staff qualifications, specifications of materials, supporting materials

3. Management, for instance supervision, incentives and control and reporting procedures

As to cleaning of carpets such performance indicators may be:

1. Vacuum cleaning each morning between 6 and 8 a.m.

2. The work is done by means of a central vacuum system by a cleaning operative with at least one year of experience

3. Total control of the work at least once a week

However, such performance indicators to input does not show whether the carpet is clean or not.

Performance indicators to output consist of functional demands to the delivered service. Such demands may be specific technical demands, for instance to the content of dust in the carpet after vacuuming. Theoretically performance indicators to output are the most relevant, as the output has importance for the users. However, it is in many cases not possible or realistic to determine measurable performance indicators to output. Hence it is often necessary to check the service quality by means of specific demands to input.

At external service provisions you must emphasise the provider's own procedures of quality control, so that the quality control of the FM function first and foremost will consist of control of the provider's adherence of control procedures. It is not common that service providers are certified in accordance with the international quality standard ISO 9001, but it may be an important future competitive parameter.

Sometimes complaints are used as a performance indicator for output. Complaints from the users must naturally always be taken seriously. However, complaints are not useful as an objective indicator for the quality of a service. At first it varies from company to company how legitimate or acceptable it is to make complaints depending on the company culture. Secondly complaints must always be considered in relation to whether they express that the decided service level is not fulfilled, or they express discontent with the decided service level. In the first case the complaint must of course be used
Service level and risk factors

The providers' quality control

Key Performance Indicators (KPI) 
as part of the quality control, whereas in the last case it must be included in the continuous evaluation of the service level.

Satisfaction surveys among the users in the shape of questionnaires may be a good basis to estimate whether the service level is reasonable. On the other hand such surveys does not express adherence of the determined service level. At implementation of satisfaction surveys it can be recommended to ask for the respondents' estimation of the importance of each service, which they are asked to evaluate. By this one achieve an expression of the users' prioritisation and better grounds to estimate the responses. At evaluation of the responses one must notice that it for complex areas such as indoor climate is difficult to gain a high level of satisfaction in comparison to more specific areas as for instance post service.

The configuration of questions in satisfaction surveys must be observed carefully. Small variations in the questions may cause considerable consequences to the result. Implementation of recurrent satisfaction surveys with identical questionnaires may cause a better feel of the development of the users' satisfaction. Of
Technical or

non-technical

background to the

facilities manager course one must observe the risk of saturation of the users with questionnaires, and one needs not to ask all or the same persons every time. If the respondents are representative to the staff, the number of respondents need not be rather high in each survey to lead to consistent results.

\subsection{Qualifications and Development of the FM Function}

\section{Job profile and qualifications}

As a management discipline, FM is generalist and cross-functional orientated. The subject area uses knowledge and tools from a number of other professions. This concerns traditional professions such as general management, business administration, personnel management, economy, architecture and building engineering. But naturally FM also uses elements from new philosophies of management and tools such as Service Management, Business Process Reengineering, Total Quality Management and Benchmarking, and also some from the IT development, cf. chapter 8 , and from the environmental area, cf. chapter 9 .

EuroFM in 2000 adopted a proposal for a common European job or competence profile as to
FM based on a profile used by BIFM for their examinations. The idea was to agree about a competence profile, which for at least $70 \%$ cover the profile to FM in each European country. The profile is important in connection with definition of extent and content of FM as a subject area, hence as basis for determination of contents of educations. The main elements in EuroFM's proposal to a competence profile is shown in case 2.e.

Some of the most important FM qualifications are abilities to manage and to communicate. The FM area includes a wide spectre of specific competences in relation to for instance handicraft, technique, finances and customer service. Naturally the manager of an FM function cannot master all the specific competences. However it is a great advantage if the facilities manager has enough knowledge to all fields within the area to know what is special and important within each field, so that the facilities manager in a competent manner can represent the entire FM area in relation to the company's top management, and in relation to the internal customer representatives.

It is much discussed whether a facilities manager preferably must have a technical background with management graduate studies, or whether a commercial non-technical management background with the necessary support by specialists is to be preferred. It is essential that the facilities manager needs knowledge from both the commercial and the technical area combined with abilities to manage. In stead of a specific educational background, it is the personal qualifications and the impact that have importance. With the proper personal qualities it will be possible to add the necessary specific knowledge.

The facilities manager should primarily be aware of the strategic development possibilities, so that the FM function will be able to act proactive in stead of reactive. The closest possible contact to the top management of the company is hence crucial, and the favourable situation is when the facilities manager can foresee the ideas and questions the top management will put forward, so that the preliminary work for preparation of proposals for solutions and answers has been made. Politically flair is a priceless qualification.

It is also crucial that the facilities manager know how to build up a multi-disciplinary team, which covers all important special competences, and 
which is able to collaborate as a unit. The composition of the team must have special attention - in Denmark not the least, as there at present are no specific educations within FM at a high level. At first the multi-disciplinary team must handle the different professional considerations in a qualified manner. Secondly the team must ensure a comprehensive view considering the overall goals of the company. Thirdly the team must ensure an efficient and rational customer service. Ideally a FM organisation consists of number of generalists with each their own specialty.

An important criterion to professional behaviour is that you know the limits of your own knowledge. This especially concerns managers and staff in a FM function. Hence it is necessary to supplement yourselves with external consultants in the special areas where you do not yourself have the necessary competence. The costs of external consultants may seem high, but it is a good insurance against the damages which may occur, if you take steps on to unsecure professional grounds. It is difficult to evaluate the consultants' professional qualifications, and it is important to choose consultants who you trust. Personal references from colleagues in other companies are useful in connection with selection of consultants.

\section{Service Management}

Among the new management philosophies Service Management probably has the greatest importance in relation with FM. Compared to traditional management philosophies aiming at industrial companies, Service Management is characterised by a change from interest in internal effects of performance to the external effects, and a change of focus from structure to process.

Among the most known advocates for Service Management is the former SAS chief executive
Jan Carlzon who during the 1980 'ies became famous for his reorganisation of SAS from the concept of Service Management. Carlzon determined people as being the most important resource of a service company, and he introduced the staff idea of "the independent responsibility taking individual". The slogan was "Progress through the people in an organisation and a work environment characterised by trust, changes and possibilities" (Braagaard, 1993).

Service is characterised by a number of differences compared to physical products, cf. figure 2.7. Service is provided by persons, and so the customer's experiences during the contact with the service provider's representative is crucial to the customer's experience of the service. Often the interaction between the service provider and the customer is quite short. Jan Carlzon mention "the moment of the truth". The general impression which the airport passenger gets of the SAS employee during one minute's service at the check-in is crucial to the customer's experience of SAS's service.

Hence Service Management is depending on the employees' appearance in relation to the customer. It is crucial that the employees act competent and customer oriented. Motivation and delegation of responsibility to the employees is an important part of Service Management, and hence of FM. An important factor of motivation is to understand the importance of the work in a greater perspective. Education of the service staff must include three main elements (Grönroos, 1990):

- Development of a comprehensive view of both the organisation and its sub functions as a service organisation, and of how it works in a market orientated manner

- Development of professional qualifications in order to handle various tasks

\begin{tabular}{|l|l|}
\hline Physical products & Service \\
\hline Tangible & Intangible \\
Homogeneous & Heterogenous \\
$\begin{array}{l}\text { Production and distribution separated from } \\
\text { consumption }\end{array}$ & $\begin{array}{l}\text { Production, distribution and consumption } \\
\text { in one concurrent process } \\
\text { A thing } \\
\text { Core value is produced in a factory }\end{array}$ \\
$\begin{array}{l}\text { An activity or a process } \\
\text { (Normally) customers do not participate in } \\
\text { the process of production } \\
\text { Can be stored }\end{array}$ & $\begin{array}{l}\text { Core value is produced in interaction } \\
\text { Customers participate in the production }\end{array}$ \\
Transfer of ownership & Cannot be stored \\
\hline
\end{tabular}

People are the most important resource
Motivation and delegation of responsibility
Figure 2.7

Differences between service and physical products (Source: Grönroos, 1990) 


\section{Case 2.e: Competence Profile for FM}

(Source: BIFM, 1999)

The profile is divided in the 20 items showed below, which are grouped under 6 management areas. Each of the 20 items is furthermore specified in 4-9 sub items - in total 116 sub items. To each item and sub item there is a description. Below is alone mentioned the 6 management areas and the headlines of items and sub items.

\section{Understanding Business Organisation}

1. Understanding the Structure and Behaviour of Organisations

1.1 Understand the ways in which organisations are structured

1.2 Understand how organisations operate

1.3 Understand the decision-making process within organisations

1.4 Identify and understand company culture

1.5 Understand the business life-cycle from startup to maturity

1.6 Understand the concept of continuous improvement

1.7 Understand the management of changes

2. Understanding Business and Organisational Strategy

2.1 Understand the way organisations develop and implement strategy

2.2 Understand how strategy is developed for functions within an organisation

2.3 Understand business planning

2.4 Understand principles of objective setting

2.5 Understand principles for performance measurements

2.6 Understand the importance of scenario planning

\section{Developing FM Strategy}

3.1 Develop and implement FM strategy

3.2 Understand the relationship between core business and FM strategies

3.3 Modify organisational structure to reflect FM strategy

3.4 Review, evaluate and modify the FM strategy

3.5 Keep up to date with new developments in the FM industry

\section{Managing People}

\section{People Management}

4.1 Understand and implement resource planning

4.2 Select and recruit appropriate people

4.3 Train and develop staff

4.4 Motivate, reward and retain staff

4.5 Management and lead staff

4.6 Management and monitor staff performance

4.7 Manage dismissals, resignation, redundancy and retirement

4.8 Introduce new ways of working

4.9 Keep abreast with new employee regulation

\section{Communication}

5.1 Understand the benefits of good communication

5.2 Demonstrate good written communication skills
5.3 Demonstrate good presentation skills

5.4 Demonstrate good listening skills

5.5 Understand group dynamics

5.6 Set a strategy and objectives for negotiation

5.7 Negotiate effectively - individually and in a team

5.8 Minimise risk, maximise benefits

5.9 Successfully manage complex negotiations

6. Workings with Suppliers and Specialists

6.1 Understand the roles of specialists in the FM industry

6.2 Build and manage multi-discipline teams

6.3 Select and appoint suppliers and specialists

6.4 Manage and monitor suppliers' performance

6.5 Keep up to date with new ideas for supplier relationships

6.6 Manage the close-down of supplier relationships

\section{Managing Premises}

\section{Property Portfolio Management}

7.1 Understand the property industry

7.2 Develop and implement a property portfolio strategy

7.3 Manage the property portfolio to meet business needs

7.4 Understand and manage property costs

7.5 Keep abreast of property legislation

7.6 Set up and manage the property and asset register

8. Understand Building Design

8.1 Understand building types and uses

8.2 Understand structure and its effect on building use

8.3 Understand building services and their effect on building use

8.4 Keep abreast of the legislation affecting buildings

9. Building Fabric Maintenance

9.1 Understand the maintenance implications of building structures

9.2 Develop a fabric maintenance strategy

9.3 Develop and manage fabric maintenance programmes

9.4 Deliver an effective fabric maintenance service 


\section{Managing Services}

\section{Managing Building Services}

10.1 Understand building services

10.2 Develop a maintenance strategy for building services

10.3 Develop and manage building services maintenance programmes

10.4 Deliver effective building services maintenance

10.5 Understand building management systems

10.6 Understand energy management

10.7 Keep abreast of legislation applicable to building services

\section{Managing Support Services}

11.1 Understand the full range of FM support services

11.2 Develop a strategy to support service provision

11.3 Manage support services

11.4 Keep abreast of legislation applicable to support to services

\section{Project Management}

12.1 Understand the role of the project manager

12.2 Understand common FM projects

12.3 Develop project briefs

12.4 Develop, manage and monitor project programmes

12.5 Manage project budgets

12.6 Assemble and manage project teams

12.7 Manage project handover and close-out

13. Managing Customer Services

13.1 Understand the service culture

13.2 Deliver a customer focused service

13.3 Access customer requirements and satisfaction levels

13.4 Develop and manage Service Level Agreements (SLA's)

13.5 Understand the importance of soft issues

\section{Managing the Work Environment}

14. Environmental Issues

14.1 Develop and manage of a policy to protect the environment

14.2 Understand environmental impact

14.3 Manage the control, recycling and disposal of waste

14.4 Keep abreast of environmental legislation and guidelines

15. Space Management

15.1 Develop a strategy to space allocation

15.2 Understand the impact of structure and services on space use

15.3 Preparation briefs for space layouts

15.4 Programme and manage of changes in accommodation

15.5 Keep abreast of new developments in space use

15.6 Keep abreast of legislation with impacts on space use

\section{Managing Resources}

16. Procurement

16.1 Develop a procurement strategy to goods and services

16.2 Understand contract types

16.3 Develop standard specifications for goods and services

16.4 Develop and use standard terms and conditions

16.5 Evaluate and compare cost models

16.6 Keep abreast of contract legislation and practice

\section{Risk Management}

17.1 Understand and apply risk management techniques

17.2 Carry out risk analysis

17.3 Manage and reduce risk

17.4 Understand and apply risk transfer

17.5 Develop a business contingency plan

\section{Financial Management}

18.1 Understand financial systems and processes

18.2 Manage capital and revenues budgets

18.3 Manage cash-flow

18.4 Understand VAT and tax implications in FM activities

18.5 Prepare financial cases

\section{Quality Management}

19.1 Understand the principles of quality strategy, assurance and control

19.1 Apply quality management principles to initiate improvements

19.1 Design and manage quality systems and procedures

19.1 Understand quality standards and accreditation schemes

20. Information Management

20.1 Collect and analyse data

20.2 Use of information efficiently

20.3 Manage information flow

20.4 Keep abreast of new developments in IT

20.5 Understand the applications and benefits of IT

20.6 Successfully implement IT systems

20.7 Keep abreast of the legislation which applies to $1 \mathrm{~T}$ 


\section{Case 2.f: Self Managed Groups at Gardening in Novo Nordic}

In October 1996 the department for building maintenance in Novo Nordic began a project with the headline "self managed groups". The project related to grounds maintenance, where half was handled in-house by employed gardeners, whereas the remaining part was outsourced. The background for the project was a benchmarking between in-house and outsourced grounds maintenance, which showed that the outsourced part was the cheapest. They had furthermore observed internal problems and quite a bad work environment in the gardening department, which was organised in three gardener workshops with a common foreman.

In stead of outsourcing the entire grounds maintenance they decided to implement project "self managed groups". The goal to the project was that these two criterion for success must be fulfilled within two years:

- An economically competitive gardener workshop

- A good, efficient and inspiring workplace to the employees

After a dialogue between the management and the gardeners they reached an agreement with the following main items:

- There would no longer be a daily foreman for the gardener workshop. The employees in the three self managed groups would handle the daily planning such as buying tools and materials, planning of holidays et cetera

- The three internal gardener workshops would work with the same task descriptions as the external contractors. The self managed groups hence would consider themselves being small independent contractors, which would accept to have their results compared to the results in the outsourced part of the grounds maintenance of the company.

After some doubt from the employees they quickly obtained a number of positive results, which were much better than the economical target. The employees developed engagement and sense of responsibility to the whole. Earlier on it was usually the management who stopped cost consuming proposals, but now the employees themselves estimate the profitability and critically evaluate the necessity of new cost proposals. This especially concerns the question of engaging of new employees.

Furthermore the employees have built up a number of administrative competences which enable them to work with tasks that formerly were handled by the foreman. There are many examples showing that the employees on their own initiative has recommended new and better ways of organising and working, and many of these proposals obviously derived from the new competences, which the employees has developed in the self managed groups.

Especially the preparation and the implementation of the project puts great demands on the management. The process demands a lot of support and help in the beginning, and the key words are communication and active presence. And in the long term support and training is needed, for instance in relation to planning and utilisation of the resources. 
- Development of specific communication and service oriented skills

The first of these main elements primarily aims at motivation. In his book "Moments of Truth" from 1987 Jan Carlzon shows the meaning of this by the following anecdote - and practically the same anecdote is told by Mikhail Gorbachev in his book about Perestroika from the same year:

There is no better way to summarise my experiences than the story of the two stonecutters who hewed granite into square blocks. A visitor at the quarry asked what they were doing. The first stonecutter looked rather grumpy, and he mumbled, "I hew these cursed stones into blocks". The other stonecutter who in return seemed to be content with his work proudly answered, "I am a member of the team which build a cathedral" (Grönroos, 1990).

The increased emphasis on service orientation have manifested in a number of new ways of organising. Learning organisation and self managed groups are examples of such organisational innovations. The learning organisation can be defined as an organisation which encourage to new way of thinking - where the employees learn from their own and from others experiences - and learn how to learn together. Case 2.f provides an example of self managed groups from the Danish pharmaceutical company Novo Nordic.

\section{Development of the FM function}

The goal to organisational and process development in the FM function is to create efficient and highly motivated teams of employees who are able to implement continuous improvements of their performances. This concerns the learning organisation and self managed groups, which were mentioned in the previous paragraph. Often the development of the FM function takes place as part of a general organisational and process development in the company. In the following Business Process Reengineering, Total Quality Management and Lean Production are mentioned as three commonly used examples of such development concepts.

\section{Business Process Reengineering (BPR) typi-} cally derives from intentional strategic considerations with a view to strengthen the company's competitiveness and market position. BPR is based on a holistic consideration with basis in customer needs and customer expectations. In stead of orientating the company according to its functions, the company must be orientated according to processes. The company's processes should be considered crosswise to implement simplifications and new combinations et cetera, hence the number of handlings and the need for information transfers and coordination are minimised. Implementation of new technology, including IT technology to support de reorganised work processes are often included as an important part in connection with implementation of BPR.

The advocates of BPR say that one can make quantum leaps in the company with savings and improvements of more than $20 \%$ by implementation of BPR. The most important parts of the BPR thinking are:

- The company is organised according to the actual customer needs

- The lead time from order to provision af products or services must be significantly reduced

- All activities which do not create value to the customer must be minimised

- The technology must be used at the maximum, not just to automate old working procedures

- The preparedness to change must be increased in order to meet new conditions

Total Quality Management (TQM) is a management philosophy about continuous improvements of products, processes and services by means of activities involving the entire company in integrated efforts for the purpose of meeting customer demands and expectations. It is emphasised to involve the entire company and to ensure the employees' efforts and engagement. As part of TQM both management and employees must systematically work with the following:

- Determine the quality

- Prevent lack of quality

- Measure the quality

- Improve the quality

At TQM and other quality control systems it is emphasised to prevent costs in connection with errors. As shown in figure 2.8, in investing more resources to prevent errors, relatively more are saved in costs for control and error; hence resources for development and higher profitability are released.

Lean Production is a similar management philosophy which was developed in the car indus-
Process orientation in stead of functional orientation

Continuous

improvements

The learning

organisation

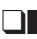

Prevention of errors 
try in Japan. The focus is on maximising value to the customer and minimising waste during the production. Lean has been applied to other fields than production, for instance under the terms Lean Construction, Lean Design, Lean Administration and even Lean Research. The principles of Lean has been mostly been implemented in the area of FM on big industrial corporation as part of a general implementation of Lean in the corporations.

To implement development of the FM function it is desirable to measure the performances. It is a prerequisite to be able to set up quantitative goals to the development, and it is necessary to be able to document to one self and others that you have implemented improvements. There are various development tools which are based on measure of performances. The most important is benchmarking, which is thoroughly discussed in chapter 3 about financial management.

Benchmarking is often based on comparisons of economical key indicators, but with this basis the benchmarking may lead to comparisons of for instance work processes and procedures.

In connection with the development of FM it is important to remember the customers' point of view - regardless if the customers are internal users or external customers. At the use of systematic gathering of the customers' points of view it may be relevant, as mentioned in the previous section, to introduce satisfaction surveys in the shape of questionnaires and interviews. In connection with relocation and introduction of new work methods it is useful to implement such surveys before and after changes, hence you have an actual frame of reference.
Another possibility to a systematic gathering of points of views from the customers is to establish focus groups. Focus groups are often used by politicians to have points of views from their "customers" - the voters, but focus groups are also a useful tool in the contact between the FM function and its customers. The power of focus groups is that it is possible to have a thorough perspective of a specific topic using selected persons with interest and insight of the topic, hence all relevant aspects and new ideas to improvement of the service which the FM function provides can be evaluated.

In the continuous contact with the customers it is important that the FM function has a simple and efficient gateway to enquiries - a so-called helpdesk or call centre. Here all notifications of errors, orders, wishes and inquiries will be received, either by person, by telephone or by mail. All inquiries must be handled professionally:

- All inquiries are recorded in an IT tool

- The customer will have an immediate response about the handling of the inquiry

- Relevant staff in the FM function are informed

- It is quickly clarified which employee in the FM function is responsible

- There is a continuous follow-up and notification of completion

- Statistical data of inquiries and response time can be withdrawn, for instance to the use of evaluation of adherence of agreed performance goals

- As regards to IT the helpdesk is connected to other relevant systems, for instance maintenance system and purchase system
Figure 2.8

Value creation through the TQM process

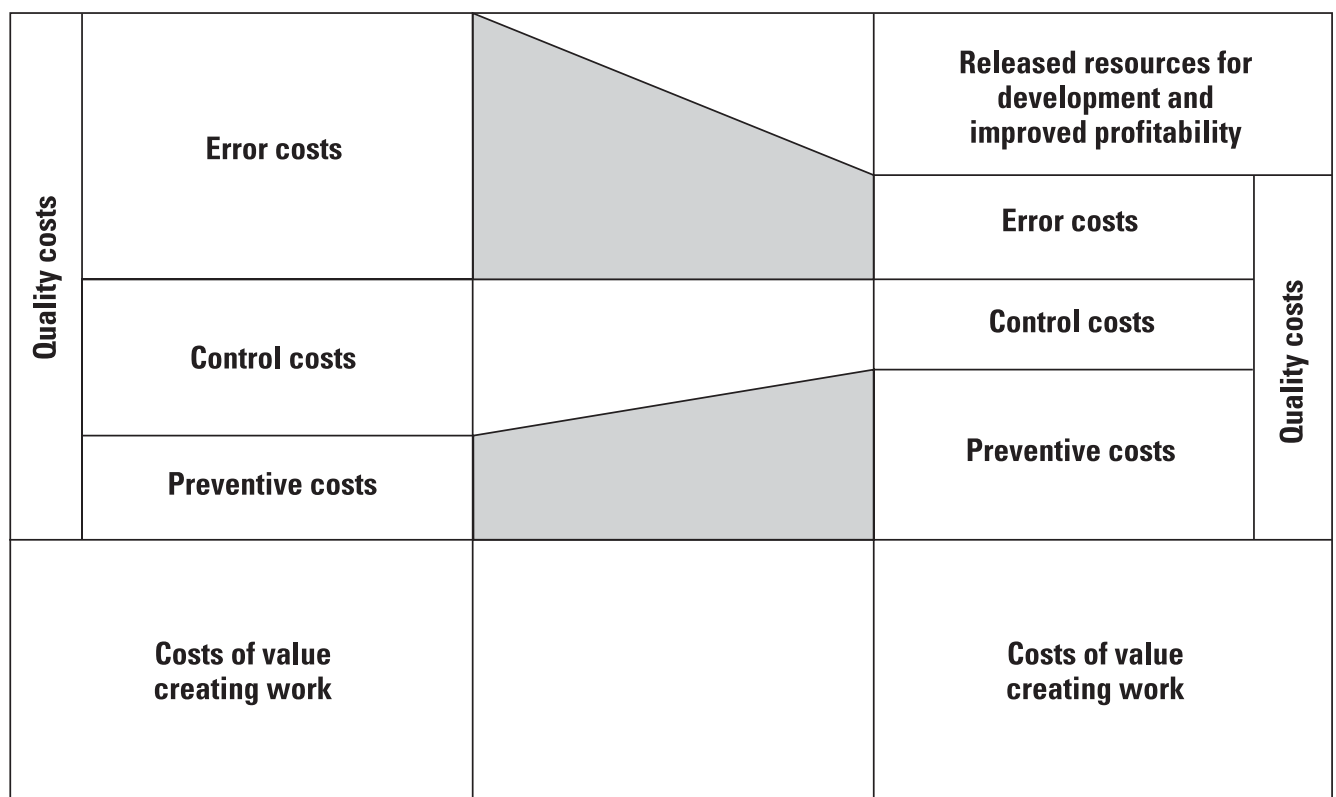


As to IT tools for the use of development of the FM function we refer to chapter 8 .

\section{FM and the value creation in the company}

In English one distinguish between efficiency and effectiveness in relation to the development of organisation and productivity, where efficiency is to do things right, whereas effectiveness is to do the right things (Duffy, 1997). In the examples of development of the FM function, which were mentioned in the previous section, the emphasis is mostly on efficiency by rationalisation and process development, and less emphasis on effectiveness increase in terms of added value and product improvements.

The concept of value derives from economic theories, but is to a great extent now used within management philosophies. In this context it is a fairly vague and very relative term. In connection with introduction of digital technology in stead of analogue technology in the media world, they mention the digital added value. This means, that the digital technology gives new functionalities to recipients of digital signals on digital equipment compared to analogue equipment. With digital equipment the product gains an added value to the recipient.

But can support functions in a company create value at all? Normally they create no earnings to the company. But if the support functions are not valuable, i.e. create value, to the company, they must be unnecessary. If the support function does not work, any company will quickly stop due to lack of heating, post distribution, telephone exchange, cleaning of toilets, repair of equipment et cetera. If only the support functions work, the company in return will have no earnings. The core business is necessary to create earnings, but both core business and support functions create value. The core functions create value to the external marked, whereas the support functions create value to the core business at the internal market of the company. One may say that the value creation of the core business is direct whereas the value creation of the support functions is indirect.

In FM circles there are arguments against the point of view that FM primarily includes support functions in stead of core business. An example often referred to is catering in hospitals. This function may be considered being a routine provision of services. You may also consider hospital catering as an important part of care and cure of the patients. However it does not contradict the distinction between core business and support functions. In stead you may argument that catering to the patients is or must be considered being part of the core business of the hospital, whereas catering for the hospital staff is a support function.

Similar you may in other companies choose how to prioritise and how to consider various service functions. Catering may be considered a routine service to the company's staff. You may also choose to develop the catering function for instance in engaging a French cook, so the daily lunch become an attractive event, which create added value to the company by attracting and retaining highly skilled staff members. Furthermore the catering function can be used to give the company's visitors a culinary experience in stead of inviting customers to expensive restaurants down town. Hence the catering function can be partly considered part of the core business.

The concern that FM primarily is considered being a support function probably relates to the fact that it may risk to be a blind alley to the subject area, if the perception of it as a support function involve a downgrading, where one primarily count on cost reduction through rationalisations and outsourcing. On the other hand you may say that the great challenge to FM is - also being competitive concerning price - to ensure a continuous development by creating added value in various fields of FM.

In connection with product and process development there are many examples, that product development within part of a supply chain may imply process development in the subsequent chain. From the construction area you can see, that product innovations in building component companies, which imply increased prefabrication in relation to the work in the construction site contribute to a process development of the building. Similar to this product development in a support function may lead to process development in a core function of the company.

Subsequently you will see some typical examples of how FM functions may contribute to creation of added value in the company:

- Organising of an efficient helpdesk in the FM function makes it easier and more safe to the employees to make requests about errors, orders, wishes and enquiries with evident feedback of what will happen and when, so that the employees must not be
Do things right - or: Do the right things

The concept of value

Direct and indirect value creation

Catering as a support or core function 
irritated and remind of feedback, but can concentrate of their work.

- Establishment of a clear system to internal rent in the company will provide each department in the company with possibilities to gain cost reductions, if they cut down on the use of space.

- A good strategic overview of the company's total space portfolio and foresight in relation to future needs of space may cause great savings on the property budget, and ensure continuous adaptation between the present space and the needs of the organisation.

- A flexible layout of space with adjustable furniture creates opportunities to quickly meet the changing needs in each department of the company causing great influence on the employees' productivity.
- User-friendly IT systems where each employee has access to information about drafts make good possibilities to communicate in connection with relocations and changes of interior layout.

- Healthy and inspiring buildings with a comfortable indoor climate, where the users have possibilities to control their surroundings, may reduce sickness absence and increase the employees' productivity.

The book on FM Best Practice in the Nordic Countries (Jensen et al, 2008) includes a number of other examples of added value of FM and also presents a conceptual model to explain the different ways that FM can create value to both the core business and the surroundings called the FM Value Map. 


\section{References}

Among the literature and websites below Bernard William's book about "Facilities Economics" (Williams, 1996 - new edition) can be recommended with a straight and down-to-earth introduction to the organisational and managerial aspects to FM, and the book also contains a comprehensive description of economic relations to various fields in FM. Furthermore, Stormy Friday and David G. Cotts' book of "Quality Facility Management" (Friday \& Cotts, 1995) can be recommended, with a practical introduction to quality control of services emphasising customer orientation.

\section{Literature}

Keith Alexander (editor): Facilities Management - Theory and Practice.

E \& FN Spon, London \& New York, 1996.

BIFM: The BIFM Examination Syllabus, Part 1. The British Institute of Facilities Management, 1999 (www.bifm.org.uk)

R.W. Carey \& N. Clarke: Partnership: the Strategic Choice for Succes. Documentation from EuroFM/IFMA conference in Barcelona, May $5^{\text {th }}$ to $7^{\text {th }}, 1996$.

John Conner, Procord/Johnson Controls: Outsourcing facilities management.

Article in John Worthington (editor): Reinventing the Workplace. Architectural Press, 1997.

Peter F. Drucker: Managing for the Future. Butterworth-Heinemann Ltd., 1993.

Stormy Friday \& David G. Cotts: Quality Facility Management - A Marketing \& Customer Service Approach. John Wiley \& Son, Inc., 1995.

EuroFM: European Job Profile for the Facility Manager. Proposal issued to members of EuroFM, July, 2000.

Christian Grönroos: Service Management and Marketing - Managening the Moments of Truth in service Competion. Lexington Books, 1990.

IFMA: Outlook on outsourcing. Press release on a website published December 15th, 1999.

Jørgen K. Jakobsen, IBM Denmark: Outsourcing Facilities Management in IBM. Documentation from a conference organised by IIR Denmark in collaboration with DFM and the Administrator Association, February, $3^{\text {rd }}$ to 4th3.-4. February 1997.

Per Anker Jensen, Kjeld Nielsen and Susanne Balslev Nielsen: Facilities Management Best Practice in the Nordic Countries - $\mathbf{3 6}$ cases. Centre for Facilities Management, Technical University of Denmark, 2008.

Anders Krabbe, SAS: Passenger service at Copenhagen Airport - îThe non-airport airportî. Proceedings from EuroFM/IFMA conference in Torino, June $1^{\text {st }}$ to $3^{\text {rd }}, 1997$.

Cor Ouwehand: Professional Frontliners in Facilities Management. Article in The European Facility Manager, Number 1, 1999.

Phil Roberts $\underline{\&}$ David Mosey: Public/Private Partnerships: Creating Future Value. Proceedings from EuroFM/IFMA conference in Maastricht, June $7^{\text {th }}$ to $10^{\text {th }}, 1998$.

Bernard Williams Associates: Facilities Economics. Building Economics Bureau Limited. Kent, revision 1, 1996.

Bernard Williams: Output, Input - All Fall Down! Performance Measurement in Practice. Article in Facilities Management UK. 1999.

\section{Websites}

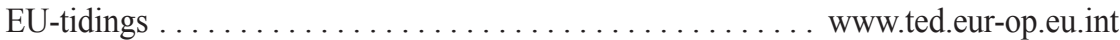

The National Association of Municipalities in Denmark. . . . www.kl.dk

The Danish Competition Authority. ............... www.ks.dk 


\section{Figures}

3.1 Expenses included in internal rent in Danish companies. . . . . . . . . . . . . . 54

3.2 The administration layers in relation to property management

3.3 DFM-benchmarking's cost structure for property management and services. . . 57

3.4 Possibilities to learn by benchmarking between organisations

3.5 Main results from DFM-benchmarking's data collection for property management.

3.6 Property management related to age in owned and rented out properties used for administration . . . . 63

3.7 Services in owned and rented out properties related to employed and employed+users

3.8 Comparison between key indicators from DFM-benchmarking and DR for owned property.

3.9 Internal benchmarking among three alike owned properties in DR

3.10 Benchmarking between two lessors of administration properties

3.11 Saving potential for benchmarking .... . 69

3.12 Factors influencing cost for cleaning ... 69

3.13 International benchmarking of maintenance expenses.

\section{Cases}

3.a System to Internal Rent in DR

3.b Benchmarking between Two Danish Companies

\section{FM in the Company's General}

Financial System ................. 50

Internal Rent. . . . . . . . . . . . . . . 51

- The background to internal rent .................. 51

- A survey of internal rent ....................... 53

Financial Management in the FM Function .... 55

Benchmarking and Key Indicators . . . . . . . . 57

- Benchmarking ............................ . 57

- Key indicators ............................. 59

- Benchmarking with key indicators . ............... 61

References...................... 70 
Traditional financial control

Activity Based Costing
Financial management is an essential part of FM as it is the case in practically all other managerial areas. However, to FM it includes the demands of efficient financial control in a number of levels and in various connections.

At the superior level the facilities manager of course must handle the ordinary financial control of the entire function in relation to the annual budgets. Furthermore the FM function is responsible to multi-annual financial control in relation to property investments and maintenance planning as to buildings. Project management and the connected financial control are also an important work area to the FM function. Normally the purchase department is part of the FM function, and here as well financial control is an integrated part of the work area. Furthermore, most employees in the FM function are involved in the ordering of services and in the follow-up, hence financial control must be an important aspect.

In this chapter a number of aspects in connection with FM and financial management are discussed. FM in relation to the general financial system is discussed in section 3.1. In many companies a kind of internal market is introduced as part of the financial control to make visible the expenses in connection with internal services. This is a kind of financial control which is often used in the relation between the FM function and the internal customers.

A common kind of internal market is internal rent, which is the topic to section 3.2. The background to implementation of internal rent is also discussed in this section.

In most companies it is a problem that the company's general financial system is not fit to manage the financial control of the FM function, hence it may be necessary to establish a supplemental financial control system. This problem is discussed in section 3.3 about financial control in the FM function, in which the importance of appropriate charts of accounts is stressed.

Benchmarking and key indicators are the topic to section 3.4, and this is the most comprehensive section in the chapter. It is initiated with a thorough discussion of benchmarking and description of the related terms and procedures, including ethical rules to benchmarking. Subse- quently the use of key indicators are discussed and a number of examples of benchmarking with the use of key indicators are presented both from Denmark and other countries, including attempts to connect financial key indicators to quality levels of FM services. The chapter is finished by references.

\subsection{FM in the Company's General Financial System}

The traditional way of implementing financial control in companies and public institutions is to prepare a budget for the coming year divided in relation to the company's or the institution's various areas of activity in accordance with the company's line organisation. During the year the expenses in relation to the budget are recorded, and the crucial target to the financial control is to keep the budget to each item. All significant deviations must subsequently be substantiated in accounts explanations.

It is a simple and easily understandable control system which is a natural follow-up to the demands for accounting in accordance with company and tax legislation and also various circular letters for public institutions. On the other hand it is a rather static control system in which you can only gain overview of the correlation between earnings and expense at the top level. Hence there is a need for a supplementary control system, which is not just based on functional and organisational division, but also divides the financial data in accordance with products and processes - or more precisely activities. This is called Activity Based Costing $(\mathrm{ABC})$.

In a production company it is natural to assess expenses and earnings for each product to be able to calculate the price basis and profitability of each product. In a craft company or a consulting company, in which the activities are mainly sale of staff-hours, an activity based control is a foundation to invoicing of work. In many other types of companies, and not at least in public institutions, activity based financial control is not commonly used.

In connection with an activity based financial control, the cost of services from the FM function must also in principle be allocated to each activity. Hence is the best possible visibility cre- 
ated of the support functions' cost, and the potential negative effects of internal monopolies can be limited. Hence it may be suitable that the internal customer / provider relations possibly reflect themselves in the superior financial control within the company.

This may be done by creating a sort of internal market between customers and providers. However, this is a fine balance how formalised an internal market system should be organised. On one hand a certain degree of formalising is necessary; hence there will be some administrative exercises at a high level in the company. On the other hand the administrative burden of internal invoicing may become exorbitantly incriminating.

This balancing depends among other things on the size of the company. As mentioned in figure 2.1 , it is in large groups suitable to organise FM in an independent organisation. It may be a separate company or a profit centre within the company, in which a weekly invoicing between the FM function and the customers is made.

However, a position of the FM function as a line organisation is not suitable to large groups.

The most important is to create visibility of the costs, in which the customers have possibilities to change the expense level through a changed demand of the services. The ultimate target is to achieve a behavioural regulation with the customers. The most visible area is probably canteen service, in which each employee entirely or partly pays for the service compared to his consumption in most companies, hence an individual user charge.

It is similar to services which are specifically requested by an internal customer like a department, for instance furniture acquisition, internal relocations transportation tasks, travelling and proper purchases. To such ordered services an internal invoicing is often appropriate.

To many other services it can be much more difficult to define a certain internal customer or group of customers, who can influence the service and expense level. Many services cover the entire company or an entire property, for instance reception, telephone exchange, post distribution and security. It is the similar to property management and operation in the shape of maintenance, supplies, cleaning, caretaking, monitoring and supervision, insurances, rent and property taxes.
To some of these areas it is possible to vary the service level to users in certain areas of a property, but the question is whether it for the company is politically wise that each department itself must decide for instance the cleaning standard. Many of the expenses are to a great extent depending on the size of the building, so the best would be a behaviour regulation of the use of space. This can be done by introduction of internal rent, and this is shown in the next section.

To the strategic and partly also the tactical tasks in the FM function it is in principle the entire company or its top management who are the customer. It is of course possible to make internal settlement of these tasks. It can for instance be done similar to payment of external consultants as project licences or hourly payment for specific projects and tasks, eventually with an overhead allowance for make-up and maintenance of the necessary level of competence and the availability of expert knowledge. Another possibility is to also include the expenses for such tasks in an internal rent.

With a starting point in the above mentioned principles the FM function can be included as a financially self-sustaining unit, in which the expenses of the function must be counterbalanced by earnings from the internal customers.

\subsection{Internal Rent}

\section{The background to internal rent}

Internal rent is implemented in many large private companies and groups. Groups often consists of a number of partly independent companies located in properties which are administered by a common property administration or a real estate agency, and internal rent is a necessity for each company to be able to show accurate accounts. In companies where various areas are separated as profit centre, internal rent is also a necessity for the same reason.

In other companies as well internal rent may contribute to make visible the expenses to provide space. If the internal rent also should act as behaviour regulating, it is important that the internal rent burdens each cost bearing unit at the lowest possible level in the company. Each unit must be able to see financial advantages in savings on the use of space. However, the tendency is that it is primarily to units which are measured on their financial result, i.e. units with

Internal customer / provider relations

口a

Visibility and behaviour regulation

Cost burden at a low level 


\section{Case 3.a: System for Internal Rent in Danish Broadcasting Corporation (DR)}

As part of introduction of a new way of financial control in $D R$, an administrative system was prepared to manage internal rent in DR. The internal rent should contribute to the cost awareness among those with budgetary responsibility and thus ensure that the amount and allocation of space match the programme production's financially prioritised needs. So far the space in principle were given on the basis of shared space standards, which made it difficult to redistribute space from departments with too much space to departments with actual lack of space. The administrative system for internal rent therefore should meet two requirements:

1. The expenses which form the basis of the internal rent had to be visible.

2. It must have financial consequences to the users to have too much or too little space.

Introduction of internal rent should be made according to the so-called office hotel model. This implies that the lessor not only put building space at disposal, but that the lessor also delivers a number of services, so the internal tenant will be able to dispose of operational, yet un-furnished, spaces with the necessary supplies, cleaning and other specific services. Furthermore the following general principles to the internal rent system were determined:

- The rent would be the same per $\mathrm{m}^{2}$ regardless of situation in Denmark, and regardless whether DR owns or rent the building

- The rent would be cost based without inclusion of interests or depreciation of DR's investments in the building stock

- As basis for the internal rent an internal rent contract would be signed with each division in DR

- The rental conditions should in principle be as on the open market with the modifications included in the above mentioned principles

- The rent should be settled with each budget area of responsibility at an annual budget transfer based on budgets and without subsequent adjustment

In the internal rent would be included all expenses for operation and maintenance of buildings, including salaries and department costs for operational and administration staff, and also a number of services. The rent would be based on the net spaces of which each budget area had disposal.

The rent was subsequently differentiated in five various types of space:

- Television studios

$200 \%$

- Radio studios and other technical radio and television facilities $150 \%$

- Offices, meeting facilities, workshops

- Archives on office floors, storage space and garages

$100 \%$

- Basement space

$75 \%$

$50 \%$

The plans for introduction of internal rent were made at a time where it had been decided to acquire a CAFM system for the property administration in DR. For the use in the internal rent administration all rooms in the CAFM systems hence were categorised according to the above mentioned types of rooms.

However, the above system was not implemented in DR for political reasons. 
the responsibility to both earnings and expenses, where it is possible to achieve a behaviour regulating effect.

To the property management the internal has an important advantage, that the users have an interest in the central recording of the use of space is correct. Hence the property management will have an active tool for a continuous overview of use of space, and not at least vacant spaces. Thus internal rent is both an important work task and an important tool in connection with space management, which is thoroughly discussed in chapter 5. Implementation of specific IT tools such as CAFM is often made in connection with introduction of internal rent.

Internal rent is an efficient tool to create the necessary respect and a serious handling of the resources which spaces and properties are to a company. Internal rent also implies a centralisation of information, control and power of the company's space allocation, which may be controversial. This and the administrative costs at administration of internal rent may be arguments against internal rent. Hence it is a general experience that successful implementation of internal rent requires support from the top management of the company.

Within the governmental administration in Denmark they have operated with internal rent since 1990, and it was in 1999 decided to implement internal rent more generally within the state area. In a report on the state property and construction administration from august 1999 it was recommended that the state space policy is changed towards an increased market orientation, and that rent settlement and free choice of provider to selection of space for state use is implemented as a main rule. Based on the report it was decided to introduce rent settlement in the state area from 2001. This property management in the Danish and the Finnish state is described in section 4.3 of the book on FM Best Practice in the Nordic Countries (Jensen et al, 2008).

In case 3.a an example of a system for internal rent is described.

\section{A survey of internal rent}

As part of the preparation of a system for internal rent the author in 1992-93 completed a survey of how internal rent is managed in a number of larger Danish companies. The description below of internal rent is primarily based on this survey, which included five large companies within various industries and with very different structures. The survey is anonymised.

\section{Determination of internal rent}

Like external rents, internal rents typically consists of two main elements: Base rent and operational expenses. However it may vary what is included in these main elements at internal rent compared to external rent. The following alone concern the conditions related to internal rent. Base rent includes in principle the expenses which are related to the disposal right of a property or a tenancy. These expenses will be the same no matter the use of the spaces. And if the spaces are not used, you must pay the rent to have the disposal right.

In practice it is different what is included in the base rent. For own buildings the base rent typically consists of:

- Rate of return and possible depreciation of the invested capital

- Taxes and levy

- Insurances (building fire and property contents)

- Contribution to building owner's property administration

- Possible external maintenance

For rented spaces the internal base rent typically consists of the entire external rent, no matter if it in the external rent contract is divided into fixed and variable expenses. The external rent includes the external lessor's expenses for:

- Rate of return and possible depreciation of the invested capital

- Taxes and levy

- Insurances (building fire)

- Maintenance of the building except from internally in the tenancy

- Contribution to shared expenses (caretaker et cetera)

- Contribution to the external lessor's property administration

- The external lessor's profit

The base rent may vary from being a mere cost related internal rent to being market dependent internal rent. In the cost related internal rent is alone included the direct expenses, perhaps without capital expenses except from external rents. The market dependent rent is an internal rent which in principle is determined according to the market rent. The private companies in the survey had either a full market dependent inter-
Space management 
nal rent or a form in between, which was closer to the market dependent than to the cost related internal rent.

Operational expenses include in principle the costs which follows the specific use of a building or a tenant. The main items are:

- Maintenance (only internal to tenants or own building, if external maintenance is included in the base rent)

- Supply (heating, electricity et cetera)

- Cleaning

The limitation of the cost items which are included as operational expenses in internal rent varies much depending on who in each company handle various tasks.

In all companies user departments pay separately for rebuilding and acquisition of furniture. As an illustration, yet rather extreme, of the importance of this, one of the companies mentioned the following: At occupancy in a new building the user departments at the beginning did not themselves pay for rebuilding, and they spend $€$ 2.1 million to rebuilding the first year. On basis of this user payment was introduced, and hence the rebuilding expenses went down to approx. $€$ 0,3 million annually.

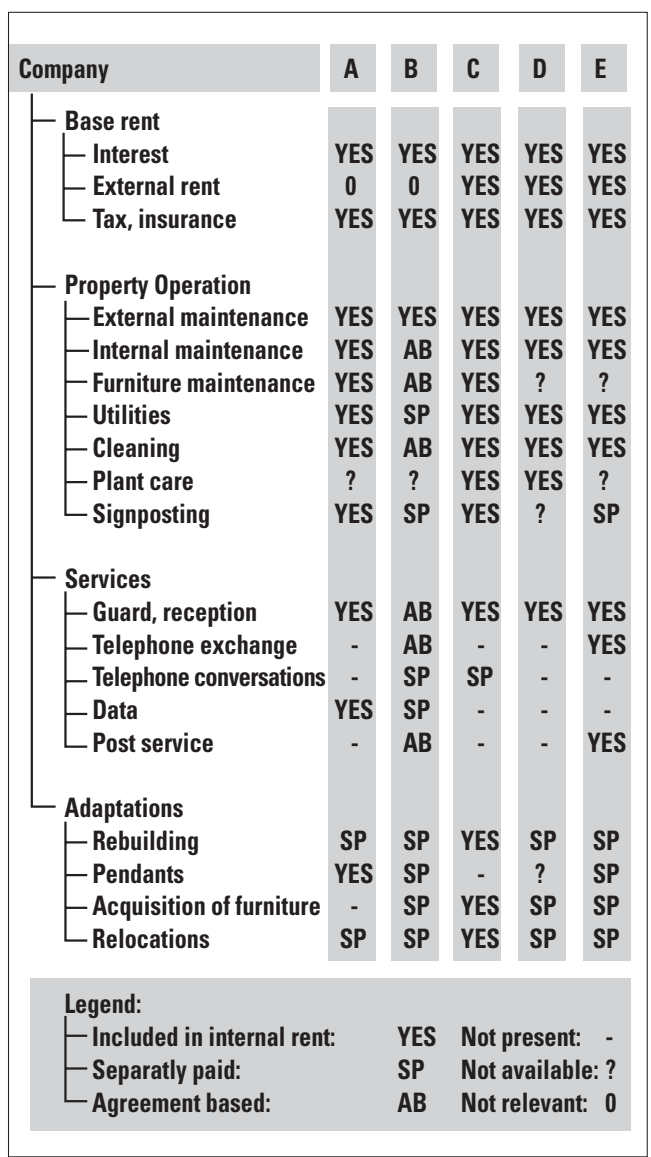

The method of payment of the internal rent varies between two extremities. Some companies pay exclusively in relation to the budgeted expenses. In other companies the rent is initially paid according to the budget, but it is regulated later based on the actual cost. Also here there were forms in between, for instance exceptional additional adjustment and settlement in accordance to budget for some kind of expenses, and from actual expenses to other kinds of expenses.

Figure 3.1 shows a survey of the kind of expenses which are included - or not included - in the internal rent within the 5 Danish companies which were included in the investigation.

\section{Allocation of the rent}

Apart from a single company in which the internal rent was allocated from number of employees, it is the use of space which is the basis of the allocation. In the company where the number of employees was the basis, the rent system related to a domicile property entirely with office functions.

It varies whether it is the use of net area or gross area which is the basis of the rent. In one company the rent was alone calculated from making up net areas. In two companies they used making up of net areas, which were converted into gross areas from each building's gross/net ratio. In the last company with the use of space as basis they used gross areas with added share of common area.

There were also great variations of how they differentiated in relation to types of spaces, yet the majority operated with 2-4 types of rooms.

One company had chosen the simple solution to operate with two types of spaces: offices and stores, and the rent to stores were determined to half the rent to offices. At the determination of space, the common areas furthermore were spread on offices and stores in the ratio $2: 1$.

Another company differentiated among 3-4 types of rooms, including offices with a rent per square metre twice the amount of laboratories and workshops.

A third company differentiated among the following four types of rooms: Offices (100\%), conference rooms et cetera without daylight $(70 \%)$, storerooms $(50 \%)$ and printing rooms $(30 \%)$. They operated with the same rent per square metre net area, but they made a notional 
reduction of the net area with the percentages stated.

A fourth company with many complex properties and 24-hours operation differentiated among nine types of rooms, including offices with normal cleaning, offices with two-shift operation and offices with three-shift operation.

\section{Internal rent contracts}

There were many variations in the formalising of the internal rent contracts, settlement frequencies and terms of space changes among the five companies.

In one group they had rent contracts with 6-7 subsidiaries who settled quarterly in account rent. Furthermore some of the subsidiaries made an internal allocation of the rent. There were no rules of notification to space changes. Space management was made by using a set of rules to space assignment, confirmed by the group management. $12 \mathrm{~m}^{2}$ for single offices, $18 \mathrm{~m}^{2}$ for main department manager, $24 \mathrm{~m}^{2}$ for chief executives and $6.5 \mathrm{~m}^{2}$ for workplace and $1.5 \mathrm{~m}^{2}$ for archive per person in large offices.

Another group had rent contracts with approx. 30 subsidiaries. Rent settlement was made with each subsidiary, whereas the controlling company settled with each division. The rent settlement was made quarterly on the basis of invoice. There were no fixed rules of notification to space changes.

One company had contracts with approx. 10 divisions, which were managed by a divisional manager referring directly to the chief executive officer. Rent settlement was made to each department (budgetary unit) by monthly transfer. Spaces could be denounced with one months' notice to the end of a quarter. There were fixed rules to space allocation and room sizes. After a financial cutback in the company they had seen a substantial interest from the departments to have less space than fixed by the rules of space allocation, thus the departments would be able to limit the rent expense.

Another company had no internal rent contracts. Settlement was made from approx. 300 budgetary units, who each month had forwarded a space and rent statement, even if settlement was made by automatic transfer. Rules for rent estimation, entry and terms of notice appeared from budget guidelines from the company's finance department. Term of notice was six months for single rooms and one year for own buildings. These terms of notice were observed in connection with external tenants. Space allocation was made from fixed space standards. This company too had experienced substantial interest from the budgetary units to use spaces optimally, thus to limit the rent expense.

The last company had contracts with 16-17 units with reference to board of directors. Settlement was made from each budgetary unit by automatic monthly transfer. There were no fixed rules of notification except for external tenancies, where their rules of notification were observed. There were also no fixed rules for space allocation. Especially at the budget phase the internal rent was important to the department's cost-consciousness.

\subsection{Financial Management in the FM Function}

As it goes for the entire company it also goes for the FM function, that a targeted financial control requires possibility to follow up on the various activities which are included in the function. Through market orientation either by outsourcing or internal settlement, the FM function is forced to calculate the expenses in relation to each activity and service. But also without a real market orientation an activity based financial control of the FM function is essential to be able to make visible and justify the cost level.

This can for instance be done through benchmarking, which is thoroughly discussed in the section after this. At benchmarking the company's performances in various areas of activity are compared with the performances in other companies, for instance by use of welldefined key indicators. Hence it can be ensured that the FM function is competitive without real market testing, and establishment of administrative systems for internal settlement may be avoided.

\section{Charts of accounts and cost structure}

The basis for an activity based financial control is an appropriate chart of account for the FM function. In most companies - private as well as public - the general financial system with matching chart of accounts is insufficient in connection with the needs of the FM function. Thus in most cases it is necessary that the FM function supplement the general chart of 
accounts for the company with a specific chart of accounts for the use of own financial control of FM.

This is illustrated in figure 3.2 in relation to the property management at a Danish university, in which there are three layers of administration.

At the political / financial layer the information requirements are determined by the Ministry of Finance's budget instruction, which for instance include a standard chart of accounts, by the requirements from the Ministry of Science and the Ministry of Education, and by the needs with the political management of the university. At the lowest administration layer the information requirements are decided by the FM function's activity needs.

As there in the 1980 'ies was an increased focus on property operation in Denmark considerable amount of efforts were used in the construction and property sector to arrange an appropriate chart of accounts for managing the operational costs. On the basis of these efforts a rather precise structure and terminology for handling of the property operation in Denmark was created. Generally seen the distinction between on one hand construction of buildings, including improvements, and on the other hand operation of property, including maintenance, was specified.

In connection with $\mathrm{DFM}^{\prime} \mathrm{s}$ benchmarking project which was completed in the first half of the 1990'ies the above mentioned structure with a small adaptation was the basis of key indicators in relation to property management. This was made after testing in a number of larger both private and public companies.

For the relation between owners and user the following distinctions were made:

- Properties which are owned and used by the same company

- Properties which are rented out

- Tenancies

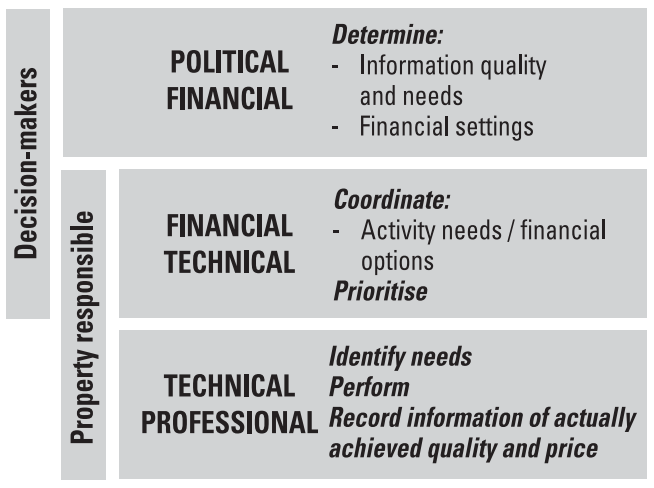

In figure 3.3 is shown a survey of the expense structure from DFM-benchmarking's instruction for cost structure. It is based on the five main cost categories to property management: Maintenance, Utilities, Cleaning, General operation and Fixed property expenses. The cost structure furthermore includes the main category Services segregated in the categories: Guard and security, Reception and telephone exchange, Post service, Data infrastructure and Canteen.

For a closer discussion of property management and services you are referred to chapters 6 and 7. You will furthermore find the definitions to the categories in DFM-benchmarking's cost structure in the Definitions of terms at the back of the book.

\section{Standards to property management and FM}

There is at present no standardised chart of accounts for property management or FM in a wider sense in Europe or in Denmark. The European standard on FM Terms and definitions specify a division between demands related to Space \& Infrastructure and People \& Organisation. This resembles the distinction between Property management and Services used by DFM-benchmarkning and also the common distinction between Hard FM and Soft FM. The ongoing European FM standardisation work on a taxonomy for FM may provide a common classification that can be used as a standardised European chart of accounts for FM.

\section{Accounting and economic analyses}

In connection with the financial control in the FM function it is important continuously to ensure that the chart of accounts is observed. Therefore all involved employees must not only know the chart of accounts, but also understand the definitions, on which the chart of account is based, and for what the chart of accounts should be used for. Here as in many other fields the correct data are best achieved if the persons who produce data have their own interest in using correct data.

In order to achieve correct data, accounting must be made by the persons who have the direct professional responsibility to the expenses in question. At external services the accounting must appear at the request of the service, hence the accounting has been decided at the time of requisition. In many cases the text in the provider invoices is practically incomprehensible, and all invoices must refer to a requisition, from
Figure 3.2

The administration

layers in relation to

property management 
which the ordering person's information of for instance the accounting appear. The development of electronic invoicing is an important tool to enforce the necessary discipline.

The administrative system to accounting and invoice handling must be organised, so the level of detail in the accounting is related to the follow up, which you want to make on the economy. It is for instance of crucial importance to the FM function that the expenses can be arranged according to each property. However you must seriously consider if you also need to arrange the expenses according to each building unit, or according to specific users. When the administrative system is into operation, it is often much time consuming to arrange the information in other ways than planned at the design of the system.

\subsection{Benchmarking and key indicators}

\section{Benchmarking}

Benchmarking is a method to gain improvements in an organisation through systematic

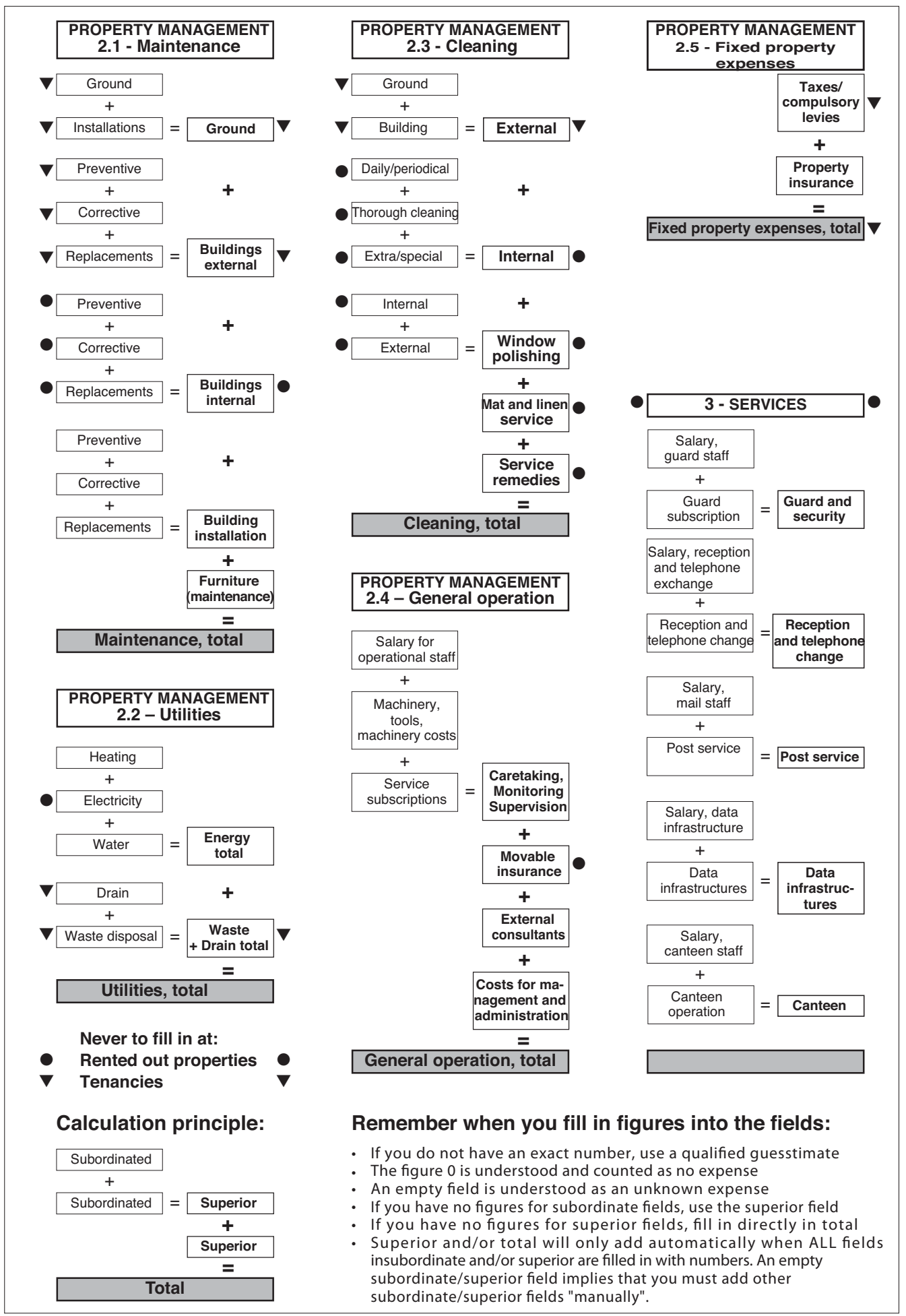

Figure 3.3:

DFM-benchmarking's cost structure for property management and services 
Definitions of benchmarking

\section{Best practice}

Types of benchmarking comparisons with the performance in one or more other organisations. The term is based on the word benchmark, which is a technical expression from the land surveyor trade meaning fixed point or measuring point. The origin of benchmarking as a method is usually ascribed to the company Rank Xerox, which experienced an increased competition within its industry from Japanese companies, and hence began a benchmarking analysis in network collaboration with other large companies with a view to gain improvements.

There are many definitions of the benchmarking term. In a leaflet from the Danish Ministry of Finance about benchmarking in the public sector it is stated that there are practically as many definitions of the term, as there are publications about the topic. An American survey shows that the main part of the definitions derive in terms such as performance, comparison, comparing, measuring, outstanding, best, improvement, process and practice.

A recurring feature of the many definitions is that one at benchmarking aim at measuring one's own company with the company which represent best practice. When you compare yourself to the best company within the field, it is possible for one to improve one's own performance. Often best practice is seen as equal with cheapest performance, but this is not always the case. On the contrary it is important to look at price and quality as connected to one another.

Financial comparisons can be an appropriate basis for a benchmarking, as quantitative data are often more easy to reach and more easy to relate to than qualitative data. On the other hand it may be limited what you can learn from the quantitative data alone. An important aspect is that you can use benchmarking as a method to begin learning processes through knowledge sharing and in connection with this the quantitative comparisons can be used as key indicators to identify areas in which there is a need to improve the performance.

There are a number of various types of benchmarking. Below some of the types of benchmarking which are especially relevant to FM are mentioned. In connection with what is benchmarked a distinction can be made between result benchmarking and process benchmarking.

Result benchmarking typically relates to quantitative comparisons of own performances to others. Result benchmarking is also called performance benchmarking and data benchmarking.

Process benchmarking relates to comparisons of own work processes and procedures to others with a view on revealing differences of importance to the performances. Process benchmarking may include both quantitative and qualitative comparisons. Process benchmarking is often implemented within a limited area in continuation of result benchmarking within a wider area.

In relation to who is benchmarked a distinction can be made between internal benchmarking, competitor or family benchmarking, crosswise sector benchmarking and one against many benchmarking.

Internal benchmarking relates to internal comparisons in own company, when there in more places are produced and provided comparable services, for instance benchmarking of the property management among the various localities of the company.

Competitor or family benchmarking relates to comparisons among two or more companies or organisations within the same industry or sector, where there are fundamental similarities among the organisations' activities. As examples of family benchmarking can be mentioned benchmarking among a group of manufacturers from various industries, and benchmarking among a circle of municipalities.

Crosswise sector benchmarking relates comparisons to quite different types of companies or organisations, in which there are comparable processes, in spite of general differences.

\section{One against many benchmarking relates to} comparisons among data to own performance and average data from a number of others efforts. It will typically be result benchmarking. An example of this is comparison of own key indicators to data from DFM-benchmarking, cf. the following section.

A comparison of what it is possible to learn by various types of benchmarking is shown in figure 3.5. In accordance with the figure the relative possibilities to learn by benchmarking are increased in the following sequence:

1. Combined result and competitor/family benchmarking gives possibilities to small but targeted continuous improvements 
2. Combined result and crosswise sector benchmarking gives possibilities to a bit larger improvements an also involves bigger challenges

3. Combined process and competitor/family benchmarking gives possibilities to larger improvements towards best practice

4. Combined process and crosswise sector benchmarking gives possibilities to further improvements in the shape of process innovations

5. However, the largest improvement potential is seen in making a thorough paradigm shift in the shape of Business Process Reengineering, cf. section 2.5. However, this can not be seen as a benchmarking activity in a limited sense.

Robert Camp, who is among the pioneers within benchmarking with a background at Xerox and author of a standard work about the topic (Camp, 1989), states in an interview, that internal benchmarking is one of the greatest unexploited possibilities, because much can be learned by internal benchmarking, and it is also a much more user friendly method. Furthermore Robert Camp points out that the preliminary step in benchmarking to understand the company's own processes and situation is often underestimated, and lack of preparation is often the cause of not achieving a satisfactory result of benchmarking (Loveday, 1997).

Implementation of benchmarking may be done in various ways and will for instance be dependent on the specific purpose of the benchmarking, and which kind of benchmarking is in question. For instance benchmarking can be implemented as a one-time-process, for instance in connection with evaluation of an organisation, or as a continuous or recurring process. In relation to financial control it is appropriate to implement benchmarking as an annually recurring process in connection with procedures to the closing of the annual accounts and budgeting. In this connection use of key indicators is most relevant, as discussed in the following section.

A combined result and process benchmarking is typically carried out with a planning phase, an analysis phase and an implementation phase, and each phase includes some steps as described below.

The planning phase:

- Identification of the work areas which must be included in the benchmarking
- Selection of companies or organisations to which you will benchmark

- Decision and implementation of data collection

The analysis phase:

- Exchange and juxtaposition of data

- Analysis of differences and reasons for the differences

- Decision of focus areas and targets to improvements

The implementation phase:

- Preparation of plans of action to improvements

- Completion and follow up of plans of action

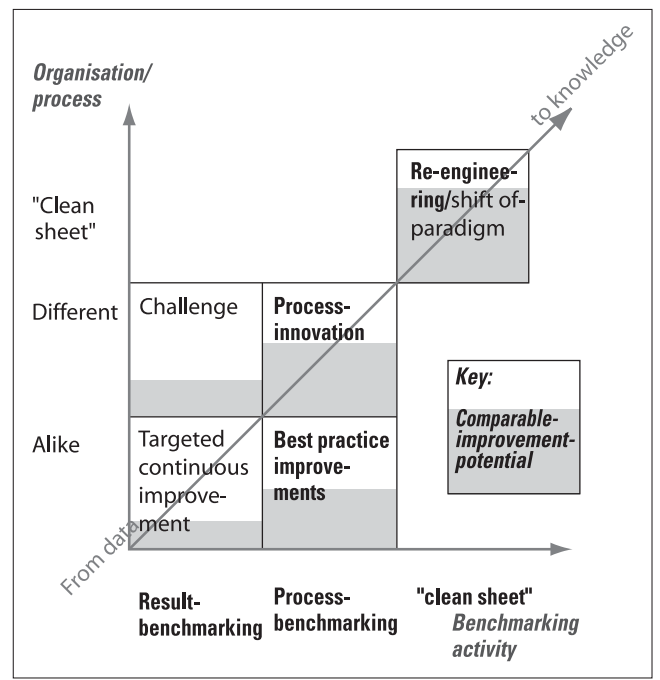

Benchmarking between competitors may imply difficulties due to competition, as the risk of either to reveal company secrets to the competitor, or to allegations of making competition limited agreements may be obvious. To limit such risk factors there are in various connections prepared ethical rules to benchmarking called Code of

Conduct. Several examples of such codes of conducts can be found on the internet and they are usually based on similar principles, for instance:

- Keep it legal

- Be willing to contribute as you receive

- Respect confidence

- Keep information internally

- Use appointed benchmarking contact

- Do not refer to benchmarking partners without permission

- Be prepared at the first approach

In companies where FM is not a core function, such risk factors are often limited, but in all cases implementation of benchmarking with other companies demand a considered and considerate behaviour.
Figure 3.4

Possibilities to learn by benchmarking between organisations

Benchmarking procedure

Code of Conduct 
In the Danish Ministry of Finance's leaflet about benchmarking it is an essential message, that comparisons and knowledge sharing may be even more relevant and useful within the public sector than within the private sector. This is for instance caused by the fact that public institutions are not typically competitors in the same way as in the private sector. Public institutions do not have the same needs to "keep their cards close to their chest" with regards to competition.

\section{Key indicators}

A key indicator is a relative figure shown as a fraction or a ratio, which can be used as a comparative measurement. A key indicator must in all cases be seen in relation to another figure. Key indicators must draw the attention to the significant and give real change signals. Are we doing the right things? And are we doing them well?

Key indicators are in themselves an important information tool in connection with the financial control in the FM function. By means of appropriate key indicators it is possible to the management of the FM function continuously to monitor whether the cost level is reasonable in relation to determined goals. Key indicators are also a useful tool in connection with planning and budgeting of activity changes. If you for instance must enter into a new tenancy, by means of key indicators you will be able to budget the expected additional expenditure for the property management.

Internal key indicators are sufficient to the above mentioned provided that these are calculated at a similar basis each time. However, the applications for key indicators are significantly increased if they are based on a standardised basis. Hence the key indicators are used as communication tool between the company and its partners, for instance service providers and consultants. Furthermore the key indicators can be the basis for exchange of experience as benchmarking with other companies.

In relation to the company's top management, the documentation value of the FM function's key indicators is increased, when they can be supported by key indicators from other companies, as it is possible with key indicators from DFM-benchmarking. However, this implies that the company's FM function is active in collecting data for key indicators and ensure that this is done due to the shared order and structure, which is defined by DFM-benchmarking, $\mathrm{cf}$. former section and figure 3.4. The activities in DFM-benchmarking are furthermore described in chapter 10 .

DFM-benchmarking primarily operates with financial key indicators to property management and to services. To property management the key indicators are made up in cost per square metre. The cost are in DKK and $100 \mathrm{DKK}$ is equivalent to $€ 13$ (May 2008). The expenses are found from the annual accounting figures divided in cost categories as shown in figure 3.3, and with definitions as shown in the Terms and Definitions at the back of the book. The space is in most cases building operational space, but key indicators can also be calculated from ground operational space, heated space and cleaning space. Terms of spaces is further discussed in chapter 5, and is also defined in Definitions of terms.

DFM-benchmarking has collected key indicators for each year since 1995. In the pilot project about key indicators prior to the establishment of DFM-benchmarking a single data collection of the year 1992 was finished, but the analysis of these data was made on an adjusted IT system, hence the key indicators to 1992 are not included in the databank of DFM-benchmarking.

Figure 3.5 shows diagrams with the main results of DFM-benchmarking's data collections for property management covering the period of 1995 to 1998 for owned, rented out and rented properties, respectively. For the years before 1998 there has been made an indexing of the figures on the basis of the development of the net price index. At comparison of the three diagrams it is seen that the expenses for property management to rented out and rented properties totally are at the same level as owned properties.

This is a natural consequence of the fact that the lessor's and the tenant's expenses are complementary in relation to companies, which own and use a property. It can furthermore be mentioned that the expenses to property management to owned properties in average amount scarcely $10 \%$ of the properties' official value assessment. Hence, this is equal to the accumulated property expenses for approx. 10 years amount the official value assessment.

As it is seen from figure 3.5 the variation for each year is very limited, which is seen as high reliability of the key indicators at this overall 
level. The rather high reliability of the overall key indicators for property management however covers great statistical variations. At the overall level it evens out due to a relative large amount of data, but at lower levels and by analyses of limited parts of the amount of data, the uncertainty can be rather high due to great variations and the limited size of the amount of data. Experience shows that the most important reasons for the variations are differences in the main use and age of the properties.

In figure 3.6 are shown diagrams divided into construction periods for owned and rented out properties, which all have administration (offices) as main use. It is obvious that the property management expenses are increased along with the age of the property. It is noticed that data for owned properties in the period 1901 to 1920 alone represent one property, and it must subsequently be taken with many reservations.

The key indicators for services are far less reliable than the key indicators for property management. This is primarily caused by the fact that contents and size of services vary much among companies. The expenses for the property management have a high extent of connection with the size of the property, and the expenses for services are to a greater extent depending on the specific activity in the building, and not at the least by the number of persons. Hence DFMbenchmarking has chosen to make up key indicators for services on the basis of number of persons, partly number of employees, partly number of employees + users.

Figure 3.7 shows expenses made up in relation to number of employees in the years 1995 to 1998. Expenses for services are primarily relevant to properties which are owned and rented, whereas these expenses are rarely relevant to rented out properties. As seen the total expenses per employee are rather alike for each year, whereas the expense per employee plus user is much more variable. There are also considerable differences in the expenses' division from each year. See also chapter 7 .

When using financial key indicators you must be aware of the limitations and risk factors which are related to this tool. The following conditions are emphasised:

- It is crucial that key indicators are based on similar preconditions in relation to chart of accounts, data structures and definitions.
- Key indicators express a real but not necessarily optimal cost level. This limitation can be met through benchmarking with companies which show better results. On basis of this, realistic goals to own performance can be set up.

- Key indicators can vary considerably for each year. At estimation of own key indicators one must take into account the factors which have inflicted on the numbers of the year. Maintenance expenses can especially vary in connection with replacements, and heating expenses are naturally dependent on the number of degree days of the year and the market price for energy products.

- The quality level must be known to use key indicators as a control instrument.

- The danger of improper use of key indicators can be significant, if they are used by persons who do not know the conditions of the figures.

Besides the financial key indicators mentioned above it may in relation to FM be relevant to have a number of other key indicators, for instance space key indicators and energy key indicators, and also other types of financial key indicators. In the following chapters some of these are discussed. Above key indicators, which are relevant to the financial control, have been presented and discussed and in the following is mentioned how such key indicators can be used in connection with benchmarking.

\section{Benchmarking with key indicators}

Key indicators from DFM-benchmarking can be used for many sorts of result benchmarking. The most immediate use is one against many

benchmarking, in which a company compare key indicators for own properties with key indicators for similar properties from DFM-benchmarking. An example of comparison of key indicators at this type of benchmarking is shown in figure 3.8 concerning Danish Broadcasting Corporation (DR).

The example includes key indicators to all DR's owned properties in the years 1992, 1995, 1996, 1997 and 1998, and similar average figures to all owned properties, which as to 1992 are based on the data collection from DFM's pilot project, whereas the key indicators from 1995 and later on are from DFM-benchmarking's data collections. It must be noticed that indexing is not made by the key indicators, so we speak of the actual figures to the years in question. 


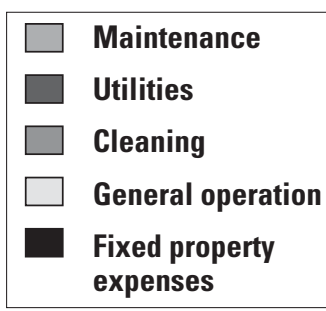

Figure 3.5

Main results from DFM-benchmarking's data collections for property management

\section{Owned properties:}

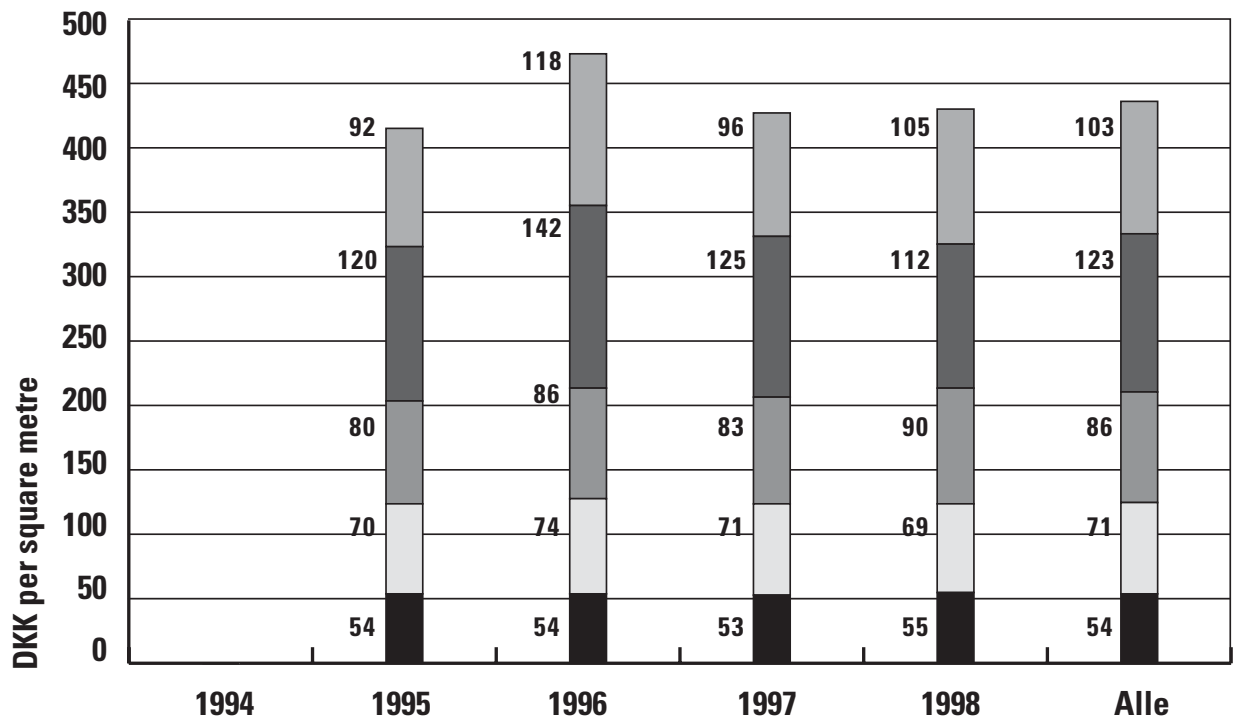

Rented out properties:

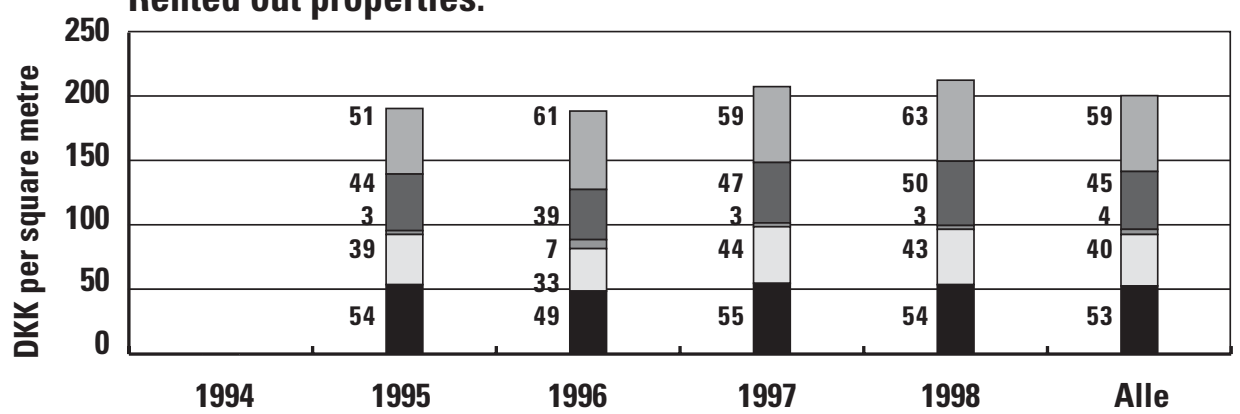

Tenancies:

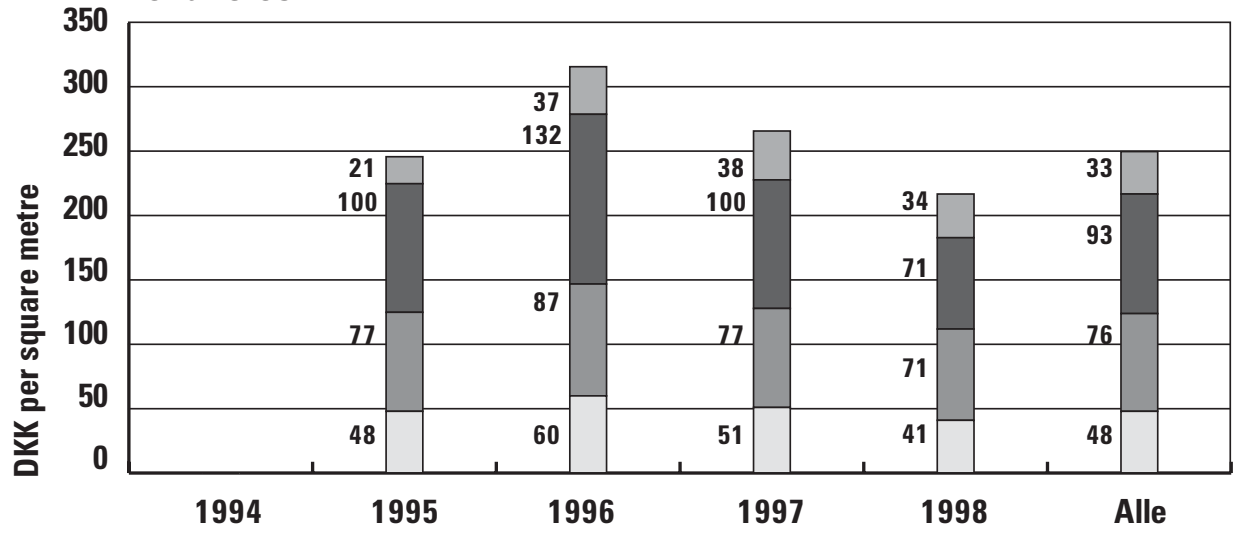

From the comparison of the key indicators the following can be deduced:

- The expenses for property management in DR's owned properties are in general 10-20 $\%$ higher than the average to all owned properties, which for instance can be justified by the facts, that DR's properties are rather complex and heavy with installations and have extraordinary long weekly operation times.

- DR's expenses were for maintenance in 1992 significantly below the average, and in 1998 significantly above the average, whereas it from 1995 to 1997 was close to the average. This must be seen in connection with the fact that DR's property administration has actively used the key indicators for 1992 to increase the maintenance budget, and in 1998 extraordinarily many replacement works of building fabrics and installation systems have been finished.

- DR's utilities expenses were in 1992 close to the average, whereas it later on was below average, which for instance was caused by a continuous expansion of building management systems.

- DR's cleaning expenses showed a significant fall from 1996, which is connected with the implementation of EU-procurement of the cleaning, cf. case 2.c. 


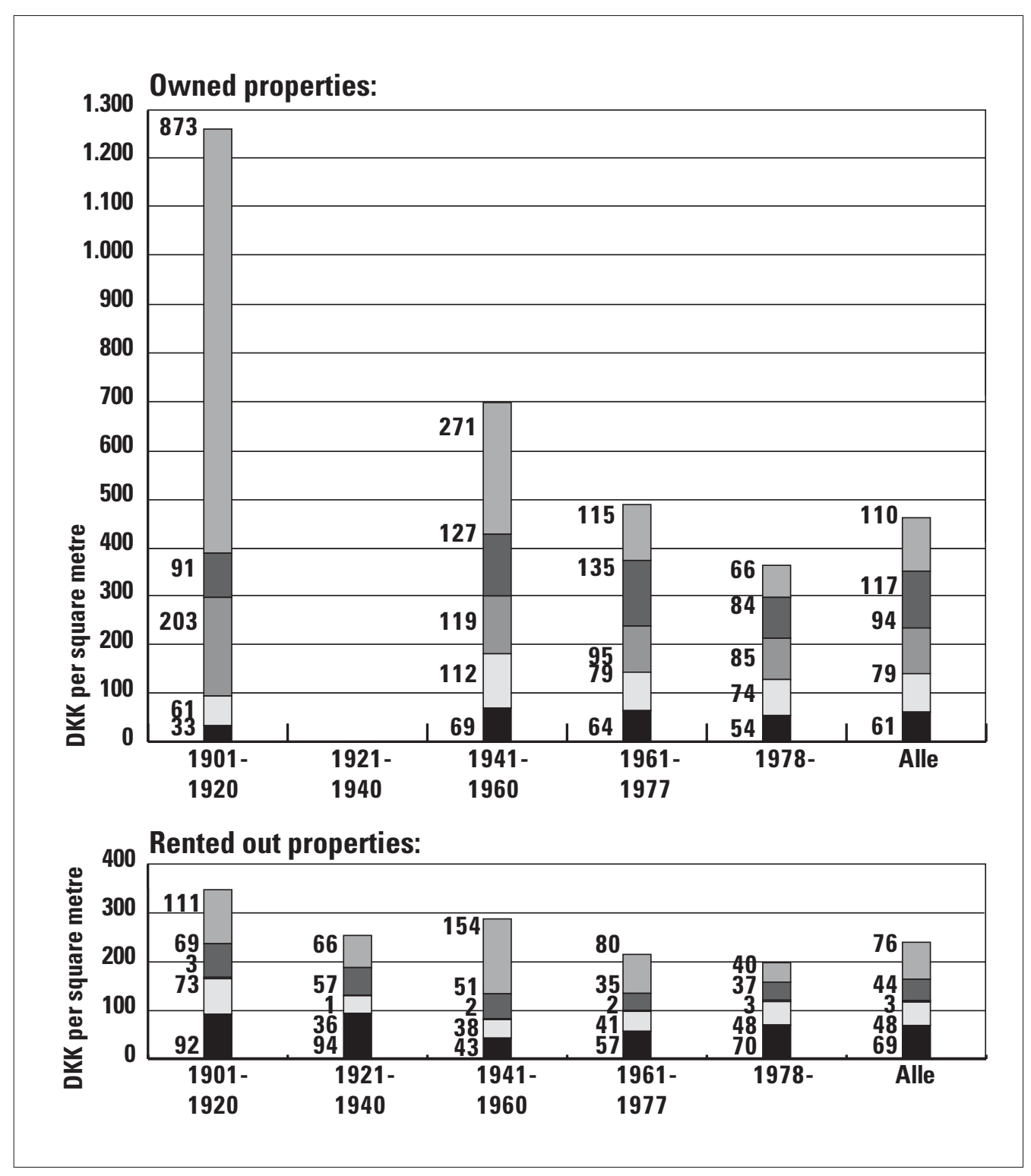

\begin{tabular}{|ll|}
\hline$\square$ & Maintenance \\
$\square$ & Utilities \\
$\square$ & Cleaning \\
$\square$ & General operation \\
$\square$ & $\begin{array}{l}\text { Fixed property } \\
\text { expenses }\end{array}$ \\
\hline
\end{tabular}

- DR's expenses to general operation is significantly above the average, which for instance is caused by the above mentioned general characteristics at DR's properties and property management. A reduction of the cost level from 1995 to 1996 has taken place compared to implementation of an internal rationalisation and reorganising. The increased cost level in 1998 was mainly caused by extraordinary expenses for external consultants compared to the extraordinary extent of replacement works.

- DR's fixed property expenses are in general above the average, whereas the cost level is rather constant throughout the period - both to DR and to the average of all owned properties.

- Apart from the high deviations of maintenance expenses in 1992 and 1998 DR's expenses for property management is rather constant throughout the years calculated in the year's prices, which implies a vaguely declin- ing tendency in fixed prices. Contrarily to this the average to all owned properties is increasing in the year's prices, and also vaguely increasing in fixed prices, cf. figure 3.6.

\section{Internal benchmarking}

In the above example average key indicators for DR's owned properties are used. Similar to this a benchmarking with basis in key indicators to specific properties in a company can be made. This can be done by internal benchmarking through comparison between two or more properties. The key indicators to all the company's properties and to all owned properties in DFMbenchmarking's data collection can represent a shared frame of reference at such an internal benchmarking.

An example of comparison of key indicators at an internal benchmarking is shown in figure 3.9. The example in question includes three totally alike properties built at almost the same time by
Figure 3.6

Property management related to age in owned and rented out properties used for administration 


\begin{tabular}{l}
$\square$ Canteen \\
$\square$ Data \\
infrastructure \\
$\square$ Post service \\
$\square$ Reception and tele- \\
phone exchange \\
Guard and security \\
\hline
\end{tabular}

Figure 3.7

Services in owned properties related to number of employees and employees + users

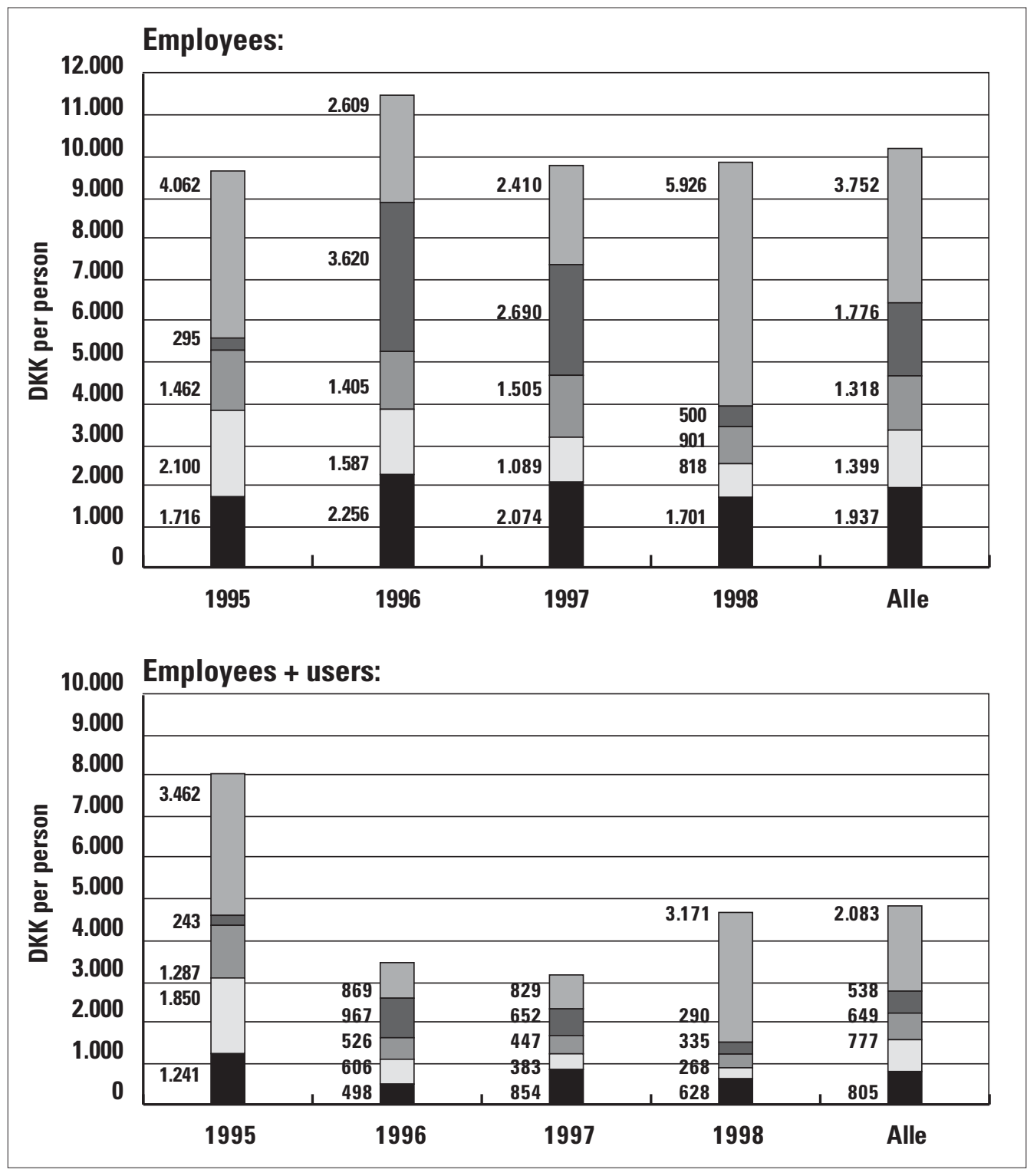

$\mathrm{DR}$, and for the same use - regional radio houses - on the outskirts of Odense, Vejle and Aalborg. The number of employees is almost alike in the three buildings, and the property management is handled by the same operational function situated in Aarhus using local service providers. It must be noticed that as in figure 3.8 there is not made an indexing of the key indicators, hence you see the actual figures to the year in question.

It appears from figure 3.9 that the expenses in the three properties are rather close to each other, and it varies each year between the properties where the cost level is the highest and the lowest. The variation primarily originates from the maintenance expenses, which is naturally connected with the extent of replacements and they vary for each year to each property. In 1998 there is a quite extraordinary high expense for maintenance of one of the properties. This is parallel to the variations which were seen in the maintenance expenses for all DR's properties in
1998, cf. figure 3.8 .

A more systematic difference can be observed in relation to fixed property expenses, where one of the properties during all the years except from 1998 is higher than the remaining properties. At the same time the fixed property expenses were in 1992 significantly higher compared to later on, which is connected with a reduction of the public value assessment of real property to all those properties after DR's complaints of the assessment of real property for 1992.

\section{Competitor or family benchmarking}

Two different examples of competitor or family benchmarking are illustrated in figure 3.10 and case $3 . b$.

The example in figure 3.10 concerns administration properties belonging to two lessors - lessor 1 and lessor 2. Both lessors own a considerable number of administration properties, and the key indicators to those are compared divided 
into age groups similar to figure 3.6, which hence make a shared frame of reference with average key indicators to all rented out administration properties included in DFM-

benchmarking's data collection for 1998 .

On basis of the comparison in figure 3.10 the following can for instance be deducted:

- The cost level to lessor 1 is in average approx. $20 \%$ above the cost level to lessor 2 , which to a great extent is caused by much higher expenses for shared operation for lessor 1, whereas lessor 2 actually has higher expenses for maintenance and supply.

- Both lessors are however below the average to all rented out administration properties in figure 3.6.
- The general tendency for increased cost level in connection with the property's age is to both lessors seen through some significant variations for some of the groups of age.

- To both lessors the expense division varies considerable from one group of age to another, and only the significantly higher cost level for shared management for lessor 1 is general to all groups of age.

- A benchmarking process completed by the two lessors has revealed that the higher expense level to lessor 1 is caused by a generally higher quality level, for instance in connection with various types of tenants.

The example in case 3.b relates to two state companies which on initiative from one of the

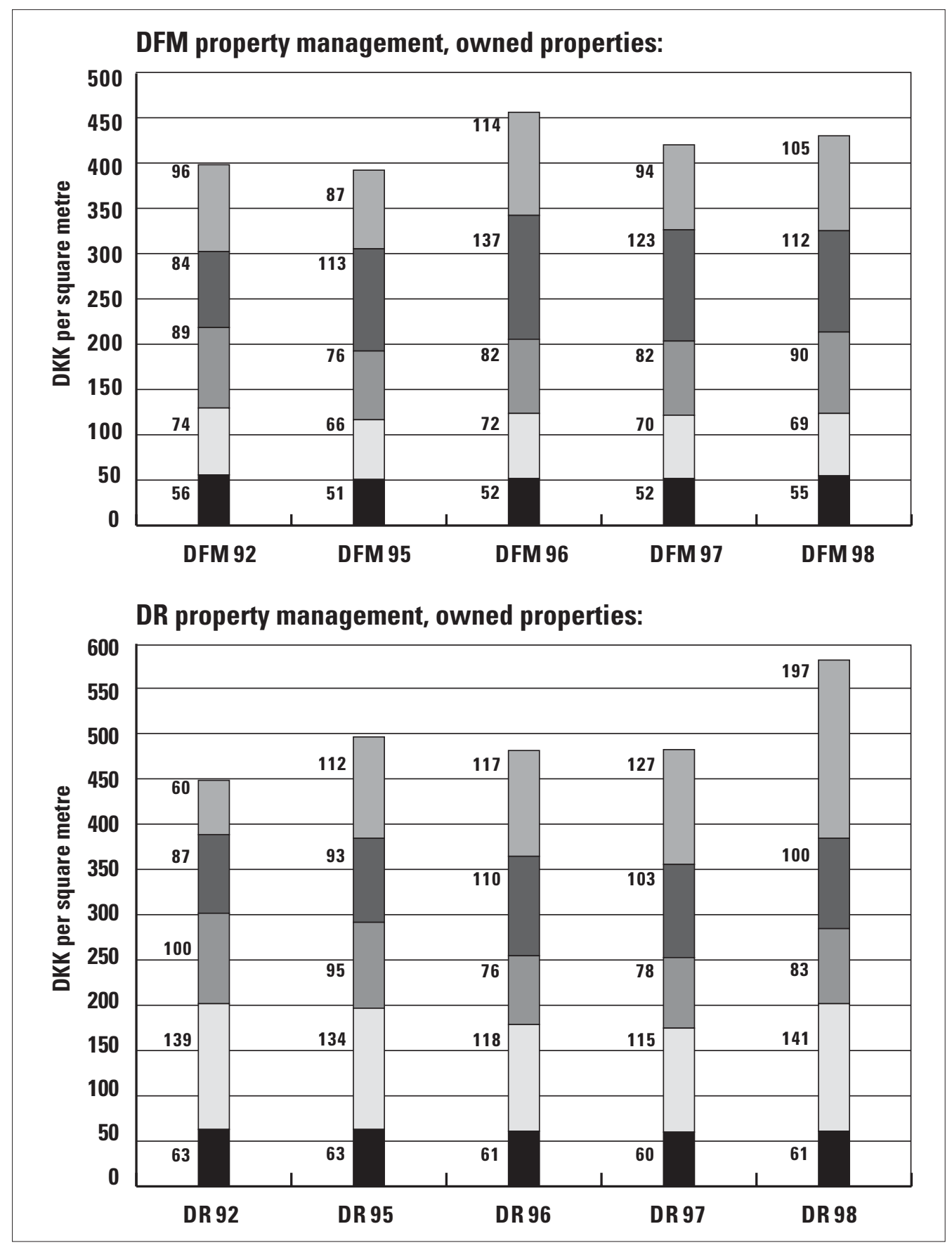

Figure 3.8

Comparison between key indicators from DFM-benchmarking and $D R$ for owned properties. 
companies and with assistance from DFMbenchmarking's secretariat in the beginning, have completed a benchmarking processes including owned properties and tenancies. In the case description the emphasis is on the process which was used at the benchmarking.

In the above mentioned examples the basis is in benchmarking from DFM-benchmarking's methodology. Benchmarking using key indicators can however be implemented in many ways. EuroFM has carried out a project which compared the benchmarking systems in six European countries (EuroFM, 2001). In the following three examples from benchmarking activities in other European countries are presented.

\section{Example of benchmarking from Finland}

In figure 3.11 is shown an example of how the Finnish KTI (Institute for Real Estate Economics) presents key indicator results for a property. As it appears, the relative level for the property's different sorts of expenses in relation to other similar properties is shown in a diagram. To the sorts of expenses, which are higher than the median, the potential annual saving is calculated, if the cost level was reduced to the median level. Furthermore, each saving possibility is summarised to the total annual saving possibilities.

One may criticise this way of presenting key indicators to be rather mechanical as it as an implicit presumption includes that the median value is the "true" expense without considerations to quality and service level. The risk at improper use at such a presentation of key indicators is impending. On the other hand such a presentation gives a fine overview of whether there may be reasons to concentrate on improvements and savings.

\section{Benchmarking with quality levels in the Netherlands}

In DFM's benchmarking project it was from the beginning considered whether quality levels in relation to the key indicators should be given. There were proposals of questionnaires for data collection, to ask for information as to the properties' state of maintenance, the level of heat insulation and cleaning friendliness et cetera as high, medium or low. However this was decided being too subjective. Information of quality level hence originally was kept outside the data collection due to lack of objective criteria. In was discussed later on in DFM-benchmarking, and some overall quality measures have been implemented.

Besides that the users of key indicators from DFM-benchmarking must use their knowledge of own properties' quality level compared to the key indicators. It may be supposed that the average key indicators show an average quality and service level. When you compare key indicators for own properties, you must consider their quality and service levels in evaluating whether the cost level is reasonable. At benchmarking with others you have the possibility to make a direct comparison of quality and service levels, cf. case 3.b.

An interesting example of inclusion of quality and service levels in connection with key indicators has been developed in the Netherlands. The principle is to determine a number of objective criteria to whether the quality and service level is high, medium or low. They speak of "factors influencing cost" and divide them in three types:

\begin{tabular}{|l|l|}
\hline$\square$ & Maintenance \\
$\square$ & Utilities \\
$\square \quad$ Cleaning \\
$\square \quad$ General operation \\
$\square$ \\
$\begin{array}{l}\text { Fixed property } \\
\text { expenses }\end{array}$ \\
\hline
\end{tabular}

Figure 3.9.

Internal benchmarking among three alike owned properties in $D R$

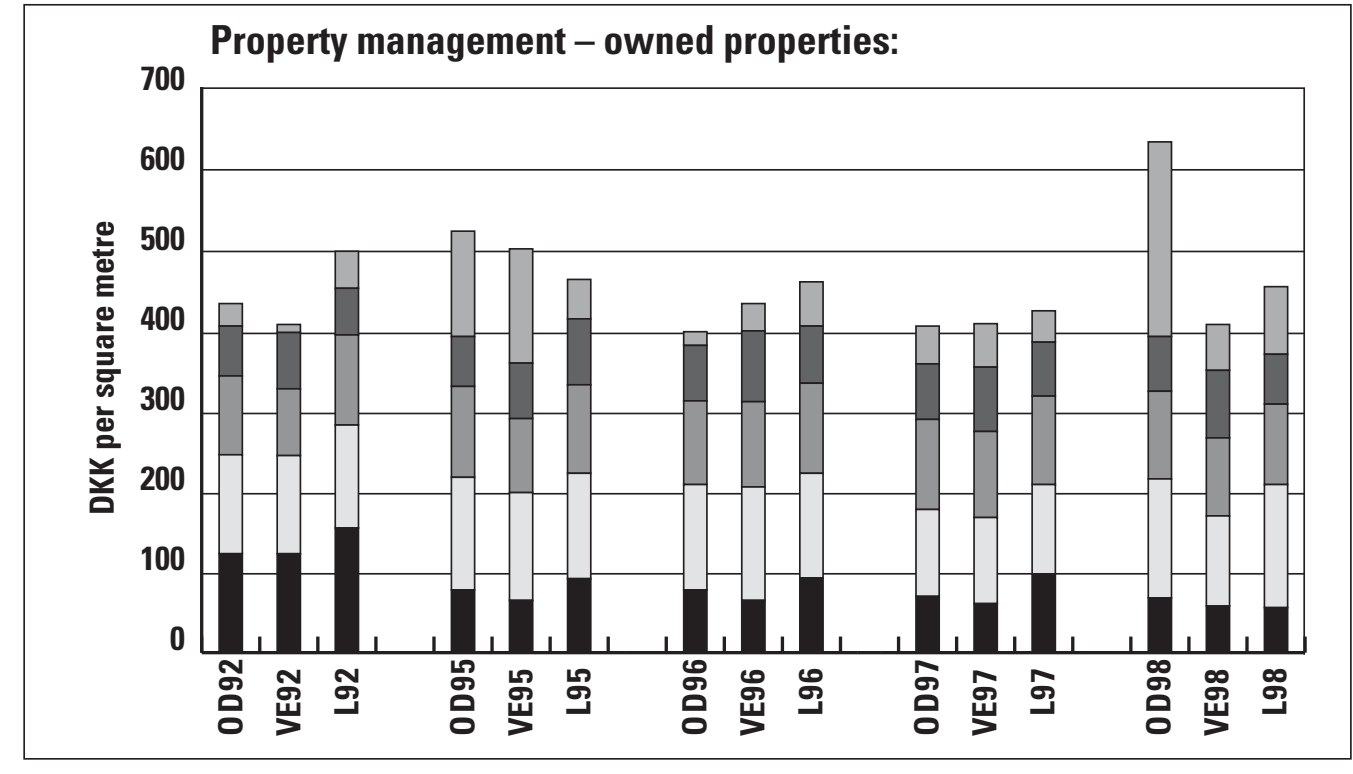

Facilities Management for Students and Practitioners - Chapter 3: Financial Management 


\section{Case 3.b: Benchmarking between Two Danish Companies}

In the spring 2000 a Danish state company (company A) took the initiative for a benchmarking process about property management with another Danish state company (company B) using DFM-benchmarking's methodology and data. The background for this was that company A due to its result contract must complete benchmarking with similar companies. In preparation for this company A became a member of DFM-benchmarking, and by means of the association's secretariat the company searched for a benchmarking partner among other members.

At the selection they for instance emphasised that it had to be a state company, which both had own properties and tenancies just like company A. The association's secretariat contacted member companies which fulfilled the criteria and asked for the interest of participation in the benchmarking. After company B had shown interest, company A was informed of name and contact person in company B, so a direct contact could be made. The remaining part of the benchmarking process was completed without the assistance of the association.

At a meeting with representatives from the companies they both presented key indicators to relevant properties and tenancies, and they were compared to each other and to similar average figures from DFM-benchmarking. In connection with the key indicator comparisons, similarities and differences in the property management were discussed. It was decided to continue with a detailed benchmarking between an owned property and a tenancy from each company, and the data in question were exchanged.

The further benchmarking analysis was made in company $A$, but with a continuous contact to company $B$ to clarify detail questions and inspection of a building in each company to estimate level of quality et cetera. The result of the benchmarking was a comprehensive report describing the benchmarking process and analysis and recommendation to the management in company $A$ to prepare plans of action for savings of the property management in a number of specific areas. The report was sent to company $B$ as orientation and to be commented on.

In the report key indicators were compared as shown in the chart below at the overall level to tenancies, and also in a similar way on lower levels.

\begin{tabular}{|l|rr|rr|rr|rr|}
\hline & $\begin{array}{c}\text { DFM-benchmarking } \\
\text { Tenancies, adm. } \\
\text { Number of } \\
\text { answers }\end{array}$ & $\begin{array}{c}\text { DKK/m² } \\
\text { Property management }\end{array}$ & $\begin{array}{l}\text { Company B } \\
\text { Number of } \\
\text { answers }\end{array}$ & DKK/m² & $\begin{array}{c}\text { Company A } \\
\text { Property management } \\
\text { Number of }\end{array}$ & $\begin{array}{r}\text { DKK/m² } \\
\text { answers }\end{array}$ & $\begin{array}{r}\text { Diff. } \\
\text { A-DFM } \\
\text { DKK/m² }\end{array}$ & $\begin{array}{r}\text { Diff. } \\
\text { AKK/m² }\end{array}$ \\
\hline Maintenance & 21 & 37 & 1 & 37 & 1 & 99 & 62 & 62 \\
Utilities & 21 & 62 & 1 & 81 & 1 & 126 & 62 & 45 \\
Cleaning & 21 & 70 & 1 & 89 & 1 & 116 & 46 & 27 \\
Shared operation & 21 & 49 & 1 & 89 & 1 & 72 & 23 & -17 \\
\hline Total & 21 & 218 & 1 & 296 & 1 & 413 & 195 & 117 \\
\hline
\end{tabular}

As it can be seen there were significant variations of expense levels, and they could to a certain degree be explained by variations in quality levels. With the basis in the benchmarking it was possible to make visible the financial consequences of a high quality level and to give basis for decision whether saving possibilities should be used. 
- Process depending factors, i.e. conditions in connection with the way of which services are executed, for instance the organising of the work and time for its execution

- Product depending factors, i.e. conditions in connection with the quality of the service

- Context depending factors, i.e. condition in connection with the property and the localities where the service is executed

In figure 3.12 is shown an example of a diagram for indication of level to factors influencing cost related to cleaning.

Regardless that the methodology in the Dutch model seems very convincing it must be complicated to integrate such a model in the data processing of key indicators, as it must be necessary to develop similar models to each key indicator, with a similar considerable increased data quantity. It is the question whether it is more appropriate to use a similar methodology for an overall classification of properties. On basis of this, the property classification might be included as a parameter in connection with key indicators. Such a classification is closely presentetd in chapter 4 .

\section{Difficulties at international \\ benchmarking}

With the background in an international benchmarking it will finally be illustrated what kind of difficulties you will have when you want to make a benchmarking without a common chart of accounts and data structure. The example is based on a benchmarking process of property manegement by a Norwegian company and companies from Denmark, Sweden and Finland. The case is explained in more details in section 6.2.1 in the book on FM Best Practice in the Nordic Countries (Jensen et al, 2008).

The specific example here only concerns expenses for maintenance between the Norwegian and a Danish company. In figure 3.13 is shown a comparison of the maintenance expenses in the two companies. To gain an equal comparability it was necessary to make corrections to whether planning and external consultants were included or not, whether share of administration and management were included or not, and whether operation of CAFM system was included or not. However, it was not possible to segregate rebuilding expenses from maintenance in one of the companies; hence the total result was not fully satisfactory, in spite of the efforts and corrections.

\begin{tabular}{|ll|}
\hline$\square \quad$ Maintenance \\
$\square \quad$ Utilities \\
$\square \quad$ Cleaning \\
$\square \quad$ General operation \\
$\square$ \\
Fixed property \\
expenses
\end{tabular}

Figure 3.10.

Benchmarking

between two lessors

of administration properties

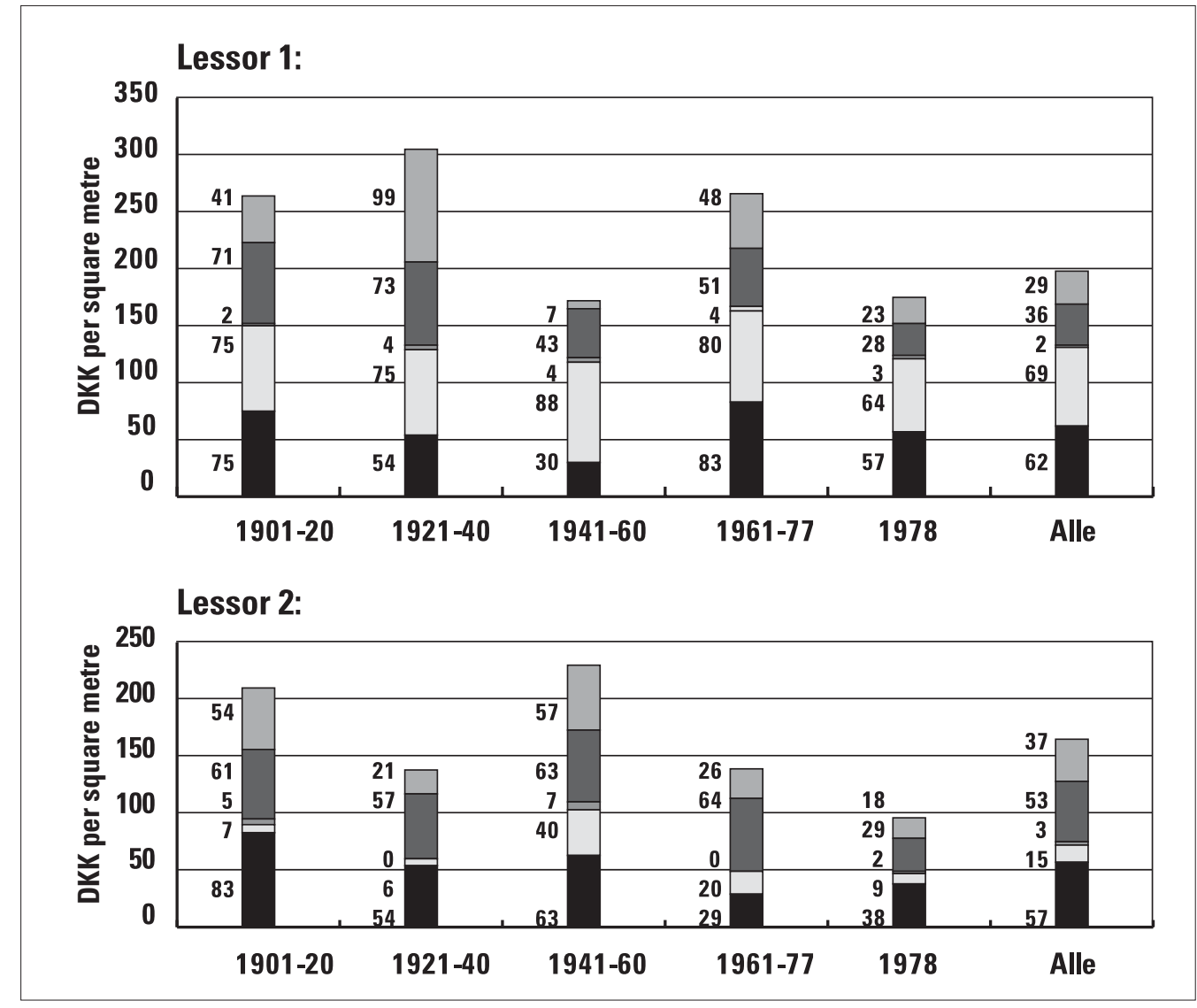

Facilities Management for Students and Practitioners - Chapter 3: Financial Management 


\begin{tabular}{|c|c|c|c|c|c|}
\hline Sort of expense: & $\begin{array}{l}\text { Lower than } \\
\text { the bottom } \\
\text { quartile: }\end{array}$ & $\begin{array}{l}\text { Between bot- } \\
\text { tom quartile } \\
\text { and median: }\end{array}$ & $\begin{array}{l}\text { Between up- } \\
\text { per quartile } \\
\text { and median: }\end{array}$ & $\begin{array}{l}\text { Higher than } \\
\text { upper } \\
\text { quartile: }\end{array}$ & $\begin{array}{l}\text { Potential } \\
\text { annual } \\
\text { saving in } € \text { : }\end{array}$ \\
\hline Administration & & & & $\bullet$ & 5.107 \\
\hline Maintenance & & $\bullet$ & & & \\
\hline Grounds & & & • & & 152 \\
\hline Cleaning & $\bullet$ & & & & \\
\hline Heating & & $\bullet$ & & & \\
\hline Water and drain & $\bullet$ & & & & \\
\hline Electricity & & & & $\bullet$ & 6.958 \\
\hline Waste disposal & & & $\bullet$ & & 512 \\
\hline Insurance & & & $\bullet$ & & 32 \\
\hline Land tax & & & $\bullet$ & & 4.238 \\
\hline Property tax & & & & $\bullet$ & 4.306 \\
\hline Other expenses & & $\bullet$ & & & \\
\hline Repairs / replacements & & $\bullet$ & & & \\
\hline Total annual saving possi & ties: & & & & 21.305 \\
\hline
\end{tabular}

Figure 3.11: Saving potential at benchmarking (Source: KTI, 1999).

\begin{tabular}{|c|c|c|c|c|c|c|}
\hline \multicolumn{2}{|c|}{ Factors influending cost: } & \multicolumn{5}{|l|}{ Categories: } \\
\hline \multicolumn{2}{|c|}{$A=$ Process, $B=$ Product,$C=$ context } & \multicolumn{2}{|l|}{1} & \multicolumn{2}{|l|}{2} & \multirow{2}{*}{$\begin{array}{l}3 \\
6: 00-20: 30\end{array}$} \\
\hline A.1 & Moment of cleaning & Continuous & $\square$ & $<6: 00$ or $>20: 30$ & $\square$ & \\
\hline A.2 & $\begin{array}{l}\text { Ratio juveniles: total } \\
\text { cleaning personnel }\end{array}$ & $<1: 10$ & $\square$ & $1: 10-1: 8$ & $\square$ & $>1: 8$ \\
\hline A.3 & $\begin{array}{l}\text { Ratio inspectors: } \\
\text { executory }\end{array}$ & $<1: 5$ & $\square$ & $1: 5-1: 10$ & $\square$ & $>1: 10$ \\
\hline A.4 & Management form & Own control & $\square$ & Combination & $\square$ & $\begin{array}{l}\text { Contracted } \square \\
\text { out }\end{array}$ \\
\hline B.5 & Cleaning quality & Bacteriologic & $\square$ & Hygienic & $\square$ & Visual $\square$ \\
\hline C.6 & Floor finish & $\begin{array}{l}\text { Hard floor } \\
\text { with vax }\end{array}$ & $\square$ & $\begin{array}{l}\text { Hard floor } \\
\text { without vax }\end{array}$ & $\square$ & Carpet \\
\hline C.7 & Area per office workplace & $<14 \mathrm{~m}^{2}$ & $\square$ & $14-18 m^{2}$ & $\square$ & $>18 \mathrm{~m}^{2}$ \\
\hline C.8 & Area per sanitary unit & $<5 \mathrm{~m} 2$ & $\square$ & $5-10 m^{2}$ & $\square$ & $>10 \mathrm{~m}^{2} \square$ \\
\hline C.9 & Year of construction & Before 1945 & $\square$ & $1945-1975$ & $\square$ & After $1975 \square$ \\
\hline C.10 & $\begin{array}{l}\text { The net floor area } \\
\text { of building }\end{array}$ & $<1.000 \mathrm{~m}^{2}$ & $\square$ & $1.000-5.000 \mathrm{~m}^{2}$ & $\square$ & $>5.000 \mathrm{~m}^{2} \square$ \\
\hline C.11 & Own factor: & & $\square$ & & $\square$ & $\square$ \\
\hline
\end{tabular}

Figure 3.12: Factors influencing cost for cleaning (source: N.E.F.M.A., 1004)

\begin{tabular}{|l|r|r|}
\hline Maintenance expenses Euro pr. $\mathbf{m}^{2}$ & Norwegian company & Danish company \\
Maintenance, incorrected & 35,8 & 23,0 \\
\hline Planning / external consultants & Included & 4,6 \\
\hline Administration / management & Included & 3,0 \\
CAFM-operation & 1,6 & Included \\
Maintenance, corrected & 37,4 & 30,6 \\
\hline Rebuilding & Included & Not included \\
\hline
\end{tabular}

Figure 3.13:

International benchmarking of maintenance expenses 


\section{References}

In relation to benchmarking Robert C. Camps' book on the topic is a standard (Camp, 1989).

\section{Literature}

Robert C. Camp: Benchmarking: The Search for Industry Best Practices that Lead to Superior Performance. Quality Press, 1989.

John Connor, Procord/Johnson Controls: Outsourcing facilities management. Article in Worthington, 1997.

EuroFM: Facilities Management Benchmarking in Europe - A Comparative Study of FM Benchmarking Systems in Six European Countries. European Facilities Management Network, 2001.

IFMA: Benchmarks 1991. Research Report \#7. International Facility Management Association, 1992.

$\underline{I F M A}$ : Benchmarks II. Research Report \#13. International Facility Management Association, 1994.

Per Anker Jensen, Kjeld Nielsen and Susanne Balslev Nielsen: Facilities Management Best Practice in the Nordic Countries - $\mathbf{3 6}$ cases. Centre for Facilities Management, Technical University of Denmark, 2008.

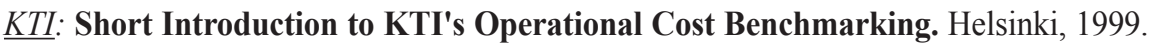

Marion Loveday: When only the best is good enough. Article in Measuring Business Excellence, Volume 1, Number 1. European Quality Publications Limited, 1997.

N.E.F.M.A.: Manual of Facilities Key indicators. The Netherlands, March 1994.

Bernard Williams: Benchmarking - Kill or Cure? Article in Facilities Management UK. 1999a.

Bernard Williams: Benchmarking Quality and Risk. Article in Facilities Management UK. 1999b.

Bernard Williams: Benchmarking in practice - life at the coal face. Article in Facilities Management UK. 1999c.

Websites

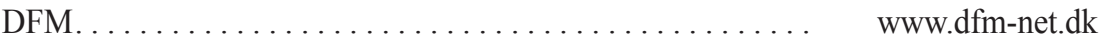

DFM-benchmarking $\ldots \ldots \ldots \ldots \ldots \ldots \ldots \ldots \ldots \ldots \ldots \ldots \ldots \ldots \ldots \ldots$ www.dfm-key.dk 


\section{Strategic Planning}

\begin{tabular}{|c|c|}
\hline \multicolumn{2}{|c|}{ Figures } \\
\hline 4.1 & $\begin{array}{l}\text { Adaptation possibilities for the } \\
\text { property portfolio............. }\end{array}$ \\
\hline 4.2 & $\begin{array}{l}\text { The principle of calculating life } \\
\text { cycle costs and annual costs.. }\end{array}$ \\
\hline 4.3 & $\begin{array}{l}\text { Development of quality level at } \\
\text { various maintenance methods .. }\end{array}$ \\
\hline 4.4 & $\begin{array}{l}\text { Norwegian table for value analysis } \\
\text { of building condition ............. }\end{array}$ \\
\hline 4.5 & $\begin{array}{l}\text { BQA's points for emergency } \\
\text { power supply in an office building. }\end{array}$ \\
\hline 4.6 & $\begin{array}{l}\text { Correlation between BQA points and } \\
\text { construction expenses } \ldots \ldots \ldots \ldots \ldots 89\end{array}$ \\
\hline 4.7 & Process procedures at risk control . . . . 89 \\
\hline 4.8 & $\begin{array}{l}\text { The risk expenses' correlation } \\
\text { with the safeguard level ....... }\end{array}$ \\
\hline \multicolumn{2}{|c|}{ Cases } \\
\hline 4.a & $\begin{array}{l}\text { Property Strategy in Danish } \\
\text { Broadcasting Corporation (DR) ........74 }\end{array}$ \\
\hline 4.b & $\begin{array}{l}\text { Life Cycle Costs of Owned } \\
\text { versus Leased Space ....... }\end{array}$ \\
\hline 4.c & $\begin{array}{l}\text { Maintenance Strategy in Danish } \\
\text { Broadcasting Corporation (DR) .. }\end{array}$ \\
\hline \multicolumn{2}{|c|}{ Check lists } \\
\hline 4.A & Acquisition of Existing Property . . . . . .76 \\
\hline 4.B & $\begin{array}{l}\text { Entering of Lease Contract for a } \\
\text { New Lease } \ldots \ldots \ldots \ldots \ldots \ldots\end{array}$ \\
\hline 4.C & Insurance. ................. 90 \\
\hline
\end{tabular}

Property Strategies $\ldots \ldots \ldots \ldots \ldots \ldots \ldots \ldots, 72$

Adaptation of the Property Portfolio

for the Organisation. ................. 73

Investment Analysis and Life Cycle Cost. . . . . . 77

The Building Client Function . . . . . . . . . 79

Maintenance Strategies. . . . . . . . . . . . 82

Building Investment and

Maintenance Planning . . . . . . . . . . . . 83

Building Assessment and Classification . . . . . 85

Examples of assessment and classification systems . . . . . . 86

Risk Management $\ldots \ldots \ldots \ldots \ldots \ldots \ldots \ldots .88$

References. . . . . . . . . . . . . . . . . . 91 
The strategic planning tasks in the FM function mainly consist of the following:

- Estimation of the company's long-term needs of space for various purposes and various localisation

- Investment analyses and strategic evaluation related to the property portfolio

- Preparation of proposals for larger re-dispositions and plans for expansion, reduction and relocation

- Preparation of construction plans and maintenance plans for the property portfolio

These tasks are discussed in the chapter along with some associated topics such as assessment and classification of buildings and risk management.

In section 4.1 property strategies are discussed in general and with a special focus on the question whether a company should own or lease the space that they use. The adaptation between the property portfolio and the company's organisation is discussed in section 4.2 emphasising acquirement of property and signing lease contracts.

At investment analysis calculation of Life Cycle Cost is a useful tool. With this tool, as explained in section 4.3, construction expenses and operational expenses are compared on an equal footing. Hence alternative property investments and alternatives between own or lease of space can be compared considering the total cost over the entire lifetime of a building or during a more specific period.

FM is mostly concerned with the operational function, but in connection with planning of expansions or relocation of companies the function as building client has focus. Handling the building client function in connection with larger construction projects is discussed in section 4.4.

To companies who own their buildings it is important to maintain the value which the buildings represent. Maintenance strategies are discussed in section 4.5, and construction and maintenance planning are discussed in section 4.6.

In chapter 2 the problems by determining service quality and service levels were discussed. The problems are no less when it comes to assessing the quality of buildings. In section 4.7 various types of property assessments are mentioned, and some examples of systems for building assessment and classification are presented.

Handling of risk is a general element within most management disciplines, but to FM risk management is also a specific work area, and this topic is discussed in section 4.8, where the topics security and insurance are also mentioned.

You may find references at the end of the chapter.

As to more specific discussion of space allocation, refurbishment, rebuilding, interior layout and relocation et cetera, we refer to chapter 5 about Space Management.

\subsection{Property Strategies}

The handling of a company's long-term interests related to property and space portfolio is an important strategic field of work within FM and perhaps also the most important aspect at FM in relation to company strategy. Sometimes the work field is called Corporate Real Estate Management (CREM) and by some it is seen as a separate and superior field of work compared to FM as a mostly operational field, but in this book CREM is seen as part - and a very central part - of FM.

When property strategies are so important it is due to the fact that the company's properties and space simultaneously serve or may serve a number of vital functions related to the company's development possibilities:

1. Fixed property investments are often one of the most important assets of a company both in a narrow financial sense, but also as part of the company's culture and image.

2. Properties and space constitute the physical surroundings of the company's activities, hence design and quality have a substantial importance to the organisation and production development of the company's core functions.

3. The design and quality of properties and space are also important so that company's 
support functions can give appropriate and economical service to the core functions.

4. Implementation of new activities with new products and/or in new markets requires provision of the necessary physical surroundings prior to initiation of the activities.

According to Arthur Andersen Real Estate Service Group $75 \%$ of the business properties in Europe are domicile properties. At the same time real estate represents at the least $20 \%$ of a typical Danish company's total assets. The total property costs are often the largest operational cost next to the staff costs. In spite of this, property issues are still rather insignificant to the top management in many companies; hence 45 $\%$ of all European companies have no property strategy. Properties are considered a necessary cost and/or "dead" capital.

In case 4.a an example of property strategies in a company is shown.

One of the central questions in relation to property strategy is whether the company itself must own its properties/space, or whether the company should release itself from tied-up capital in real property, and instead make leases. During the 1990'ies there has been a significant tendency that more companies has changed from owning its facilities and in stead lease them as sale and lease back or financial outsourcing.

So far the tendency has been stronger in USA and in some larger European countries than in the Nordic countries. For instance, Shell in Great Britain has sold off 180 of their service stations and Marks \& Spencer has sold off the major part of their shops. The German supermarket chain Metro has also sold out 290 properties, and the French hotel chain Accor has sold out 22 hotels. In Denmark the tendency has for instance showed itself in multinational companies such as IBM, and also among consultant engineering companies.

The reason to implement sale and lease back is to release capital either due to lack of funds for the regular operating activities and necessary investments, or because investment of the released capital can give a higher yield through alternative investments than the yield from investments in the company's own properties.

In a report from the Danish Ministry of Finance about the State Property and Building Adminis- tration from August 1999 it is suggested as mentioned in chapter 3 to reach a higher degree of market-orientation, including rent settlement and free choice of provider. However, it was regarded as too risky to submit the ownership, hence risking the state users' space supply, unless there is a well-functioning market with more competing providers. This conditions was estimated only to be fulfilled for approx. $1 / 2$ million of the in all 8 million $\mathrm{m}^{2}$ floorage, which the state owned at the time.

Within the evaluation of the expediency of own or lease it is a question of whether there are particular needs of space, which can only be met in buildings built for the specific purposes of the company, or whether the need of space is general, which can be met in buildings built for an unknown market, for instance common office buildings. The development of the real estate value and the financing expenses has also major importance, especially to private companies. So it is not hardly accidental that the tendency of more lease than own has gained acceptance in the 1990 'ies with a rather low inflation, interest rate and increase of real estate value.

If the company owns its properties or part of them, it is or ought to be a primary target to the property strategy to ensure the economic value of these properties. This is expressed in strategies and plans of maintenance and refurbishment of the properties. It may of course also imply buying and selling of properties. The overall goal with property strategies is also to ensure the best possible long-term adaptation between on one hand the company's organisation and development needs, and on the other hand the company's property and space portfolio. This is for instance seen in property related construction plans. These topics will be discussed in the following section.

\subsection{Adaptation of the Property Portfolio for the Organisation}

The development in a company's activities and organisation will continuously imply changed demands to the property portfolio, both qualitatively and quantitatively. To meet these demands it is crucial that the FM management knows the company's general development strategies and plans of activities. The FM function must at any time be prepared to present proposals with a short notice of how to change the property portfolio to meet the changed needs.

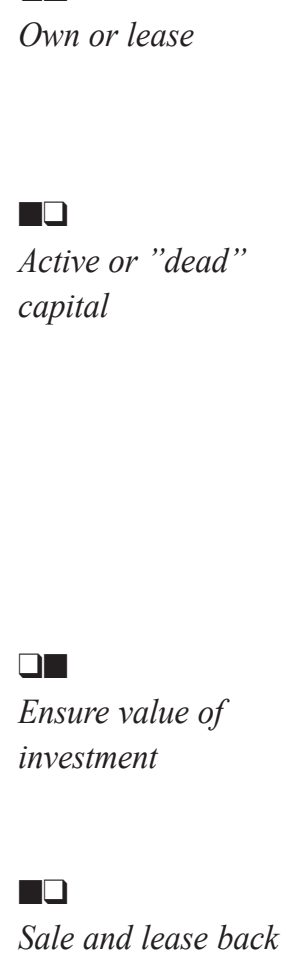

Sale and lease back 


\section{Case 4.a: Property Strategy in Danish Broadcasting Corporation (DR)}

In DR it was in 1994 determined that it is the goal to solve long-term space needs in own buildings, because lease is more expensive, and to gather the activities around the three centre TV City, Radio House, R/TV House in Aarhus and nine regional centre. It was not possible to implement this goal in all cases. Hence DR is spread over many addresses, including some leases. The fact that DR leases however gives flexibility, and the leases can be terminated with a shorter timeframe, just as a number of DR's own properties probably can be sold.

During the last half of the 1990 'ies DR has finished a number of former leases. In connection with the plans of relocating all DR's activities in the Copenhagen region to the new headquarters DR City, it was at first decided to complete the new build in collaboration with an investor, hence DR leased the building for a longer period. However, DR's board of directors decided that DR itself must complete the building on an owner base, even if this gives a higher annual financing expense in the beginning than the annual lease expenses at investor financing. As a state owned company DR has obtained authorisation from the Parliaments's finance committee to take out state guaranteed loans for financing of the construction.

DR had earlier several times considered resolving the problems of space and proximity at Radio House through expansion on the Radio House site or through new building opposite Radio House in front of the exhibition centre Forum, where there now has been established a Metro station. The expansion on Radiohuset's site is possible, but complicated due to need of demolition of some existing smaller buildings, and much limited space conditions. A new building in front of Forum has been considered at a lease basis with Forum's owner as investor. In case 4.b are shown Life Cycle Cost calculations for the two alternatives. In DR's proposal for a decision about this case the following statements were also included concerning the important advantages and disadvantages at the respective solutions, besides the financial ones:

\section{Leased building by Forum}

\section{Owned buildings at the Radio House site}

\section{Advantages}

- Purpose specific designed space (unlike the present leases)

- Proximity (unlike the present leases)

- External financing (DR's construction expenses are limited)

- Can be denounced (though not before after $15-20$ years)

- Parking conditions (possibility to rent many parking places)

- Influence on the property of neighbour opposite

\section{Disadvantages}

- Limitations to the use (no possibility to radio studio et cetera)

- Infrastructure (not ideal in spite of large investment in gangway/tunnel)

- Dependence of lessor (foreign decision maker at construction and operation)

- DR investments in a property owned by somebody else

- Space problems at large studio are not solved

- The old building Worsaaesvej 17 must be refurbished

- Use-related flexibility (may be developed for DR's specific needs)

- Infrastructure (correlation to the functions of radio production can be optimally met)

- Independence from other decision makers

- Space problems at large studio can be solved

- Buildings and site remain DR's property

- Refurbishment of the old building Worsaaesvej 17 can be avoided

- Inconveniences during the construction period

- Demolition and temporary relocation necessary

- Longer construction time due to demolition, establishment of basement parking et cetera

- Parking problems (not enough parking places in basements)

- Self-financing (considering DR's limited construction funds) or authorisation for loan financing

- Difficult to sell off (cannot be denounced)

A thorough analysis of DR's real estate strategies over time can be found in Jensen (2007).

Facilities Management for Students and Practitioners - Chapter 4: Strategic Planning 


\begin{tabular}{|c|c|}
\hline Reduction & Expansion \\
\hline \multicolumn{2}{|l|}{ Closing down / new establishment } \\
\hline $\begin{array}{l}\text { - Sale or demolition of property } \\
\text { - Termination of tenancy }\end{array}$ & $\begin{array}{l}\text { - Acquisition of an existing building or construction } \\
\text { of a new building } \\
\text { - Entering of tenancy }\end{array}$ \\
\hline \multicolumn{2}{|l|}{ Change of existing property } \\
\hline $\begin{array}{l}\text { - Reduced use of space by renting out a part of } \\
\text { the property } \\
\text { - Demolition of unnecessary buildings }\end{array}$ & $\begin{array}{l}\text { - Improved space allocation at refurbishment } \\
\text { and modernising } \\
\text { - Increased amount of space at new building } \\
\text { or extension }\end{array}$ \\
\hline \multicolumn{2}{|l|}{ Relocation in owned buildings } \\
\hline $\begin{array}{l}\text { - Sale of property and acquisition of a smaller } \\
\text { existing property } \\
\text { - Sale of property and construction of a smaller } \\
\text { new building on new site }\end{array}$ & $\begin{array}{l}\text { - Sale of property and acquisition of larger existing } \\
\text { property } \\
\text { - Sale of property and construction of a larger } \\
\text { new building on new site }\end{array}$ \\
\hline \multicolumn{2}{|l|}{ Change from owned property to lease } \\
\hline $\begin{array}{l}\text { - Sale of owned property and entering of lease } \\
\text { contract for a part of the property }\end{array}$ & $\begin{array}{l}\text { - Sale of owned property and entering of lease } \\
\text { contract for a part of the property and additional } \\
\text { space }\end{array}$ \\
\hline \multicolumn{2}{|l|}{ Change from lease to owned property } \\
\hline $\begin{array}{l}\text { - Acquisition of leased property with renting out } \\
\text { of part of the property }\end{array}$ & $\begin{array}{l}\text { - Acquisition of leased property and construction of } \\
\text { a new building or extension of existing building, } \\
\text { or acquisition of other property }\end{array}$ \\
\hline \multicolumn{2}{|l|}{ Change of lease } \\
\hline $\begin{array}{l}\text { - Termination or sublease of a part of a lease } \\
\text { - Termination of lease and relocation to smaller lease }\end{array}$ & $\begin{array}{l}\text { - Expansion of lease } \\
\text { - Entering new lease and relocation for new lease }\end{array}$ \\
\hline
\end{tabular}

The fundamental possibilities of adaptation at expansion and reduction respectively are shown in figure 4.1. Naturally you may think of combinations of the various fundamental possibilities. As it appears the fundamental adaptation possibilities are multiple, and even if not all fundamental possibilities will be relevant to each company, the actual possibilities will be immensely comprehensive. So it is important to have a prepared strategy to the company's goals, and clarity of which considerations that must be given a high priority.

It is also crucial that the FM function has a good overview of the company's existing property and space portfolio. It is especially about the following types of information:

- Space information about sites and properties, including gross and net areas divided between building sections and use

- Planning information (region and municipality plans) about applications, floor space index, extension possibilities, declarations, parking conditions et cetera

- Financial information about assessment of real estate and operational expenses et cetera
- Other property related information, including condition assessments, insurance, soil conditions et cetera

Such information can suitably be encompassed in an IT system with digital drafts and databank, cf. chapter 8 .

In checklist 4.A and 4.B are listed a number of factors of which one must observe at acquisition of existing property and entering a lease contract. Both at acquisition and sale of property, and at entering lease you must always ensure qualified legal advice. At acquisition of property and entering lease you must also make a thorough examination of the market before entering serious negotiations of a specific property or lease to be as best as possible equipped for such negotiations.

In Denmark there is a specific law on business lease and the latest was enforced in Denmark from January $1^{\text {st }} 2000$ (law number 934 from December $\left.20^{\text {th }}, 1999\right)$. The law represents a liberalisation and includes not to the same extent protection of the tenant as the former legislation. The law prepares the ground to a high degree of freedom of agreements among equal parties.
Figure 4.1

Adaptation possibilities for the property portfolio

Survey of the portfolio 


\section{Checklist 4.A: Acquisition of Existing Property}

The following is based on a draft for a checklist, which was published in DFM's newsletter 6, January 1993. The checklist is a gross list with introductory considerations at acquisition of an existing business or housing property - not just acquisition of site.

The goal is expressed in connection with:

- Purpose, size (organisation, number of employees)

- Space, logistics, efficiency criteria

- Possible categories of existing buildings

- Location is identified

At assessment of a specific property with buildings the following information and documents are provided and examined:

- Location

- Cadastre

- Register book - last land register

- Municipal declaration of the property

- Local plan

- Former use

- Heating planning act, possible future demands

- Possible pollution (chemical waste et cetera)

- Owner information from the Building and Housing Register

- Assessments

- Mortgaging

- Taxes and levies

- Insurances

- Homeowner's association or other associations - shared costs

- Lease contracts

- Lease records

- Resident representatives

- Lease guarantee agreements

- Last notification of lease increases

- Measuring drafts

- Last accounts

- VAT accounts

- Account for internal maintenance

- Account for external maintenance

- Homeowner's association investments

- Building licences and attestations

- Drafts and description and further technical documentation (calculations)

- Energy due conditions

- Heating inspection

- Maintenance and operating expenses, directions

- Last years accounts, maintenance, cleaning

- Possible engagements of operational staff

- Caretaker - sweep declaration

- Workmen - fixed service contracts

- Service facilities

- Special installations
- Alarms

- Utility companies

- Last heating accounts / shared bill

Subsequently inspection at the site is made, where for instance the following conditions can be seen and evaluated. Use of photo/video is recommended.

Situation:

- Surroundings

- Traffic conditions

- Relations to neighbours

The site:

- The configuration

- Situation of the buildings, including orientation in relation to corners of the world

- Accessibility

- Parking conditions

- Other facilities, including waste disposal

- Planting

- Possible pollution risks

The building / the buildings:

- Age

- Size and geometry (storey height, depth, staircases, lifts)

- Flexibility (partitions, installations)

- Gross / net factor

- Building fabric

- External surfaces / operational friendliness

- Load bearing structures

- Foundation

- Ground water and drainage (basements)

- Various utilities (electricity, water, heating, ICT)

- Technical installations

- Special installations

- Equipment and fittings (what is included)

The further considerations:

- Include the pricing and other circumstances. Prior to this is a financial evaluation of operation, concluding in first year's yield

- Lack of maintenance / repair work are listed and priced

- Summed up in recommendation or not

- Purchasing agreement and agreement of operation / maintenance during transition period 


\subsection{Investment Analyses and Life Cycle Cost}

At evaluation of long-term investments in construction and analyses of alternative solutions of long-term needs of space there is often comparisons made of construction expenses and continuous operational expenses. For the use of such analyses calculations of Life Cycle Cost (LCC) - also called Whole Life Costing - are useful and helpful tools.

LCC calculations include the initial investment and the expected future expenses. The future expenses spread over time within a selected observation period are discounted back to the starting point. Hence one speaks of the "Present Value" or the "Net Present Value", abbreviated NPV. Discounting back is a reverse interest calculation, and is carried out on the basis of a fixed discounting rate.

At discounting a capitalisation of future operational expenses is made, which make them comparable to the construction expense. By summarising construction expenses and capitalised operational expenses the LCC of a building can be calculated. With such calculations it is possible to compare alternative investments and space solutions, including lifetime costs at owning and lease of a building.

Use of NPV calculations is common among professions like economists and investors. Within the construction area a wider interest to LCC has arisen during the 1980 'ies with the increased focus on property operation and quality assurance. The Danish government has published a number of directions and guidelines on use of LCC and the Danish Building Research Institute has carried several research projects on the issue including a project in collaboration with the other Nordic countries. One of the results was a proposal for a joint Nordic classification of LCC (Annex 3 in Bjørberg \& Haugbølle, 2005).

In Norway they have worked intensely with LCC under the label "Annual cost" which covers the annual lifetime costs. In figure 4.2 is shown the principle of a total economically estimation of LCC and LCC converted to annual costs.

A first Norwegian standard for LCC was published in 1988, and it was replaced in 2000 by a new edition (NS 3454). The international standardisation organisation ISO has in 2002 pub- lished a standard for Whole Life Costing as part 5 of a standard on service life planning for buildings and constructed assets (ISO, 2002).

In Norway there has been since 1998 a requirement for all new state building that the design consultants deliver annual cost estimates in connection with schematic design, and from 2000 , due to a revised law on public acquisitions, LCC and environmental consequences must be considered in the planning of all public construction. In Denmark it also from 2000 was made compulsory to consider LCC as part of quality assurance in all state and state supported building projects, which include social housing and urban renewal projects.

The ambitions for use of LCC calculations are often to support choice of solutions for building systems and parts. This is not problematic to calculate, but available and reliable data for maintenance costs and lifetime expectancies of building systems and part are rather limited. On more superior levels for decision concerning support of investment decisions, it is much easier to find sufficient reliable data.

The basic formulas for LCC calculations are rather simple, and they are included in most spreadsheet programmes and in some pocket calculators. With a basic understanding of the calculation method it is possible to make LCC calculations on an ordinary computer without other software than an Excel spreadsheet or similar.

Before beginning a LCC calculation one must clarify the following preconditions:

- Which alternatives should be analysed, and which direct and derived expenses, earnings and savings must be included in the estimation model. Circumstances which are alike as to the alternatives can eventually be excluded from the analysis.

- Which period of time must the estimation include, and should the possible residual value of the building at the end of the period be included. The mortgage loan period is often the basis in the case of new building. The shorter the period, the larger importance a possible residual value will have.

- Which discounting interest rate should be used? Normally one does not include inflation effects; hence we speak of a net rate of return, which in principle must be decided from interest rate subtracted inflation rate, which actually could be gained from an 


\section{Checklist 4.B: Entering a Lease Contract for a New Lease}

Initially space needs and expected level of quality is stated, for instance in the shape of a space program and a list of minimum requirements.

For the use of the evaluation of a possible lease the following information are requested by the lessor:

- Storey plans with demonstration that the space program can be met

- Space information divided between space of the leased and possible percentage of shared spaces

- Information about parking conditions

- Information about rent divided between lease and percentage of operational expenses

- Information about terms of settlement and regulation

- Information about handover and termination terms

- Information about technical installations, for instance lift, ventilation cooling, fire protection, burglary protection, access control, telephone, IT

- Information about condition at handover, for instance fully renovated and designed for the user, including user's possibilities to decide the layout and surfaces such as flooring and wall colours

At inspection of the tenancy the following are evaluated:

- Possibilities for public transportation

- The location, appearance and surroundings of the property

- Neighbours and neighbours opposite

- Accessibility to staff, guests and goods transportation

- Configuration and condition of shared spaces

- The tenancy's appearance and condition

- The appropriateness and flexibility of the

alternative investment with a similar risk level.

The main part of the work efforts at a LLC estimation consist of finding the economical data which are included in the calculation. Normally the data are distributed on each year in the period, and when all data has been entered in the spreadsheet, the result immediately appears. You must evaluate the result closely and examine which items in the estimation model are most important to the differences between alternatives. There is often a high variation of the layout

- Light conditions, daylight and artificial light, including possibilities of regulation

- Surfaces

- Installations and ducts

- Fixtures and white goods (what is included)

At negotiation of the lease contract the following items must be observed:

- Who is the lessor (legally and contact person)

- The tenancy's space division on storeys

- The amount of the lease and its composition

- Rent regulation

- Renegotiation of the rent

- Payment of rent

- VAT conditions

- Heating expenses

- Percentage of shared expenses, specified

- Irrevocability period

- Term of notice

- Sublease

- Date of handover

- Municipal authorisation of use

- Number of parking places

- Condition at handover, documentation

- What is included

- State at delivery

- Allocation of obligations for maintenance and cleaning

- Who implement and pay for adaptations for initial layout, including responsibility of building license

- Who implement and pay ICT installations

- Schedule for initial adaptation

- Rights to make later adaptations

- Re-adaptations at termination should be limited to special arrangements

- Registration to utility companies

- Signposting

- Marking of contract

uncertainty among various items, and if some very uncertain items are decisive to the variations, you must try to qualify the estimation to the items in question.

It can also be useful to implement sensitivity analyses in relation to the chosen consideration period and the internal rate of return. When the estimation model and the data basis are clarified, such sensitivity estimations can be done very fast. The interesting thing is, whether minor changes will have crucial importance to the differences among alternatives. 
By use of LCC calculations qualified basis can be made to estimate the financial consequences at alternative long-term investments. With a basic understanding of the method, it is simple to work with, and the result is immediately understandable. The disadvantage of the method is that for persons who lack a basic understanding of the method it may seem mystifying and abstract. On the other hand it ought to be worth the efforts for persons who are in a position, where they must decide larger long-term investments, to achieve a basic understanding of a rather elementary financial estimate.

In case 4.b an example of an investment analysis with LCC calculations of the two alternatives mentioned in case 4.a is shown.

\subsection{The Building Client Function}

The FM function is by definition primarily a building operational function, but in most companies there are also building client tasks, which are naturally handled by the FM function. In fact the professional handling of FM in many companies has derived from building related units, which traditionally have been concerned with construction related tasks like new building, extension and rebuilding projects. At the same time planning and management of larger maintenance tasks are professionally seen convergent with the similar functions at construction tasks.

When the building client function is mentioned here it is in connection with companies in which this function fulfils the company's own needs for built facilities. It does not concern the building client function at property investors et cetera, who continuously implement investment construction, or other permanent building client organisations. It is primarily the building client tasks in connection with new building which is discussed in this section, whereas tasks in relation with rebuilding et cetera is discussed in chapter 5 .

The importance of the building client function is highly depending on the company's general development. To companies within a heavy expansion there are often strong needs of space extensions, which typically imply focus on comprehensive new building. This results in the fact, that the main part of the managerial attention in relation to the FM function will be aimed at these activities.
In the first half of the 1990'ies most companies were within a state of the market which is marked by financial crisis with focus on reductions, and especially in the FM area they focused on savings for instance in the shape of outsourcing and space limitations. A significant exception in Denmark was at that time the LEGO concern who implemented a comprehensive construction programme in Billund and abroad. Later on the development of LEGO has been somewhat tense, whereas companies such as Nokia has initiated comprehensive expansions plans many places, including in Denmark.

To companies without expansive tendencies the building client function may in periods have an increased importance. This concerns the thorough reorganisations in companies with for instance Business Process Reengineering, where outdated construction related frames are given up in favour of relocation of the company to new building. The process of relocation of DR to DR City is an example of this.

The building client role in the preliminary phases is correlated to the real estate strategy tasks. In the decision-making process about possible new building often involves a number of alternatives that have to be analysed. The consequences at the various alternatives must be clarified as a basis for decision proposals to the company's top management.

When it has been decided to built a new building, the company's top management must take the lead in relation to the company's staff and communicate the vision, to which the new building will contribute. The building client typical-

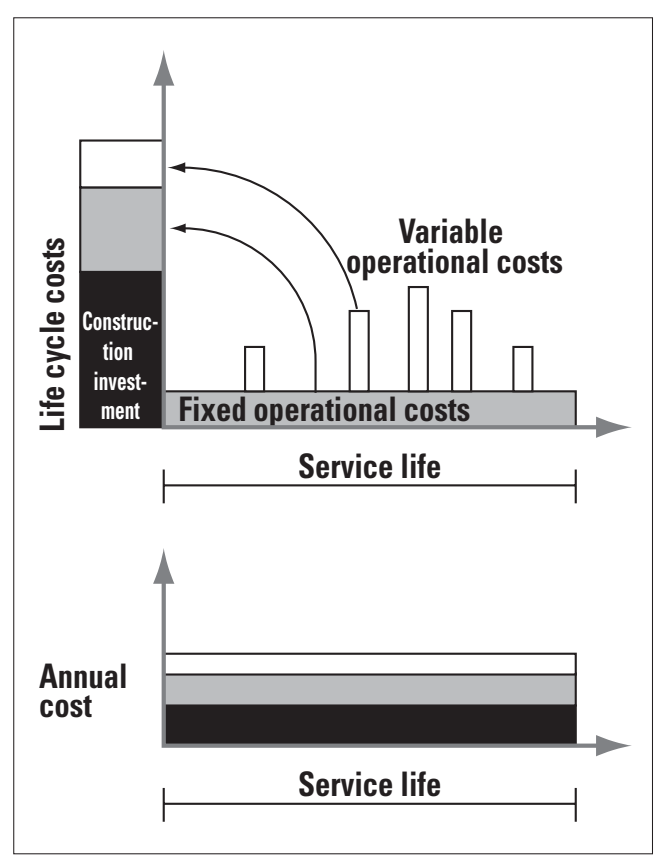

Life cycle costs and annual costs
Figure 4.2

The principle of calculating life cycle costs and annual costs 


\section{Case 4.b: Life Cycle Costs of Owned versus Leased Space}

The following LCC estimations are based on the example from Radio House, which was discussed in case 4.a. Estimations were made for two variables for each of the two main solutions. The estimation model included the following 4 solutions:

\section{A. Leased new building at Forum with $\mathbf{1 5}$ years irrevocability}

The main items at this solution was the lease expense itself, savings at finishing of the main part of former leases and one-off expenses for specific arrangements in the lease and gangway to Radio House.

\section{B. Leased new building at Forum with $\mathbf{2 0}$ years irrevocability}

The main items were the same as in solution A - yet the lease expense was somewhat lower.

\section{Expansion of Radio House with phase 1}

The main items at this solution were the construction expense, savings at finishing of some former leases and savings at demolition instead of refurbishing of the property Worsaaesvej 17.

\section{Expansion of Radiohuset with phase 1 and 2}

The main items at this solution were as in solution $\mathrm{C}$ - yet both the construction expense and the savings at finishing former leases were higher.

At first DR implemented LCC estimations without considering financing costs, and sensitivity analyses were made with internal rates of return of 2, 4 and $6 \%$, and periods of 15,20 and 30 years. Subsequently there were made further estimations in collaboration with a finance company based on mortgaging of the construction expense at solution $\mathrm{C}$ and $D$. The results of DR's estimations with $4 \%$ interests were as follows:

\section{LCC as present value}

A. Forum lease, $\mathbf{1 5}$ years fixation

Similar expenses at status quo

B. Forum lease, 20 years fixation

Similar expenses at status quo

C. Radiohus expansion, phase 1

Similar expenses at status quo

D. Radiohus expansion, phase $\mathbf{1 + 2}$

Similar expenses at status quo
15 years

20 years

30 years

\begin{tabular}{|c|c|c|}
\hline$€ 15.2$ million & $€ 17.9$ million & $€ \mathbf{2 2 . 0}$ million \\
\hline$€ 8.4$ million & $€ 10.4$ million & $€ 13.3$ million \\
\hline$€ 9.6$ & $€ 10.9$ & $€ 13.0$ \\
\hline$€ 8.4$ & $€ 10.4$ million & $€ 13.3$ \\
\hline$€ 9.3$ & $€ 7.8$ million & $€ 5.7$ \\
\hline$€ 6.7$ million & $€ 8.2$ million & $€ 10.5 \mathrm{~m}$ \\
\hline$€ 14.3$ mill & $€ \mathbf{1 2 . 1}$ million & $€ 8.7 \mathrm{n}$ \\
\hline$€ 9.3$ & $€ 11.6 \mathrm{n}$ & $€ 14.9 \mathrm{n}$ \\
\hline
\end{tabular}

Leases become more expensive whereas on the opposite new building in own auspices become cheaper at a longer view of period, and also at a lower interest. A solution with leases with fixation in 15 years was in all estimations most expensive, whereas the Radio House expansion with phase 1 in all cases was the cheapest. In relation to the status quo expenses new building in own auspices would imply substantial savings. It must be noticed, that residual value was not included in the estimations, and inclusion of this would favour new building in own auspices even further. The estimations from the finance company supported these conclusions. 
ly has a position as a staff function, which assists the corporate management and ensure a professional implementation of the construction project, but it is to all parties important that there is a lucid mission with the project, and that this mission is rooted in the top management and the overall strategy of the corporation.

It is also crucial as early as possible to establish the core part of the organisation which must ensure the implementation of the construction project. In companies who do not by routine implement larger new building projects, it is recommended from the very start of such projects to engage an experienced building client consultant from a consulting company. This can for instance be as project manager, where the building client consultant takes on the entire overall management of finances, time and quality from the beginning to the end. In some countries there are examples that project management companies even take on financial risk in connection with construction projects. This is not yet common practice in Denmark, but it is possible to make incentive agreements with a consulting company.

At the beginning of the collaboration the top management and the building client function in the corporation spend time together with the building client consultant to have the company's vision for the construction processed, and to convert them into some overall intentions, which the construction project must meet. This process is called strategic briefing. It may for instance relate to the image that the new building must communicate, and the changes in the company's internal work methods and relations, which the physical surroundings must support. This can be done through arranging workshops and study tours to relevant constructions. The result of such an opening phase results in a strategic brief for the building project.

As part of the strategic programming it can be useful to implement a risk analysis of which factors and incidents may possible endanger the project. On basis of such an analysis the work efforts in the further work with the project can be prioritised to meet the risk factors in the best possible way. A shared understanding among the key persons is also achieved concerning what the priorities are in the project; hence all work towards the same goal.

One of the central tasks to the building client function is to take advantage of their knowledge of the company's core functions and development perspectives to identify the company's requirements for the building. One of the most important tasks of building client function is to ensure contact and communication between on one hand the company's other functions, management and staff, and on the other hand the external consultants.

So it is important that the building client function is internal and partly represents experience and insight in the company's situation, and partly a wide building competence, hence the building client can act as a professional sparring partner with external consultants. In so doing it can be made useful that the consultants look at the company's needs with new eyes based on their knowledge from other companies, and at the same time make a professional check that the company's needs are not misinterpreted.

It is also important that the company's employees are included in the planning of the building project. This is of particular importance if the building project is part of a Business Process Reengineering or implementation of new ways of working in the company. The staff involvement can typically be made in the shape of work groups med participation of representatives from staff who contribute to the design briefing and the planning of interior layout and moving in.

In due time before the building's completion, the building client must initiate the planning of the move. It can be crucial to whether the new building from the very start will be regarded positively by the staff, that the relocation process itself is implemented fast and smooth. Regarding the relocation planning, see chapter 5 .

Another important task to the building client function is to ensure that considerations are taken to operational conditions.

With a background in a FM function the building client must have en optimal basis for this. The following considerations should be made:

- Flexible building with possibility to rearrangement of layout and changes in installations with the least possible intervention to the building

- Appropriate infrastructure and logistics with central location of internal services and good internal transportation service

- Minimising of the energy consumption

- Attractive indoor climate with good possibilities for regulation

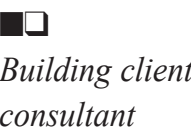

consultant 
- Operational friendly building with easy service possibilities for technical installations

- Dirt-absorbing access and cleaning friendly surfaces, both internally and externally

- Lasting and easily changeable building components and materials

- Appropriate space and transportation possibilities for waste handling

- Maintenance friendly external areas

- Appropriate level of building automation systems and monitoring of building performance

Even during the planning of the building project, the building client function must decide an operational concept to the finished building. Part of the operational concept can be, to which extents the operation must be handled by own staff, and which extent of external provider companies. On the other hand the operation should be planned so it is possible to handle an efficient operation with well defined and measurable service levels and performance indicators, cf. section 2.3, no matter if the operation is handled internal or external. A possible solution is to ask for optional bids on the cost of building operation for a number of years in the tendering process of the construction work.

At new building the building client function must also exploit the possibility to have the documentation of the building structured and organised in a way which can ensure an optimal IT based handover of the documentation. For further reference to this, see chapter 8 .

In relation to this it is a problem that there is tradition that contractors and consultants do not handover the operational documentation before the end of the construction period - in the best cases at the building handover procedure. It is natural that some parts of the documentation cannot be delivered until at the end of the construction process. This includes certain measuring reports from commissioning of technical installations and similar documentation. However, this is primarily part of the quality control documentation.

It should be possible to provide the part of the documentation which includes operational and maintenance instructions long time before the handover of the finished building, so that this can be the base of the detailed planning at the very start of occupation, including possible procurement of operational tasks. Building clients with a background in FM must lead and make requirements to the consultants and the contractors about this.

\subsection{Maintenance Strategies}

The overall goal of maintenance strategies is to ensure the value of the property. This implies both the financial value and the use value. The considerations to the financial value can be seen as the building owner's interest, whereas the considerations to the use value can be seen as the building user's interest.

Even though the building owner and the building user can be the same company, the various interests will appear through various parties within the company. To each department in the company the most important is the use value, and it is often rather short sighted. Hence it is the FM function and the top management of the company which primarily must handle the building owner's long-term considerations to the financial value of the property.

The difference between long-term and shortterm considerations is not alone evident in relation to maintenance tasks, but also at determination of quality levels at refurbishment and modernisation. This may bring the FM function in a conflict-ridden situation, where they on one hand must act as a service organisation towards the users, and on the other hand must ensure overall company considerations. To handle such potential conflicts it is important that the longterm maintenance planning is made at strategic level in the FM function, and that lucid strategies and quality goals to the property's maintenance, refurbishment and major modifications.

A common starting point to evaluate the quality of a property is the state which the property had at the construction, "quality level as built". The need to maintenance is correlated to the deterioration of the building which occurs, for instance due to climatic and use influences. The quality goal to maintenance hence can be defined as the degree "quality level as built" must be sustained throughout the lifetime of the building.

Maintenance can be made from principally different methods:

- Preventive maintenance is done before the performance of the property is at a dissatisfactory level in relation to use, or to prevent secondary damage.

- Replacements imply a jump in quality, 
which entirely or partly raise the property (or part of the property) to "quality level as built". Thus covers the total replacements of building systems, for instance the entire roofing, all windows, installations or important part of it.

- Corrective maintenance is made to correct urgent damage or breakdown.

Of these methods the two first mentioned are planned maintenance, whereas the third is not planned, and are also termed daily maintenance.

In relation to the starting point "quality level as built" there is over time a development of the general quality for buildings. This can be based on changed legal requirements for buildings, where the constantly increased requirements for reducing energy consumption at new building are a typical example. However, there can also be legal requirements which put demands to existing buildings, for instance phasing out of CFC and new lift declaration. The compliance to such new legal requirements should in principle be considered as construction investments, also if the demands concern existing buildings.

Correspondingly there are also in other areas continuous changes of the technology and quality of buildings, for instance introduction of new building materials and new electronic control systems. In connection with maintenance strategies one must also consider whether the building's quality must be raised to "quality level as today's new building”. If so, we speak of a refurbishment of the property, which also should be seen as a construction investment.

In figure 4.3 is shown the fundamental progress of the development in the property's quality concurrently with time and dependent of the maintenance method.

When preparing property strategies the overall intentions regarding the property's quality level must be decided as well as guidelines for the consideration which must be prioritised in the maintenance planning. In case 4.c is shown an example of maintenance strategy.

\subsection{Building Investment and Maintenance Planning}

Preparation of building investment plans and preparation of maintenance plans have many similarities. In both cases there are activities which demand technical building competences. To the building investment planning the starting point is often needs and wishes from the company's core business. This may also be the case to the maintenance planning, but here it is to a greater extent input from the property operation and condition reports of the properties, which make the base. In both cases the planning must often be based on rough estimations of the financial size of the activities, and it is also in both cases appropriate to implement the planning each year with a multi-annual target.

Planned and daily maintenance

The FM function must also consider the investment and maintenance plans in correlation. It will sometimes be appropriate to implement maintenance projects in connection with building projects. For instance a replacement of windows can be made with less inconvenience to the employees in the building, if it is implemented when an area are emptied for employees due to a rebuilding or modernisation project than if window replacement is done separately. In this way a coordinated planning of investment and maintenance projects may give considerable advantages to the core business of the company.

The decision-making procedure to investment and maintenance projects may vary from one company to another, but after a decision in principle about implementation of a project, a preproject is usually made, in which a basis for decision with specification of the project's contents and size and also estimation of a budget and time schedule is prepared with a view to final decision of approval and initiation of the project.

A difference between building investment planning and maintenance planning is that the maintenance planning typically includes a much larger number of projects than the construction planning. The investment planning in the property area is furthermore often made in connection with the overall investment planning of the company, and the tool for this is often the company's general financial system.

The maintenance planning is to a greater extent made within the FM function's own frames, and due to the significant number of projects of various size there is in larger companies needs of a dedicated IT tool for the use of this planning. Such tools are mentioned in chapter 8 . 


\section{Case 4.c: Maintenance Strategy in Danish Broadcasting Corporation (DR)}

In 1998 DR's management approved an overall property strategy plan, which included the following maintenance strategy.

It is DR's strategy to maintain the functional level of our locations, and to re-establish an acceptable aesthetic level. With this at the starting point maintenance funds are allocated from the following prioritisation criteria:

1. To maintain a sound safety level (i.e. to ensure that no inconveniences occur in relation to the health and safety legislation).

2. To meet the functional needs (i.e. to ensure that no inconveniences occur in relation to building fabric and supply of electricity, water and heating, and to ensure that the necessary cooling of production and broadcasting equipment is present).

3. To establish and maintain an acceptable aesthetic level in connection with DR's quality level (i.e. to ensure an aesthetic level adapted to the use of the spaces, and in general to support an appropriate and inspiring physical work environment).

With the present budget it is only first and partly second priority which can be met. Due to the attrition funds are also allocated to the aesthetic maintenance in the most worn areas, primarily in the extrovert areas.

\section{Management principles}

Figure 4.3

Development of quality level at various maintenance methods
The planning of maintenance activities can be done from three in principle different management principles:

- Interval based maintenance where the maintenance activities are done with fixed intervals to each building system.

- Condition based maintenance, where the maintenance activities are prioritised and determined on the basis of recurring condition reports.

- Risk based maintenance, where the maintenance activities are prioritised and determined based on a risk assessments.

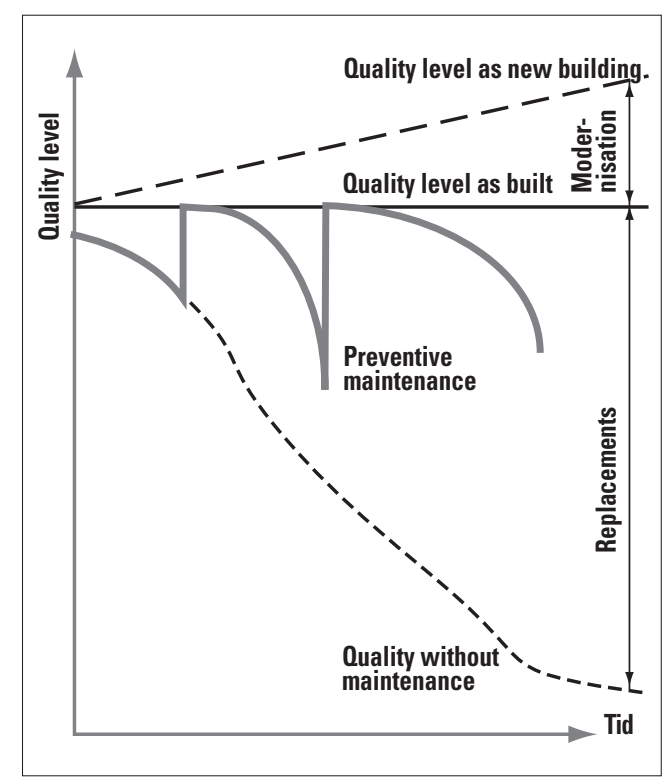

The interval based maintenance is to a certain degree parallel to the service checks recommended by the car producers, where some activities are done annually and others with longer intervals. As the term service check indicates, however, it also concerns risk based and condition based maintenance, where the car repair shop point out circumstances which must be repaired immediately or soon, if they are related to safety, or if there are signs of reduced performance. In the same way planning of property maintenance will be most appropriately based on a combination of the three management methods.

A purely interval based maintenance will often be unnecessarily cost-consuming. On the other hand an interval based maintenance plan gives a fine systematic basis, which appropriately can be supplemented by condition reports and risk evaluations. To structures and surfaces surveyor reports are rather substantial as basis for the maintenance planning. To building installations interval based and risk based maintenance can be most appropriate.

At planning of both building projects and maintenance projects it can be useful to group them in various categories.

To building projects this can for instance be the following: 
- Necessary investments, including obeying legal requirements and consequences of former decisions

- Strategic investments, i.e. modernisation projects which support the company's strategic development, for instance organisational changes, implementation of new technology and environmental improvements

- Rational investments, for instance new building and modernisation projects which enable finishing of leases and energy projects with operational cost savings

To maintenance projects it can be:

- Necessary and urgent refurbishment, including repairs of structures and installations with a risk of functional defects, and repair of accelerating damages

- Necessary but urgent refurbishments, including repairs of structures and installations where the risk of functional defect is limited

- Aesthetic maintenance, including user desired repairs

By means of such categorisations the prioritisation of building and maintenance activities can be eased, so that the unavoidable activities, which do not need closer decision, are separated from the categories, where a more company financial prioritisation of the, at any time, limited resources can be made. Besides the categories mentioned, to both the building and the maintenance planning it is necessary to allocate not ear marked amounts or pools for various new needs, which arise or are revealed during the year.

\subsection{Building Assessment and Classification}

A facilities manager in many connections needs to make assessments of properties, buildings and spaces. At benchmarking of property operation, quality is an essential factor for evaluation of cost levels. At considerations of acquirement or lease the quality is naturally also an important decision parameter, and at refurbishment of existing buildings or planning of new building the future quality level must be determined. Systematic methods of assessment and definition of property quality are however few, and methods for classification of properties in relation to quality are even fewer.

To real estate agents one of the main tasks is to assess properties and leases. However, it is mainly a financial assessment, which aims at determining a market value in relation to the present market level. The location of the property and the lease are often very important factors, whereas the use qualities are second. It is the same as to the public building value assessment in Denmark, which also in principle aims at estimation of the market value of properties.

Another type of assessment of buildings is made in connection with entering building insurances. Besides a risk assessment it also primarily concerns a financial assessment, but this assessment does not aim at a determination of the commercial value, but on the contrary the compensation sum at total damage of the property, primarily in case of a fire. The insurance sum to new building hence can be seen as an evidence of the property's replacement value, or as an evidence of the value of the property to the owner of the company.

All these values can vary a lot, depending on whether the owner himself use the property or rent it out to others. This is for instance documented by data from DFM-benchmarking, which show that the fire insurance sum is in average four times larger than the public building value at properties which are owned and used by the same company, whereas the fire insurance sum only in average is twice the public building value at rented out properties.

A third type of assessment is assessment of return of investment of properties, which is also a financial assessment. In such assessments are included estimates of the expected financial and operational expenses, and also expected earnings on a long-term basis. In relation to this the Danish Real Estate Association has established a "Danish Property Index", which collects annual information about market value, lease income, operational and maintenance expenses, investments et cetera, to each of the participants' properties for the use of benchmarking. The purpose is for instance to create a more lucid property market and to increase institutional investors' trust in property investments. Similar indexes are produced annually in a number of other European countries.

A fourth type of assessments is building condition assessments, which primarily aim at evaluating the state of buildings in relation to maintenance and energy conditions. In connection with transaction of buildings for housing it is mandatory in Denmark that a condition report is avail-
Categorisation of construction projects

\section{Categorisation of maintenance}

Return on investment assessment

Condition assessment 
able, and a standard method and report has been developed for this purpose. For transaction business properties is has become increasingly more and more common to make similar building assessment as part of a due diligence process. A case on technical due diligence is included as section 5.4.3 in the report on FM Best Practice in the Nordic Countries (Jensen et al, 2008).

\section{Examples of assessment and classification systems}

In Norway they have a Norwegian standard for Condition Analyses of Buildings, in which for instance degrees are defined for the state of a building in relation to a number of factors. The assessment is divided according to the following three overall parameters: Technical condition, Functionality and Indoor climate. Based on this standard the consulting company Multiconsult AS has developed a method for a value analysis of the state of buildings based on a simplified condition assessment to characterise the quality level of a building.

In figure 4.4 the table for the value analysis is shown. They operate with 4 degrees, termed $0-3$, where 0 is good state and 3 is bad state. Due to the characters of each factor an overall evaluation of the degree to each of the 3 parameters is determined. The total assessment degree of the building is determined by a weighed calculation, in which the weighing varies depending on the use of the property.

With the use of value analysis methodology the Norwegian system provides possibilities to have a total quantitative expression of the state of the building. With inclusion of the parameters indoor climate, and especially functionality, the Norwegian system proceeds further than just to a technical assessment of the maintenance level and towards a more user orientated quality assessment. A significant advantage to the system is that it is simple and clear. As a whole the system is aimed at assessment of buildings in operation and is not suitable for use at planning of new buildings.

Another and far more comprehensive system directly aiming at assessment of building quality is Building Quality Assessment (BQA). This system was originally designed by the architect department at University of Victoria I Wellington, New Zealand. In 1995 the system was introduced in Europe after being adapted to the European marked by the English building research institute Building Research Establish- ment (BRE). BQA aims at objective assessment and comparison of building projects' quality seen from a user's point of view. The assessment includes 137 factors divided on a number of sections within the following nine categories (Williams, 2000):

1. Architectural appearance

2. Space related functionality

3. Accessibility and internal connections

4. Staff facilities

5. Support services

6. Work environment

7. Health and safety

8. Structural conditions

9. Property operation

Similar to the Norwegian system BQA is based on value analysis methodology with points on the basis of determined criteria. To each of the 137 factors can be achieved a mark from 0 to 10 points with 0 as the lowest and 10 as the highest. An example of criteria to the mark is shown in figure 4.5 .

Besides to use the result of BQA assessment to compare quality among various buildings it is possible to use the requirements related to the point in BQA in connection with building projects, which are put out for tender at an early stage in the project procedure. The requirements can defined at varying levels, for instance to each of the above mentioned categories, at underlying section levels or at single factors. It is furthermore possible to see the BQA assessment in relation with the construction expenses for building projects as illustrated in figure 4.6.

BQA has also been used at comparison between refurbishing of an existing building and construction of a new building. Economically the refurbishment of the existing building was the cheapest and hence apparently most beneficial. A BQA comparison of the two alternatives shows however, that the quality difference between the alternatives was larger than the economical, so that the new building alternative on the basis of this could be seen as the most beneficial (Williams, 2000).

It is obvious that the weighting of the various characters may have a decisive role to such comparisons. In connection with BQA, BRE has completed questionnaire surveys to a typical selection of building owners, contractors and consultants to determine the weighing. The prioritisation of such conditions will probably vary 


\begin{tabular}{|c|c|c|c|c|}
\hline & State degree 0 & State degree 1 & State degree 2 & State degree 3 \\
\hline \multicolumn{5}{|c|}{ Technical condition } \\
\hline Ventilation & $\begin{array}{l}\text { Newer system with good } \\
\text { capacity. } \\
\text { Reliable. }\end{array}$ & $\begin{array}{l}\text { System until } 15 \text { years, } \\
\text { good capacity, a few } \\
\text { defects and stoppages }\end{array}$ & System until 30 years & System older than 30 years \\
\hline $\begin{array}{l}\text { Heating / } \\
\text { Sanitation }\end{array}$ & $\begin{array}{l}\text { Newer system with large } \\
\text { energy flexibility. } \\
\text { Reliable. }\end{array}$ & $\begin{array}{l}\text { System until } 15 \text { years with } \\
\text { good capacity and some } \\
\text { energy flexibility. }\end{array}$ & System until 30 years & System older than 30 years \\
\hline $\begin{array}{l}\text { Electricity } \\
\text { installations }\end{array}$ & $\begin{array}{l}\text { Newer system with good } \\
\text { capacity without defects. }\end{array}$ & $\begin{array}{l}\text { System until } 15 \text { years with } \\
\text { good capacity. }\end{array}$ & System until 30 years & System older than 30 years \\
\hline $\begin{array}{l}\text { Building } \\
\text { damages }\end{array}$ & No damages. & Smaller damages. & $\begin{array}{l}\text { Need of replacements, } \\
\text { bad windows. }\end{array}$ & $\begin{array}{l}\text { Large subsidence, roofing } \\
\text { and concrete damages. }\end{array}$ \\
\hline Lift & Newer lift. & $\begin{array}{l}\text { Lift until } 15 \text { years with a } \\
\text { few / some stoppages. }\end{array}$ & $\begin{array}{l}\text { Older lift with } \\
\text { comprehensive defects. }\end{array}$ & $\begin{array}{l}\text { Building without lift, but } \\
\text { with a great need of a lift. }\end{array}$ \\
\hline Fire / security & $\begin{array}{l}\text { OK in accordance with } \\
\text { present demands and } \\
\text { regulations. }\end{array}$ & $\begin{array}{l}\text { OK in accordance with } \\
\text { recommendations. May } \\
\text { have deviations which } \\
\text { compensate for other risk } \\
\text { reducing initiatives, for } \\
\text { instance dispensations. }\end{array}$ & $\begin{array}{l}\text { Deviations which can be } \\
\text { repaired within practical } \\
\text { and financial and sound } \\
\text { limits. }\end{array}$ & $\begin{array}{l}\text { Larger deviations which } \\
\text { demand expensive } \\
\text { repairings / renovations. }\end{array}$ \\
\hline \multicolumn{5}{|c|}{ Overall evaluation } \\
\hline \multicolumn{5}{|c|}{ Functionality } \\
\hline Layout & $\begin{array}{l}\text { Works well to the company } \\
\text { in the building. }\end{array}$ & Needs of smaller changes. & $\begin{array}{l}\text { Unsuitable, complicate } \\
\text { efficient use. }\end{array}$ & $\begin{array}{l}\text { The property is not suitable } \\
\text { for a modern company - } \\
\text { many complaints. }\end{array}$ \\
\hline Flexibility & $\begin{array}{l}\text { High flexibility. The } \\
\text { building can easily be } \\
\text { adapted to changed needs. }\end{array}$ & $\begin{array}{l}\text { Flexible building. Easy to } \\
\text { make smaller changes of } \\
\text { the design. }\end{array}$ & $\begin{array}{l}\text { Low flexibility. Larger } \\
\text { changes of the design are } \\
\text { difficult and expensive. }\end{array}$ & $\begin{array}{l}\text { Minimal flexibility. The } \\
\text { bearing structure } \\
\text { makes changes of the } \\
\text { design impossible. }\end{array}$ \\
\hline $\begin{array}{l}\text { Operational } \\
\text { friendliness }\end{array}$ & $\begin{array}{l}\text { Reliable technical installa- } \\
\text { tion and appropriate } \\
\text { choice of materials, } \\
\text { arrangement and design } \\
\text { make the operation } \\
\text { without problems }\end{array}$ & $\begin{array}{l}\text { The building is on the } \\
\text { whole without problems in } \\
\text { the daily operation. }\end{array}$ & $\begin{array}{l}\text { Continuous problems with } \\
\text { technical installations and/ } \\
\text { or inappropriate choice of } \\
\text { materials, arrangement } \\
\text { and design make the } \\
\text { operation difficult. }\end{array}$ & $\begin{array}{l}\text { Continuous stoppages of } \\
\text { technical installations. } \\
\text { Comprehensive use of } \\
\text { inappropriate materials } \\
\text { and designs make the } \\
\text { operation difficult and } \\
\text { simple changes difficult } \\
\text { and expensive. }\end{array}$ \\
\hline Fire & $\begin{array}{l}\text { The safety for persons is } \\
\text { fully covered. Escape } \\
\text { routes and signposting 0K. }\end{array}$ & $\begin{array}{l}\text { The safety for persons is } \\
\text { covered, but with a little } \\
\text { deviation. Escape routes } \\
\text { with small deviation in } \\
\text { accordance with rules } \\
\text { and regulations. }\end{array}$ & $\begin{array}{l}\text { The safety for persons lack } \\
\text { coverage. Escape routes } \\
\text { with deviations in } \\
\text { accordance with rules and } \\
\text { regulations. }\end{array}$ & $\begin{array}{l}\text { The safety for persons with } \\
\text { severe lacks in coverage. } \\
\text { Escape routes with larger } \\
\text { deviations in accordance } \\
\text { with rules and regulations. }\end{array}$ \\
\hline \multicolumn{5}{|c|}{ Overall evaluation } \\
\hline \multicolumn{5}{|c|}{ Indoor climate } \\
\hline Cleaning & $\begin{array}{l}\text { Central hoover. Surfaces } \\
\text { which are easy to clean. } \\
\text { No complaints. }\end{array}$ & $\begin{array}{l}\text { Surfaces which are easy to } \\
\text { clean. Appropriate solution } \\
\text { details. Little complaints. }\end{array}$ & $\begin{array}{l}\text { Design which makes } \\
\text { cleaning difficult. Surfaces } \\
\text { which demands much } \\
\text { maintenance. }\end{array}$ & $\begin{array}{l}\text { Design and detail solutions } \\
\text { which make the cleaning } \\
\text { especially difficult. }\end{array}$ \\
\hline Air quality & No complaints. & A few complaints. & $\begin{array}{l}\text { Relatively many } \\
\text { complaints. }\end{array}$ & $\begin{array}{l}\text { Many and comprehensive } \\
\text { complaints. }\end{array}$ \\
\hline Aesthetics & $\begin{array}{l}\text { Bright and nice rooms. } \\
\text { Special emphasis on } \\
\text { ergonomic conditions. }\end{array}$ & $\begin{array}{l}\text { Bright and nice rooms, but } \\
\text { a few complaints. }\end{array}$ & $\begin{array}{l}\text { Rather large dissatisfaction } \\
\text { with the rooms' layout } \\
\text { and furnishing. }\end{array}$ & $\begin{array}{l}\text { Dark and gloomy rooms } \\
\text { which do not motivate the } \\
\text { company in the building. }\end{array}$ \\
\hline \multicolumn{2}{|c|}{ Overall evaluation } & & & \\
\hline
\end{tabular}

Figure 4.4: Norwegian table for value analysis of building condition (source: Multiconsult, 2000) 
from each country and adaptation may have to be made for the use in other countries than the UK.

Another system which will be briefly mentioned is Serviceability Tools and Methods (STM) which was developed at International Institute of Facilities in Canada (Davies, 1993). The system is built on the basis of similar principle as BQA, but as the term "Serviceability" suggests, the system is to a greater extent than BQA oriented towards operational and user supporting aspects at buildings. STM offers a standardised methodology to handle user needs and buildings' physical performances. However, the complexity of the system has entailed that STM has been used to a limited extent (Klammt, 1998).

In Norway there is a system for construction certification based on an assessment whether a number of minimum demands have been fulfilled in relation to technical conditions, operation and maintenance. Besides the above mentioned systems there are more systems for environmental assessment of buildings, which are mentioned in chapter 9.2.

\subsection{Risk Management}

Risk Management is a managerial task concerned with continuously monitoring and evaluating the risks, which the company is or may be subject to, and to implement suitable arrangements to prevent or limit the consequences of unacceptable risks. Such arrangements can typically consist of prevention in the form of securi- ty installations and guarding, preparedness in the form and of disaster and emergency plans, and insurances which limit the financial consequences.

Risk Management can be described as a systematic process for identification, measurement, monitor and financial control of threats against a company's assets and future earnings. This can be illustrated as shown in figure 4.7.

As basis for preparation of policies for security and insurance it can be useful to make up the total risk expenses. They include besides administration of expenses for damage prevention, insurance, own damages and excess. Increased expenses for damage prevention will normally lower the expenses of the other areas. The typical correlation between risk expenses and safeguard level is illustrated in figure 4.8.

As it appears the total risk expenses has a typical minimum point. In an overall evaluation other conditions than the purely financial ones must be included. For instance may considerations for person risk suggest a higher safeguard level. Comprehensive damages can also imply considerable indirect consequences such as delay of development projects and negative mention.

In order to make up the total risk expenses it is necessary continuously to record and calculate the actual damages. This concerns both the insurance covered and the not insurance covered. Such a recording is also an important basis to be able to prioritise damage prevention.
Figure 4.5

$B Q A$ 's points for emergency power supply in an office building (source: Williams, 1999)

\begin{tabular}{|c|c|c|}
\hline Points & General meaning & Specific criteria \\
\hline 10 & Excellent & $\begin{array}{l}100 \% \text { standby generator - automatic running-in: } \\
\text { Minimal delay, supply to all building installations. } \\
\text { Maintenance report is available. }\end{array}$ \\
\hline 8 & Very good & $\begin{array}{l}50 \% \text { standby generator - automatic running-in: } \\
\text { Minimal delay, supply to all important building installations } \\
\text { and some not important, possibility to upgrade to } 100 \% \text {. }\end{array}$ \\
\hline 6 & Good & $\begin{array}{l}\text { Standby generator - automatic running-in. } \\
\text { Only lift and emergency installations. }\end{array}$ \\
\hline 4 & Bad & $\begin{array}{l}\text { Standby generator - manual start: } \\
\text { Only lift and emergency installations. }\end{array}$ \\
\hline 2 & Very bad & $\begin{array}{l}\text { Standby generator - manual start: } \\
\text { Only emergency installations. }\end{array}$ \\
\hline 0 & None & No standby generator. \\
\hline
\end{tabular}


In a number of areas there is in the legislation related to safeguard and safety. This concerns especially the following legislation:

- The construction legislation, including for instance the building regulations with demands for houses' and buildings' design, and demands of for instance fire safeguard.

- The preparedness legislation with regulations of for instance disaster planning, airraid shelters, fire protection and preparedness in especially inflammable areas of companies, and also fire inspection in buildings with especially large fire and/or person strain.

- The health and safety legislation with regulations of for instance health and safety organisation, machinery safety and design of workplaces.

- The environmental legislation with regulations of for instance labelling of dangerous material and of especially pollutive companies.

In relation to fire safeguard the construction legislation serve to ensure persons and fire personnel, but not values, whereas the preparedness legislation besides to ensure persons also serve large values.

In spite of the correlation between expenses for damage prevention and insurance which is shown in figure 4.8, it can be difficult to gain premium reduction on continuous insurance on the basis of increased investments in damage prevention. Hence it is by experience not possible to get information from an insurance company which discount on the premium you will gain at for instance installation of a sprinkler system in a building. The insurance companies refer to the fact that the premium is determined on the basis of an overall evaluation.

On the other hand large savings can be obtained at buying of insurances by the means of pro-

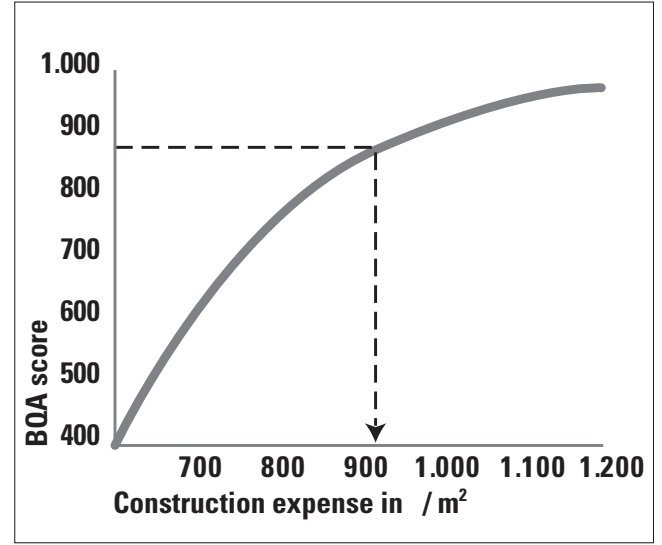

curement, in which the real and possible planned level of damage prevention is included as part of the procurement basis. It can be recommended to engage an insurance broker to assist in preparation and implementation of insurance procurement, especially the first time it is done. Often considerable savings of the insurance expenses can be achieved by such a process.

In relation to insurance, see checklist 4.c.

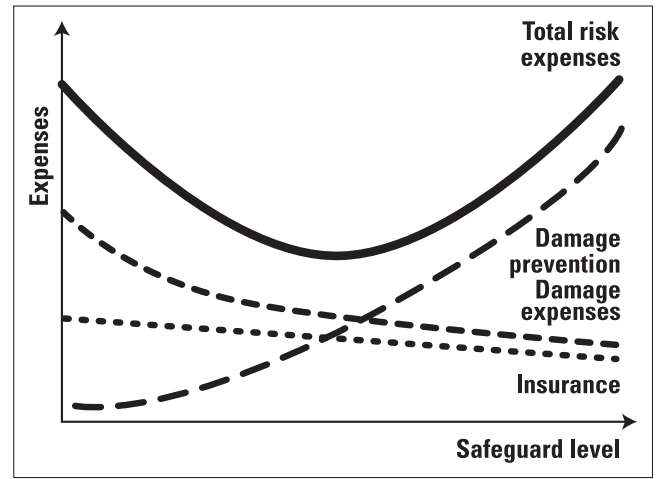

Figure 4.8

The risk expenses' correlation with the safeguard level (source: Storgaard, 1994)
Figure 4.6

Correlation between

$B Q A$ points and construction expenses (source: Williams, 2000)

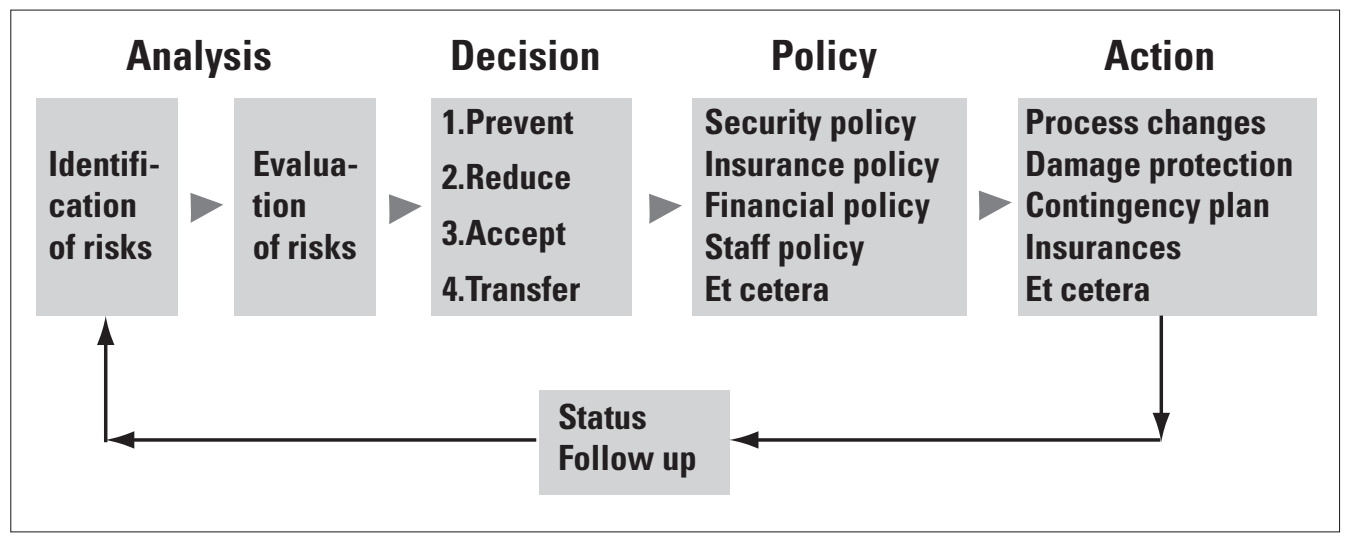

Figure 4.7

Process procedures at risk control 


\section{Checklist 4.C: Insurance}

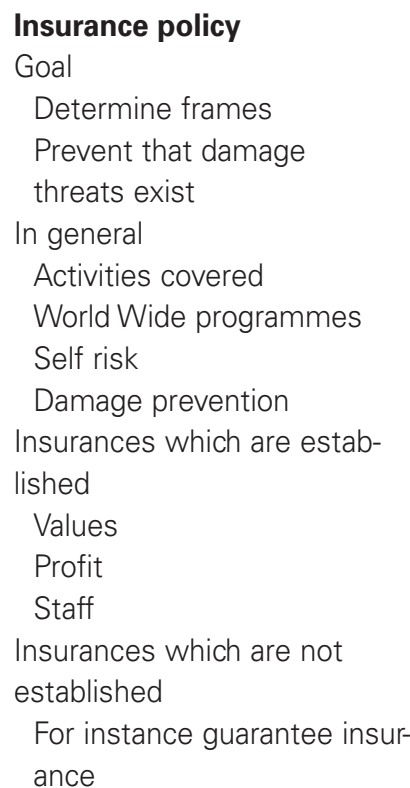

Administration of insurance
policy
Goals
How to insure
Areas of responsibility
Who does
What are done

When must it be done

Damage prevention

Proposals to the management

Counselling, insurance broker Approval, insurance company

\section{Insurance coverage}

Buildings

Building damages

Lease loss

Building owner responsibility Building contract insurance, Including:

Damage on existing building and construction, Building owner responsibility

Machines and equipment Operational equipment IT

Self-propelled work tools

Products

Declaration terms

Replacement price

Selling price

Money and documents

Consequential loss

Backwards regulation
Contribution period

Direct production salaries

Provider/purchaser coverage

Machine consequential loss

Transport

Buying, selling, exhibitions, repair

Means of transportation

Cars

Self-propelled work tools

Responsibility

Trade and product responsibility

Excess

Geographical area

Pollution responsibility, or

Environmental responsibility

Management and board responsibility

Professional responsibility Staff

Industrial injuries insurance

Collective travel insurance

Pension scheme

Group life insurance

\section{Insurance of properties}

Own, leased, rented out

Contract demands

Mortgagee demands

Insurance forms

Completed buildings

Building fire - possible part

of other insurance

Building insurance

Building owner insurance

Property insurance

All Risk company insurance

Expansions to the above:

Glass, piping damages, lease loss in addition to standard, residual value, dry rot and insect

Buildings under construction Building contract insurance including:

The building contract

Existing buildings and constructions

Building owner responsibility

Special areas

Clean-up / destruction

Is standard coverage suffi-

cient?

Ground damage coverage or building damage

Legalising

Buildings or movable

Distribution guidance

By appointment

Responsibility coverage concerning buildings

Property owner responsibility

Self-propelled work tools

Pollution responsibility, or

Environmental responsibility

Use of more insurance companies

Buildings, movables, consequential loss should be insured in the same company

Exceptions- excerpt:

Foundations below 1 metre below surface or basement floor Light signs et cetera Equipment which do not serve the building's operation

Hot work

Remember to make demands

Remember inspection

\section{Handling of damage}

Procedure

Immediate report

Use disaster plan at larger damages

Allow for possible pollution

Own report / record

Agreed operational plan Record of all damages, also without excess Inform tenants of procedures The insurance company's operational plan

Preliminary damage report Appraiser inspection and agreements

Damage report from company and appraiser Processing / recording Insured abroad

Procedures can be different 


\section{References}

A general introduction to Corporate Real Estate Management can be found in the anthology by Dewulf et al (2006). A very interesting American analysis and theory of space strategies has been made by O'Mara (1999) and the theory has been used in an analysis of the space strategies over time in Danish Broadcasting Corporation can be found in Jensen (2007).

\section{Literature}

Svein Bjørberg, \& and Kim Haugbølle (eds.): LCC for byggverk. Nordisk hovedprosjekt - sluttrapport (LCC for Buildings and Constructions. Nordic main project - final report) (In Danish, Swedish and Norwegian with summary in English). Hørsholm: Danish Building Research Institute, SBi 2005:01.

Gerald Davies: Serviciability Tool - Volume 1. Methods for Setting Occupant Requirements and Rating Buildings. International Centre for Facilities, Canada. 1993.

$\underline{I S O}$ : ISO/DIS 1568-5 - Buildings and constructed assets - Service life planning - Part 5: Whole life costing. Genève: International Organisation for Standardisation, 2002.

Geert Dewulf, Peter Krumm and Hans de Jonge: Successful Corporate Real Estate Strategies. Arko Publishers. 2006.

Per Anker Jensen: Space for the Digital Age - Defining, designing and evaluating a new world class media centre. BYG-DTU, Research report R-175. Technical University of Denmark, 2008.

Per Anker Jensen, Kjeld Nielsen and Susanne Balslev Nielsen: Facilities Management Best Practice in the Nordic Countries - $\mathbf{3 6}$ cases. Centre for Facilities Management, Technical University of Denmark, 2008.

Fred J. Klammt: How are your Facilities Performing? Proceedings from EuroFM/IFMA Conference Maastricht, June $7^{\text {th }}$ to $10^{\text {th }} 1998$.

Multiconsult $A S$ : State analysis as basis for value estimation. (Tilstandsanalyse som grunnlag for verdifastsettelse). 2000.

Martha O'Mara: Strategy and Place - Managing Corporate Real Estate and Facilities for Competitive Advantage. The Free Press. 1999.

Bernard Williams: Benchmarking Quality and Risk. Article in Facilities Management UK. 1999.

Bernard Williams: Measuring Quality. Article in Private Finance Initiative Journal, Volume 5, Issue 1, March/April 2000.

Geoff Woodling, CBB-Rebus: Competing for the Future of Corporate Real Estate. Article in John Worthington (editor): Reinventing the Workplace. Architectural Press, 1997.

\section{Websites}

BRE (British Research Establishment)........... w ww.bre.co.uk

SBi (Danish Building Research Institute).......... $\quad$ www.sbi.dk

Norwegian Construction Certification ............ www.byggsertifisering.no 


\begin{tabular}{|c|c|}
\hline \multicolumn{2}{|c|}{ Figures } \\
\hline 5.1 & $\begin{array}{l}\text { DFM's space definitions from a } \\
\text { functional user point of view. . . . . . } 96\end{array}$ \\
\hline 5.2 & $\begin{array}{l}\text { Storey plan with illustration of } \\
\text { DFM's space definitions ......... } 97\end{array}$ \\
\hline 5.3 & $\begin{array}{l}\text { Example of relative space distribution } \\
\text { in an office building } \ldots \ldots \ldots \ldots \ldots . . .98\end{array}$ \\
\hline 5.4 & $\begin{array}{l}\text { Example of absolute space } \\
\text { distribution in an office building .. }\end{array}$ \\
\hline 5.5 & Three office generations ........... 115 \\
\hline 5.6 & $\begin{array}{l}\text { Traditional and future } \\
\text { office environments. . . . . . . . . . } 117\end{array}$ \\
\hline 5.7 & $\begin{array}{l}\text { Typical time related use of an } \\
\text { individual office workplace .... }\end{array}$ \\
\hline 5.8 & $\begin{array}{l}\text { Job functions in relation to } \\
\text { independence and interaction. . }\end{array}$ \\
\hline 5.9 & $\begin{array}{l}\text { Office environments in relation to } \\
\text { independence and interaction..... }\end{array}$ \\
\hline \multicolumn{2}{|c|}{ Cases } \\
\hline 5.a & $\begin{array}{l}\text { Former Space Standards in Danish } \\
\text { Broadcasting Corporation (DR) .......100 }\end{array}$ \\
\hline 5.b & $\begin{array}{l}\text { Space Brief at Relocation of a } \\
\text { Unit to a New Lease.......... }\end{array}$ \\
\hline 5.c & $\begin{array}{l}\text { Example of Space Brief in } \\
\text { a Churn Plan } \ldots \ldots \ldots \ldots \ldots\end{array}$ \\
\hline 5.d & $\begin{array}{l}\text { Example of Time Schedule for a } \\
\text { Large Churn Project } \ldots \ldots \ldots \ldots\end{array}$ \\
\hline $5 . e$ & $\begin{array}{l}\text { Canon Svenska AB's Work Where } \\
\text { You Want Concept. . . . . . . . . . . } 116\end{array}$ \\
\hline $5 . f$ & IBM's Project e-place . ........... 118 \\
\hline 5.9 & $\begin{array}{l}\text { New Ways of Working in the Danish } \\
\text { Palaces and Properties Agency....... } 119\end{array}$ \\
\hline \multicolumn{2}{|c|}{ Checklists } \\
\hline $5 . \mathrm{A}$ & Planning and Implementation of Churns . . 104 \\
\hline 5.8 & Entering and Finishing Tenancies ....... 105 \\
\hline 5.C & Larger Moves ... . \\
\hline 5.D & $\begin{array}{l}\text { Implementation of New } \\
\text { Ways of Working. ......... }\end{array}$ \\
\hline
\end{tabular}

Spaces........................ 94

Space terms . . . . . . . . . . . . . . . . . . . . . . . . . 94

Functional spaces. . . . . . . . . . . . . . . . . . . . . . . 95

Space key indicators and standards. . . . . . . . . . . . . . . 96

Space briefing ....................... 99

\section{Adaptation between the Physical Frames}

and the Organisation . . . . . . . . . . . . . . 101

Churns .............................. 101

Rebuilding and maintenance works . . . . . . . . . . . . . . . . 107

Moves. . . . . . . . . . . . . . . . . . . . . . 111

Workplace Design . . . . . . . . . . . . . . . . . . 113

New ways of working . . . . . . . . . . . . . . . . . 113

The planning process . . . . . . . . . . . . . . . . . . 115

References..................... 123 
Strategic and tactical planning

Spaces and legislation

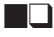

Poor standardisation

The building code
Space Management is the work area within FM which concerns analyses of space requirements, adaptation and allocation of space, planning and implementation of churns and relocations, and also interior design.

Space Management is close connected with property strategies and strategic planning, which were discussed in chapter 4. However, Space Management is to a greater extent a tactical task rather than a strategic task. One may say that the purpose of the strategic planning is to ensure that there in the longer run are physical frames of a size and quality so the organisation can develop due to the company's strategic plans. The purpose of Space Management is within the present frames to ensure the best possible continuous adaptation between the organisation and the present spaces, possibly supplemented by short-term adjustments of the physical frames for instance through temporary use of office pavilions or entering new leases.

Hence Space Management is about to ensure the most efficient use of the resource which space represents. In most companies it is a scant resource, which represents a considerable value and cost. In spite of this it is remarkable to which limited extent companies often keep account of this resource. Implementation of internal lease, c.f. the mention in chapter 3 can be an important tool to create a necessary focus on and respect of this resource.

Spaces make a central work related element to many other trade groups than facilities manager and space managers. This concerns for instance architects, engineers, land surveyors, insurance agents, real estate agents, property administrators and managers of public space registers. In spite of this, or maybe due to this, there is a poor standardisation of the definitions of space. This concerns both Denmark and internationally. Thus the possibilities of comparing spaces and space related indicators are complicated. This problematic is further illustrated in section 5.1, where a number of various space terms are defined.

Section 5.2 concerns the central work tasks with adaptation of the physical limits, which include planning and implementation of churns, rebuildings and relocations. Some examples of such tasks are presented, as there are checklists for churns, moving in and out from tenancies, and also larger relocations. In connection with rebuilding tasks, maintenance tasks are also mentioned, as they have large process related similarities.

In section 5.3 the actual workplace design is discussed emphasising office work. It concerns an area in which there is a rapid development, for instance due to changes of work processes and collaboration forms due to the development in information and communication technology, and also implementation of Business Process Reengineering. There are many terms to this development and the possible solutions, for instance "New Ways of Working", "New Office" and "Future Office", which occasionally is used here in Denmark. In this book the term New Ways of Working will be used.

\subsection{Spaces}

\section{Space terms}

Space terms are used in many connections and with various purposes in legislation and public administration. The following examples can be mentioned:

- In the planning legislation as basis of determination of use and land use ratio to various areas

- In the tax legislation as basis of determination of assessment of property, land taxation and property taxes

- In the construction legislation as basis of calculation of land use ratio and regulations for smallest room sizes and size of fire section et cetera

- In the housing legislation as basis of subsidies for building of social housings and rent subsidy

The large problem is that there is no correspondence between the space definitions, which are used in various legislations. Most grotesque in Denmark is the situation in the housing area, where two identical flats have various living floor space, if one of them is in social housing and the other in a private housing. In both cases the spaces must be assessed due to a guideline from the Ministry of Housing (today the Ministry of Social Affairs), but the guideline differs for the two types of housing.

The building code in Denmark determines guidelines for calculation of storeys' gross spaces. The sum of the storeys' gross space repre- 
sent the gross storey area of the building, which along with the site's space form the basis of calculation of the floor space index. In the building code there are differences of which spaces particularly concerning basement areas for technical use - have to be included in the calculation of the gross storey area for housing estates and other buildings.

In connection with hiring out the term rental area is used for the total space to which the rent is calculated. For business tenancies there are no legal rules for calculating the area as there is freedom of agreement. Hence air-raid shelters, technique premises and other basement rooms can be included in business tenancies, whereas basements cannot be included at housing tenancies.

In lack of a general usable space term DFMbenchmarking has defined its own term called building operational area (BDA). This term in principle covers all building areas which are included in the building operation. In practice the space is calculated with basis in the space definitions in the Danish Building and Housing Register (BBR). A standardisation work was started in 2007 under CEN/TC348 to develop a European FM standard for space measuring.

The building operational area to owned and rented out properties is defined as the sum of the total building space, including areas of utilised part of top storey and total basement areas to all buildings in an estate. All those space components are in Denmark included in the messages to building owners from the Building and Housing Register. To tenancies the building operational areas is defined as tenancy space with operational obligations.

Parallel to the building operational areas DFMbenchmarking has defined the term ground operational area (TDA), which is defined as the ground area deducted the built-up area. This area includes the total ground space, which the building owner is obligated to maintain and keep clean et cetera.

Furthermore, DFM-benchmarking has defined two other operational space terms, which cannot be calculated on the basis on BBR information, but demands own making up from the operational organisation:

- Heated area is defined as the sum of space directly and indirectly heated to at least $18^{\circ}$ $C$ to all buildings of the property or to the share of tenancies.
- Cleaning area is defined as the sum of floor spaces, which are included in cleaning at least every second week, to all buildings of the property or to the share of tenancies.

\section{Functional spaces}

One of the space terms which may cause most trouble is the net area. At first the term is used with a different meaning by lessors and users of buildings. To lessors the term is usually used to describe the part of a tenancy space, which tenants have at their disposal, i.e. the rented out space exclusive percentage of shared spaces. The lessor has an interest in the size of the space; hence it is in Denmark normally measured from outside to outside of facades to the entire tenancy including walls, chutes et cetera. However, to users of buildings net area is usually on the contrary pure floor spaces, i.e. measured inside each room. The rules and conventions of measuring net area vary from country to country.

Secondly the making up of net area can vary depending on the phase in a building's life cycle and use cycle. In the briefing phase of a new building the space demands are usually determined to usable spaces as net area. It can vary which functions are included in the building brief and which are left to the designers to devote for the necessary functions in the outline. Often mandatory demands of for instance access space, toilets, wardrobes and air-raid shelters will not be defined in the building brief and the same is often the case for the building's technical functions such as heating central, ventilation rooms and cleaning rooms. On basis of this there are often variations in how the building owner and the architect calculate the net space.

In the operational phase the situation in larger organisations will typically be that various departments organise their spaces, whereas other spaces are shared to the users of the property. Such shared spaces include typically lobby, corridors, staircases, lifts, toilets, wardrobes, copying rooms, mail rooms, kitchenette, canteen and a possible exercise room and basement parking. These spaces are relatively static regarding disposal, whereas spaces of which the departments have at their disposal may be subject to frequent changes according to the development of the organisation.

Therefore the last mentioned spaces have most interest in relation to Space Management and are termed the usable space. The usable space can furthermore be subdivided in primary usable
Net area

Building Operational Area 
Figure 5.1

DFM's space definitions from a functional user point of view (source: DFM Networks, 1995)

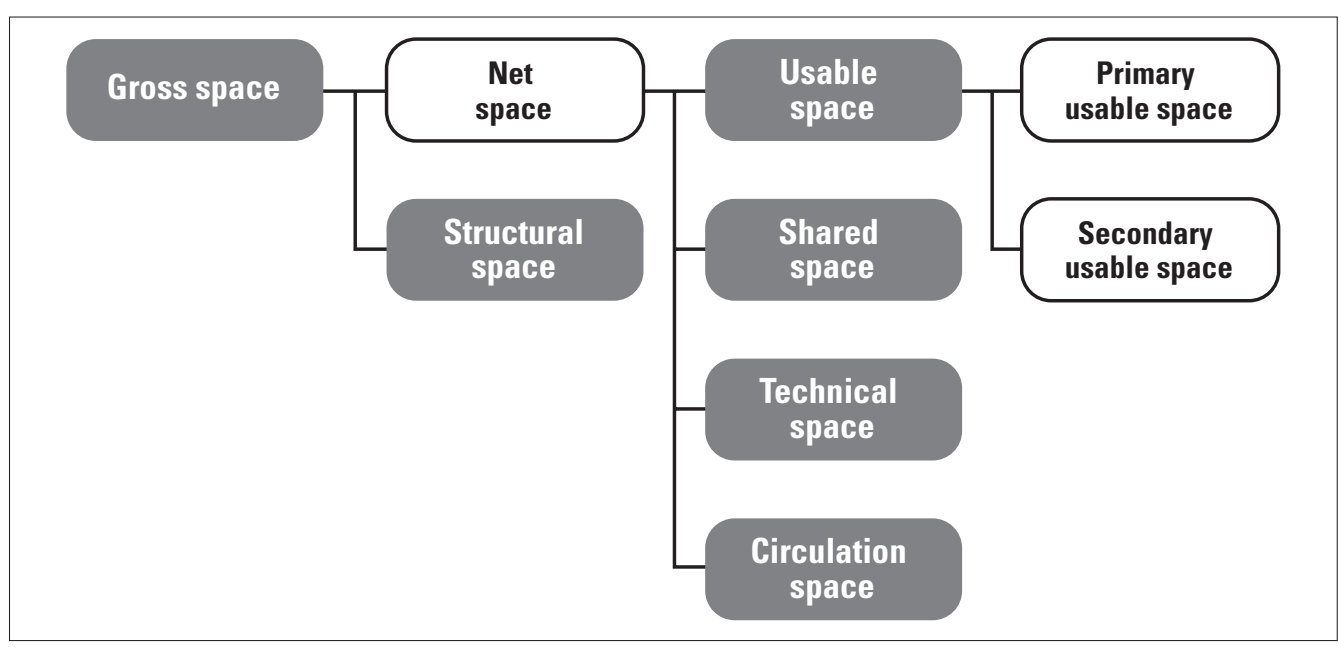

space including spaces with daylight and therefore possible to use for workplaces, and secondary usable space in the shape of cores and basements which are only usable for archives et cetera.

These space terms were defined in a work group as part of DFM's benchmarking project and first published in 1995. The correlation among the various space terms seen from a functional user point of view is illustrated in figure 5.1 and more thoroughly in figure 5.2.

As it appears from figure 5.1 net space is defined as gross space deducted construction space, but the term net space is not central in DFM's definitions. In general it must be recommended only to use the term net space, when it appears clear from the context what is implied with the term.

DFM's space definitions are inspired from various foreign space definitions, for instance from the German DIN norm 276 and from IFMA (Winkler, 1988 and IFMA, 1993).

DFM's space definitions are close to the German ones. IFMA's space definitions operate with "rentable area", which is exclusive outside walls and shafts, hence it is at first oriented towards rented out buildings, and secondly based on another measurement practice than the Danish one, but to a great extent corresponding to the British tradition, where they normally make up storey spaces exclusive outside walls.

In figure 5.3 is shown an example of the relative space distribution in an office building based on the space definitions shown in figure 5.1 and 5.2. In figure 5.4 is shown an example of a similar absolute space distribution.

\section{Space key indicators and standards}

Key indicators for spaces in relation to Space

Management particularly relate to the following areas:

- Key indicators for space needs for typical functions for the use of space planning and arrangement, for instance space per office workplace

- Key indicators to the space utilisation in a building or part of a building for the use as indicator of efficiency et cetera

There is of course some correlation between the two types of key indicators. However, you cannot directly calculate one type from the other. The first type of key indicators relates to space needs for planning purposes, and the second relates to the actual space use in a planning proposal or a realised one. The measurement of the actual space use may eventually be used to adjust the planned space needs for each function. The measurement of space efficiency is however to a high degree a measurement of the building's efficiency. Hence, the shape of the building has great importance for the efficiency of use of space.

Especially in the early phases at planning of new buildings you need key indicators of the space need to estimate the total gross space of the building on the basis of the programmed net space requirements. Key indicators for the gross/net ratio are important, both as a goal for space efficiency and as a planning tool. At the same time it is probably the most used space key indicators in Denmark in spite of lack of standardisation of especially the net space term as mentioned earlier. Similar to the recommendation for the use of the net space it must be recommended only to use the gross/net ratio, when it clearly appears from the context what is implied with the term. 


\section{Gross space:}

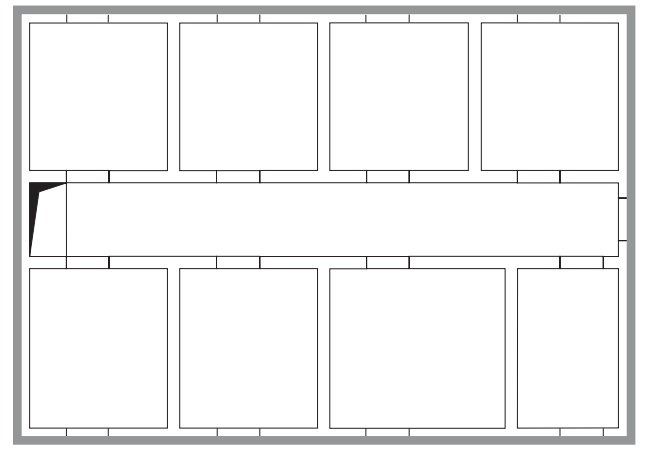

Usable space:

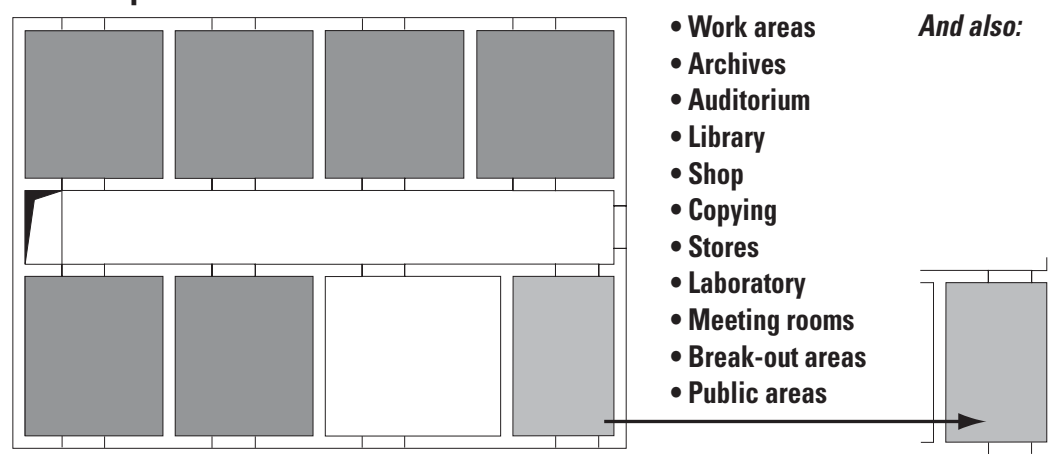

- Work areas

- Auditorium

- Library

- Shop

- Copying

- Stores

- Laboratory

- Break-out areas

Public areas
Figure 5.2

Storey plan with illustration of DFM's space definitions
Structural space:

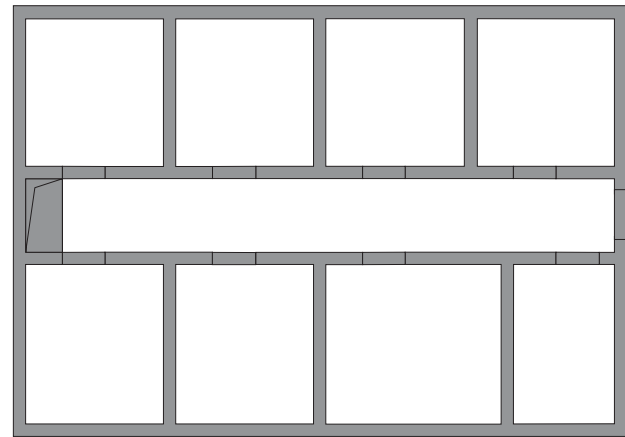

- Shafts (not climbable)

-Walls

Technical space:

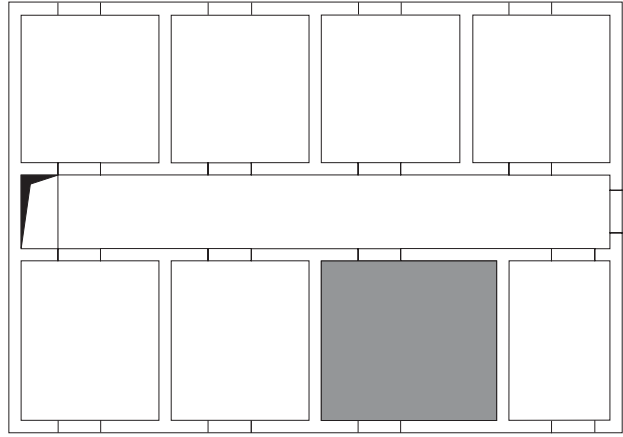

- Building technical • Emergency

areas

-Ventilation rooms $\bullet X$-field rooms

- Power transformer $\bullet$ Cleaning rooms

rooms

\section{Circulation space:}

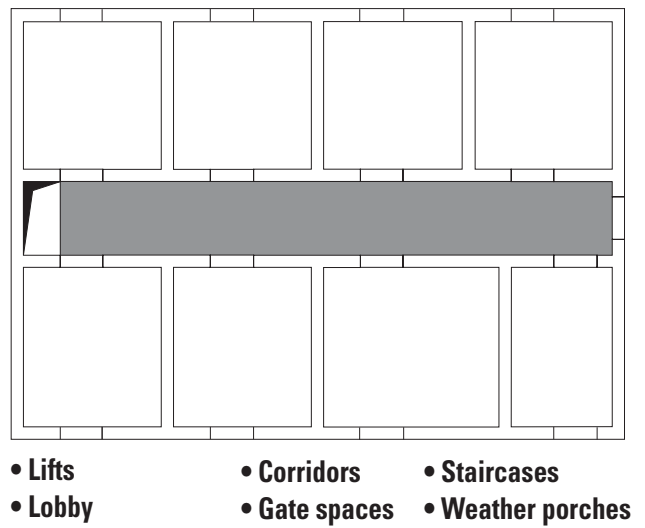

\section{Shared space:}

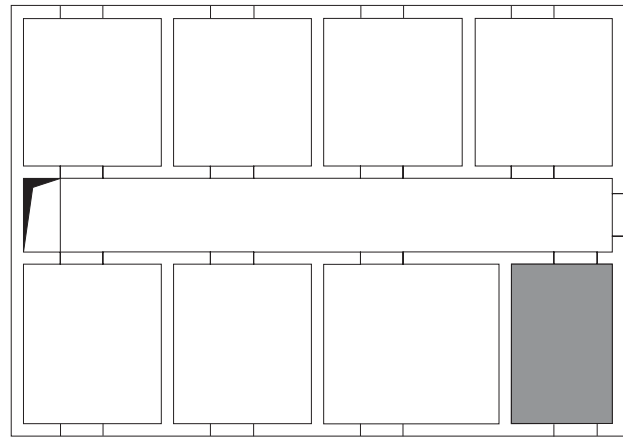

- Bathroom, toilet • Wardrobes • Reception

- First aid rooms - Kitchen - Post rooms

- Garage
- Bathroom, toilet

- First aid rooms

Garage

- Kitchen

- Canteen

- Reception

- Post room

- Air-raid shelters

(when they are

not shared areas) 
Figure 5.3

Example of relative

space distribution in

an office building
Health and safety regulation

\section{Space use per} workplace

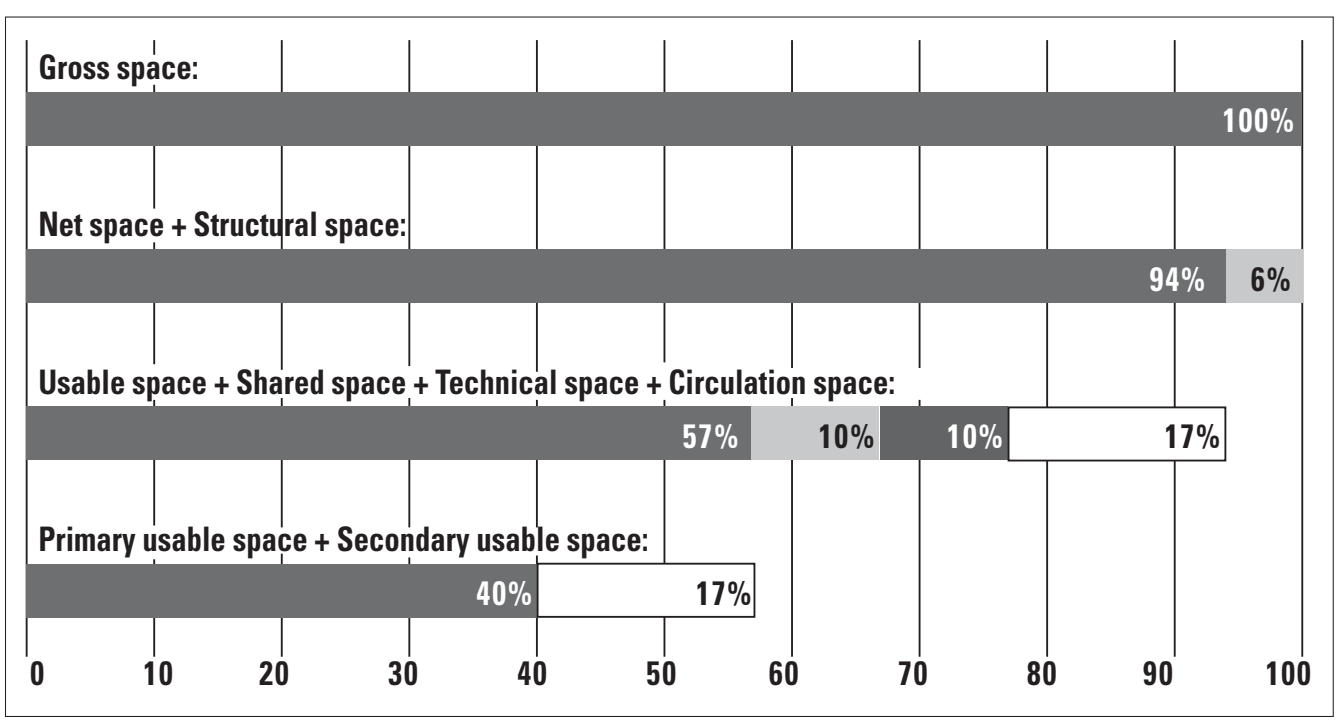

If the difference between the gross space and the net space is only the structural space as shown in figure 5.1 and 5.2, the gross/net ratio can typically vary between 1.01 and 1.15 . The lower ratio is achieved at hall buildings with large span, where the structural space on the whole only includes outside walls with a large space to the opposite walls. The highest ratio is achieved in tower blocks with a small ground surface, where there besides heavy structures also are included many shafts for installations, which are included in the structural space.

Another important space key indicator is the gross/usable ratio, which will often amount 1.70-2.00 in office like buildings, but it can be considerably higher in buildings with especially large shared spaces. A variant which is also a common key indicator is the gross/usable + shared ratio and this ratio will typically amount $1.40-1.70$ in office like buildings.

The above ratio's are key indicators related to the design of the building, but it has also become more and more common to use key indicators for the utilisation of space based of gross space or net space per employee or per workplace. In modern regular office buildings there typically is $15-30 \mathrm{~m}^{2}$ gross area per workplace. In older buildings this is typically somewhat higher due to poorer use of space, typically $30-40 \mathrm{~m}^{2}$ per employee and workplace, and in former housings rebuilt for offices 40-50 $\mathrm{m}^{2}$ per employee and workplace is not unusual. As further mentioned in section 5.3, new flexible ways of working where some workplaces are used in turn by more employees, may imply a considerable less space per person than the above mentioned $15-30 \mathrm{~m}^{2}$ per employee.
For these reasons alone it can be financially beneficial to companies to move into new office building. Older buildings are also often situated in areas with high land prices, hence the sales price or the lease saving may often over time finance a new and more efficient new building in a development area with lower land prices.

In figure 5.4 is shown an example of an absolute space allocation in an office building med a gross space of $25 \mathrm{~m}^{2}$ in average per employee. The allocation corresponds to the shown relative space allocation in figure 5.3.

Based on consideration for work environment and indoor climate the Danish Building Research Institute recommends a net space per employee of 10-12 $\mathrm{m}^{2}$, depending on the type of work (Valbjørn et al, 2000). There are no specific legal requirements in relation to this. In the Building Regulations it is required that work rooms must have a space of at least $7 \mathrm{~m}^{2}$. This implies that offices as a minimum must be of this size, but in principle there can be more workplaces in the room.

The Danish Health and Safety Authority's regulations of work rooms at fixed workplaces determine the following regulations, which limit the number of workplaces in a room with a specific space (The Danish Working Environment Authority, 1996):

- The room height must normally be at least $2.5 \mathrm{~m}$

- An air volume of $12 \mathrm{~m}^{2}$ to each employee in the work room will normally be sufficient. If there is mechanical ventilation this can be reduced, yet never to below $8 \mathrm{~m}^{2}$ per employee. Room heights over $4 \mathrm{~m}$ are not included at the calculation of air volume. 


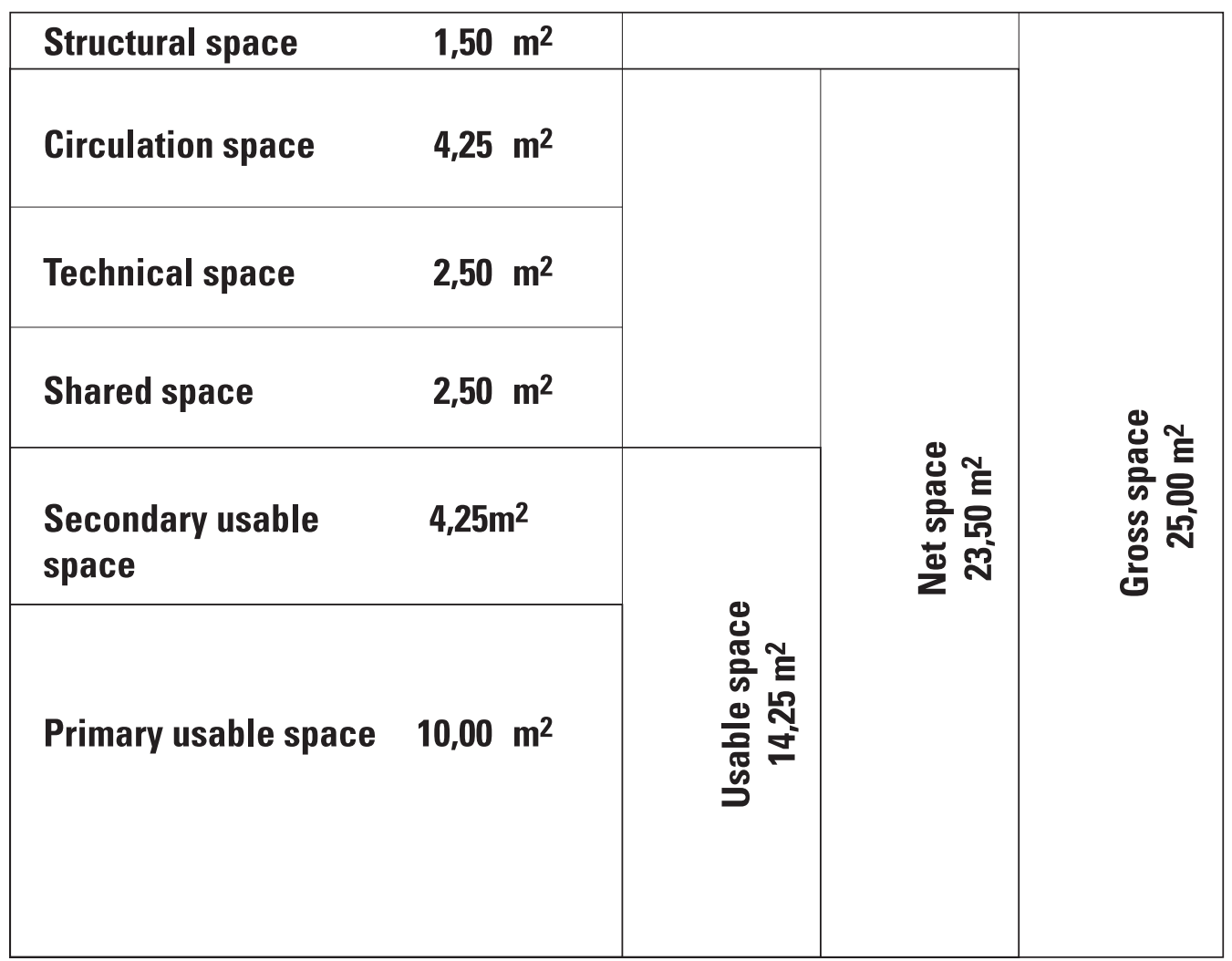

Figure 5.4

Example of absolute

space allocation in an

office building

These demands imply that in work rooms with a height of $2.5 \mathrm{~m}$ there must be at least $4.8 \mathrm{~m}^{2}$ per employee in rooms without mechanical ventilation, and $3.2 \mathrm{~m}^{2}$ in rooms with mechanical ventilation. A work room of $7 \mathrm{~m}^{2}$ with mechanical ventilation can consequently in principle be a fixed workplace to two persons. However, it will not be difficult to design appropriate office workplaces within this limited space.

Besides the above mentioned there is not as to legislation specific standards to space needs for workplaces. In return many larger companies have determined their own internal space standards. An example of this is described in case 5.a. However, such space standards should be changed in time or replaced by more flexible requirement estimations along with changes in work processes, IT technology and work design, which are further discussed in section 5.3.

\section{Space briefing}

Space briefing is an essential element of Space Management, which is included in practically all Space Management tasks, including planning of new building and extensions, at moving in new acquired property or tenancies, and also at internal relocations and new interior layouts.

Above all space briefing is a needs analysis of the necessary space to accommodate an organisational unit, and the result of this analysis con- sists of a specification of the space requirements for various functions. Depending of the task the space brief can also include more or less detailed specifications of needs and wishes to each function, and also proximity relations between the functions and maybe also to other organisational units. At new building the space brief is included as an integrated part of the building brief, where there conditions are closely detailed.

In case 5.b is shown an example of a space brief for an organisational unit and a comparison to the corresponding spaces in two potential leases for the unit.

Space standards

The preparation of a space brief must to a great extent be based on data collection through meetings with the management and staff in the organisational unit in question. As a preparation to this one must collect the information, which already is available about the unit and its present space allocation.

During the meetings one must try to have answers of for instance the following questions:

- Which tasks and activities does the unit handle

- How many employees are there in the unit at present

- Has there been made decisions of changes in the number of employees 


\section{Case 5.a: Former Space Standards in Danish Broadcasting Corporation (DR)}

The following net area were in 1984 determined as a precondition to space allocation in DR. During the 1990 'ies there space standards were less used in favour of individual requirement estimations.

1 person with independent work. $28 m^{2}$ and meeting facilities for 6-8 persons (for instance a chief executive)

1 person with independent work. $24 m^{2}$ and meeting facilities for 6-8 persons (for instance a programme manager)

1 person with independent work. $19 m^{2}$ and meeting facilities for 4-6 persons (for instance a deputy manager)

1 person with independent work. $14 \mathrm{~m}^{2}$ and meeting facilities for 2-3 persons (for instance a chief editor)

1 person with independent work.

(for instance an independent journalist)

1 person with independent work,

(but connected to an editorial group)

Offices for more than 2 persons, per person ca. $7 \mathrm{~m}^{2}$

Group rooms $42 m^{2}$

(for instance an editing secretariat for 4-6 persons and meeting facilities for 10 persons)

Meeting room up to 10 persons, per seat. ca. $2 \mathrm{~m}^{2}$

Meeting room for more than 10 persons, per seat. ca. $1,8 \mathrm{~m}^{2}$

Shared rooms, per employee in the group

(Shared rooms are only established for staff groups which do not have a fixed workplace in a room) 
- How does the employees spread on various functions

- How are the employees at present located

- Which space requirements and design considerations are there to each function

- Are there special needs of equipment, installations, devices or accessibility

- How are the mutual relations among the functions

- Are there relations to other organisational units of importance to the location

- Which changes are expected at long-term of activities and number of employees

- Is there possibilities to have written material such as description of the unit, staff survey, internal phonebook and organisation chart

If it is an existing organisational unit which must move to a new location or a rebuilding with a new layout, one must make an inspection of the present premises. The inspection must be done with a representative of the unit, who can explain the characteristics of each function, which is well functioning, which is less well functioning, and also the changes which must be made. The basis is often that the organisational unit must be changed or new established. In this case one must primarily base the planning on the information, with which the future manager of the unit can contribute about the plans to the changed or new unit.

At such meetings the representative of the unit will of course try to obtain the best possible future conditions to the unit. This is often seen as blown up space requirements and a long wish list for other space improvements, especially in cases where the unit does not pay internal rent, and must not itself pay for rebuilding and furniture et cetera.

Therefore it is important to make a critical estimation of space requirements and various wishes. Use of space standards as well as other policies and guidelines for the company's property is an important tool in such estimations. It is furthermore useful to make a close distinction in the space brief between demands and wishes, i.e. needs which are necessary ("need to have"), and "needs" which you would like to have fulfilled, but without which you can function ("nice to have").

As space manager one must also be very aware that persons, who do not work with spaces as a daily routine, have great difficulties in "reading" and understanding a draft of a building storey, especially if they do not know the storey, so there are no known configurations in the draft. Hence, in the dialogue with the users it is important to speak concrete about space requirements et cetera. References to spaces which are known by both parties are in such a dialogue a much safer target for space requirements than number of $\mathrm{m}^{2}$.

Especially to larger projects it is necessary to prepare the ground for final approval with the responsible management of the company along with the necessary documentation and description of conditions and arguments for the stated demands and wishes. It can especially be necessary with a political decision how much space for expansion of each unit must be taken into consideration.

\subsection{Adaptation between the Physical Frames and the Organisation}

\section{Churns}

The common way to adapt the organisation to the physical frames is to relocate the staff. At larger organisational changes this can imply comprehensive churns, which demand thorough planning and management. It will usually also imply adaptation of the physical frames to the changed organisation through rebuilding and new interior layout of existing buildings. In this section is at first the planning of churns closely discussed, and secondly are the rebuilding and maintenance projects and also relocations discussed.

In checklist 5.A is described some typical tasks in connection with planning and the implementation of churns, which both imply rebuilding and relocations.

Change of organisation will often be related to up or down adjustments of the activity level in the company. In such cases the churns will imply changes of the total space requirements, which in connection with activity expansions can be done at entering new leases or mounting of pavilions. On the other hand can activity decrease imply termination of leases or renting out part of the company's space.

In checklist 5.B is as supplement to checklist 5.A described the further tasks, which typically will be involved in a churn, which imply entering or finishing of a lease.
References

Inspection 


\section{Case 5.b: Space Brief at Relocation of a Unit to a New Lease}

This case originates from the selection process of a new lease to a unit in Danish Broadcasting Corporation (DR). As part of a rationalisation plan the unit had to reduce the staff with $20 \%$ over a period. Among the preconditions was introduction of a new IT system and also relocation from an old office building in which the unit's 60 employees were divided at 3 small storeys, and to a modern office building, in which the unit would be gathered at the same storey and with possibility to arrange a shared offices for the main part of the staff.

Below the space brief is compared to two potential leases (lease A and B). Besides the spaces in the brief the lease would include the necessary amount of toilet rooms, wardrobe rooms, cleaning rooms and kitchen facilities, which are included in the gross/net ratio.

\begin{tabular}{|c|c|c|c|c|}
\hline & Staff & Space needs & Lease A & Lease B \\
\hline \multicolumn{5}{|l|}{ Offices et cetera: } \\
\hline Office manager & 1 & $19 m^{2}$ & $19 m^{2}$ & $27 \mathrm{~m}^{2}$ \\
\hline Vice office manager & 1 & $14 m^{2}$ & $19 m^{2}$ & $14 \mathrm{~m}^{2}$ \\
\hline Coordinator & 1 & $9 m^{2}$ & $13 m^{2}$ & $14 \mathrm{~m}^{2}$ \\
\hline Secretaries office & 3 & $30 m^{2}$ & $33 m^{2}$ & $55 \mathrm{~m}^{2}$ \\
\hline Post room / scanning & 2 & $20 m^{2}$ & $20 m^{2}$ & $13 \mathrm{~m}^{2}$ \\
\hline Accounts / finance & 4 & $32 m^{2}$ & $33 m^{2}$ & $45 \mathrm{~m}^{2}$ \\
\hline Support & 4 & $32 m^{2}$ & $33 m^{2}$ & $26 \mathrm{~m}^{2}$ \\
\hline IT coordination & 2 & $18 m^{2}$ & $20 m^{2}$ & $26 \mathrm{~m}^{2}$ \\
\hline Section leader 1 & 1 & $9 m^{2}$ & $13 \mathrm{~m}^{2}$ & $11 \mathrm{~m}^{2}$ \\
\hline Section 1 & 21 & $168 m^{2}$ & $180 m^{2}$ & $172 m^{2}$ \\
\hline Section leader 2 & 1 & $9 m^{2}$ & $13 \mathrm{~m}^{2}$ & $20 \mathrm{~m}^{2}$ \\
\hline Section 2 & 21 & $168 m^{2}$ & $165 \mathrm{~m}^{2}$ & $160 \mathrm{~m}^{2}$ \\
\hline Sum, usable space & 62 & $528 \mathrm{~m}^{2}$ & $561 \mathrm{~m}^{2}$ & $583 \mathrm{~m}^{2}$ \\
\hline \multicolumn{5}{|l|}{ Other rooms with daylight: } \\
\hline Guest reception & & $8 m^{2}$ & & $28 \mathrm{~m}^{2}$ \\
\hline Meeting rooms $\left(10 \mathrm{~m}^{2}+20 \mathrm{~m}^{2}\right.$ & & $30 \mathrm{~m}^{2}$ & $39 m^{2}$ & $27 \mathrm{~m}^{2}$ \\
\hline Smokers room & & $8-10 m^{2}$ & & $13 \mathrm{~m}^{2}$ \\
\hline Lunch room (30 seats) & & $30-40 m^{2}$ & $45 m^{2}$ & $38 \mathrm{~m}^{2}$ \\
\hline Disposable & & & $82 \mathrm{~m}^{2}$ & $19 \mathrm{~m}^{2}$ \\
\hline Sum, usable space & & $76-88 \mathrm{~m}^{2}$ & $166 \mathrm{~m}^{2}$ & $125 \mathrm{~m}^{2}$ \\
\hline \multicolumn{5}{|l|}{ Rooms without daylight: } \\
\hline Office archive & & $10 m^{2}$ & $11 m^{2}$ & $26 \mathrm{~m}^{2}$ \\
\hline Machine room (2-3 rooms) & & $20-30 m^{2}$ & $21 \mathrm{~m}^{2}$ & $28 \mathrm{~m}^{2}$ \\
\hline Sum, usable space & & $30-40 \mathrm{~m}^{2}$ & $32 \mathrm{~m}^{2}$ & $54 \mathrm{~m}^{2}$ \\
\hline Total usable space & & $634-656 \mathrm{~m}^{2}$ & $759 \mathrm{~m}^{2}$ & $762 \mathrm{~m}^{2}$ \\
\hline \multicolumn{3}{|c|}{ Lease space (exclusive percentage of shared spaces) } & $1.241 \mathrm{~m}^{2}$ & $1.162 \mathrm{~m}^{2}$ \\
\hline \multicolumn{3}{|c|}{ Gross/net ratio (lease space /usable space) } & 1,6 & 1,5 \\
\hline
\end{tabular}

As it appears the two leases meet the usable space requirements with proximately the same amount of space, even though the use of space in lease B in total is a little better. 


\section{Preparation of churn plans}

Churn is used as a term for the process of carrying out a series of internal relocations of staff to optimise the physical location in accordance with the needs of the organisation. Planning of churns is mainly based on space briefing as described in section 5.1 to each of the involved organisational units. However, at the churn planning the space brief must be converted into solutions. Therefore the space planning only produces a part of the data basis at the churn planning. One may say that the space brief is the demand part of the space planning.

However, it is also important to have a good data basis of the supply part in the "space market". The space supply however includes the available spaces, which the organisational units that are intended to be relocated will release. There will often be a mismatch between the space supply and the space demand. Besides the need to achieve at match of the spaces there are often restrictions consisting of proximity relations among various units, which also must be taken into consideration. This can limit the possible solutions considerably, and it is not always possible to solve the puzzle without consulting the organisation.

Hence it may be necessary to examine the potential space supply consisting of spaces which are handled by units, which not necessarily have to be relocated. In order to accommodate the direct needs for the churn, it may be necessary to include such units in a reshuffle. In this way even limited organisational changes can imply considerable relocations, if all employees in the same unit must be located together.

There are examples of the necessity of relocating 60 employees to make room for 2 new employees, who had to be located in a certain organisational unit. In particular small organisational units without strong proximity relations to other units can be subject to frequent relocations, so that other units' need for organisational adaptations can be met.

In case 5.c is shown an example of a space brief in connection to a churn plan as part of a larger reshuffle. The space brief includes former space and location and future space and location to each unit supplemented with a remark from which former unit the relocated employees came.
As basis of the churn planning it is necessary to have updated information about the space allocation. The best tool for this is a CAFM system in which such information at any time can be seen on storey plans. By means of a CAFM system there can also be made simulations of churns with calculation of space consequences, and coloured drawings can be printed out, which easily explain proposals of relocations, even to employees who are not used to study drawings. See chapter 8 for a closer description and examples of the use of CAFM systems.

In connection with preparation of proposals for changed space allocation it should be a target that the space utilisation is optimised. Therefore it must be considered at each proposal, whether it is possible to improve the space allocation. An important tool in connection with this is key indicators for space per employee, or space per workplace at various types of employees or types of workplaces. On the other hand one must consider the work environmental conditions, so there is enough space for the various types of work.

It must furthermore be considered whether to pay regards to future staff expansions within each unit. Location of spare meeting rooms or project rooms among various units' spaces can for instance contribute to give flexibility in the space allocation.

Preparation of churn plans for the physical relocation of units and perhaps the individual employee is the first main task in connection with churn planning. It can often be necessary to prepare more alternative proposals for relocation plans. Such proposals quite inevitably affect the company's internal status hierarchy, of which units are located closest to the centre of power or in the most desired locations. By presentation of alternative proposals such decisions can be moved to a higher level of the organisation, hence the space manager will not have the responsibility for the final decision.

\section{Implementation planning}

When the relocation plan has been approved the next main task consists of preparation of a total plan for implementation of the churn. The major problem in connection with this is often how to create the necessary space to begin the relocation. When space has been created for the first move, the sequence of the succeeding relocations will follow in a natural way. 


\section{Checklist 5.A: Planning and Implementation of Churns}

Planning of churns with rebuilding and relocations:

- Reveal space requirements and location wishes through meetings with the affected units/functions

- Prepare one or more proposals for changed space allocation (which spaces for which units/functions)

- Obtain approval in principle of a proposal from the management

- Plan arrangements in collaboration with the affected units/functions

- Clarify the degree of rebuilding, installation changes and equipment acquirements

- Prepare drafts of rebuilding and new interior layout

- Obtain approval af drafts from the affected units/functions

- Examine if there are rebuildings which need building permit, eventually through a meeting with the authorities, and submit building petitions

- Prepare estimate of expenses for the rebuildings, installation changes and equipment acquirements and relocation

- Prepare time schedule to implementation of the entire churn process, including rebuildings, equipment supplies and relocations

- Obtain approval of budget and time schedule from the management

Implementation of churns with rebuilding and relocations:

- Obtain tender and enter agreements of rebuilding, installation changes, equipment supply and relocation

- Have a contact person and coordinator in each unit/function in connection with rebuilding and relocation

- Arrange procedure in connection with the relocation with each coordinator, including who ensure the following:

- ordering moving boxes

- packing away into moving boxes, including shared archives et cetera

- marking of moving boxes and equipment, including shared equipment et cetera

- unpacking

- Eventually prepare a written relocation instruction, which is handed over to all employees, which are included by the relocation with a clear indication of what each person must do and at which time

- Before each move order change of:

- telephone numbers

- online access

- signs

- locks/keys/cards

- If necessary order craftsman assistance (typically carpenter and electrician) during the relocation itself for dismantling and remantling various fixed inventory, equipment and installations

- Order cleaning before each move

- Make detailed arrangement with the relocation coordinator about the sequence of each relocation

- Make sure that there during the relocation itself are persons selected by the relocation coordinator present from each unit/function, both where they are moved out, and where they move in, to indicate sequence and location to the removers

- Inform continuously all involved parties, and at appropriate times, and also the surroundings of the churn plans 


\section{Checklist 5.B: Entering and Finishing Tenancies}

This checklist must be seen as a supplement to checklist 5.A, as alone the conditions which are special in connection with a churn, including acquisition and moving into a new tenancy an/or moving out at settlement of a former tenancy. As to entering tenancies is referred to section 4.2 and checklist 4.B.

\section{Entering a tenancy:}

- At entering of a tenancy is agreed which building and installation changes the lessor manage, and which the tenant himself implement, including responsibility to authority permissions and how possible financial matters are established and settled

- Before the acquisition registration to telephone company, including possible data connections

- Arrange a meeting with the lessor on the day of acquisition with a view to:

- review of the tenancy as to flaws and deficiencies

- reading of meters to electricity, heating, water et cetera

- agreements of who report reading of meters and registration with supply companies - handover of keys

- In connection with the acquisition, photo or video recording of the tenancy's state are made

- After the acquisition of the tenancy follow up on possible flaws and deficiencies and on financial matters

\section{Finishing a tenancy:}

- Consider the need for legal adviser at notice to quit and agreements with the lessor in connection with moving out

- Send notice to quit with registered mail in accordance with the lease contract's term of notice

- Plan moving out so possible re-establishment and rectifying can be made before the end of the tenancy

- Arrange inspection with the lessor in due time before the moving out, so there can be made arrangements as to the following:

- extent of possible re-establishment and rectifying which the tenant is obliged to make in accordance with the lease contract

- to which extent such re-establishment and rectifying works must be done by the lessor, or possibly settled between the parties, and how such works if so must be priced

- the lessor's possible takeover of for instance carpets, curtains, lamps, white goods and fixtures, which the tenant has acquired and do not wish to reuse

- Before the end of the tenancy the following are implemented:

- cancellation of various service contracts (cleaning, guard et cetera)

- moving out of the tenant's staff, furniture, data equipment, archives et cetera

- re-establishment and rectifying, which are agreed that the tenant must make

- cancellation of telephone subscription, including possible data connections

- cancellation of safeguard systems (burglar and fire alarms et cetera)

- end cleaning of the tenancy

- Arrange a meeting with the lessor at the end of the tenancy in preparation for:

- inspection of the tenancy as to flaws and deficiencies

- reading of meters to electricity, heating, water et cetera

- agreements of who report reading of meters and registration with supply companies

- agreements of final payment between tenant and lessor

- handover of keys

- After the end of the tenancy make follow up on possible flaws and deficiencies and on final payment 


\section{Case 5.c: Example of Space Brief in a Churn Plan}

Below is a smaller excerpt of the space brief from a churn plan in connection with a larger internal relocation plan in Danish Broadcasting Corporation (DR). The units in question were mainly located in an office tower block called $\mathrm{KH}$ in TV City. Besides spaces there are also stated the number of window sections, which is a well known standard to employees in this building, and hence easier to relate to than sizes of space.

\begin{tabular}{|c|c|c|c|c|c|c|c|c|c|c|c|c|}
\hline \multirow[b]{2}{*}{ UNIT } & \multirow[b]{2}{*}{ PERS. } & \multirow[b]{2}{*}{ LOCATION } & \multicolumn{4}{|c|}{ PRESENT SITUATION } & \multicolumn{5}{|c|}{ FUTURE SITUATION } & \multirow[b]{2}{*}{ REMARK } \\
\hline & & & SEC. & DAYLIGHT & DARK & SUM & LOCATION & SEC. & DAYLIGHT & DARK & SUM & \\
\hline \multirow{4}{*}{$\begin{array}{l}\text { CHIEF } \\
\text { EXECU- } \\
\text { TIVE }\end{array}$} & 4 & $\mathrm{KH} 7$ & 13 & 90,0 & 9,0 & 99,0 & $\mathrm{KH} 7$ & 13 & 90,0 & 9,0 & 99,0 & INCLUDING FRONT OFFICE \\
\hline & 2 & $?$ & & & & & KH 6 & 6 & 33,0 & 0,0 & 33,0 & CONSULTANTS \\
\hline & 3 & ØSTM & & 40,5 & 0,0 & 40,5 & KH 6 & 6 & 33,0 & 0,0 & 33,0 & FROM LOU \\
\hline & 9 & TOTAL & 13 & 130,5 & 9,0 & 139,5 & TOTAL & 13 & 156,0 & 9,0 & 165,0 & \\
\hline \multirow{4}{*}{$\begin{array}{l}\text { MANAG- } \\
\text { ING } \\
\text { DIREC- } \\
\text { TOR }\end{array}$} & 8 & $\mathrm{KH} 7$ & 20 & 120,0 & 50,0 & 170,0 & $\mathrm{KH} 7$ & 20 & 120,0 & 50,0 & 170,0 & FROM TV-PS \\
\hline & 4 & $\mathrm{KH} 9$ & 7 & 38,0 & 0,0 & 38,0 & $\mathrm{KH} 7$ & 7 & 38,0 & 0,0 & 38,0 & FROM RKT \\
\hline & 2 & $\mathrm{KH} 8$ & 4 & 23,0 & 0,0 & 23,0 & $\mathrm{KH} 7$ & 4 & 23,0 & 0,0 & 23,0 & FROM RKT + BYFO \\
\hline & 14 & TOTAL & 31 & 181,0 & 50,0 & 231,0 & TOTAL & 31 & 181,0 & 50,0 & 231,0 & \\
\hline \multirow[t]{7}{*}{ IT } & 2 & $\mathrm{KH} 2$ & 3 & 17,5 & 0,0 & 17,5 & $\mathrm{KH} 6$ & 3 & 17,5 & 0,0 & 17,5 & FROM DATA SHARED \\
\hline & 10 & $\mathrm{KH} 2$ & 18 & 106,0 & 0,0 & 106,0 & $\mathrm{KH} 6$ & 18 & 106,0 & 0,0 & 106,0 & FROM DATA DEVELOPMENT \\
\hline & 2 & KH 6 & 5 & 27,0 & 0,0 & 27,0 & KH 6 & 5 & 27,0 & 0,0 & 27,0 & FROM DATA DEVELOPMENT \\
\hline & 4 & KH 6 & 10 & 57,5 & 0,0 & 57,5 & KH 6 & 10 & 57,5 & 0,0 & 57,5 & FROM DATA SUPPORT \\
\hline & 2 & KH STUE & & 4,0 & 0,0 & 4,0 & KH 6 & & 4,0 & 0,0 & 4,0 & FROM DATA TECHNIQUE \\
\hline & 1 & $\mathrm{KH} 1$ & 2 & 10,5 & 0,0 & 10,5 & $\mathrm{KH} 6$ & 2 & 10,5 & 0,0 & 10,5 & FROM DATA TECHNIQUE \\
\hline & 21 & TOTAL & 38 & 222,5 & 0,0 & 222,5 & TOTAL & 38 & 222,5 & 0,0 & 222,5 & \\
\hline \multirow[t]{9}{*}{ ARC } & 7 & ST & & 295,5 & 0,0 & 295,5 & ST & & 295,5 & 0,0 & 295,5 & FROM LIBRARY \\
\hline & 5 & BLOK A/1 & & 80,0 & 5,0 & 85,0 & BLOK A/1 & & 80,0 & 5,0 & 85,0 & NEWSPAPER MICROTEC \\
\hline & 12 & BLOK B/S & & 151,5 & 0,0 & 151,5 & BLOK B/S & & 151,5 & 0,0 & 151,5 & PICTURE ARCHIVE \\
\hline & 17 & BLOK A/1 & & 179,0 & 169,0 & 348,0 & BLOK A/1 & & 179,0 & 169,0 & 348,0 & TV ARCHIVE \\
\hline & 3 & KH 6 & 7 & 37,5 & 25,0 & 62,5 & $?$ & & 37,5 & 25,0 & 62,5 & HISTORICAL ARCHIVE \\
\hline & 2 & GLMV & & & & & & & & & & FROM BEA \\
\hline & 2 & TC STUE & & & & & TC STUE & & & & & FROM BEA \\
\hline & 4 & BF & & & & & & & & & & FROM BEA \\
\hline & 52 & TOTAL & 7 & 743,5 & 199,0 & 942,5 & TOTAL & 0 & 743,5 & 199,0 & 942,5 & \\
\hline \multirow[t]{7}{*}{ PGR.RED. } & 7 & $\mathrm{KH} 7$ & 14 & 85,0 & 0,0 & 85,0 & $\mathrm{KH} 7$ & 14 & 85,0 & 0,0 & 85,0 & FROM TV-PS \\
\hline & 23 & TC STUE & & 76,5 & 296,0 & 372,5 & TC STUE & & 76,5 & 296,0 & 372,5 & FROM UDS \\
\hline & 18 & TC 2. SAL & & 188,0 & 92,0 & 280,0 & TC 2. SAL & & 188,0 & 92,0 & 280,0 & FROM UDS \\
\hline & 5 & $B F$ & & & & & $\mathrm{BF}$ & & & & & FROM BEA \\
\hline & 11 & $\mathrm{KH} 7$ & 19 & 118,0 & 0,0 & 118,0 & KH 6 & & 118,0 & 0,0 & 118,0 & PRESS SECRETARY \\
\hline & 8 & GLMV & & & & & TC? & & & & & FROM TOP \\
\hline & 72 & TOTAL & 33 & 467,5 & 388,0 & 855,5 & TOTAL & 14 & 467,5 & 388,0 & 855,5 & \\
\hline RESEARCH & 6 & $\mathrm{KH} 13$ & 11 & 59,5 & 448,0 & 507,5 & $\mathrm{KH} 6$ & 13 & 70,0 & 0,0 & 70,0 & FROM MEDIA RESEARCH \\
\hline \multirow[t]{7}{*}{ LAW } & 3 & $\mathrm{KH} 7$ & 7 & 38,5 & 0,0 & 38,5 & $\mathrm{KH} 7$ & 7 & 38,5 & 0,0 & 38,5 & FROM TVD \\
\hline & 1 & $\mathrm{KH} 7$ & 2 & 10,5 & 0,0 & 10,5 & $\mathrm{KH} 7$ & 2 & 10,5 & 0,0 & 10,5 & FROM TV-PS \\
\hline & 1 & KH 12 & 3 & 16,5 & 0,0 & 16,5 & $\mathrm{KH} 7$ & 3 & 16,5 & 0,0 & 16,5 & FROM DS \\
\hline & 4 & KH 10 & 8 & 45,5 & 0,0 & 45,5 & $\mathrm{KH} 7$ & 8 & 45,5 & 0,0 & 45,5 & FROM PAK \\
\hline & 1 & KH 11 & 3 & 24,0 & 0,0 & 24,0 & $\mathrm{KH} 7$ & 3 & 16,5 & 0,0 & 16,5 & FROM UL \\
\hline & 1 & KH 11 & 4 & 22,0 & 0,0 & 22,0 & $\mathrm{KH} 7$ & 3 & 16,5 & 0,0 & 16,5 & FROM TD \\
\hline & 11 & TOTAL & 20 & 118,5 & 0,0 & 118,5 & TOTAL & 19 & 105,5 & 0,0 & 105,5 & \\
\hline
\end{tabular}

Extra space

Temporary arrangements
If you have vacant space or make a space extension this problem is immediately solved. In other cases it can be necessary to make temporary relocations by for instance to confiscate meeting rooms or locate some employees at a smaller space than normally. In connection with large churns it can be necessary to mount temporary pavilions or to make short tenancies, in order to create the necessary space for the churn to take place.

Such temporary arrangements are both delaying and costly for the whole churn, and can cause considerable nuisances to the involved employees, and also turbulence in the entire organisa- tion. Therefore it is of great importance to the flexibility in the organisation, that the organisation at any time has extra space. Such extra space should optimally be $5-10 \%$ of the entire space in a dynamic organisation.

It is by the same reasons important that no part of the organisation are allowed to use more space than necessary, just because the space is vacant at a time. If that is allowed, it will after some time be difficult to "wrest" the space from the unit in question, because the unit in the meantime has found an "almost essential" use of the space. There is always demand for scant resources, and space is almost always in short 
supply. Therefore space must be treated as a valuable resource to the organisation, and an essential task for the space manager is to economise with this resource.

Another element of the implementation plan is to evaluate the duration of each relocation. The move itself is usually rather short, but often there must also be made various rebuildings and maybe modernisation of the left premises. It demands a specific rebuilding plan to each location, before the duration can be determined. If also new equipment must be acquired, one must also allow for the delivery time in the planning. In case 5.d is shown an example of a time schedule for a very comprehensive churn with a total duration of 1 year and 3 months. The churn in question implies for instance moving out from a property consisting of approx. $7.000 \mathrm{~m}^{2}$ with a view to sell off, and as replacement of some special facilities considerable rebuildings had to be done.

Space Management in connection with planning of churns is a task, which within the same person demands a thorough knowledge, partly of the company's organisation and its work processes, partly of the design, space distribution and possibilities of use of the buildings in question.

So it is a function, which in dynamic companies with frequent churns most appropriate is handled internally.

\section{Rebuilding and maintenance works}

Rebuilding can be part of a major company churn as described in checklist 5.A. However, churns can be limited to changes in one single organisational unit, for instance caused by introduction of new technology, changed work processes, establishment of new functions and/or changes of the staff. Irrespective of the rebuilding's correlation with churns or other causes, it is mainly the same work tasks and phases, which are included in the rebuilding process.

There is furthermore many similarities between the rebuilding process and the process in connection with refurbishing and maintenance tasks. The purpose of maintenance tasks is to maintain the building's performance, and hence it cannot be said to be a part of the adaptation between the physical frames and the organisation. The process related similarities and the fact that it is often appropriate to implement rebuilding and maintenance works integrated or closely coordinated is the reason for handling mainte- nance works along with reconstruction works in this section.

In the following the basis is rebuilding works, and only where there are essential variations, maintenance works will be especially mentioned. The description will be made with basis in the following main phases:

- Preparation of decision proposal

- Preparation of project

- Procurement and contracting

- Construction

- Occupation and follow-up

The basis is that the building works are handled by construction companies in trade contracts or a main contract, which is the most common. In the description there is no distinction whether planning, design and inspection are handled inhouse or by external consultants. As the conclusion of this section these relations are discussed.

\section{Preparation of decision proposal}

Typically the basis of decision consists of a description of the purpose and scope of the project together with cost calculations, overall time schedule and principle drafts. On this basis the responsible management can decide whether the project proposal should be implemented, whether to make adjustments, for instance savings in the project, or whether it must be given up. The basis of decision may include alternative proposals, of which the management can decide.

To be able to prepare a decision proposal it is necessary with a data basis. In connection with rebuilding that may consist of a needs analysis in the shape of a space brief as described in section 5.1, from which a solution proposition could be worked out. To maintenance tasks the data basis is often a condition report. Depending on the project's character and size it will be necessary to involve various technical specialists in preparation, evaluation and pricing of the propositions.

In connection with rebuildings it is crucial to have a good dialogue with the users as to the solution propositions, and to obtain the users' approval of the solution which is included in the final decision proposal. In connection with maintenance tasks the need of a dialogue is the largest at internal maintenance of work premises et cetera, whereas this is not so important at for instance maintenance of the technical systems or the external building fabric.
Main phases

Time schedule

Rebuilding and maintenance

Dialogue with the users 
Case 5.d: Example of Time Schedule for a Large Churn Project

\begin{tabular}{|c|c|c|c|c|c|c|c|c|c|c|}
\hline & & || january & february & march & april & may & june & july & august & septem \\
\hline Id & Opgave & \begin{tabular}{|l|l|l|l|l|}
1 & 2 & 3 & 4 & 5 \\
\end{tabular} & & & & & & & & \\
\hline 1 & TV-U to TV City / DR-M to ØSTM & & & & & & & & & \\
\hline 2 & DR-Service from $\mathrm{KH} 9$ to $\mathrm{KH} 11$ & 五 & & & & & & & & \\
\hline 3 & DR-EA to $\mathrm{KH} 9$ & 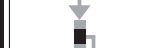 & & & & & & & & \\
\hline 4 & TV-U to $\mathrm{KH} 8$ & & & & & & & & & \\
\hline 5 & DR-M to ØSTM & & & & & & & & & \\
\hline 6 & DR purchase to $\mathrm{KH}$ & & & & & & & & & \\
\hline 7 & TV-UHA red. from $\mathrm{KH} 2$ & & & & & & & & & \\
\hline 8 & DR-IT to $\mathrm{KH} 2$ & & & & & & & & & \\
\hline 9 & DR-OVK to $\mathrm{KH} 10$ & & & 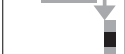 & & & & & & \\
\hline 10 & DR-OPH to $\mathrm{KH} 10$ & & & & & & & & & \\
\hline 11 & $\mathrm{DR}-\varnothing \mathrm{C} / \varnothing \mathrm{P}$ to $\mathrm{KH} 11$ & & & & & & & & & \\
\hline 12 & DR-EA to $\mathrm{KH} 11$ & & & & 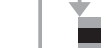 & & & & & \\
\hline 13 & DR-BUR churns on $\mathrm{KH} 9$ & & & & & & & & & \\
\hline 14 & DR-Indkøb to KH 9 & & & & & & & & & \\
\hline 15 & DR-S-Øst to KH 9 & & & & & & & & & \\
\hline 16 & Library to block $\mathrm{A}$ & & & & & & & & & \\
\hline 17 & DSB/Europcar to $\mathrm{KH} 10$ & & & & & & & & & \\
\hline 18 & TV-Presse to $\mathrm{KH} 1$ & & & & & & & & & \\
\hline 19 & TV-PR to $\mathrm{KH} 0$ & & & & $y$ & & & & & \\
\hline 20 & TV-TEK-service to TC & & & & & & 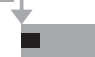 & & & \\
\hline 21 & Library to block $\mathrm{A}$ & & & & & & & & & \\
\hline 22 & Television Technique churn & & & & & & & & & \\
\hline 23 & Produktion churns in DK-3 & & & & & & & & & \\
\hline 24 & Maskeværksted to DK & & & & & & & & & \\
\hline 25 & Centralservice to ST & & & & & & & & & \\
\hline 26 & Udførelse to Vognbygning & & & & & & & & & \\
\hline 27 & Ledelse $\mathrm{m} . v$. to $\mathrm{DK}-2,1$. & & & & & 7 & & & & \\
\hline 28 & Videoservice to Tjørneskov & & & & & & & & & \\
\hline 29 & Projektering to DK-2, 1. & & & & & & & & & \\
\hline 30 & Churns in DK-2, 0 & & & & & & & & & \\
\hline 31 & Videoservice to ST & & & & & & & & & \\
\hline 32 & Tjørneskov clearing & & & & & & & & & \\
\hline 33 & Television programme divisions & & & & & & & & & \\
\hline 34 & Tekst-TV churns & & & & & & & & & \\
\hline 35 & TV-A udstyrsdepot churns & & & & & & & & & \\
\hline 36 & År 2000 to blok C & & & & & & & & & \\
\hline 37 & TV-Drama to Pav. 5-6 & & & & & & & & & \\
\hline 38 & TV-UHA to $\mathrm{KH} 3$ & & & & & & & & & \\
\hline 39 & TV-UHA rebuilding $\mathrm{KH} 4$ & & & & & & & & & \\
\hline 40 & Produktionshoteller in Pav. 4 & & & & & & & & & \\
\hline 41 & GLMV clearing & & & & & & & & & \\
\hline
\end{tabular}


In connection with major rebuildings - and also for smaller rebuildings, where they may be doubts as to the permissions of the authorities one should already during the preparation of the proposal contact the local building authorities to go through the project. By doing this before the final decision of the project it can be clarified, whether the authorities see any problems within the project, including areas where there will be made special demands to the project, maybe implying considerable financial consequences. It is often the fire related conditions which may cause uncertainty, for instance because it in many areas it is the local authorities who must make an assessment in relation to the rules on the Building Regulation.

\section{Preparation of the project}

At minor rebuilding and maintenance tasks there are no needs of preparation of a detailed design besides what is included in the proposal. In connection with rebuildings you must in most cases send a building petition including drafts to the building authorities, whereas it usually is not necessary in connection with maintenance works.

In connection with major rebuildings and complex maintenance tasks it is necessary to implement a specific design process, hence all necessary details in the project can be worked on, illustrated by drawings and described. The design is a divided process involving a number of technical specialities depending on the character and size of the project. The most common building related specialists are architect/building technologist and structural engineer, whereas the most common installation related specialists are electricity engineer and HVAC-engineer.

The number of specialists is often considerably larger at rebuilding works than at maintenance works. The last mentioned has often either focus on mere building works without involving changes in installations to a wider extent or mainly focus on mere installations without much building work, whereas rebuildings usually include the entire spectre. Even ordinary changes of moving dividing walls will often imply changes of the electricity installations and maybe also ventilation et cetera.

The result of the design typically includes a number of drafts and work descriptions divided into craftsman professions, where the most common in relation to construction are carpenter, bricklayer, painter and floor man, whereas the most common installation related are electrician, heating and sanitation and ventilation. Concurrently to the design a detailed time schedule must be prepared to the implementation, and also description of the legal conditions which will be in use during the construction.

Such conditions will often be mainly identical each time, hence it is appropriate to make a standardisation, either as a paradigm, which is suited to each case, or using actual standard conditions, where additions and deviations can be stated. In its simple form the conditions can in Denmark primarily consists of a reference to the general condition for construction and civil engineering work from 1992 (AB92). However, it must be included into the conditions that AB92 is in force with further specified additions and deviations.

In the conditions the following must be specified:

- Considerations at nuisances to the company staff (performance of especially noisy works during weekends or at evenings/nights, limitation of dust et cetera)

- Conditions at the construction site (accessibility, transport roads, electricity, craftsman facilities / sheds, waste handling, cleaning)

- Insurance (building client, constructor)

- Conditions of possible penalties and incentives

- Demands of guarantees from the contractors

\section{Procurement and contracting}

In connection with minor tasks it can be appropriate to use fixed attached craftsmen, with whom you make a frame agreement of hourly prices and settlement principles; hence you can make agreements without an actual procurement. This implies time related advantages and reduces the administrative work to both building client and craftsman, and the craftsmen know the building and all conditions. The work can be initiated by making out an intent maybe with the basis of an estimate from the craftsman company.

In connection with major tasks it is common to make an actual procurement, in which more companies compete with each other about the price of construction of the work into trade contract, or in total to all trades in a main contract. Such procurements assume that all tenderers receive the same project materials as basis for the tendering. 
From construction to operation

\section{口}

The building client's responsibility
In accordance with the Danish tendering act an actual blind tendering procedure must be made if you call for more than three bids at the same work. At a blind tender all bids must be delivered at the same time and place, where the bids are opened and announced before the tenderers Today is has become possible to make electronic tendering procedures. Even if the building client can choose freely among all tenderers, the procedure is based on the fact that the tenderer with the lowest price get the job. Hence you are only allowed to negotiate with the lowest bidding tenderer.

The contracting usually just consists of a written acceptance of the bid with specification of the documents, which are the basis of the acceptance and the most important conditions, including demands of guarantee. If the procurement prices are totally higher than the budget, it may be necessary to implement a saving round beforehand, and the result of this must be taken into considerations in connection with the preparation of the acceptance.

\section{Construction}

Prior to and during the construction it is important to inform about the work to the company staff, both in general and targeted to the employees who will be included to the nuisances in connection with the work.

During the performance the building client in trade contracts must see to the necessary coordination of the work. In connection with major construction cases this typically takes place at a weekly construction meeting. In connection with main contracts this task is handled by the main contractor. Yet the building client must through frequent meetings with the main contractor, for instance every second week, followup on the construction.

Furthermore the building client has in Denmark the responsibility to prepare a health \& safety plan, and to coordination of the health \& safety work at the construction site. Yet this responsibility can be delegated to a consultant or a contractor. In the last case it must be part of the procurement conditions. At construction sites with at least 10 employed at the same time from several companies, health \& safety meetings must be held.

Furthermore the building client must see to a continuous and qualified inspection with the performance of the work. Only in doing this it can be ensured that the quality of the work will be as expected. It is also important in order to be able to ensure the desired progress and to oversee that the nuisances to the company staff is limited most possible.

The construction work is finished with a handover procedure with each contractor, in which the finished work is examined to errors and defects. They a listed in a handover report along with agreements about time schedules and withhold in the contract sum for the remaining and rectifying work.

\section{Occupancy and follow-up}

In connection with moving in and occupancy it is a good idea to make a handover procedure with the users, in which the renovated area is inspected and possible errors, defects and need for adjustments are recorded.

Furthermore it must be ensured that employees with responsibility to the operation af the building and the technical installations at the latest in connection with the occupancy receives the necessary information to be able to take over the responsibility for the operation. This is especially important in cases, where there has been made essential changes of the technical installations.

After delivery and handover the building client function must naturally follow up on the noted errors and defects and settle the financial matter with the contractors. One year after the handover the rectifying period expires in Denmark according to AB92, so the building client must beforehand ensure that there are no needs of further repair, either in asking the users and the operational function, or at a proper inspection as at the handover.

The contractor's warranty period, hence responsibility of hidden errors and defects, expire in Denmark after five years from the handover unless the building client before has called attention to errors or defects, of which the contractor is responsible. At major construction projects a five year warranty inspection ought to be made.

\section{In-house or external}

The building client function will always be an internal function in the company, and it is appropriate that it is an internal employee who provides the data basis to rebuilding in the shape of a space brief et cetera. On the contrary 
it is in most companies inappropriate to keep all the necessary technical specialties in-house in order to be able to make a proper design, and correspondingly for preparation of decision proposals to major and complex works. However, it is important that there at any time is an internal project manager who is in touch with external consultants' work, and who can handle the contact to the company staff.

The same applies in relation to the construction, where it at major works can be appropriate with an external construction manager and external professional inspections, but it is important that the work is being followed up internally. In connection with minor works it can be appropriate that the company has professional qualified employees internally to handle construction management and inspection, both by financial reasons, and to ensure that the company's interests are met, not at the least in relation to the contact with the other staff in the company.

\section{Moves}

Moves can be divided into external moves, i.e. joint move of the entire company or major parts of the company into new facilities in connection with relocation, and internal moves, i.e. move of groups of employees, for instance departments, or single persons to another location within the company's existing facilities in connection with a churn. So an internal move can both be a move within the same building and a move between two of the company's existing properties.

In IFMA's benchmark examinations they distinguish between three levels of internal moves (IFMA, 1992 and 1994):

- Move of staff to existing workplaces, i.e. just move of the staff's office remedies and archives, no move of furniture and IT equipment, and no change of buildings and installations. This type can be termed person moves

- Move of work stations, i.e. besides move of the staff's office remedies and archives and also move of their furniture and IT equipment, but no change of buildings and installations. This type can be named furniture moves

- Move which demands rebuilding, i.e. besides move of the staffs' office remedies, archives, furniture and IT equipment also making of building changes (wall movings et cetera) and installation changes. This type can be termed rebuilding moves
The expenses connected with the different types of moves are naturally rather different. In accordance to IFMA's examinations furniture moves are approx. three times more expensive than person moves, whereas rebuilding moves are approx. 20 times more expensive than person moves. Furniture moves were the most common type of moves. However, the trend has with more open office environments increasingly developed towards more person moves.

Concurrently with the office work being generally more project orientated and dynamic, the need for internal moves has increased considerably. In this connection one talk about the churn rate, which by DFM-benchmarking is defined as the number of internal moves during a year in relation to the total number of employees. A churn rate of $20 \%$ hence implies that every fifth employee has moved once within the year in question, and this corresponds to each employee in average moves workplace every fifth year. In a large Danish consultant engineer company the churn rate increased during 6 years from $30 \%$ to more than $100 \%$.

In checklist 5.C the most important phases of planning and implementation of larger moves are described. See also checklist 5.A about churns and checklist 9.A about move of IT equipment.

Planning of larger moves is similar to planning of churns a task, which within the same person demands a thorough knowledge, partly of the company's organisation and its work processes, and partly of the buildings in question. Hence it is a function which in dynamic companies with much relocation most appropriately is handled internally.

The physical move itself is most appropriately handled by a professional moving company. In connection with continuous internal moves it is useful with one or a few permanently associated moving companies. They can be selected and in time tested in competition of a frame agreement, in which hourly prices, settlement principles, insurance responsibility et cetera is determined.

In connection with major moves specific tenders from several moving companies ought to be called for. It must be noted, that moves are not included in the Danish tendering act for construction and civil engineering works, and only very large moves exceed the threshold values of demanding EU procurement to public compa-
Churn rate

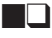

External moves

Internal moves 


\section{Checklist 5.C: Larger Moves}

The checklist below is to be seen as a supplement to checklist 5.A, and it has been prepared on the basis of own experiences and inspiration from articles in DFM's newsletters over the years.

\section{The planning of the move:}

- Make the record at storey levels of the present locality of what must be moved, including workplaces and employees, meeting furniture, archives and special equipment

- Plan arrangement at storey levels of the new locality with location of workplaces and employees, meeting furniture, archives and special equipment

- Prepare a detailed time schedule of the move, so that the nuisances to the company staff and its functions are minimised, including moves which must take place during weekends and/or at special times, and possible move of archives et cetera, before or after the main move

- Go through both localities in preparation for necessary safeguard arrangements during the move itself of vulnerable entrances and also floor and wall surfaces, including stairways, corridors, doors, vulnerable wall corners and lift cars, and make photo records to document the state before the move to meet possible compensation demands

- Make agreements with IT specialists which arrangements must be taken in relation to IT equipment, cf. checklist 9.1. in chapter 9

\section{Selection and agreements with moving company:}

- Select a smaller number of moving companies (2-5) with experience from moves of similar size and character

- Go through the present and the future locality with each moving company and explain what must be moved, and indicate which transit roads, including which exits and entrances, staircases and lifts, can be used, and which safeguard arrangements must be taken

- During the review make inquiries to the moving company about their proposals for implementation of the move, for instance alternative transit roads with lift and through windows, and use the possibility to evaluate the management qualities, approaches and "chemistry"

- Get bids with insurance information from each moving company and select the one which at a total evaluation of price, experience, capacity and management qualities et cetera is the best

- Make a contract with the selected moving company, in which the task and its conditions in relation to size, settlement, time schedule, safeguard arrangements and insurance are stated

\section{The actual move:}

- Ensure that everything is arranged so the moving men can work most efficient

- Ensure continuous contact through a mobile phone among the company's move manager and the moving company's operation manager, and also between the move manager and the move coordinators

- Ensure that lift service is on stand-by

- Ensure plain marking of entrance roads and rooms in the new locality, for instance coloured codes at various stairways or areas, and a furnishing plan at the entrance to each room

\section{After the move:}

- Implement handover procedure with the moving company

- Ensure a complaint and tracer system with follow-up and feedback

- When everybody is seated and settled in, an opening reception in the new premises can be arranged 
nies. Hence there are free negotiation possibilities with tenderers, and as selection of other partners it is important to select a company in which you have trust.

A fine way to test this is to start a dialogue with each tenderer of how the move operation is best organised. After the selection you must also establish a close collaboration with the moving company's manager of the operation to make the best use of their expertise, in order to carry out the move in the best possible way.

Usually it is an advantage to the company's function to carry out the move as fast as possible. This especially concerns the staffs' workplaces and the most necessary equipment in relation to the daily work, for instance computers and printers. At the planning of major moves it must be considered whether other moving items can be moved before or after the main move. This may include archives, libraries, meeting furniture and special equipment, which the staff can manage without for a period.

At planning and implementation of the move it is important to have a clear and precise project organisation. The FM function's responsible person must be the company's move manager, who has a contact in each of the involved departments, who can act as move coordinator. Through this internal organisation the detailed planning of the move is handled, and it is ensured that all affected staff are involved and orientated to the necessary extent.

The move manager handles all formal contact to the moving company's operation manager. Prior to the move there must be clear agreements among the parties of who from each party has authority to make decisions and to give orders. During the move it is an advantage that only the persons, who have a specific role in relation to the relocation, are present to avoid unnecessary interference in the move and conflicting messages to the moving people. Just for this reason it can be appropriate to implement moves during weekends or at evenings. When a large number of moving men initiate the move, it is important, that they can work freely without unnecessary interference.

\subsection{Workplace Design}

\section{New ways of working}

When the author was a child there was a saying, that soldiers could sleep anywhere, at any time and with anyone. Nowadays it maybe the same, but there is the change since then, that the work now increasingly can be done anywhere, at any time and with anyone. This concerns at first the professional knowledge work, which previously was done in offices.

This development has mainly its background in the technological development within IT and telecommunication. With the development within the data communication it has become a realistic possibility to work at distances, for instance at home. With mobile IT equipment and mobile phones it has furthermore been possible to work roughly speaking everywhere - in the car, the plane, the airport, in trains, at hotels, in cafés, in the park and even in the street. With wireless data networks in buildings you can anywhere in a building connect your laptop computer to the network, and through e-mail and internet you can get and send data everywhere on the planet earth.

Concurrently with this development there are also great changes in our way of working inside office buildings. Until approx. 20 years ago it was common that the employees in an office wrote their manuscripts by hand to pass them on for word processing by a secretary. Today very few office workers do not themselves make the work processing. The routine secretary work has been reduced considerably, and each office worker can handle his work tasks independently.

Concurrently the office work has increased considerably. Today more than half of the working part of the world's population has the office as their work place - and it is increasing. Already in the 1990'ies the "white collar workers" made approx. $60 \%$ of the working part of the population in the most developed European countries. Hence the office is without any comparison the most common workplace in the world.

So it is not surprising that there has been an increased focus on limiting the costs, which the office workplace represents. The development within IT and telecommunication has contributed to streamline and rationalise the office work, but it has also increased the financial burden of the office work due to the investments in the new technology. So it becomes more important to limit the building related costs to the office workplace, especially in a situation with increased international competition. 
Interactive
collaboration

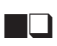

From cell offices to open environmenst

Open-plan offices

Teleworking
One of the most efficient ways to limit the costs for office buildings is to achieve a more intensive use of space. It can be done by reducing the average space per workplace. In case 5.f is mentioned an example of a company, which changed from having 2 employees sharing an office of $17 \mathrm{~m}^{2}$ to 3 employees sharing a similar office. So the same building can accommodate $50 \%$ more employees.

Through change of the office arrangement from the division in cell offices to open environments considerable streamlining of the use of space can be achieved.

Considerable saving can furthermore be achieved through internal churns, hence rebuilding at internal moves can be avoided, cf. section 5.2.

The walls itself around a cell office takes a considerable ground area. An office at $4.00 \times 2.50$ $\mathrm{m}$, which is $10 \mathrm{~m}^{2}$, has a circumference of 10.50 $\mathrm{m}$ exclusive the exterior wall. With a wall thickness of $15 \mathrm{~cm}$ and division of partitions with one half at each neighbour office and inclusion of the entire corridor wall, the ground area of the walls will amount $1 \mathrm{~m}^{2}$, i.e. $10 \%$ af the office's floor area. This implies that the net space is increased with $10 \%$ just by removing the office walls.

Removal of the partitions furthermore imply that a considerable larger flexibility of the design can be achieved, and also that much "waste space" can be avoided. In connection with open environments it is furthermore possible to use buildings with a large building depth in a far more flexible way. The share of closed corridors can be kept at a minimum; hence the share of the gross space of the disposable space is significantly increased in relation to office buildings with a through corridor with cell offices at both sides.

Use of open environments with large room offices is not a new phenomenon. Already in the 1960 'ies some European companies began to introduce open-plan offices, the first was the German publisher Kommissionshaus Buch und Ton with their "Bürolandschaft" in 1961 with 250 workplaces at $2.950 \mathrm{~m}^{2}$. The most known Danish example is Topsikring's open-plan office from 1974 with 800 employees.

The new thing is that we by means of the technological possibilities have started to work in other ways than formerly in the office. As the IT and telecommunication has rationalised the office work and has removed much routine work, IT and the attached technologies have created a number of new ways of working, where there are increased demands of creativity and collaboration. Hence the office work more often is project work and other kinds of interactive collaboration among independent knowledge workers.

These changes of the office work is in figure 5.5 described as 3 generations of offices, where there in the third and new generation is distinguished between share based models and process based models.

The first and probably best known example of a new office environment in Denmark is hearing aid company Oticon, who in the beginning of the 1990'ies introduced a new office environment, where the shocking news was that the staff did not have personal workplaces. The idea was that the physical frames would support a project organisation, or a so-called "spaghetti organisation".

Share based models are during the 1990'ies introduced in a number of companies with many employees, who work a lot outside the office, for instance with customers as salesmen or consultants, or at homework. In case 5.e is described a case from Canon Svenska AB, where they from the mid 1990'ies introduced shared workplaces in offices with many sales employees.

Another example is from the accountancy and consultant company Arthur Andersen, which in 1993 moved into a new office building at the Copenhagen harbour (Midtermolen). The arrangement of the new office was based on the principles that partners had their own office, managers had their own workplace in the open environments, and to the remaining staff there were established shared workplaces which corresponded to $0.5 \mathrm{~m}^{2}$ per person. Compared to the former office they achieved $50 \%$ space saving.

In connection with the share based models teleworking is often an important precondition. Teleworking can be divided in 3 main groups (Becker \& Steele, 1995):

- Home based telework, where the work for part of the time is done at a workplace in the home

- Telework centres, where the work part of the time is done in a commercially managed 


\begin{tabular}{|l|l|l|l|}
\hline $\begin{array}{l}\text { Office } \\
\text { generation }\end{array}$ & $\begin{array}{l}\text { Organisational } \\
\text { driver } \\
\text { Support of: }\end{array}$ & $\begin{array}{l}\text { Primary considerations at space } \\
\text { allocation }\end{array}$ & Consequences to office design \\
\hline First & $\begin{array}{l}\text { Status and } \\
\text { hierarchy }\end{array}$ & $\begin{array}{l}\text { Differentation of the personal space as } \\
\text { reflection of hierarchic position }\end{array}$ & Size and finish of offices \\
\hline Second & Function and task & $\begin{array}{l}\text { Increasing standardisation to make } \\
\text { changes easier }\end{array}$ & $\begin{array}{l}\text { Few space standards and use of ergonomic } \\
\text { criteria }\end{array}$ \\
\hline Third & Time and process & $\begin{array}{l}\text { Share based models: } \\
\text { Support use in turns at the expense of } \\
\text { personal ownership }\end{array}$ & $\begin{array}{l}\text { Few space standards and use of ergonomic } \\
\text { criteria. Personal effects (archive) is } \\
\text { centralised away from workplaces }\end{array}$ \\
\cline { 2 - 4 } & $\begin{array}{l}\text { Process based models: } \\
\text { Support varying work processes and } \\
\text { planning for groups in stead of individual } \\
\text { planning }\end{array}$ & $\begin{array}{l}\text { A wider choice of workplaces and shared } \\
\text { spaces. Planning of flexible work } \\
\text { environments for groups }\end{array}$ \\
\hline
\end{tabular}

centre or in a satellite office established by the company

- Virtual office, where the work part of the time is done "in the field" with mobile equipment

The Danish telecommunication company TeleDanmark is one of the companies, which in Denmark has worked much with teleworking, naturally based on a clear commercial interest in promoting the telework. TeleDanmark has for instance published a comprehensive guide to companies and employees about introduction of teleworking, which for instance include cases, analysis model and examples of an agreement between company and employee.

Process based models primarily aim at supporting collaboration, interaction and knowledge sharing among the employees. This has partly background in the fact that much office work has become more projects oriented, partly from realising that the informal communication and contact among the employees is essential to the creativity. In some connections the term team based models is used.

The importance of informal contacts was shown in the 1970'ies by Professor Thomas Allen, MIT. Through investigations in research and development departments there proved to be a close correlation between the performance level and the number of informal contacts which the employees had to other persons, both outside as inside their own department, discipline and project group (Becker \& Steele, 1995).

One of the main ideas in the process based models is to design the office environment with various facilities, which support de varying needs, which the work in time implies. The employee move around in the office environment independent of a possible need to work together with others or alone, whether the work must be structured or more a rough exchange of ideas, whether there is need of being much concentrated et cetera. Process based models can to a great extent imply sharing of the facilities and space savings, but the basis is first and foremost to encourage creativity and collaboration, whereas to the share based models it more just space savings.

In case 5.f. is described IBM's project e-place.

Figure 5.6 summarises the changes from the traditional to the future office.

\section{The planning process}

The planning of workplace design depends on whether it is only a new arrangement for a unit which must move to another location without changes of the work, or whether the workplace design must support changes in work processes, implementation of new technology and new ways of working. In the first case it concerns a relative trivial planning task, especially if use of furniture is given from reuse or fixed standards. In the last case it may concern a highly complex planning process, which demands a thorough planning and involvement of specialists with specific experiences.

Professor Franklin Becker from Cornell University in USA is along with Francis Duffy and John Worthington and others from the architect and planning company DEGW in London some of the internationally known experts within new ways of working. Franklin Becker has along with Fritz Steel introduced
Figure 5.5: Three office generations (source: Bedford \& Tong, 1997)
Informal communication 


\section{Case 5.e: Canon Svenska AB's Work Where You Want Concept}

The company Canon in Sweden, who primarily sells office machines, in 1994 introduced the concept Work Where You Want (W3) with a view on achieving a larger market share. W3 was introduced as a overall sales promotion campaign with a message of testing theories about flexible work in practice. To give the concept credibility Canon itself would "take the medicine" which they asked the customers to take. The concept was gradually implemented in Canon's various local offices in Sweden.

A university, two other institutions and a management company have completed various investigations of the effects of implementation of flexible work in Canon, including comparisons between a local office, where the concept had been implemented, and another office where it was not yet implemented. Hence it is one of the best documented and evaluated examples of introduction af new ways of working in Scandinavia. Canon announced the results of the various investigations on their homepage, from which the information in this case originate (www.canon.se)

An important element in the concept with W3 and flexible work was introduction of teleworking, but it also included changed management and organisation, modernisation and new design of the offices, and also considerable investments in IT support of the work.

One of the experiences from introduction of flexible work is that there in general are new demands to the employees and to the management in particular. To use the potential of the changes the management must in particular see to the following:

- Ensure that the "released time" which arise at shift to flexible work is used for increased productivity

- To draw up clear goals, fixed and anchored in the organisation, at management of employees who no longer is within sight in the office

- To act as a coach and to take time to each employee in preparation for individual follow-up and assistance

- Maintain the organisation as a living organism, in which initiatives to changes and renewal is taken by everybody

Canon sums up the results from introduction of flexible work in the following way:

- Intentional and specific adapted solutions of organisation and IT implies, that the work does not need to become distributed according to power and traditionally coordinated - hand and spirit are united

- In spite of much reduced space and new ways of working flexible work can be more stimulating and contribute to less stress and improve the concentration for the employees

- The saving potential is large, but it is often difficult to define except from spaces and room lease, where Canon has reduced with $45 \%$ or more

- The productivity is increased in actual results and with the help from "soft factors", which create improved motivation with the staff - the results indicate 15-47 \% release of time

- The implementation of flexible work demands investments in consultant assistance and education of $25 \%$ more compared to a traditional office, and $50 \%$ more to special furniture per workplace - this is however compensated by less space and fewer workplaces

- IT investments implies cost increase of approx. $100 \%$ per employee, who must have mobile equipment, and the telecommunication costs are increased with $27 \%$ due to distributed work and mobile telephony

- The positive consequences are long-term and will make effect throughout for several years, whereas the negative are short-term and mainly attached to the implementation phase 


\begin{tabular}{|c|c|c|}
\hline & Traditional office environments & Future office environments \\
\hline \multirow{5}{*}{ 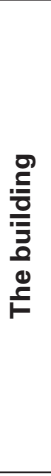 } & Medium flexibility & Designed to be adapted to various designs \\
\hline & $\begin{array}{l}\text { The interior of the building is a precise } \\
\text { reflection of the company's hierarchic } \\
\text { organisation }\end{array}$ & $\begin{array}{l}\text { The interior of the building reflects the } \\
\text { company's activities }\end{array}$ \\
\hline & $\begin{array}{l}\text { The building must be arranged to give a good } \\
\text { impression to visitors }\end{array}$ & $\begin{array}{l}\text { Buildings which are arranged appropriately for } \\
\text { their use give in themselves a good impression }\end{array}$ \\
\hline & $\begin{array}{l}\text { The property administration is primarily } \\
\text { determined from considerations to the } \\
\text { company's assets }\end{array}$ & $\begin{array}{l}\text { Active and comprehensive strategy to the } \\
\text { property administration }\end{array}$ \\
\hline & $\begin{array}{l}\text { Savings of the expenses for office facilities are } \\
\text { always good because it improve the company's } \\
\text { bottom line }\end{array}$ & $\begin{array}{l}\text { The expenses for office facilities must be kept } \\
\text { under control without causing obstruction in } \\
\text { achieving the company's superior goals }\end{array}$ \\
\hline \multirow{5}{*}{ 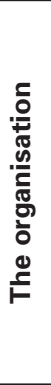 } & $\begin{array}{l}\text { Pyramid organisation with functional divided } \\
\text { management }\end{array}$ & $\begin{array}{l}\text { Flat organisation with project oriented } \\
\text { management (matrix structure) }\end{array}$ \\
\hline & $\begin{array}{l}\text { Office facilities are used as a reward or } \\
\text { encouragement to position in the hierarchy }\end{array}$ & $\begin{array}{l}\text { Office facilities are tools to have the work done } \\
\text { and are too expensive to be used as status } \\
\text { symbol }\end{array}$ \\
\hline & Focus on individual work & Focus on work in teams \\
\hline & A few external experts & $\begin{array}{l}\text { Many external experts (consultants, employees } \\
\text { from other companies et cetera) }\end{array}$ \\
\hline & $\begin{array}{l}\text { Emphasise on formalised communication } \\
\text { (meetings, conferences et cetera) }\end{array}$ & $\begin{array}{l}\text { Spontaneous interaction is supported (informal } \\
\text { areas, cafés et cetera) }\end{array}$ \\
\hline \multirow{4}{*}{ 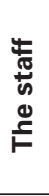 } & $\begin{array}{l}\text { Many employees work with routine processes } \\
\text { and a single activity }\end{array}$ & $\begin{array}{l}\text { Many professionals with creativity and } \\
\text { independent knowledge work }\end{array}$ \\
\hline & Mainly work alone with individual tasks & Mainly work interactive in groups with projects \\
\hline & Obvious defined individual responsibility & Has responsibility to reach a goal \\
\hline & Mainly rated on quantitative results & Mainly rated on qualitative results \\
\hline \multirow{4}{*}{ 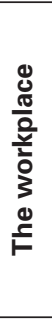 } & A person - a place with "property right" & A person - many places for common use \\
\hline & $\begin{array}{l}\text { The work is done at the work table or in a } \\
\text { meeting room }\end{array}$ & The work is done all over where the person is \\
\hline & $\begin{array}{l}\text { A few shared facilities/spaces (notice boards, } \\
\text { corridors et cetera) }\end{array}$ & $\begin{array}{l}\text { Many shared facilities (service facilities, } \\
\text { informal meeting spaces et cetera) }\end{array}$ \\
\hline & $\begin{array}{l}\text { Involvement of employees into the design is } \\
\text { too slow, too complicated and may lead to } \\
\text { chaos }\end{array}$ & $\begin{array}{l}\text { Involvement of employees into the design will } \\
\text { lead to better facilities and commitment to use } \\
\text { them in a proper way }\end{array}$ \\
\hline \multirow{4}{*}{ 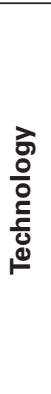 } & $\begin{array}{l}\text { Fixed equipment at each workplace (telephone, } \\
\text { PC et cetera) }\end{array}$ & Extensive use of mobile equipment \\
\hline & $\begin{array}{l}\text { No need of individual control of the work } \\
\text { station }\end{array}$ & $\begin{array}{l}\text { Great possibilities to individual control } \\
\text { (employees can adapt the work station to } \\
\text { personal needs and taste) }\end{array}$ \\
\hline & $\begin{array}{l}\text { Electricity supply with fixed situated power } \\
\text { point at walls }\end{array}$ & $\begin{array}{l}\text { Electricity supply with flexible power point in } \\
\text { floors }\end{array}$ \\
\hline & Primary use of standard IT programmes & $\begin{array}{l}\text { Varying and sophisticated IT applications } \\
\text { (network, multi media, video conferences et } \\
\text { cetera) }\end{array}$ \\
\hline
\end{tabular}

Figure 5.6: Traditional and future office environments (sources: Based on Steelcase Strafor, 1999; Worthington, 1997, and Becker \& Steele, 1995)

the term organisational ecology, as a term of the correlations among work processes, information technology and workplace design (Becker \& Steele, 1995). No matter if this term is seen as appropriate, it precisely focus the elements of which to allow for in the planning of the workplace design at new ways of working, and the need of thinking these elements together.

In connection with the planning process Becker and Steel use the term integrated workplace strategy. Hence the need is emphasised of seeing the workplace as part of a coherent system, which it is necessary to include into the plan- ning, if it must be succeeded to implement new ways of working with a positive result.

Implementation of new ways of working is a change process which demands a high level of management support throughout the entire process, and it is important that the company management initially express a vision and some obvious goals to the process. Changes in the ways of work will also imply changes in the company's culture, and the company management must determine which behaviour changes in the employees and the managers should be supported.
Organisational ecology

The management must lead

\section{Integrated workplace strategy}




\section{Case 5.f: IBM's Project e-place}

This case is based on DFM's member meeting April 11th 2000 at IBM Danmark A/S in Allerød, where there were contributions by Henrik Bergquist, IBM and Steen Enrico Andersen, PLH Arcitects.

Worldwide IBM has decided to introduce new ways of working under the term "e-place". The implementation is made from shared principles but with a certain regional adaptation. The latest development in Allerød is the first IBM building which is new built in preparation for arrangement with interactive workplaces.

The main goal to IBM is to break down barriers among teams of the staff. In an interview in the video which IBM has made about project e-place, the British management guru Charles Handy says, that earlier telephones and data were attached to a certain places, whereas they now are attached to persons. This is an important factor which has actualised the implementation of the change process in office work and office design in IBM. The course of such a process depends to a great extent of the starting point in each company.

To IBM office design has throughout the years been strongly managed by space standards, which has been globally determined to IBM with certain regional adjustments. The development on the state of the market has throughout the years led to tightening of the space standards. Until the mid 1980'ies two employees normally shared an office of $3.60 \times 4.80 \mathrm{~m}$ corresponding to $25 \mathrm{~m}^{2}$ gross per employee. In connection with the global financial crisis in the end $1980^{\prime}$ ies the space standard was changed so that three employees shared an office of the mentioned size, which corresponded to $16.5-17 \mathrm{~m}^{2}$ gross per employee. Correspondingly IBM has changed from owning buildings of a high standard to instead leasing building of normal standard.

With the implementation of e-place IBM change from cell offices to open environments, in which many workplaces are shared among a team of employees, who also are admitted to some quiet rooms and formal meeting rooms. With this new design IBM has achieved considerable space savings. However, due to the varying use of the workplaces it is less relevant to speak of space per person, but more relevant to speak of space per work station.

The development of IBM's building in USA and Europe illustrates how there internationally has been an approach of the building depths during the last years. Earlier they had, not at least in USA, but also to a certain extent in Great Britain, typically very large building depths, whereas the buildings in Scandinavia were relatively narrow at typically approx. $12 \mathrm{~m}$. Today there has been an approach so building depths of approx. $18 \mathrm{~m}$ are common in most places.

IBM's former experiences with new design are generally good. They for instance have experienced that employees from the older building sections, which are still divided into cell offices, make wishes to move to the new building section with open environments. Most complaints were from middle managers, who find it difficult not to have their own office, when they for instance must have meetings with employees. 


\section{Case 5.g: New Ways of Working in the Danish Palaces and Property Agency}

This case concerns a pilot project which has been completed in the Palaces and Property Agency (PPA) from 1998 to 2000 in preparation for spread to the entire agency's main administration in Copenhagen. PPA acts as a real estate agency to he entire central administration and has appointed itself as a pilot institution to a comprehensive experiment with alternative use of workplaces. So the example can be seen as a demonstration project.

The ambition of the project has been to use the spaces in the old city house more efficient and to create a flexible office environment. The goal has been to achieve a higher degree of knowledge sharing among the employees - not at least the employees' personal knowledge. For this reason they have until now not wanted homework to a larger extent. As part of the preparations they three times a day made measurements of the space and workplace use in 1998, where there were 102 employed. The results of the measurements were the following:

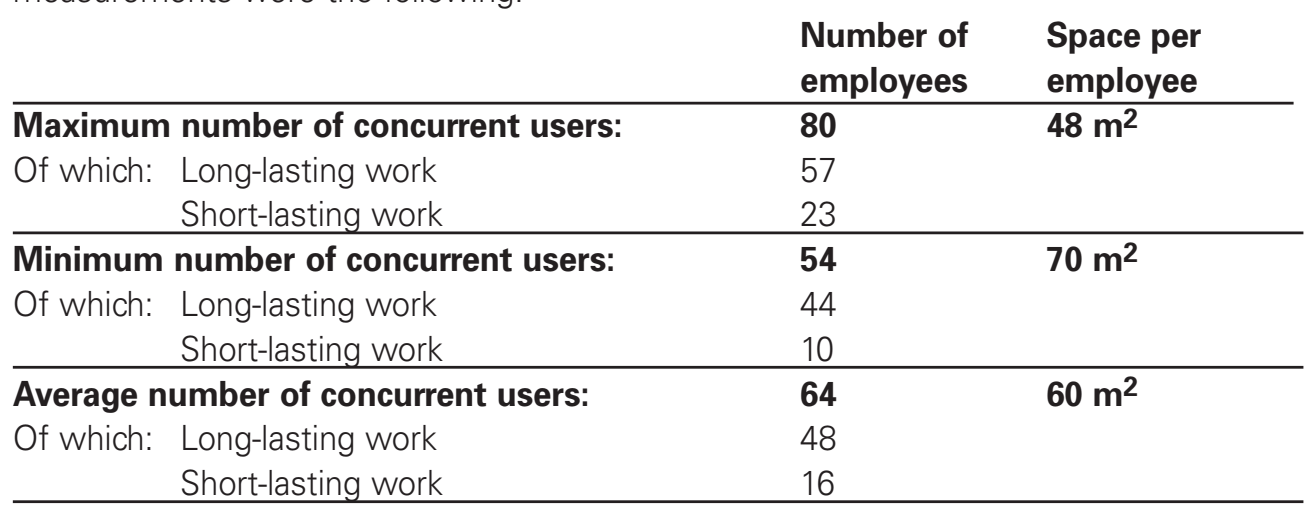

It was determined by the management to implement a pilot project including two storeys of the building and approx. 45 employees. Only the employees who were sitting at their workplace for at least $60 \%$ of the time had fixed workplace, whereas the remaining part had to share a minor number of workplaces. In total three workplaces per four employees were established. The affected employees agreed to this, assuming it was a pilot project, and that the decision could be changed depending on the results of the pilot project.

As part of the pilot project 9 work groups were appointed, and all employees attended a group. The topics of the groups were: Fixed places/bases, meeting room, quiet room et cetera, archive racks, telephones/IT, service centre, behavioural rules for noise, smoke et cetera, the physical layout of rooms and furniture et cetera, staff conference, continuous evaluation.

At a questionnaire based evaluation of the pilot project 6 months after the implementation there was a surprisingly result, that no one would return to their own offices. In return many had less contact with colleagues. To meet this they would change from entirely free location of the employees at workplaces, to the employees each belonging to a base with a small group of colleagues. This should also solve a problem of shared archive close to the workplaces.

In the book FM Best Practice in the Nordic Countries (Jensen et al, 2008) there is a comprehensive case study in section 6.3.1 of the development of offices and new ways of working in PPA and one of the other state agencies which PPA have been consulting. 


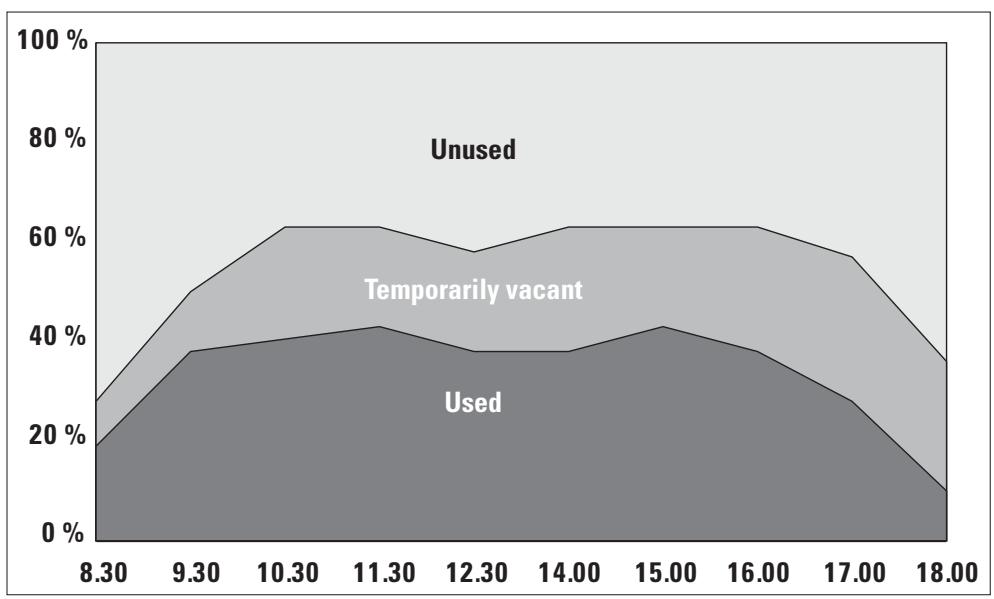

Figure 5.7

Typical time related use of an individual office workplace (source: Thomson, 1997)

Methods for data collection

Staff involvement
Figure 5.8

Job functions in relation to independence and interaction
Involvement of the staff in the planning process is also an essential precondition to a successful result. A Norwegian investigation of implementation of new ways of working consisting of 7 cases clearly shows that staff involvement is essential to achieve positive results. The investigation also shows that the companies which see the office design as an integrated part of organisational change and development processes also achieve the highest productivity increase (Arge $\&$ de Paoli, 2000).

The staff involvement must be real, and the management must determine obvious frames of what has been decided and what the staff has possibilities to affect. As at all other change processes there will from the very beginning be much uncertainty among the staff and a considerable scepticism to what will happen, and the intentions behind. Of course the fear of the unknown is in evidence, but as emphasised by a speaker at a DFM conference on new ways of working said: People are not opposed to changes, but they are opposed to being changed.
Staff involvement hence is an important element to overcome psychological resistance, but it is also a precondition to be able to use the employees' knowledge and experiences in achieving the best possible results. Besides involvement of the staff in the planning process it is important throughout the entire process to keep a high information level to the affected employees. Information to others in the company is also important to create attention of the changes and to prepare the ground for the spread of new ways of working to other parts of the company.

\section{Establishment of data basis}

Prior to the planning of the workplace design it is necessary to make an analysis of the present work functions and work processes. This can include a space brief as described in section 5.1. At implementation of more thorough changes of the ways of work it is however necessary to make more thorough investigations of the employees' present work. The following methods can be mentioned:

- Questionnaires

- Interview study

- Time measurements of the workplace use

A combination of various methods is often necessary to achieve sufficient mapping of the work. In figure 5.7 is shown a diagram with a British example of typical time related use of an individual office workplace. Such a detailed mapping is not often realistic or necessary.

In case $5 . \mathrm{g}$ is shown the use of time measurements in the Palaces and Property Agency.

An important methodology in the mapping of the work, which was developed by DEGW, is to

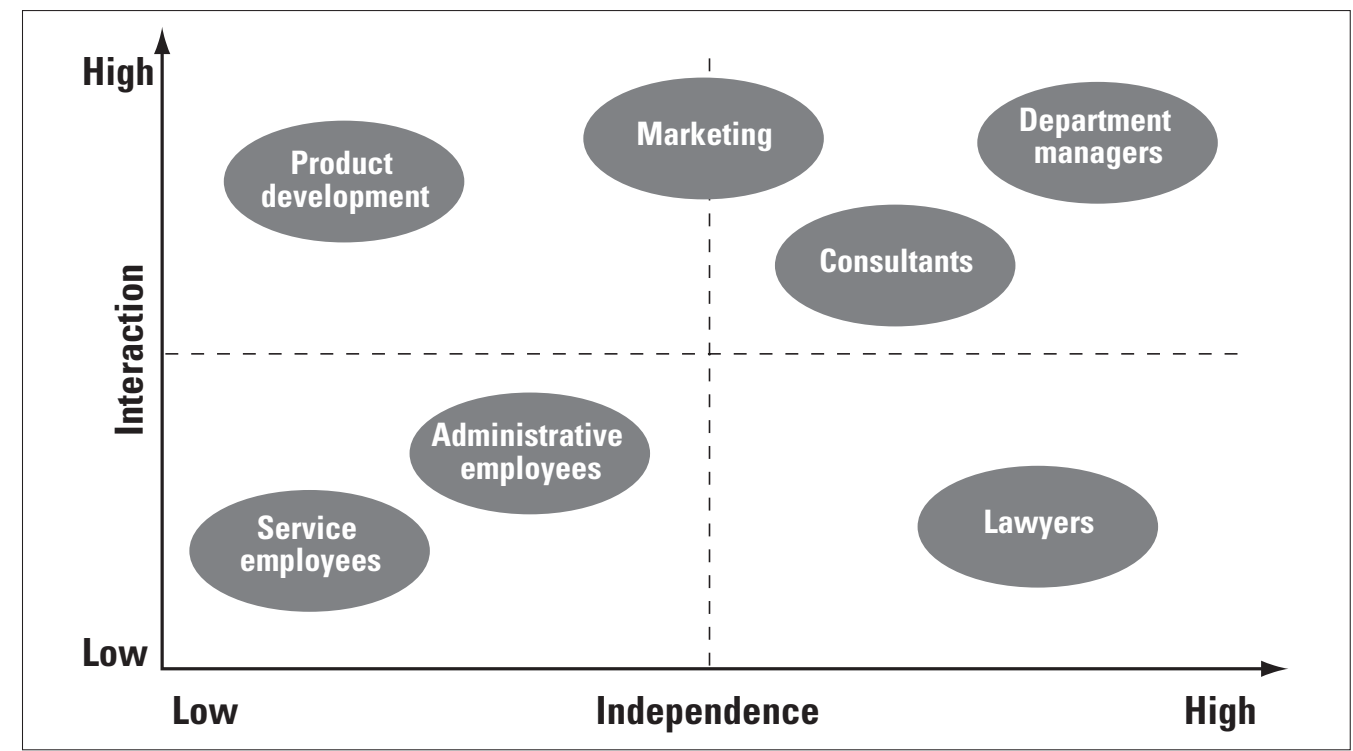




\section{Checklist 5.D: Implementation of New Ways of Working}

The checklist below is based on various literature, which are referred to in section 5.3, and own and others experiences.

\section{Overall strategy}

- Management related preconditions

- Change processes are risky and demand a competent management

- Strong management support throughout the entire process is crucial

- Prepare a vision to the company's future

- Anchoring in the company's mission

- On which values must the process be based

- Which future culture does the company wish

- Strategic choices

- Is the goal primarily savings or development of the company

- Main themes and guidelines of desired changes

- What changes of behaviour with the management and the staff are desired to be advanced

\section{Planning}

- Establishment of data basis

- Analyses of present work processes (tasks, activities, functions, interaction patterns, correlations, processes, technology et cetera)

- Analyses of present space allocation (types of workplaces, space allocation per workplace, shared facilities, special facilities et cetera)

- Analyses of time structure (time share on activities, use frequency of facilities, peak load, variation patterns et cetera)

- Definition of user profiles (interaction, independence, physical dependency, use of technology et cetera)

- Space briefing, cf. section 5.1.

- User involvement

- A high level of user involvement is an important precondition to success

- Determine frames for user involvement (what has been decided and what can be affected)

- Establish work groups with management and user representatives selected from interests and competences and with well defined terms of reference

- See to continuous information and dialogue about the process as wide spread as possible in the company

- Policies and guidelines

- Company policy in relation to home workplaces and criteria for personal offices

- Guidelines for knowledge sharing, filing, service functions and support

- Principles to IT support, telephones, mobile equipment et cetera

- Behavioural rules to noise, smoke, clean-desk et cetera

- Design

- Define building blocks at the use of detail planning

- Decide which furniture systems to use

- Determine space frames to each functional area

- Give each function area consultant assistance in relation to the detailed planning

\section{Implementation}

- Begin with a pilot project

- Implement the entire process into a part of the company

- Make a continuous dialogue with affected employees and inform widely

- Implement formalised evaluation after overcoming the outset difficulties

- Make adaptations and follow-up

- Spread the implementation of new ways of working gradually to the remaining parts of the company

- Make continual evaluations, adaptations and follow-up 
Figure 5.9

Office environments in relation to independence and interaction

\section{User profiles}

$\square$

Typical office designs

Pilot projects

$\square$

Building blocks

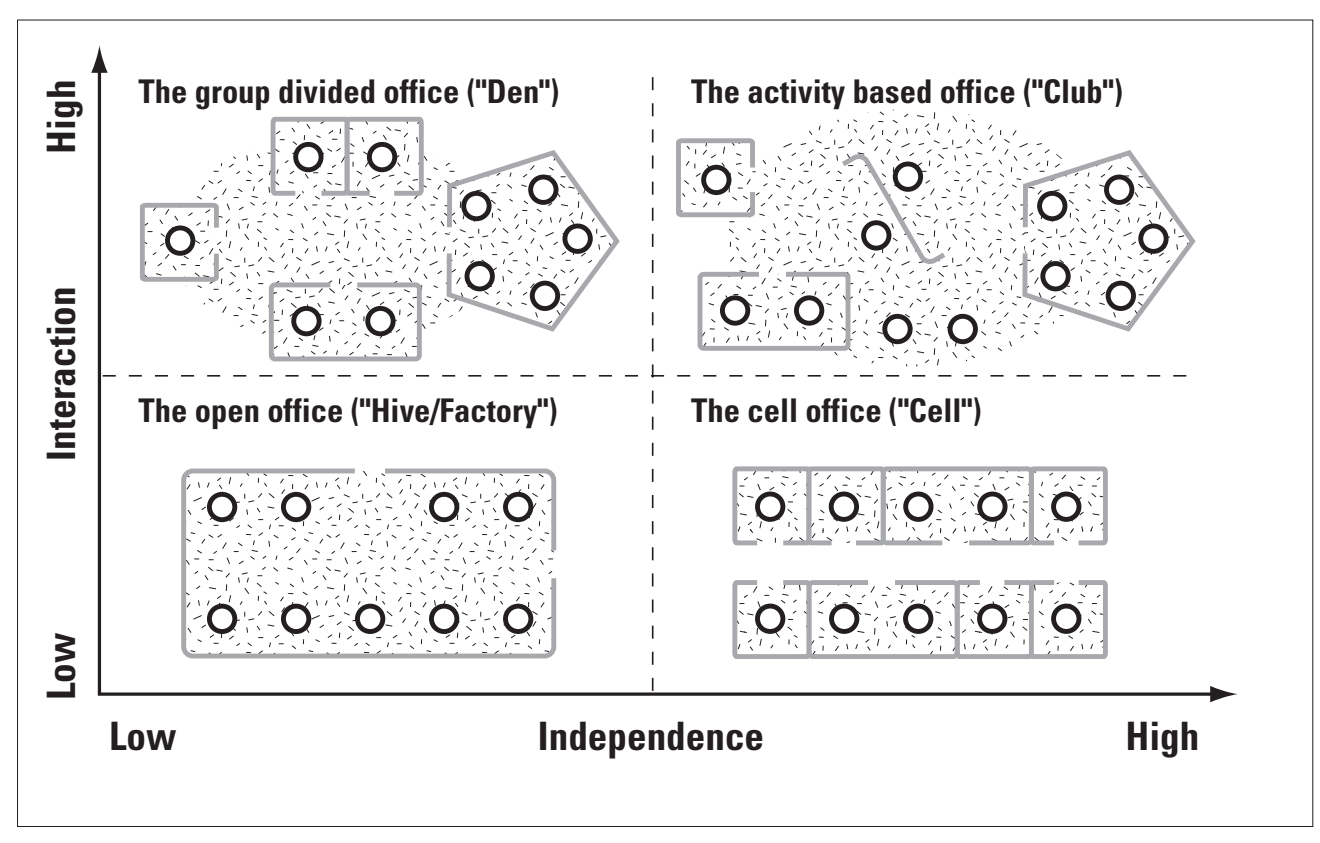

define typical user profiles. An example of this is shown in figure 5.8 in which some examples of work functions are categorised in relation to the level of independence and the level of interaction.

As shown in figure 5.9 there are to each "quadrant" in figure 5.8 some typical office designs which often has shown to be appropriate.

These office designs are:

- The open office or the traditional large office ("Hive" or "Factory"), in which both the level of independence and interaction is rather low.

- The cell office or the traditional single person office ("Cell"), in which the level of independence is relatively high, whereas the interaction level is relatively low.

- The group divided office or the team office ("Den"), in which the level of independence is relatively low, whereas the interaction level is relatively high.

- The activity based office or the innovative office ("Club"), in which both the level of independence and the interaction is relatively high.

\section{The detailed design}

The above mentioned methodology can in itself be used as a guiding principle for the type of office design, which is appropriate for various user profiles or staff categories. The detailed design must in all cases be done in a close dialogue with the affected employees.

As a tool of the detailed design it can be a useful to develop a set of building blocks consisting of typical design components. In an interactive office environment such building blocks can for instance include:

- Workplace for a permanent situated employee

- Workplace grouping for project work

- Workplace with PC for short-term work

- Workplace with mobile IT for short-term work ("touch-down")

- Workplace for manager

- Quiet/small meeting rooms

- Creative meeting rooms with white boards and possibilities for mounting of paper sheets on the walls

- Formal meeting rooms with presentation equipment for formal meetings

- Informal meeting area

- Café area

- Staffed service area

- Support functions (copying, printing, office supply et cetera)

- Mobile archives

- Archive and journal systems

- Library

Naturally it is a good idea to test the building blocks one-to-one in connection with the development. At implementation of the design it can furthermore be recommended to implement one or more pilot projects with smaller groups of employees. Through this you can achieve experiences and correct errors before all employees are involved.

In checklist 5.D are listed the most important elements in connection with implementation of new ways of working. The checklist can be seen as a summary of section 5.3. 


\section{References}

The book by Blyth \& Worthington (2000) is recommended as a general introduction to briefing. and Francis Duffy's book "The New Office" can be recommended as a good introduction to new ways of working with many examples of new office buildings presented along with many photos at a large scale (Duffy, 1997). The book "Workspace" by Karen Mosbech provides an exceptional insight in a manager and planner's experiences and reflections from implementing new ways of working in Danish State institutions.

\section{Literature}

The Danish Health \& Safety Authority: Arbejdsrum på faste arbejdssteder. AT-meddelelse nr. 1.01.12. (Work spaces on permanent workplaces.) AT-information number 1.01.12. Arbejdstilsynet. January 1996

Kirsten Arge $\underline{\&}$ Donatelli de Paoli: Strategic Workplace Design: A Tool to Assist Organisational Development. Proceding from EuroFM/IFMA conference, 2000.

Franklin Becker: The Total Workplace - Facilities Management and the Elastic Organization. Van Nostrand Reinhold, New York, 1990.

Alastair Blyth \& John Worthington: Managing the Brief for Better Design. Spon Press. London. 2000.

Francis Duffy: The New Office. Conran Octopus Limited. London, 1997.

$\underline{I F M A}$ : Benchmarks 1991. Research Report \#7. International Facility Management Association, 1992.

IFMA: Proposed New Standard Classification for Building Floor Area Measurements (Draft). November $23^{\text {rd }}, 1993$.

IFMA: Benchmarks II. Research Report \#13. International Facility Management Association, 1994.

Per Anker Jensen, Kjeld Nielsen and Susanne Balslev Nielsen: Facilities Management. Best Practice in the Nordic Countries - $\mathbf{3 6}$ cases. Centre for Facilities Management, Technical University of Denmark, 2008.

Deborah Quinn Hensel: Working outside the box. Article in FMJ - Facility Management Journal. A publication of IFMA. January/February 1999.

Karen Mosbech: Workspace. Published by the author. 2004

Steelcase Strafor: Space planning. France,1999.

Tony Thomson, DEGW London Ltd: Supporting organisational change. Artcle in Worthington, 1997.

Ole Valbjørn, Susse Laustsen, John Høwisch, Ove Nielsen and Peter A. Nielsen (red.): Indeklimahåndbogen. (The Handbook of indoor climate.) SBI directions196, second edition. The Danish State Construction Research Institute, 2000.

John Worthington (editor): Reinventing the Workplace. Architectural Press, 1997.

\section{Websites}

DFM. www.dfm-net.dk

Telework www.geocities.com/telearbejde 


\section{Figures}

6.1 Property operation expenses for owned properties in 1998 . .

6.2 Maintenance expenses for owned properties in 1998

6.3 Definition of delimitations between cleaning and maintenance.

6.4 Expenses for external building maintenance for owned properties in 1998

6.5 Expenses for internal building maintenance for owned properties in 1998

6.6 Expenses for building installation maintenance for owned properties in 1998

6.7 Expenses for utilities for owned properties in 1998

6.8 Energy expenses for owned properties in 1998

6.9 Expenses for waste disposal and drainage for owned properties in 1998

6.10 Expenses for cleaning for owned properties in 1998

6.11 Expenses for internal cleaning for owned properties in 1998

6.12 General operation expenses for owned properties in 1998.

6.13 Expenses for caretaking, monitoring and supervision for owned properties in 1998 .

6.14 Fixed property expenses for owned properties in 1998
Maintenance.......................... 126

Ground maintenance . . . . . . . . . . . . . . . . . . . . . . . . . 127

External building maintenance. . . . . . . . . . . . . . . . . 127

Internal building maintenance . . . . . . . . . . . . . . . . 130

Building installation maintenance. . . . . . . . . . . . . . . 131

Furniture and equipment maintenance . . . . . . . . . . . . . 132

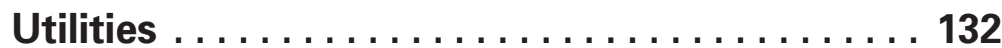

Energy ... . . . . . . . . . . . . . . . . . . . . . . . 132

Waste disposal and drainage . . . . . . . . . . . . . . 133

Cleaning $\ldots \ldots \ldots \ldots \ldots \ldots \ldots \ldots \ldots \ldots, 134$

External cleaning . . . . . . . . . . . . . . . . . . . . . . 134

Internal cleaning . . . . . . . . . . . . . . . . . . . . . 135

Window polishing. . . . . . . . . . . . . . . . . . . . . . 136

Mat and linen service. . . . . . . . . . . . . . . . . . . . . 137

Service items . . . . . . . . . . . . . . . . . . . . . . . . . . 137

General Operation .................... 137

Caretaking, monitoring and supervision . . . . . . . . . . . 137

Movable insurance . . . . . . . . . . . . . . . . . . . . . . . . . 138

External consultants. . . . . . . . . . . . . . . . . . . . . . 138

Management and administration . . . . . . . . . . . . . . . . 138

Fixed Property Expenses. . . . . . . . . . . . . . . 139

Expenses for taxes and coverage . . . . . . . . . . . . . . . 139

Building insurance . . . . . . . . . . . . . . . . . . . . . 139

References........................ 140 
This chapter concerns property operation with emphasis on the operational functions. It is based on the structure for property operation defined by DFM-benchmarking and presented in figure 3.4. DFM-benchmarking's definitions of the various activity areas will be discussed, and the allocation of the expenses in the most important cost categories will be presented with the use of circle diagrams from DFM-

benchmarking's analysis of collected data from the year 1998 .

Property operation includes all services, which are a precondition that a property can function satisfactory during use. DFM-benchnmarking divides property operation in the main fields:

- Maintenance

- Utilities

- Cleaning

- General operation

- Fixed property expenses

In figure 6.1 is shown the allocation of the expenses for property operation per $\mathrm{m}^{2} \mathrm{BDA}$ for owned properties in 1998. As to space definitions are referred to section 5.1. As it appears the expenses are highest for utilities with $26 \%$, whereas the expenses for maintenance are almost equal with $24 \%$, and the expenses for cleaning follow closely with $21 \%$. The expenses for general operation amount $16 \%$, and fixed property expenses amount $13 \%$.

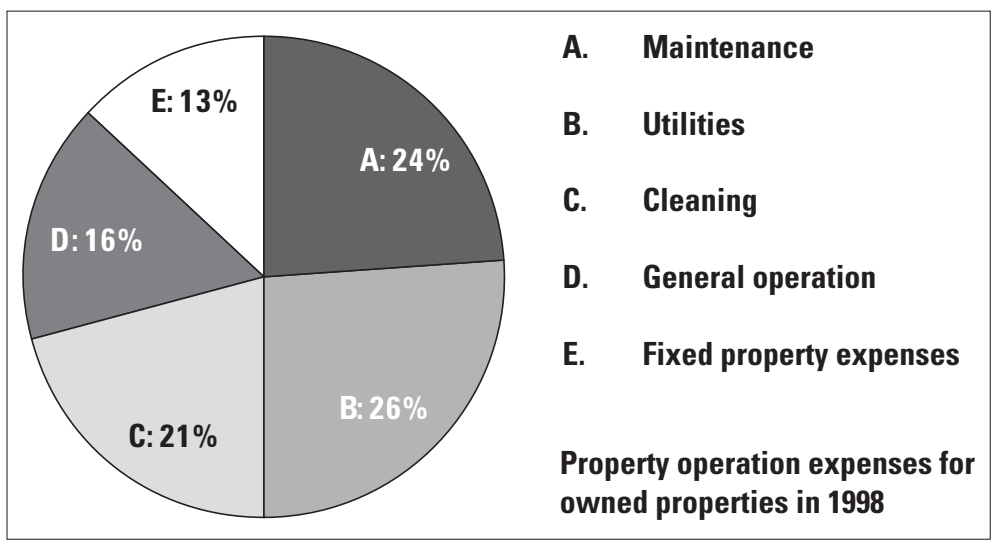

Figure 6.1

Property operation expenses for owned properties in 1998
In section 6.1 to 6.5 each activity area are described. Typical examples of the content of each area will be presented, and the most important factors of significance to quality and expense level will be shown. Conditions of importance to the handling of the activity inhouse or externally will be mentioned. There are references in the end of the chapter.
The description and figures are based on owned properties, but the activities of rented out properties and leases will amount portions of these activities, cf. section 3.3 and figure 3.4. It must be noticed, that fixed property expenses neither include capital expenses for owned and rented out neither properties nor lease expenses for leases.

\subsection{Maintenance}

Maintenance is the part of the property expense, which aims at sustaining of the property's performance. With basis in "quality level as built", the quality level "maintenance as planned" is determined. This quality level is politically decided, and is normally decreasing during the lifetime of the property. Regarding maintenance strategy and planning are referred to sections 4.5 and 4.6 .

DFM-benchmarking divides maintenance into the following fields:

- Ground

- External building

- Internal building

- Building installations

- Furniture

Maintenance expenses include craftsman expenses, including material expenses, but not expenses for planning, management and supervision, which are included in general operation. In figure 6.2 is shown the spread of the expenses for maintenance per $\mathrm{m}^{2}$ BDA for owned properties in 1998. As it appears the expenses for external building, building installations and internal building are almost similar, 32\%, $31 \%$ and $26 \%$, whereas the expenses for ground and furniture are considerably lower, $8 \%$ and $3 \%$. Building maintenance, i.e. external building, internal building and building installations, represent the major part of the maintenance expenses, in all $89 \%$.

One of the fields where it by experience is difficult to define the limits between activities in relation to the expense items are cleaning and maintenance. In figure 6.3 is shown, how a number of activities are recommended to be divided on these cost items on basis of committee work in The Danish Maintenance Association in 1989. 
DFM-benchmarking divide building maintenance into corrective maintenance, preventive maintenance and replacement, and this division is also used in the following sections, why it will be further explained:

- Corrective maintenance is maintenance, which is done to correct acute damage or failure. This kind of maintenance includes repair or replacement of defect components et cetera.

- Preventive maintenance is maintenance, which is done before the property's performance get at a use related unsatisfactory level, or to prevent consequential damage. This kind of maintenance includes typically mandatory inspections, and works which are done with fixed intervals to prevent attrition or to minimise the risk of close down of operation or accidents.

- Replacement is maintenance, which implies a quality jump, which more or less improves the building (or part of it) to a "quality level as built". This kind of maintenance typically includes total refurbishment and/or replacement of building sections, for instance the entire roofing, the entire façade surface, all windows, the entire installation system or considerable parts of it.

Corrective and preventive maintenance sometimes are termed continuous maintenance.

\section{Ground maintenance}

Ground maintenance includes maintenance/ replacement of minor buildings like sheds, building parts, ground surfaces, planting, installations in ground, installations at/over ground, and also ground furniture. Ground is defined as the part of a property which is not covered by buildings. By practical reasons maintenance of internal planting is included in ground. DFM-benchmarking divide ground maintenance in site and installations.

Site maintenance typically includes:

- Consolidated spaces (asphalt, paving stones, sett paving, footpath flags, concrete coatings, gravel)

- Repair of coatings and laying out of new wear coatings

- Removal of unwanted growth, weed and moss

- Slippery road combating during winter time

- Grass spaces: Lawn-moving, rolling, manure and possible weed control

- Plant spaces - external and internal

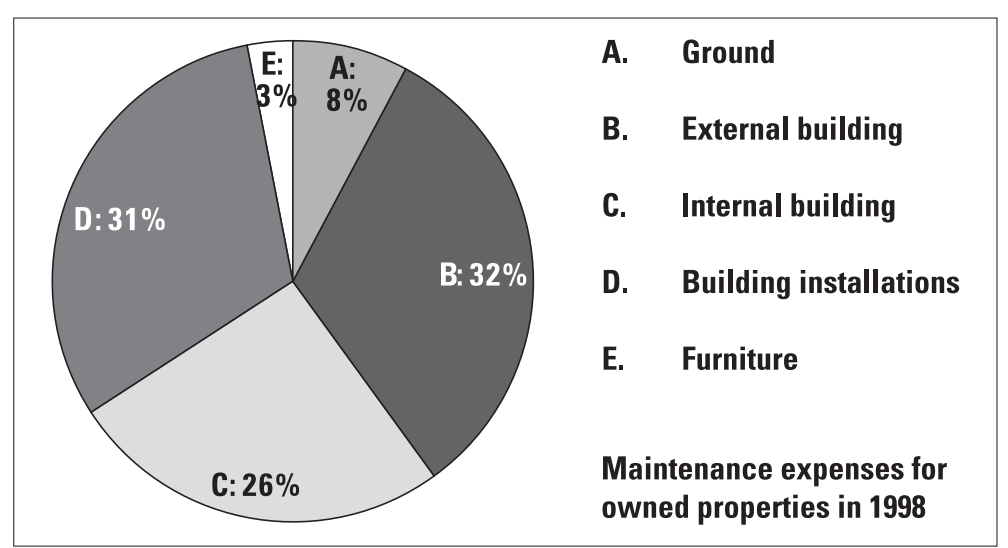

- Cleaning of external spaces for weed

Figure 6.2

- Cutting and prop up of plants, and internally possible washing

- Watering of internal plants and also of Maintenance expenses for owned properties in 1998 external plants, so they have no permanent damages

- Replacement of dead and damaged plants

- Inspection and combating of sickness and vermins on plants

- Basins, external and internal: Emptying and cleaning-up of basins

- Various maintenance of garden furniture, signposts, lighting pylons, flag poles, fences and gates

Ground maintenance of installations typically includes the following:"

- Drainage: Clean-up of wells and replacement of broken well covers

- Lighting: Repair of signpost lighting and external space lighting

The expenses for ground maintenance depend on the size of the paved spaces and the character of possible gardens. The continuous ground maintenance of the ground is often included in a gardener contract along with ground cleaning, and this makes the major expense item. However, major asphalt works with laying out of new wear coatings on internal roads and parking spaces or other major repairs of coatings can make considerable expenses for some years.

\section{External building maintenance}

External building is the part of a building which particularly is affected by the climate, i.e. at least one of the factors sunshine, major temperature changes, and temperature changing through the zero degree Celsius point or direct ground contact. DFM-benchmarking divides maintenance expenses for external building in corrective maintenance, preventive maintenance and replacement. 
Figure 6.3:

Definition of delimitations between clea-

ning and maintenance

*) Chimney sweeping is by DFM-benchmarking included in waste disposal.

\begin{tabular}{|c|c|c|c|}
\hline Object & Activity & Maintenance & Cleaning \\
\hline \multicolumn{4}{|l|}{ Ground } \\
\hline Pavements & sweeping/sluicing & & $\mathbf{x}$ \\
\hline Weed & weeding - squirting & $x$ & \\
\hline Snow & clearing & & $\mathbf{x}$ \\
\hline Snow, ice & gritting - thawing out & $\mathbf{x}$ & \\
\hline Drainage & clean-up & $\mathbf{x}$ & \\
\hline \multicolumn{4}{|l|}{ Garden } \\
\hline - paper et cetera & removal & & $\mathbf{x}$ \\
\hline - dead leaves & raking - absorption & $\mathbf{x}$ & \\
\hline - weed & weeding - squirting & $\mathbf{x}$ & \\
\hline - grass & mowing & $\mathbf{x}$ & \\
\hline Lighting/signposting & washdown & & $\mathbf{x}$ \\
\hline \multicolumn{4}{|l|}{ Building, external } \\
\hline Roofing (moss, snow) & removal & $\mathbf{x}$ & \\
\hline Gutters/drainpipes & cleaning & $\mathbf{x}$ & \\
\hline Facade & $\begin{array}{l}\text { clean-up } \\
\text { proofing }\end{array}$ & $\mathbf{x}$ & $\mathbf{x}$ \\
\hline $\begin{array}{l}\text { Windows } \\
\text { - window frames } \\
\text { - window glass }\end{array}$ & $\begin{array}{l}\text { washing } \\
\text { cleaning - polishing }\end{array}$ & $\mathbf{x}$ & $\mathbf{x}$ \\
\hline Gate & sweeping & & $\mathbf{x}$ \\
\hline Entrance & washing - vacuuming & & $\mathbf{x}$ \\
\hline Grating & cleaning - sweeping & & $\mathbf{x}$ \\
\hline Light shafts & clean-up - sweeping & & $\mathbf{x}$ \\
\hline Lighting & wiping & & $\mathbf{x}$ \\
\hline Signposting & clean-up & & $\mathbf{x}$ \\
\hline Chimney *) & sweeping *) & $\left.x^{*}\right)$ & \\
\hline Ventilation caps & cleaning & $\mathbf{x}$ & \\
\hline \multicolumn{4}{|l|}{ Building, internal } \\
\hline Ceilings & washing - vacuuming & & $\mathbf{x}$ \\
\hline Walls & washing - vacuuming & & $\mathbf{x}$ \\
\hline Building parts (for instance rails) & wiping - wash-up & & $\mathbf{x}$ \\
\hline Floors & $\begin{array}{l}\text { washing - vacuuming } \\
\text { treatment - polishing }\end{array}$ & $\mathbf{x}$ & $\mathbf{x}$ \\
\hline Sanitary installations & cleaning - decalcification & & $\mathbf{x}$ \\
\hline $\begin{array}{l}\text { Ventilations system } \\
\text { - external } \\
\text { - internal }\end{array}$ & $\begin{array}{l}\text { wiping - vacuuming } \\
\text { cleaning - vacuuming }\end{array}$ & $\mathbf{x}$ & $\mathbf{x}$ \\
\hline Heating system & $\begin{array}{l}\text { wiping } \\
\text { washing - vacuuming }\end{array}$ & $\mathbf{x}$ & $\mathbf{x}$ \\
\hline Lighting & $\begin{array}{l}\text { cleaning - vacuuming } \\
\text { washing }\end{array}$ & & $\begin{array}{l}\mathbf{x} \\
\mathbf{x}\end{array}$ \\
\hline $\begin{array}{l}\text { Windows } \\
\text {-frames, frame wood } \\
\text { - glass }\end{array}$ & $\begin{array}{l}\text { washing } \\
\text { wiping } \\
\text { cleaning - polishing }\end{array}$ & $\mathbf{x}$ & $\begin{array}{l}\mathbf{x} \\
\mathbf{x}\end{array}$ \\
\hline Gully & $\begin{array}{l}\text { cleaning internal } \\
\text { cleaning external }\end{array}$ & $\mathbf{x}$ & $\mathbf{x}$ \\
\hline
\end{tabular}


In figure 6.4 is shown the spread of the expenses for external building maintenance per $\mathrm{m}^{2}$ BDA for owned properties in 1998. As it appears the expenses for replacements make the main part with $55 \%$, whereas preventive maintenance amounts $31 \%$ and corrective maintenance only $14 \%$.

\section{Corrective maintenance of external building} typically includes:

- Roof and balconies, including flashings and drainage systems. Repair of leakages

- Facades, external staircases, light shafts and foundations: Repair of leakages and defects of staircases, gratings, railings and hand mouldings

- Windows, doors, gates: Replacement of broken glass and repair of locks and fittings et cetera

- Sunshade: Repair of errors and damages

\section{Preventive maintenance of external building}

typically includes the following:

- Roofs and balconies, including flashings and drainage systems

- Clean-up of gutters and leaf catch during springtime and autumn after leaf fall

- Combating moss and algae

- Facades

- Painting or other surface treatment

- Repair of cracks in walls and façade coverings, and also defects in sills and joints, which can cause water penetration in back wall

- Windows, doors, gates and sunshades

- Washing, painting and other surface treatment of wood and metal parts

- Repair of defect flashings, glass mouldings and weather strips

\section{Replacement of external building typically}

includes the following:

- Roofs: Renovation of roof with new roofing and new flashings

- Facades, external staircases, light shafts and foundations

- Renovation of brick-built facades with rejoint and possible rough-cast or the like

- Renovation of concrete facades with local concrete repairs and proofing or other surface treatment

- Renovation of light façade coatings with total change or partial change and repair with surface treatment of the entire surface

- Renovation of external staircases, light shafts and foundations/ footing with local

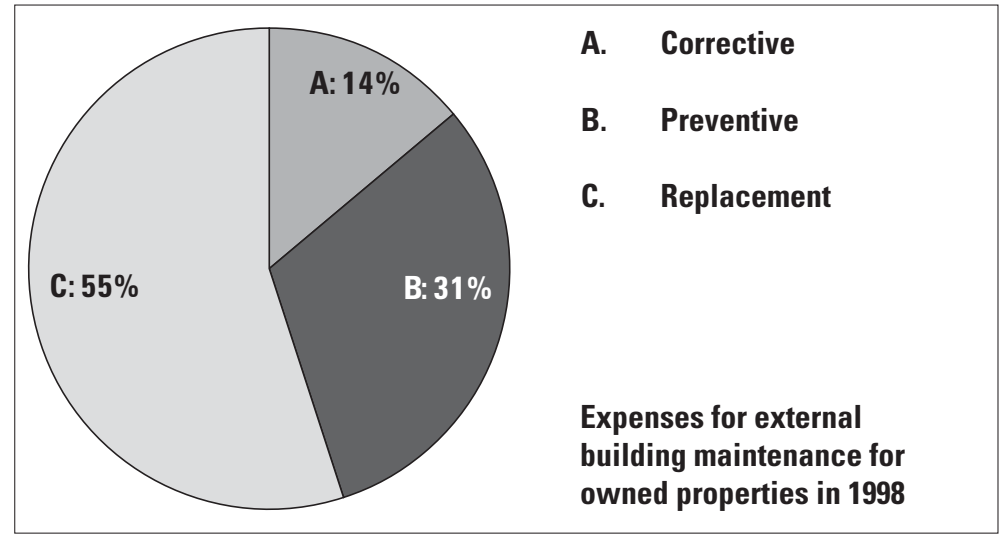

plaster and concrete repairs, and also proofing or other surface treatment

- Windows, doors and gates

- Renovation of windows including sunshades and canopies with total change or partial change and repair with surface treatment of the entire surface

- Renovation of doors and gates with total change or partial change and repair with surface treatment of the entire surface

The expenses for external maintenance are to a high degree related to the quality and design of the building. Buildings with simple facades and roofs are in general cheaper to maintain than buildings with many jumps of facades and built together of various materials.

Climate related influences of the building have also importance to the maintenance expenses. The temperature influence of a southward façade, which on the Northern hemisphere are highly influenced by sun, is far stronger than to a northward facade, and the strain of the facade materials is hence stronger, and that is why surface treatments must be done more often. Correspondingly are buildings exposed to heavy wind stronger influenced than more protected buildings.

The importance of the climate related influences partly depend on the shape of the building. Flat roof will for instance be exposed to snow strain during a longer period than roofs with a large slope. This implies a stronger static strain on the roof construction, but more important that there in a period will be changing ice formation and de-icing on the roof surface. The large number of zero degree Celsius passages in the climate of Northern European countries is generally seen as one of the strongest influences on the building fabric.
Figure 6.4

Expenses for external building maintenance for owned properties in 1998

The shape of the building

Climate related influences 


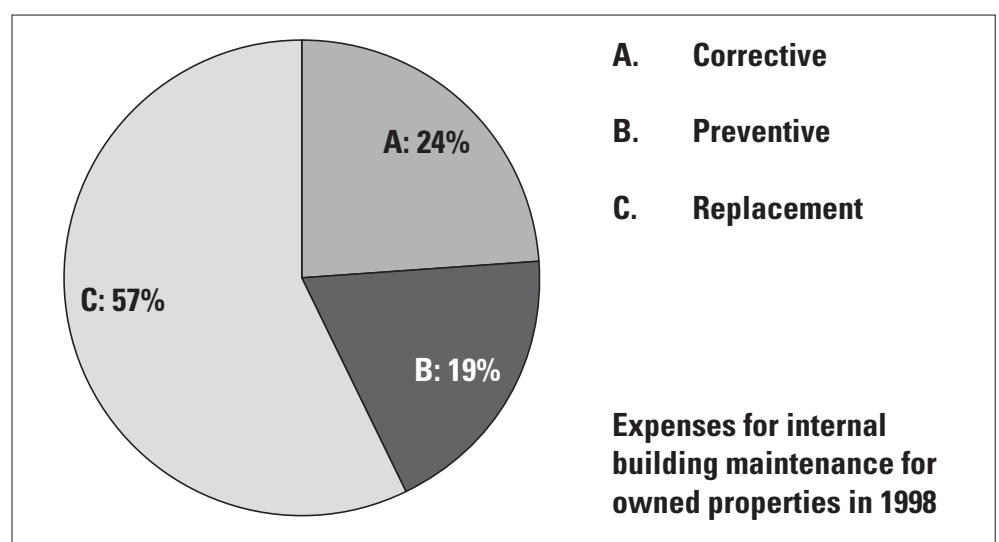

Figure 6.5

Expenses for internal building maintenance for owned properties in 1998

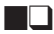

The age of the building

Maintenance strategy

The quality of

the building
Due to the climate influences the age of buildings has a major importance to the maintenance expenses, hence old buildings in general are far more expensive to maintain than new buildings. This has been documented through key indicators, which for instance appears from figure 3.7. However, there are also variations of buildings quality during various periods of time. For instance, the period during and after 2nd World War was characterised by lack of materials and many experiments with building materials and methods, which led to a rather poor building quality - not at the least compared to the interwar period. This can also be seen from figure 3.7 in connection with rented out properties.

The maintenance expenses are also dependent on the maintenance strategy. If maintenance primarily is implemented as a periodical preventive maintenance, the maintenance expenses and quality will normally be rather high. The lowest maintenance expenses are probably achieved if one only makes the most necessary corrective maintenance and replacements, but the risk of a bad image and unsatisfied users is imminent. The optimal relation between expense and quality is probably obtained through need based maintenance efforts, which in an appropriate way combine corrective, preventive and replacement maintenance.

In connection with corrective and preventive maintenance activities it can be appropriate to have one's own employees to handle the tasks, but to the major maintenance works, which have character of projects, and which typically include preventive or replacement maintenance, it will often be most appropriate to call for tenders with contractors or craftsmen companies.

\section{Internal building maintenance}

Internal building is the part of a building, which is not grouped with external building, and which in particular is influenced by use factors in rela- tion to the utilisation of the building. DFMbenchmarking divides maintenance expenses for internal building in corrective, preventive and replacement maintenance.

In figure 6.5 is shown the spread of the expenses for internal building maintenance per $\mathrm{m}^{2}$ BDA for owned properties in 1998. As it appears the expenses for replacement maintenance for internal building maintenance are the main part (57\%), whereas corrective maintenance is higher than preventive maintenance with $24 \%$ and $19 \%$ respectively.

\section{Corrective maintenance of internal building}

typically includes the following:

- Walls: Repair and painting of damages on walls or replacement of wall plates

- Ceilings: Removal and remounting of ceiling plates in connection with repair of technical installations above the ceiling

- Floors: Repair or replacement of partially worn down floorings

- Staircases: Repair of defect steps, coatings, defect mouldings and railings

- Internal doors: Repair or replacement of defect doors, door closers, door handles and locks

\section{Preventive maintenance of internal building} typically includes the following:

- Walls and ceilings: Painting of walls and fixed ceilings

- Floors and staircases: Lacquering, oil or wax treatment of floors, railings and parapets

- Windows and doors: Painting of window frames and casings and panels

\section{Replacement maintenance of internal building} typically includes the following:

- Walls: Plastering and surface treatment of brick walls or replacement of wall facings

- Ceilings: Plastering and surface treatment of plaster ceilings or replacement ceiling facings

- Floors and staircases: Replacement of flooring

- Doors: Replacement of doors

The expenses for internal maintenance correlate to the number of strains, to which the building is exposed. The number of employees and visitors in the building has importance, and also the weekly service time.

The quality of the building has also a significant importance, not at least the quality of the surfaces. A high material quality will often imply rath- 
er few maintenance expenses, whereas it in the other hand can make refurbishments more expensive. Yet, it is common that companies in a building built with a high material quality will prioritise a high maintenance level.

Regarding performance of maintenance with inhouse staff or external companies the same applies to internal building as shown for external building in the section about external building maintenance.

\section{Building installation maintenance}

Building installation includes all installations, exclusive installations in ground and installations attached to production equipment, for instance IT centre. DFM-benchmarking divides maintenance expenses for building installations in corrective, preventive and replacement maintenance.

In figure 6.6 is shown the spread of the expenses for building installation maintenance per $\mathrm{m}^{2}$ BDA for owned properties in 1998. As it appears, corrective maintenance is unlike external and internal building maintenance the largest with $50 \%$, whereas preventive maintenance amounts $37 \%$ and replacement maintenance only $13 \%$.

\section{Corrective maintenance of building installa-}

tions typically includes the following:

- Electricity: Repair of defect switches and replacement of burned out light sources and fuses

- HVAC: Repair or replacement of defect taps and toilet cisterns, cleaning of blocked drainages, and repair of leaking water pipes and drainages

\section{Preventive maintenance of building installa-}

tions typically includes the following:

- Electricity

- Mandatory inspection af lifts, automatic doors and gates and possible lift and raise systems

- Testing of RCCB relays at the power supply

- Testing of emergency and panic lighting, and also replacement of batteries

- Testing of emergency power system

- HVAC

- Testing of firefighting equipment

- Inspection and replacement of worn out strops, bearings, rotors et cetera in motors, pumps and ventilators

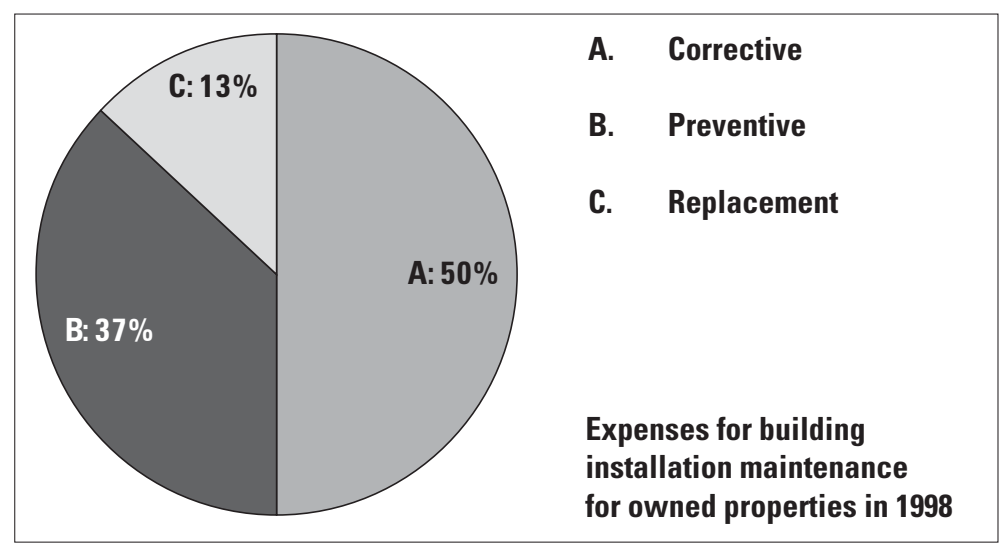

- Replacement of filters, cleaning and vacuuming of ventilation system internally, and also cleaning of ventilation covers

- Washdown and vacuuming of heating systems

Figure 6.6

Expenses for building installation mainte-

nance for owned properties in 1998

Corrective maintenance of building installations typically includes the following:

- Electricity

- Renovation of power transformer systems, and also circuit breaker panel and tracks

- Renovation of lighting systems

- Renovation of emergency power systems

- Renovation of automatic control installations and alarm systems

- Renovation of lifts

- HVAC

- Renovation of heating supply system and radiator system

- Renovation of cooling and ventilation system

- Renovation of hot and cold water system, including sanitation

- Renovation of drainage system, including downpipes and wells

- Renovation of firefighting system, including sprinkler system

The expenses for maintenance of building installations are strongly depending on the building's technical complexity, hence the size and the quality of building installations. This is also correlated to the height of the security level which the company has for the technical supplies.

Regarding performance of maintenance with inhouse employees or external companies the same applies to building installations as shown for external building in the section about external building maintenance. 


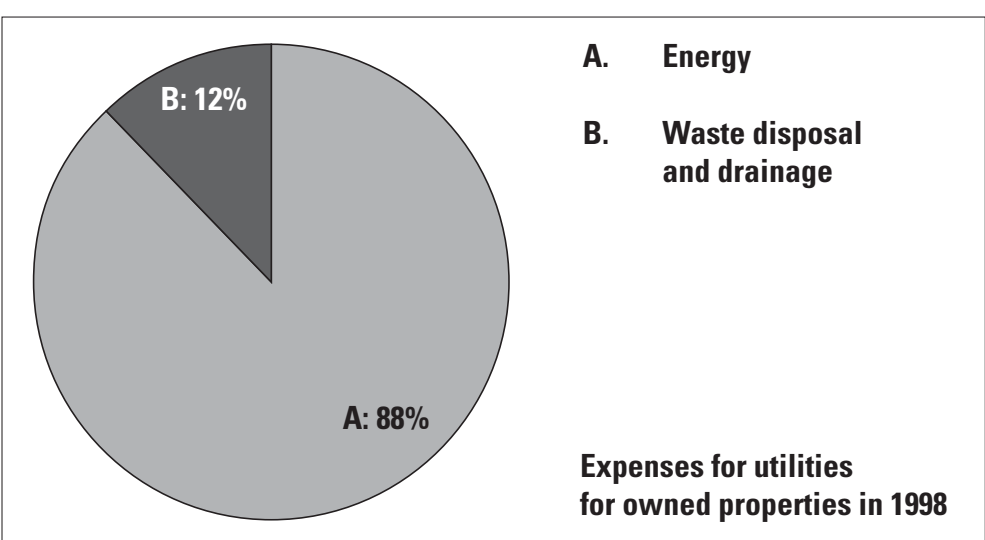

Figure 6.7

Expenses for utilities for owned properties in 1998

Energy taxes

\section{Furniture and equipment maintenance}

Furniture and equipment maintenance include in accordance with DFM-benchmarking maintenance / replacement of building furniture and equipment, and also lock systems.

Furniture and equipment maintenance typically includes the following:

- Fixture

- Surface treatment, repair or replacement of reception counters, wardrobe furniture, toilet room, shower room and exercise room furniture, kitchen and canteen furniture, compact archives, meeting room furniture (monitors), curtains, window blinds and internal sunshade, signposting and white boards

- Repair, greasing or replacement of lock systems

- Non-fixture: Surface treatment, repair or replacement of work tables, office chairs, closets, bookcases, shelves, meeting tables and meeting chairs in lobbies and other representative areas.

The expenses for maintenance of furniture and equipment depend to a great extent of the quality of the procured furniture and to which extent it is standardised.

Figure 6.8

Energy expenses for owned properties in 1998

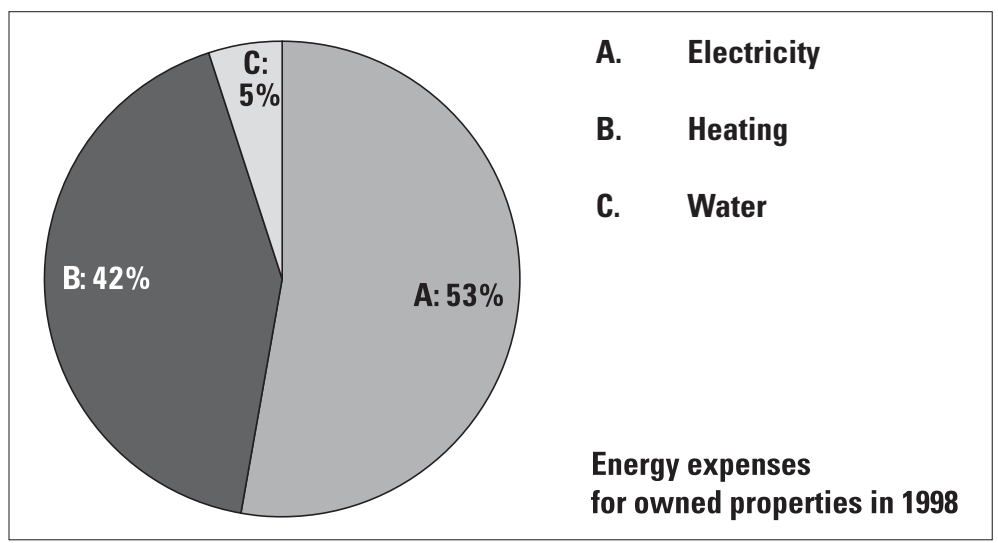

niture and equipment repairs and decide, whether it can pay to replace or repair it.

\subsection{Utilities}

Utilities include partly the necessary supply of energy et cetera in connection with operation of properties / buildings, partly waste disposal. DFM-benchmarking divides utilities in the following areas:

- Energy

- Waste disposal and drainage

In figure 6.7 is shown the spread of the expenses for utilities per $\mathrm{m}^{2}$ BDA for owned properties in 1998. It appears that the expenses for energy are quite dominating with $88 \%$, whereas waste disposal and drainage amount $12 \%$.

\section{Energy}

Energy supply is divided into heating, electricity and water. DFM-benchmarking operates with energy expenses including non-refundable energy taxes.

In figure 6.8 is shown the spread of the energy expenses per $\mathrm{m}^{2}$ heated space for owned properties in 1998. It appears that the expenses for electricity and heating are quite dominating with $53 \%$ and $42 \%$ respectively, whereas the expenses for water only amount $5 \%$.

Heating includes the expenses for heating supply. This of course depends of the actual heating system in the building, which again is decided from where the property is located in relation to the municipal heating supply plans. In larger cities district heating is common in Denmark and in such cases the heating expense consists of payment of consumption fees to the district heating company. In other areas are own heating production with oil or natural gas firing the most common, and here the expense consists of payment of the oil and gas consumption, and also possible expenses for janitor or the like. Alternative energy sources such as solar heat and photovoltaic panels are also relevant, but they are often supplements to a traditional heating and electricity supply.

The expenses for heating are furthermore primarily depending on the heat insulation, which to a great extent is connected with the age of the building and the heating insulation standards in the Building Regulations which were valid at that time. The large jump in the heating insula- 
tion standards in Denmark were made with the building codes from 1977 . The weekly service time of the building, hence the service time of the heating system has furthermore importance to the heating consumption.

Electricity includes the expenses for electricity supply, which in most cases consists of payment of consumption fees to the electricity supply company in question. The price of electricity varies considerably depending on provider and depending on possible major client discounts and the allocation of the consumption at various rates. With the liberalisation of the electricity market there are, especially to larger companies, good possibilities to obtain savings on the electricity price in using the market possibilities. Own production of electricity in the shape of combined heat and power systems, photovoltaic panels and windmills are also possibilities to some companies, and at new building it will probably in the near future be relevant with electricity from solar cells integrated in the building.

The electricity consumption is most depending on the technical complexity of the property, including whether electricity consumption at a larger scale for technical equipment is included. Electricity consumption for actual production must be separated from the building related electricity consumption. There are many possibilities to reduce the electricity consumption through energy saving lighting and other equipment, and also introduction of automatic operation of electricity consuming systems. The staffs' behaviour also influences on the electricity consumption for lighting and various devices, including computers.

Concurrently with an increasing size of heat releasing IT equipment in buildings, the electricity consumption has increased, whereas the direct need of heating during the cold months has been reduced. The need of cooling during the warm months has instead been increasing. This has altogether implied a shifting of the energy consumption from heating to electricity, which is rather inappropriate in relation to the environment, as the heating production by combined heat and power systems is partly a byproduct at electricity production. Recently cooling systems with reduced use of electricity has been introduced Denmark in the shape of see water or ground water cooling systems.
Water includes expenses for water supply, which in most cases include consumption fees to a municipal waterworks, and are in Denmark normally paid along with the property tax to the municipality, but waterworks can also be private in some areas and countries. The water consumption mostly depends of whether there is included special water consuming activities in the company, including laundry and carwash, to a greater extent. Using water saving fixtures and sanitation reductions can be achieved in part of the water consumption.

At new building you must consider to collect rain water from roof downpipes et cetera with a view to reuse for toilet flush to limit the water consumption and the water drainage. However, this requires in Denmark sanction from the municipal environment authorities. It can furthermore be relevant to reuse water from special water consuming activities such as watering plants, laundry and testing of sprinkler systems.

The energy expenses are in general an increasing expense due to increasing oil prices and green taxes, hence the saving possibilities is a focus area in many companies. See also the discussion of energy management in section 9.2.

\section{Waste disposal and drainage}

In figure 6.9 is shown the spread of the expenses for waste disposal and drainage per $\mathrm{m}^{2}$ BDA for owned properties in 1998. It appears that the expenses for waste disposal are quite dominating with $87 \%$, whereas the expenses for drainage only amount $13 \%$.

Waste disposal include expenses for waste disposal, wages for own waste disposal staff, costs for materials, and also chimney sweeping and pest control. This is an area which is under comprehensive regulation in the environmental legislation, and in Denmark each municipality has determined specific regulations for waste dis-
The heat insulation of the building

\section{Liberalisation of the electricity market}

Recycling of rain
water

Green taxes

Figure 6.9

Expenses for waste disposal and drainage for owned properties in 1998

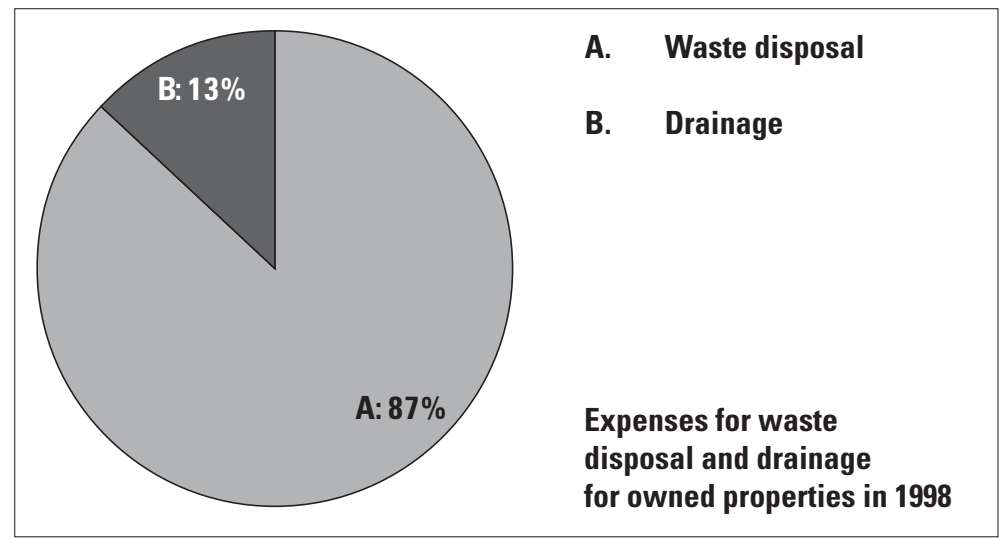


Waste plans

Consolidated spaces

Removal of graffiti posal and recycling in their area. Hence the municipalities every fourth year must prepare new waste disposal plans with description of status, prognoses, and description of goals, and also planned initiatives.

So it is important to follow he municipal regulations, both in connection with choice of haulage contractor and grading of the waste in various fractions. At disposal of dangerous materials a specific agreement must be made with the municipal environmental authorities. The best way to reduce the waste disposal expenses is through a reduction of the amount of waste with an appropriate organisation of supplies and internal procedures, including use of recycling possibilities.

Pest control includes typically combating rats and mice, but also combating mason bees, weevils, ants and fruit flies, precautions to keep doves and other birds away from balconies, and precautions to keep away animals and birds out of attics, crawl spaces et cetera. Pest control is usually done by external companies with a specific knowledge of the field.

Drainage expenses typically consist of water drainage fees, which in Denmark normally are related to the recorded water consumption, and are paid like the water consumption along with the property taxes. So reduction of drainage expenses preferably can be made through a reduction of the water consumption.

\subsection{Cleaning}

Cleaning includes activities and services, which aim at sustaining an acceptable hygienic quality level.

DFM-benchmarking divides cleaning in the following 5 areas:

- External cleaning

- Internal cleaning

- Window polishing

- Mat and linen service

- Service items

DFM-benchmarking operates with expenses for cleaning, including wages to own cleaning staff, costs for materials and machinery, but exclusive own work management and administration. What relates to the delimitations between cleaning and maintenance, see figure 6.3.
In figure 6.10 is shown the spread for the expenses for cleaning per $\mathrm{m}^{2}$ BDA for owned properties in 1998. As it appears internal cleaning is quite dominating with $86 \%$, whereas external cleaning amounts $10 \%$ and the remaining three areas each amount 1-2\%.

\section{External cleaning}

DFM-benchmarking divides external cleaning in ground and external building.

Cleaning of ground typically includes the following:

- Consolidated spaces (asphalt, paving stones, sett paving, pavement flags, concrete covering, gravel):

- Removal of all kinds of thrown away waste

- Cleaning of fixed coverings for gravel, leaves et cetera

- Snow removal during winter time

- Grass and plant spaces:

- Removal of all kinds of visible cuttings

- Garden furniture: Removal of dirt from benches, tables e cetera

- Litter boxes: Emptying

- Signposting: Wash-off and removal of graffiti

- Lighting pylons: Wash-off

External building cleaning typically includes the following:

- Facades: Cleaning of surfaces and removal of graffiti

- Gateways and external staircases: Sweeping

- Entrances: Wash-off and vacuuming

- Light shafts and gratings: Cleaning out and sweeping

- Signposting: Wash-off

- Lighting fittings: Wiping off

The main part of the expenses for external cleaning is related to cleaning of the consolidated spaces, hence the percentage of these spaces are of great importance to the size of the expenses. The expenses for snow removal naturally vary each year depending on the amount of snowfall.

The expenses for external building cleaning highly depend on the shape of the building. Possible expenses for removal of graffiti depends naturally strongly on the location of the building, whether it has an exposed location.

External cleaning is in smaller companies or at smaller properties often handled by a caretaker. 
In major companies and at larger properties ground cleaning is often part of a gardener contract, which also includes tasks in connection with ground cleaning, cf. section about ground maintenance, whereas external building cleaning is often part of a total cleaning contract.

\section{Internal cleaning}

Internal cleaning includes cleaning of internal building. DFM-benchmarking divides internal cleaning in daily/periodical cleaning, major cleaning and extra/special cleaning.

In figure 6.11 is shown the spread of the expenses for internal cleaning per $\mathrm{m}^{2}$ cleaned space for owned properties in 1998. As it appears dai$1 \mathrm{y} /$ periodical cleaning is quite dominating with $76 \%$, whereas extra/special cleaning amounts $18 \%$ and major cleaning $6 \%$.

Daily/periodical cleaning is done daily or planned with certain intervals. This if most frequently determined in a cleaning programme, which normally is specified as a three-figure code to each room. The first number in the code states number of days per week, where a basic or minimum cleaning of floors and furniture is done. Second and third number indicates number of days per week, where also a thorough maximum cleaning of floors and furniture is done.

Basic or minimum cleaning typically includes:

- Airing

- Emptying and cleaning of litter boxes and ashtrays

- Wiping off or dusting of horizontal surfaces on work tables and similar surfaces, including accessories

- Wash-off or wiping off kitchen sinks, washbasins, toilets and other sanitary et cetera, and also mirror cleaning

- Removal of patches on tiled walls

- Supplementing of consumer goods

- Mopping or light vacuuming of floors, including mats

Thorough or maximum cleaning of floor includes thorough floor washing or vacuuming.

Thorough or maximum cleaning of furniture and equipment typically includes the following:

- Wiping off or vacuuming of chairs and sofas et cetera

- Wiping off or vacuuming of visible horizontal surfaces, and also furniture and equipment and lighting up to $2 \mathrm{~m}$ above the floor.

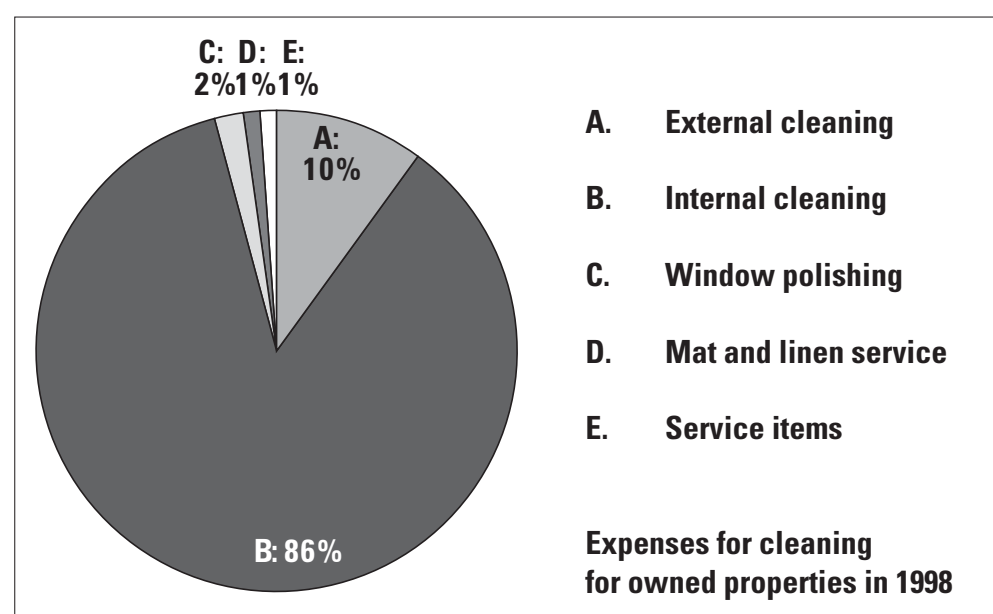

- Removal of patches on furniture and equipment and building surfaces

A cleaning code for an office can typically be Figure 6.10

Expenses for cleaning for owned properties in 1998

511, i.e. basic cleaning the five normally working days per week supplemented with a thorough cleaning of floor one day per week, and thorough cleaning of furniture and equipment one day per week. For a toilet the code can typically be 551, and to an archive room typically 110. In specially strained areas with long daily burdens all weekdays the code can for instance be 771. At cleaning several times a day an extended code system is needed.

Major cleaning includes a more thorough cleaning than the daily/periodical cleaning. This kind of cleaning can be included as a fixed standard programme, which is performed as part of the daily/periodically cleaning programme with a certain interval, but time staggered in various areas of the building, hence the entire building will be included in the major cleaning.

Such a kind of major cleaning can for instance include:

- Wiping off or dusting of horizontal surfaces on furniture and equipment: Once a month

- Wash-off or dusting of tiled walls, doors, frames and panels: Twice a month

- Wash-off or dusting of furniture and equip-

Figure 6.11

Expenses for internal cleaning for owned properties in 1998

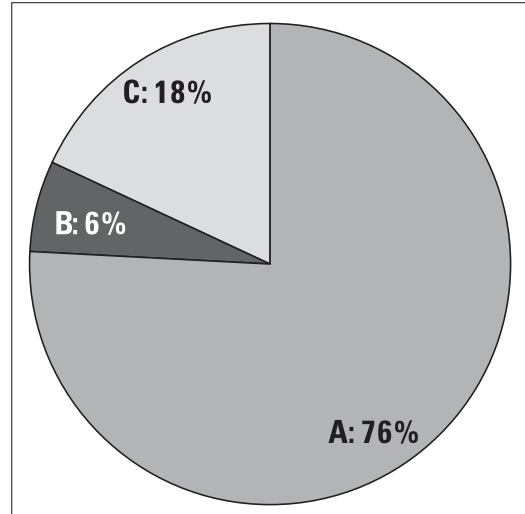

A. Daily/periodical cleaning

B. Major cleaning et cetera

C. Extra/special cleaning

Expenses for internal cleaning for owned properties in 1998 
ment and lighting above $2 \mathrm{~m}$ : Six times annually

The major cleaning can also be a fixed programme to a certain way of cleaning, which is initiated after further agreement.

Extra/special cleaning is cleaning, which is not done from a standard programme or is periodically returning. It can for instance include carpet cleaning, ceiling cleaning, curtain washing, cleaning after events, telephone and computer cleaning et cetera.

\section{Functions of importance to quality and expense level for internal cleaning}

The implementation of the cleaning is much depending on how the users of the premises arrange themselves and how they live in their daily life. To have maximum effects of the cleaning it is necessary that the users contribute.

INSTA 800

Wage level

Accessibility
The time of the performance of the cleaning is also essential, both to the expense and to the relations among the cleaning staff and the users. If the cleaning is finished before the users meet at work, the users will not have a "face" of the cleaning, and will not have the opportunity to see, how the cleaning is actually done. To the users the cleaning becomes an abstract impersonal activity, to which it is easy to be critical, but difficult to get a dialogue. However, if the cleaning overlaps for a little time with the users' work, the users will have an impression of the working conditions of the cleaning staff. There will be a possibility to a certain dialogue, and it will be much easier to solve sources of irritation and to show consideration to each other.

As cleaning is a highly manpower intensive activity, the wage level for the cleaning staff is of course of crucial importance to the cleaning expenses. Management and organisation of the cleaning activities hence are of major importance.

Other important factors to quality and expense level of internal cleaning can be:

- Demands to the result of each cleaning operations

- The frequency of the cleaning operations

- Weekly service time of the building

- The level of dirt, including whether there are efficient mat systems at entrances to the building

- The density of furnishing and tidiness, cf. the above mentioned about the use of the building
- Flooring where carpets are often the cheapest, hard surfaces such as linoleum and lacquered wooden floors are often more expensive, whereas oiled wooden floors are the most expensive

- Further choice of materials, where smooth surfaces are easier to clean than fleecy surfaces

- The shape of the building, where difficulty entrances, jump of levels and shift of floorings make the cleaning more difficult and so more expensive

- The cleaning facilities, including size and location of cleaning rooms, possibly central vacuuming system et cetera

- Space distribution, where not at the least the percentage of toilet and shower rooms are important

\section{New standard to cleaning quality in schools, day care centres and hospitals} In 2000 a new standard - INSTA 800 - for the quality of cleaning in the Nordic countries was published after five years of common Nordic work with participation of labour market representatives, users and experts. The cleaning quality is defined on a scale 1-5 for the various surfaces in a room. Hence, the demands to the cleaning quality are made as performance indicators for output, cf. chapter 3.4. INSTA 800 is adapted to a new European frame standard for cleaning, which is valid from 2001, but the new common Nordic cleaning standard is only valid for schools, day care centres and hospitals.

\section{Window polishing}

DFM-benchmarking divides window polishing in internal and external window cleaning. The size of window polishing is given from the range of glass in the building, and regarding to the main part it will be appropriate with periodical window cleaning. To top lighting and glass roofs it can be relevant with polishing according to need.

Besides the size of glass, the accessibility to be able to perform the window polishing is substantial to the expense level. To tower buildings it is of course essential whether the work can be done outside from balconies or clean bridges, whether it must be done by using a lift or a gondola, or whether the windows can be turned so the external window cleaning can be done from inside. To internal window cleaning the density of furnishing at windows and a positive assistance from the users are of major importance. 


\section{Mat and linen service}

Mat and linen service include washing of towels and tea towels to be used where there are washbasins, unfolding sinks and kitchen sinks, cleaning of floor mats and washing or cleaning of curtains, wall textiles and shower curtains.

The cost level is of course depending on the amount of mats and linen. Hence, there are various solutions of drying your hands in toilet rooms. Use of ordinary towels or towel automats will imply a large scale of linen washing, whereas paper towels/napkins will burden the expense for service items, and finally electricity driven hot air drying machines will burden the investment budget and the electricity consumption.

The last mentioned solution has primarily its advantage at public toilets, as it is hygienic and cannot be used up, as it is also rather safe to vandalism. In companies others solutions will often be preferable.

Regarding the amount of mats, one must consider the correlation with the floor cleaning, as efficient mat systems at entrances to buildings can be important in relation to a decrease of the dirt level. A suitable number of mats and the related expense for mat service can imply a reduction of the total cleaning expenses.

Mat and linen service is often part of a total cleaning contract. It is an activity which demands special washing and cleaning machinery, hence it is most often done externally. It is also an activity which implies a burden to the environment; hence you must ensure that the activity is done in an environmentally safe way.

\section{Service items}

Service items include cleansers and consumption items, i.e. toilet paper, paper towels, plastic bags, hand soap, gravel, salt et cetera. It is important to ensure that the company's environmental policy is met in connection with choice of service items - not just considering the external and overall environmental considerations, but also considering the indoor climate in the building, and also the work environment as to the cleaning staff.

The service items are often delivered as part of a cleaning contract. However, in connection with procurement it must be examined whether there can be a financial advantage if the company itself buys some of the service items.

\subsection{General Operation}

General operation includes those part of the property operation which not naturally are included under maintenance, utilities, cleaning and fixed property expenses. DFM-benchmarking divides general operation in the following areas:

- Caretaking, monitoring and supervision

- Movables insurance

- External consultants

- Management and administration

In figure 6.12 is shown the spread of the expenses for general operation per $\mathrm{m}^{2} \mathrm{BDA}$ for owned properties in 1998. As it appears, the costs for management and administration and caretaking, monitoring and supervision are quite dominating expenses with $49 \%$ and $39 \%$ respectively, whereas expenses for external consultants amount $11 \%$ and movables insurance only $1 \%$.

Figure 6.12

General operation expenses for owned properties in 1998

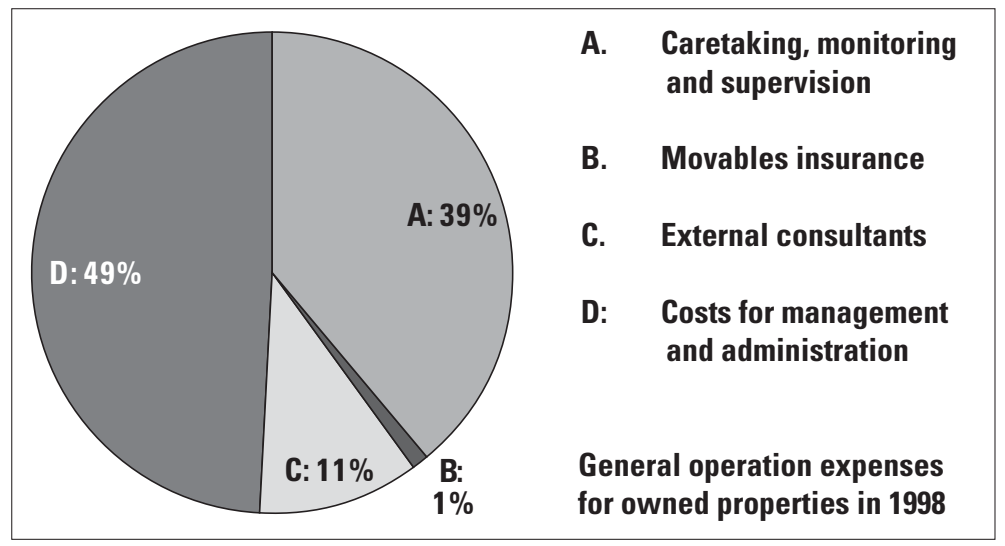

Caretaking, monitoring and supervision Caretaking are simple activities, often maintenance related, which are carried out immediately, for instance adjustment, greasing and cleaning, and which must ensure that the use of the building is not harmed more than wear and age.

Monitoring are activities, which aim at adaptation of the supply of for instance heating, ventilation and cooling for various needs.

Supervision are activities, which consist of ensuring that the normal situation is maintained, and to observe and react of deviations, for instance by means of Building Management Systems and alarm signals.

DFM-benchmarking divides expenses for caretaking, monitoring and supervision in wages for the operational staff, materials, tools and machinery costs, and also service subscriptions.
Environmental considerations 


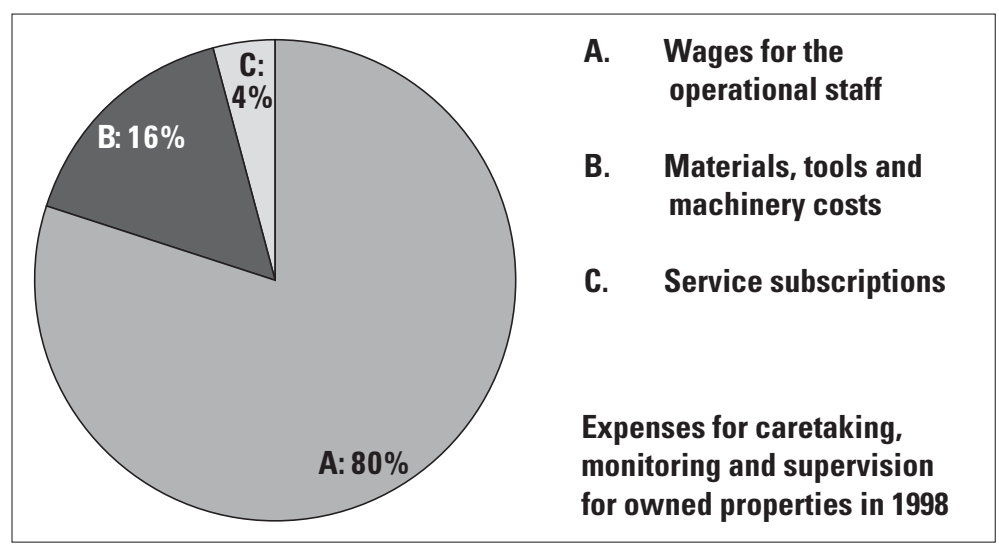

Figure 6.13

Expenses for caretaking, monitoring and supervision for owned properties in 1998

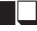

The complexity of the building

Helpdesk
In figure 6.13 is shown the spread of the expenses for caretaking, monitoring and supervision per $\mathrm{m}^{2}$ BDA of owned properties in 1998. As it appears wages for the operational staff are dominating with $80 \%$, whereas expenses for materials, tools and machinery costs amount $16 \%$, and service subscriptions only $4 \%$.

The expenses for caretaking, monitoring and supervision to a great extent depend on the technical complexity of the building, including the security level so that supplies are constant, and the vulnerability for water damages et cetera. The weekly service time of the building is furthermore of significance.

In relation with the operational function, which handles caretaking, monitoring and supervision, there normally is a helpdesk, which receive and delegate error messages and complaints from the users. During unmanned periods there must be a call system of forwarding alarms to employees, who are on stand by, or to external companies with 24 hours service desks.

\section{Movables insurance}

The movables insurance includes insurance against fire and possible theft of non-fixed furniture and equipment in the building. The movables insurance is often part of a total property insurance, cf. section 6.5. See also section 4.8 about risk management and checklist 4.C about insurance.

\section{External consultants}

External consultants typically include consulting architects and engineers and management consultants who assist the company in for instance the following operational tasks:

- Preparation of policies and strategies for the property operation

- Condition reports and preparation of maintenance plans
- Planning, procurement and supervision of maintenance projects

- Environment and energy management

- Procurement of cleaning and possible other operational tasks

It must be noticed that expenses for external consultants in relation to building projects must not be included as operational costs, but as building investments.

The expenses for external consultants are related to the size of the company's internal staff and technicians. The need of external consultants is furthermore depending on the technical complexity of the building.

It is often appropriate to use external consultants who know the buildings and the company. To achieve competition for the consulting, one can invite for tenders, but in connection with the operational tasks each task is rarely of a size, which makes this appropriate. In stead of that, the consultant tasks can be provided in accordence with frame agreements for the continuing operational consulting tasks within a certain professional area for a short number of years, typically 3-5 years. In such cases the competition must be related to the professional qualifications, but a price element can also be included in the competition in the shape of overhead payment in relation to the invoiced hourly wages, or fixed hourly wages to certain employees and/ or categories of employees.

\section{Management and administration}

Expenses for management and administration include in correspondence with DFM-benchmarking wages, office expenses, travel expenses et cetera, but not rent.

Management and administration includes the staff who for instance handles the following tasks:

- Management, organising and financial management of the property operation, $\mathrm{cf}$. chapters 2 and 3

- Strategic planning in relation with operational conditions, cf. chapter 4

- Space Management in relation with operational conditions, cf. chapter 5

- Operation of IT systems such as CAFM and maintenance systems, cf. chapter 8

- Environment and energy management, cf. chapter 9

- Work management of operational staff 
- Financial functions in relation with property operational expenses

- Management of contracts, guarantees and various property related documents

- Archive functions in relation with the property operation

- The tasks mentioned in the section about external consultants, excluded those which are not handled by external consultants

It must be noticed that expenses for management and administration in relation to building projects must not be included as an operational expense, but as a building investments. If the responsibility of property operation and building investments is handled by the same organisational unit it can, for instance in relation to key indicators, be necessary to make an estimated distribution of expenses for management and administration on building projects and on property operation.

The amount of management and administration highly depends on how much of the property operation is handled internally and externally. Besides the obvious correlation with the size of the property portfolio, the distribution of the portfolio on many properties and leases will imply an increased need of management and administration. The complexity of the building and their age is also important.

No matter if the entire property operation is outsourced, there will be a need for a certain internal management and administration to ensure the quality of the provided services and to handle contract administration and settlements in relation to external providers.

\subsection{Fixed Property Expenses}

Fixed property expenses include costs that are independent of the operation and mainly consist of mandatory expenses. These expenses must be paid no matter whether the property is in active operation or is vacant. Hence we speak of a kind of "idle expenses".

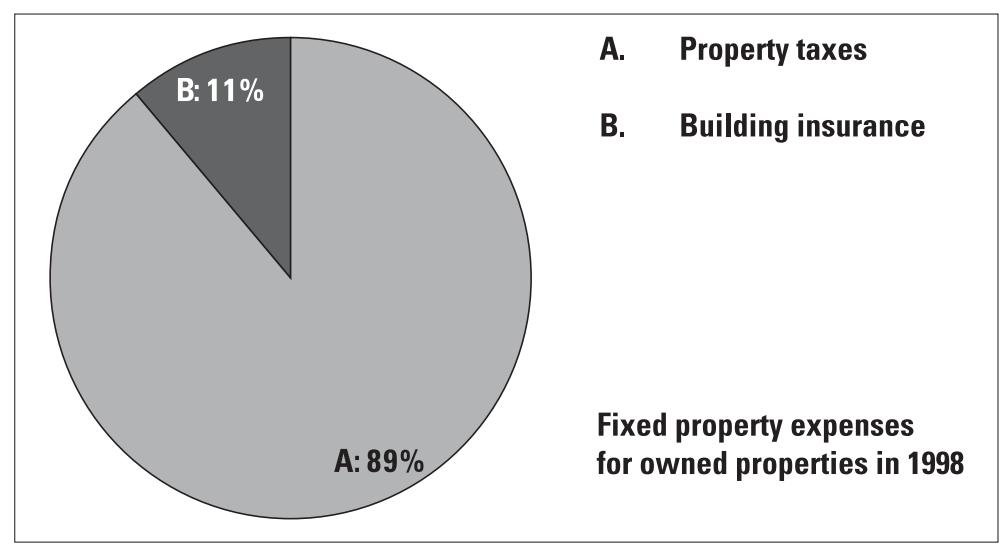

DFM-benchmarking divides fixed property expenses into property taxes and building insurance. Fixed property expenses also include capital expenses, i.e. expenses for company and depreciation of property investments and also lease expenses, but it must be noticed that DFM-benchmarking does not include these expenses in key indicators calculations.

In figure 6.14 is shown the spread of fixed property expenses per $\mathrm{m}^{2}$ BDA for owned properties in 1998. As it appears property taxes are dominating with $89 \%$, whereas building insurance amounts $11 \%$.

Figure 6.14

Fixed property expenses for owned properties in 1998

\section{Property taxes}

Property taxes in Denmark are determined on the basis of the public assessment of real property. By experience it can be financially lucrative to make complaints about the real property assessment, if it is not found fair.

It is furthermore to existing property difficult to change the size of this category of expenses, but at acquisition of ground or property it is of course an expense, which must be included in a total financial evaluation.

\section{Building insurance}

Building insurance includes mandatory building fire insurance in relation with private companies. To companies with several properties it is often profitable to make a total insurance for all properties, and it can also be profitable to invite tenders in relation with the company's various insurances. See section 4.8 about risk management and checklist 4.C about insurance. 


\section{References}

Literature

$\underline{B P S}$ : Vedligehold af ejendomme - fælles orden. (Maintenance of properties - common order). BPS Publication 66, May 1988a.

BPS: Fælles principper for vedligehold af ejendomme. (Common principles of maintenance of properties). BPS Publication 67, May 1988b.

Danish Standard: Anvisning for indvendig rengøring og vedligehold. (Directions for internal cleaning and maintenance). DS Information. 1999.

DFM: Nøgletal for ejendomsdrift til brug for Benchmarking. (Key indicators for property operation for the use of benchmarking). Copenhagen, 1995.

DFM-benchmarking: Vejledning til spørgeskema - Nøgletal for ejendomsdrift og services. (Guidance to questionnaire - Key indicators for property operation and services). $2^{\text {nd }}$ edition 1998.

Bernard Williams Associates: Facilities Economics. Building Economics Bureau Limited. Kent, revision 1, 1996.

\section{Websites}

DDV (The Danish Maintenance Association)

www.ddv.org

DFM.

www.dfm-net.dk

DFM-benchmarking

www.dfm-key.dk

The Association of Energy and Environment.

www.ffem.dk 


\section{Services}

\section{Figures}

7.1 Expenses per employee on five categories of services in owned properties

7.2 Expenses per employee for guarding and security in owned properties . . . . . .143

7.3 Expenses per employee for reception and telephone exchange in owned properties

7.4 Expenses per employee for post service in owned properties.

7.5 Expenses per employee for catering in owned properties
Guarding and Security

Reception and Telephone Exchange. 143

Post Service 144

Data Infrastructure 146

Catering . . 146

Other Services

Administrative support.

Procurement and storage.

Transportation service

Staff support.

References. 151 
In this chapter Services are discussed. Services in this context cover internal company services, which are not part of the property operation, cf. chapter 6. The basis is taken in DFM-

benchmarking's division of services:

- Guarding and security

- Reception and telephone exchange

- Post service

- Data infrastructure

- Catering

In figure 7.1 is shown the spread of the expenses per employee on the five categories in owned properties as an average of the expenses in each of the years 1995 to 1998, indexed to

Figure 7.1

Expenses per employee on five categories of services in owned properties the same price level. As it appears, the expenses for catering service make the largest percentage with $37 \%$, whereas the remaining four categories of services amount from 13 to $19 \%$ of the total expenses for the five categories.

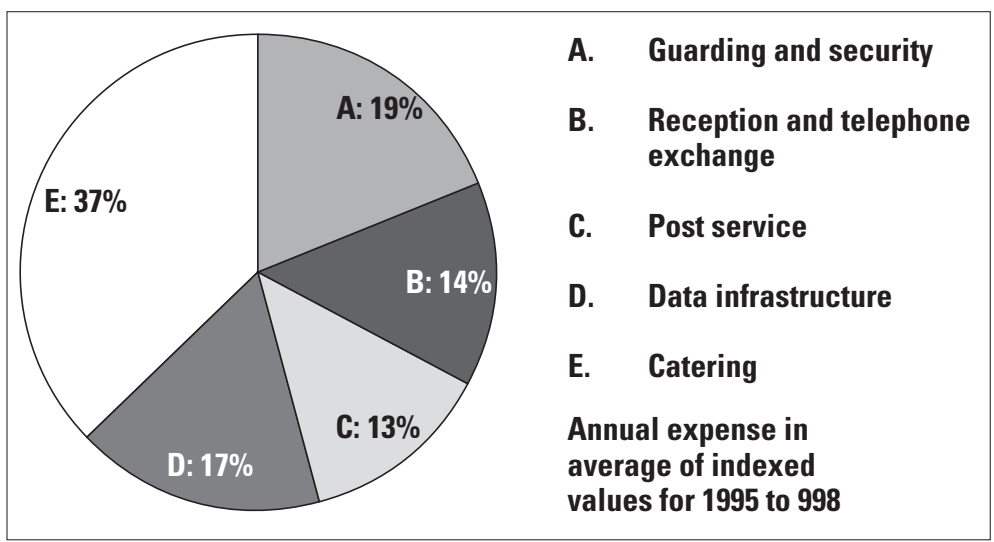

The five categories of services are separately discussed in section 7.1 to 7.5. The typical contents in each category will be described and DFM-benhemarking's specification of the expenses over years to each category will be presented. The most important factors of importance to quality and expense level will furthermore be mentioned as well as the circumstances of importance to the handling of the activity inhouse or externally will also be shown.

Finally other categories of services are mentioned in section 7.6 with emphasis of what each category includes, in what kind of companies the various categories are important, and in which way each service is typically organised in relation to other FM functions and in relation to in-house or external handling.

The chapter is finished with references.

\subsection{Guarding and Security}

Guarding and security can be considered as two different services, as guarding primarily consists of guarding inspection rounds in properties after normal work hours, whereas security primarily concerns administration and supervision of technical security precautions, including controlled access with attached administration of keys and/or identity cards.

Guarding and security are on the other hand closely connected. At first they serve the same primary purpose: to secure the property, partly against unintended person admittance, including theft and industrial espionage, partly against other damage of the property and the valuables in the property - subsidiary to limit the consequences of such incidents. Secondly are both guarding inspection rounds and technical security precautions on the communicational level linked to a shared day and night staffed security centre which can provide the necessary backup.

Besides the primary goal, guarding inspection rounds also serve a general supervision of the property, for instance in relation to limit unnecessary energy consumption by ensuring that light, business machines and coffee machines are turned off, and that doors and windows are closed. Guarding inspection rounds can furthermore be used to record errors, for instance doors and windows with functional failures, lamps without light and leakages of water and drain systems et cetera. In reporting undesirable circumstances the guarding staff's records can be used to educate the ordinary staff to show responsibility to the company's assets.

Guarding and security is furthermore often connected with reception service, cf. section 7.2. During usual working hours the admittance control is typically handled by the reception staff. This especially concerns visitors to the company, as the staffs have admittance possibilities by the use of a identity cards without personal control. After normal working hours the guarding staff handles the reception function in some companies.

In figure 7.2 are shown the expenses for guarding and security in owned properties in the period 1995 to 1998. As it appears, the expenses are steadily approx. 2.000 DKK per employee (price level 1998). It is assumed that guarding 


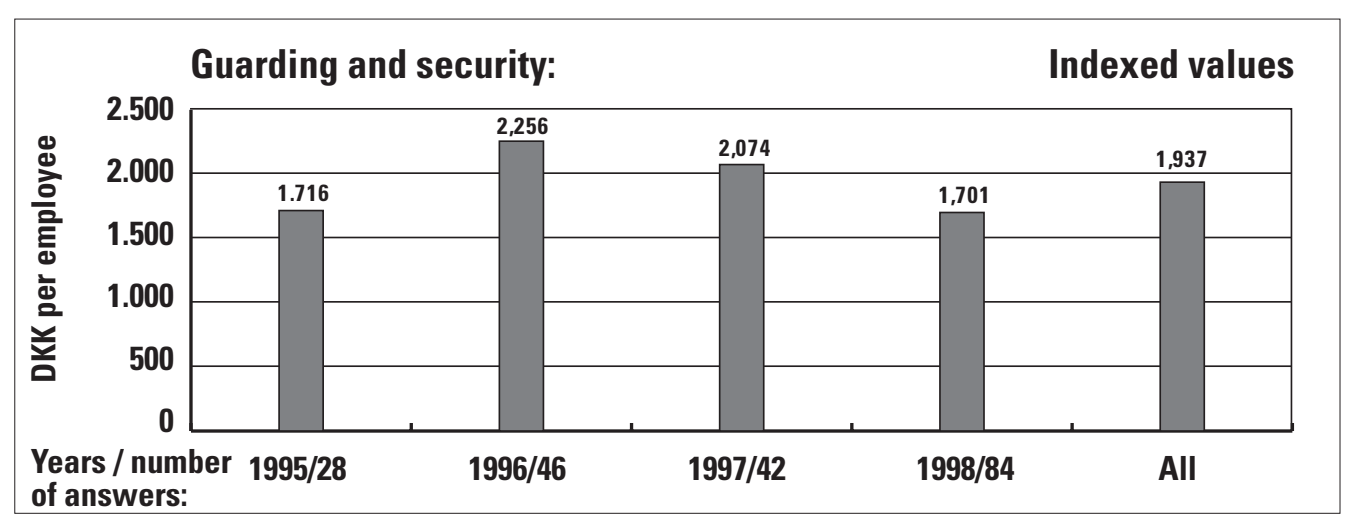

inspections rounds is the major operational expense, as it is manpower intensive work outside normal working hours. On the other hand security systems typically involve larger capital investments and maintenance expenses.

Determination of quality and service level to guarding and security must be based on a risk analysis of the company, cf. section 4.8 about risk management. It must for instance include estimations of the company's vulnerability and the probability to burglary and vandalism, for instance in relation to the social strain from the local area. Guarding and security are means to prevent and limit damages, and such security expenses must also be seen in connection with the expenses for insurance, and to which extent an insurance coverage can compensate to the possible damaging effects.

Guarding inspection rounds and all day staffed security centre are in most cases handled externally as a service subscription with a professional security company. This is caused by the fact that there is need of staff with a special education and selected from particular personal qualities in relation to the special kind of work. The possibility of finding substitutes in case of sickness and other absence, and the need of backup also suggest the use of an external company with a larger crew within this special field.

To security it is common that administration of keys and/or identity cards is handled internally. Concurrently with the increased focus on risk management and introduction of electronic access control systems there has been a change, as the internal security function primarily was a technical craftsman related function, for instance with change of lock cylinders, whereas it is now a more administrative PC based function with issue of identity cards. The organisational relationship has also changed increasingly from the property operation and the company's lock system towards the company's staff administra- tion, as the identity cards must be issued at new appointments and suspended when the employees leave the company.

During the present years there is a strong technological development in relation to electronic security systems, including distant surveillance systems with cameras and TV monitors, and these systems are increasingly becoming an integrated part of building automation systems, cf. chapter 8. Using this kind of systems it is possible to centralise guarding and security with succeeding reduction of the labour force.

Especially in connection with new building it is important to evaluate, whether one by means of electronic security systems can achieve a security level, which can eliminate or significantly reduce guarding inspection rounds. In such considerations consultants with a special knowledge about security should be included. If it is possible to reduce guarding inspections rounds significantly, the succeeding savings will in a few years compensate for the necessary investments in such technical security systems.

\subsection{Reception and Telephone Exchange}

Reception and telephone exchange can like guarding and security be considered as two different services.

Reception mainly consists of receiving visitors for the company, and to assist the visitors to make contacts with the right person in the company, or in some way or another assist in connection with the visitor's business, for instance delivery of goods or post. The reception function can furthermore, as mentioned in section 7.1, also serve as admittance control to avoid unintended admittance. Finally the reception can handle services to the company's staff, for instance receiving and handling express post, goods and messages.
Figure 7.2

Expenses per employee for guarding and security in owned properties

Risk analysis

Security company

Access control systems 
Image

Opening hours

Figure 7.3

Expenses per employee for reception and telephone exchange in owned properties
Telephone exchange consists of telephone operation from persons who contact the company by telephone, including to forward calls to the right person in the company, but telephone operation can also consist of receiving and handling messages in the employees' absence, and answering some types of inquiries.

On the other hand reception and telephone exchange are closely connected. At first they serve the same primary purpose: to serve the company's customers or others, who wish to contact the company as such, or specific persons in the company. Secondly, reception and telephone exchange are often handled - especially in smaller companies - by the same employees, and the telephone exchange function is often physically located in the company's reception.

Employees in the reception and the telephone exchange often furthermore handle other service functions, in which communication is an important element. This typically concerns administration of meeting rooms and ordering of taxies and other kinds of transportation. The reception and the telephone exchange can furthermore act as helpdesk to error complaints in relation to the property.

In figure 7.3 are shown the expenses for reception and telephone change in owned properties in the period 1995 to 1998 . As it appears, the expenses on average amount 1400 DKK per employee (price level 1998), but with a rather decreasing tendency, and this is probably caused by the fact that the need of telephone exchange has been heavily reduced, partly due to more sophisticated telephone systems with an increased use of direct telephone numbers, increased use of automatic answer phones and automatic forward, partly the explosion in the use of e-mails among companies. As a consequence of this development it has been appropriate in many companies to unite reception and telephone exchange within the same function.
However, particular in the service industry there has been a strong development to centralise the telephone exchange to national or international call centre.

The spread of the expenses for reception and telephone exchange depend on the type of company, but even if the telephone exchange expenses are decreasing, they are probably still in most cases higher than the reception expenses.

Compared to other services it is common for reception and telephone exchange that these services are both extrovert and introvert, and they are not just services. Hence, reception and telephone exchange are important parts of the company's public "face" and "voice". By determination of quality and service level the company's image and service must be considered. Due to this reception and telephone exchange is many companies is a function, which is handled in-house by own employees. In service companies with central call centre there probably is a higher degree of outsourcing.

Furthermore the expenses for reception highly depend on whether the company has only one public entrance, or whether there are more receptions. The company's opening hours for visitors and telephone calls are important to the expenses for reception and telephone exchange. The expenses to telephone exchange are highly dependent on the company's telecommunication technology, cf. chapter 8 .

\subsection{Post Service}

Post service includes the following main tasks:

- Receiving, sorting and distribution of incoming external post

- Collecting, sorting and distribution of internal post

- Stamping and sending of outgoing external post

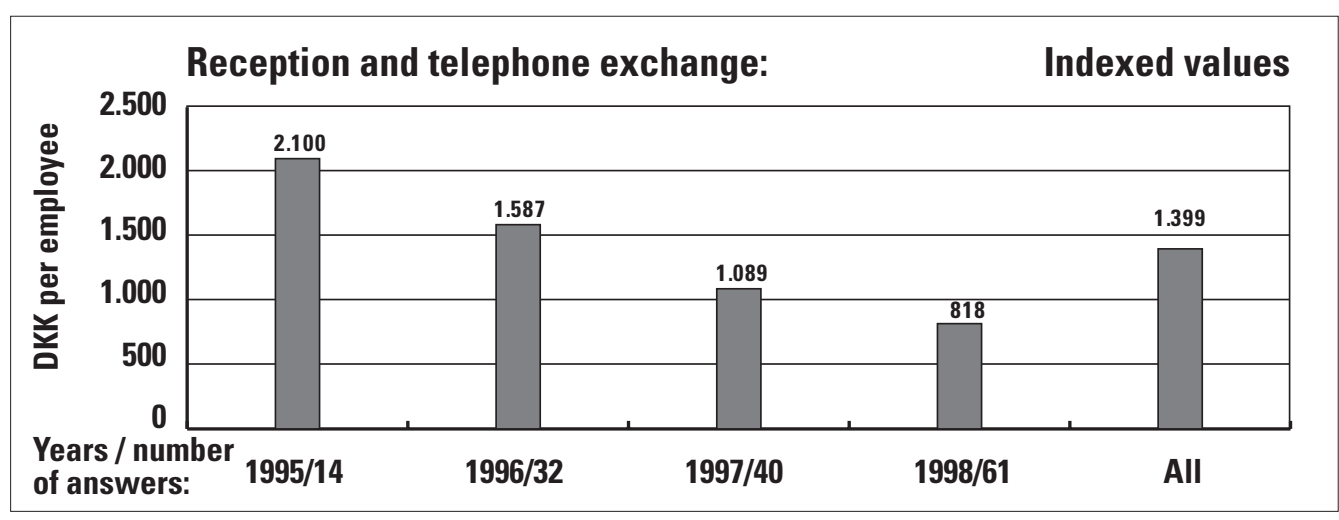




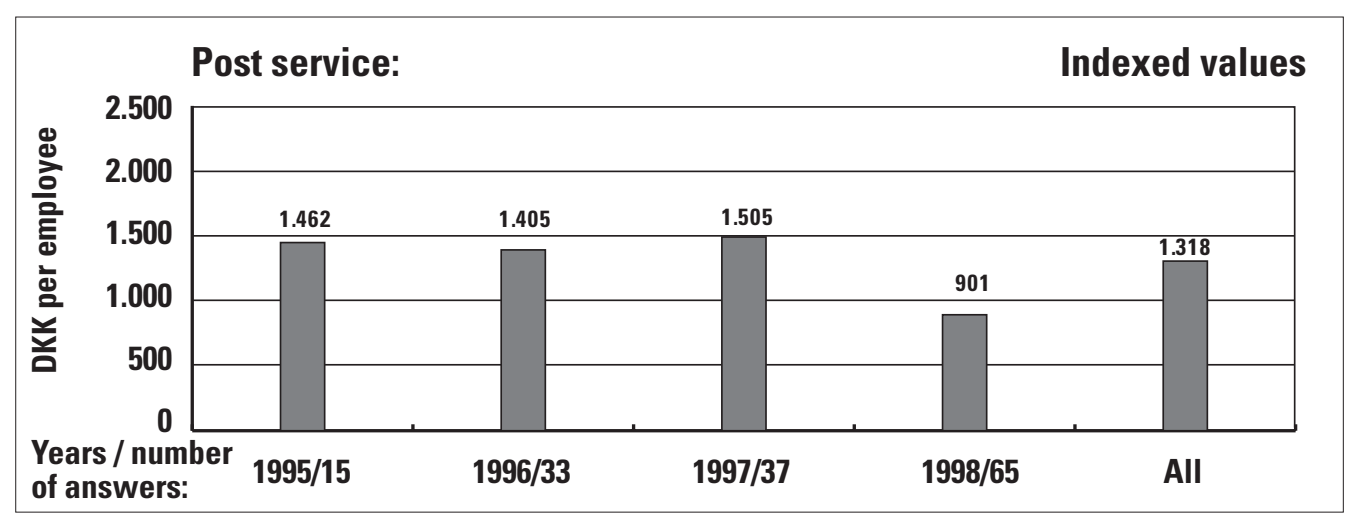

Figure 7.4

Expenses per

employee for post ser-

vice in owned proper-

ties

As to the treatment of the incoming post, there can be made a central opening and journalisation of the post. By the strong development in electronic document management this function increasingly includes scanning and electronic distribution of incoming post instead of physical post distribution. This to a great extent depends on the type and size of the company.

The internal post can also include handling of prints and internal distribution of letters for instance pay slips for the staff.

The outgoing post can also include mass distribution of letters, for instance information to customers. There can furthermore be included special tasks in the post handling in connection with customs declaration of foreign shipments, packaging of parcels, expedition of valuable shipments and express shipments et cetera.

In figure 7.4 is shown the expenses for post service in owned properties in the period 1995 to 1998. As it appears the expenses amount approx. 1.500 DKK per employee except from a decrease to approx. 900 DKK in 1998 (price level 1998). If this expresses a tendency or an accidental fluctuation of the data basis is not known. Nevertheless there is expected a certain decrease of the expenses due to an increased competition at external post due to liberalisation of former monopolies, and an increased use of electronic mail.

Post service is physically centered in a post room, which must be located strategic in the building with good transport roads, both externally and internally. From outside there must be easy access to post transports - both to the post services, various parcel post cars, bike postmen and to the company's own cars. From inside it must be easy to distribute the post with roller cars or battery driven cars, both horizontally and vertically, unless it is a building which has a paternoster system for post distribution and post collection (post lifts).

The central post room must be designed with good facilities to make reloading and sorting of the post and other post handling. Depending on the size of the company and the spread in various properties, it can be necessary to have decentral post rooms for further sorting and further distribution of the post.

The internal collection and distribution of post is typically organised as a number of daily rounds. Determination of the number of such rounds is a crucial factor in relation to quality and service level. It is also important, whether the post must be distributed to departments or to each employee. In buildings with paternoster systems the post distribution is not based on rounds, but is instead done continuously after needs, assuming that the post room is staffed continuously during working hours.

Post service is a manpower intensive area, and the expenses are highly depending on the wage level. It is to a great extent routine work, which does not imply a specific education. This applies especially sorting and internal distribution of post. And it is work tasks which in many companies are often handled by juveniles, who seldom stay long in the job.

Post service also assumes a very responsible and conscientious management, as many shipments can be critical to the company, as also handling of valuable shipments and stamping are confidential tasks. It also implies good managerial skills to make often changing young workers deliver good service efforts to the remaining part of the employees in the company.

The financial pressure to use young rather lowpaid employees to work where they move a lot around internally in the company, emphasise the importance of a responsible and highly company
Post rounds

Central post room 
loyal daily management for security reasons. Hence post service is a task, which many companies prefer handled in-house by own employees.

\subsection{Data Infrastructure}

Data infrastructure is a service field, which is difficult to define and limit precisely in a general way, partly because the technological development continuously change the preconditions, partly because the structure of the entire IT system varies for each company.

When DFM defined the overall structure for key indicators in the first half of the 1990'ies, the most used technology was central EDP systems (main-frames), and networks based on Ethernet, which is a powerful multi wire cable, which typically is led in facade tracks in all storeys in office buildings. Sockets for new computers and printers et cetera can be attached to the cable after needs, and by relocation of employees there must be made a re-attachment in a central main distributing frame, as access privileges for central applications are managed in relation to the socket number, to which each employee's computer is connected.

Compared to the above mentioned IT system, data infrastructure as a service is relatively well defined, as being the work with adaptation of new plugs and re-attachment in connection with the employees' location in relation to attachment to the socket. So the work with data infrastructure is correlated to the work with telephone service, where new sockets also must be established after needs, and where the staffs' local number is adapted in relation to the socket number.

Such an IT system structure is seldom used today, where it is more common to use clientserver systems with a combination of central IT systems and network servers, and networks based on PDS cables, which implies a separate copper cable from a local distributing frame to each computer and printer et cetera. The system is also able to identify each user from user ID and password, no matter which computer is used. In this case it is not necessary to make a re-attachment at relocation of employees.

However, establishment of new sockets is more difficult at PDS cable if there is not from the very start established enough extra sockets for adaptation to future requirements. PDS sockets can also be used for telephone connections, which increase the need of adaptation to future requirements.

In connection with the last mentioned IT system structure, the work with data infrastructure is difficult to define and limit, except from the establishment phase. The primary functions are attached to operation and maintenance of network servers, which more resembles the work with operation and maintenance of central IT systems. It probably to a greater extent will be the case in the future as wireless IT networks is becoming increasingly widespread.

The term data infrastructure as a service field is hence so uncertain that it hardly fit into estimation of general key indicators. It has more sense to look at IT service in connection with the company's total IT expenses. We refer to this in chapter 8 , in which IT and telecommunication is particularly discussed.

\subsection{Catering}

Catering in relation to FM first and foremost includes cooking and delivery of food and beverages to the employees in canteens during lunch breaks. In some types of companies the canteen can have longer opening hours and a wider selection of services in the shape of breakfast and dinner et cetera, and also guest service and service in meeting rooms can be a part of catering.

Catering service is special in relation to other services as individual user payment is charged from each employee to cover part of or all the expenses. Usually only a part of the expenses are covered, for instance only the direct expenses for raw materials or to raw materials and wages. Normally the company place kitchen facilities at disposal, without cost of space being part of the staff's payment.

So catering service can be considered a staff benefit and the company has possibilities to make this staff benefit more or less attractive by using a larger or smaller degree of subsidies. To public companies in Denmark there are limitations to this and to private companies the tax regulations also limit it. See also the discussion in section 2.4 about catering in relation with value creation in the company. 


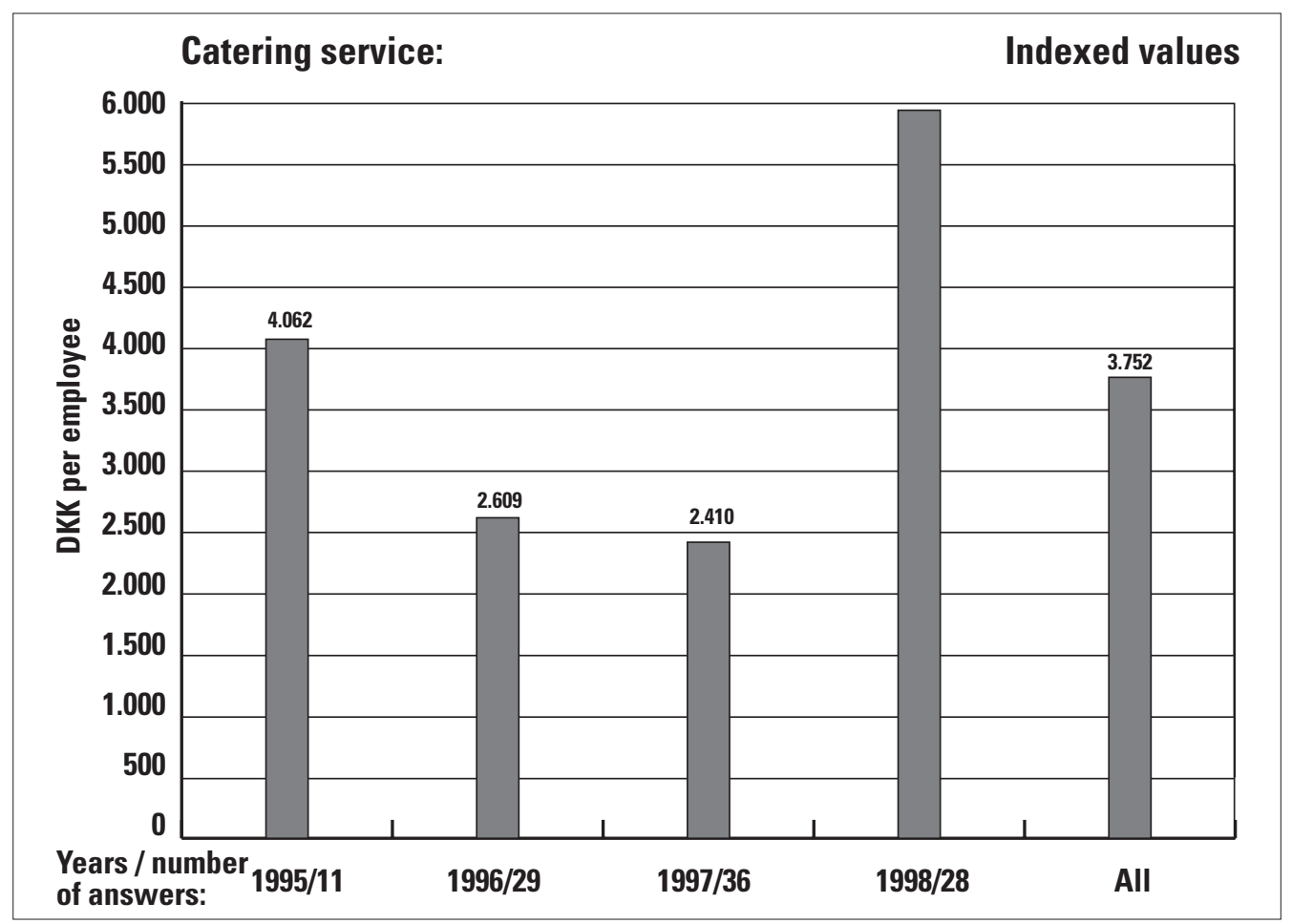

Figure 7.5

Expenses per employee for catering in owned properties

A work group in DFM-benchmarking has estimated that key indicators for catering service must be based on operational expenses exclusive subsidies and rent and only canteens with staffing and serving at least 100 employees can be included in the estimations of key indicators.

In figure 7.5 are shown the expenses for catering service in owned properties in the period 1995 to 1998. As it appears the expenses varies a lot from each year with an average of approx. 3.750 DKK per employee (price level 1998).

Quality and service level for canteens to a wide extent concerns the selection of food, including whether it must be both cold and hot kitchen. The opening hours of the canteen are also an important factor to the service level.

The expenses are naturally connected with the quality and service level, but the customer base, i.e. the number of employees, is also of importance to the cost per employee.

In smaller companies the catering service is often handled in-house by a part time employee. In larger companies it is now common to use external providers of catering service. Buying of raw materials makes a major part of the expenses at canteen operation, and specialised catering companies have the possibility to make procurement agreements of major amount of raw materials and thereby obtain economies of scale. Specialised catering companies have fur- thermore better possibilities to implement systematic staff and product development.

\subsection{Other Services}

In this section a number of various internal services will be discussed. Term, organisation and the importance of these services may vary from each company. The following grouping will be used:

- Administrative support

- Procurement and storage

- Transportation service

- Staff support

These four groups of services are discussed in each of the following sub-sections. The focus will be what each category typically includes, what types of companies of various categories has special importance, and in what way each service is typically organised in relation to other FM functions and in relation to in-house or external handling.

\section{Administrative support}

The most important and most general administrative support functions are IT and telecommunication support. Data infrastructure which is discussed in section 7.4 makes a part of it, but it is a wide area which also includes for instance supply of computers, printers, fixed network telephones, cell phones and faxes, acquisition and installation of software, and 


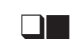

Archive service

Copying service

Printer service
Prictis

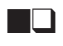

Meeting room service

Procurement

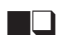

Library service hardware and software support. These services can relate to workplaces in the company's premises, home workplaces and virtual workplaces, cf. section 5.3.

These functions are often placed as a part of the company's IT department with a network of contacts (IT representatives/super users) in the various user departments. Computers are to an increasingly extent leased, and it is not unusual that the operation of central IT systems and networks are outsourced. However it is in most cases appropriate to keep the most user orientated support functions in-house. We furthermore refer to chapter 8 about IT and telecommunication technology.

Another much used support function is copying service, which partly can include servicing of de-central, user operated copying machines, partly central, staffed copying centre. In companies with publication of many leaflets this service function can also include printing works with offset printing et cetera, whereas it in consulting engineer companies et cetera may include collotyping, printing, scanning and folding of drafts in large sizes.

The fast technological development which for instance implies that copying machines, printers, fax machines and scanners now often are integrated, contributes to the fact, that it can be profitable to lease copying and printing machines with matching external servicing.

A third administrative support function includes administration of shared meeting, education and conference rooms. In the scale that such functions primarily correlate to booking, they can be integrated in reception and telephone exchange functions as mentioned in section 8.3, but they can also be placed in secretary functions de-centrally in the organisation. If it concerns a more comprehensive service with special set-up, serving and/or operator assistance, it is most appropriate to place such a service in connection with a general FM helpdesk. In all cases they are support functions which are often so integrated in the company's organisation, that it is most appropriate to handle it internally.

A fourth administrative support function is library service which is especially relevant in knowledge heavy companies. In some cases, such functions are de-central placed and are handled as a part of other administrative work.
In other cases it concerns central functions staffed with librarians et cetera to maintain the collection and serve the public. Concurrently with the IT development information search is increasingly made from data banks, and so library service have mostly become support through IT based information collection.

A fifth administrative support function is journalising and filing. This function is especially important within the public area, where there are demands of a public administration, and where some archive materials in Denmark after a number of years must be handed over to the National Archive. So this is an area, which in the public area is under fixed regulations.

In private companies there are not the same formalised regulations for journalising and filing except from the accounts area, but considerations to companies' responsibility implies a similar need of journalising and filing of important documents. Journalising and filing are functions which are close connected to the company's administrative procedures, so it is normally handled in-house except from possible remote filing and transfer to compact media such as microfilm. This area is also heavily influences by the IT development and electronic document management. Special software systems for journalising and filing have been implemented in many companies.

\section{Procurement and storage}

In production companies procurement and storing of raw materials and agreements of subdeliveries is usually a part of the company's core function and often placed in a special procurement or logistics department. In the context of FM procurement and storage is primarily related to the company's administrative functions.

In minor companies such tasks can be a part task for an administrative employee, who maintain a minor store, primarily consisting of office supplies, and who see to necessary acquirements for supplying the store and possible furniture et cetera.

In major companies there is on the other hand often a function with several employees, who for instance work with the following:

- Procurement of various articles and services

- Goods reception

- Central store function

- Preparation and updating of various product catalogues 
- Internal commercial counselling, for instance in connection with EU procurements for public organisations

- Preparation and entering commercial contracts and agreements

- In addition to central store functions there can in large and geographically spread companies be local buffer stores of office supply et cetera.

In major companies procurement and administration of furniture and equipment often is a special area, which can be connected with furniture maintenance. The attached services to this can typically include the following:

- Procurement of new furniture and equipment

- Consulting about furniture and equipment

- Preparation of furniture and equipment catalogue and guidances

- Administration of store for furniture and equipment spare parts and reusable furniture and equipment

- Scrapping/sales of used furniture and equipment

In connection with scrapping/sales of used furniture and equipment there may also be scrapping/sales of various technical equipment, for instance computers, printers, copying machines et cetera.

Procurement and storage are in most company handled internally, but there are clear tendencies of cutting down on the central procurement and store functions. Implementation of IT based procurement systems has supported this development, so that procurement more and more is done de-central and on-line. The store function is also more and more handled by providers (producers/wholesalers) with agreements of supply of fewer goods after needs as just-in-time deliveries. Procurement through the internet is growing very fast these years.

As an early example of internet based procurement the Lego Group in Denmark in 2000 announced that they during the next 12 months would cut down on the number of providers of goods and services, which are not included in the production, with $60 \%$ from 10.000 to 4.000 provider companies. This included for instance providers of machinery, office equipment, buildings, maintenance, advertising et cetera. By procurement through an internet based system, Lego expected considerable rationalisations implying large savings.

\section{Transportation service}

Transportation service can imply much, from administration of taxi checks to management of a company's internal vehicle fleet of hundreds of cars, without being companies with transportation as their core function. This naturally entirely depends on the company's needs of transportation. To companies with various addresses, the geographical spread will in itself create a considerable internal need of transportation. Correspondingly, companies with many customer visits, at building sites or elsewhere outside the company's own addresses, will have a large need of transportation.

In companies where primarily single employees must be transported it will often be appropriate, if the employees us their own car with mileage allowance. To salesmen and others with individual needs of transportation a company car may be the right solution. In companies with needs of transportation of equipment or materials at a larger scale, an internal company vehicle fleet of delivery vans or lorries will be relevant.

Management of the company's vehicle fleet implies the following:

- Receive reservations and organise cars short-term and long-term

- Prepare cars, hand over cars and take cars back

- Administration of credit cards for fuel and payment of bridge and ferry toll

- Handle service, garage visits and normal maintenance

- Handle car certificates and the obligations to the authorities

- Handle contact to insurance companies, including handling of damage cases

- Acquisition and sales of cars

Instead of having your own vehicle fleet it is possible to lease the cars. However, this is primarily a financial change, as the company still must handle the main part of the above mentioned tasks.

A major relief can be achieved at a continuous collaboration with a car lease company, but if you can achieve a reasonable coefficient of utilisation of the vehicle fleet, it will normally be cheaper with your own vehicle fleet.

Travel and hotel reservation is a special type of transportation service, which in most companies is handled through a continuous collaboration with a travel agency. In major companies it
Furniture and equipment service

Vehicle service 
Sport

Health and

well-being

Fringe benefits has been common that the travel agency had an office with the company with possibilities for personal service. Internet based travel and hotel reservation has changed the use of travel agencies and made a combination of decentralised in-house handling and use of travel agencies.

Moves are another special kind of transportation service. We refer to a discussion about this in section 5.2 .

\section{Staff support}

Catering can be considered as a staff support, cf. section 7.5. The same goes for company internal sport facilities as for instance exercise rooms, table tennis rooms, billiard rooms, petanque fields, badminton fields and shooting ranges or company subsidies to rent these facilities close to the workplace.

It can be discussed whether health and wellbeing arrangements such as offers to visits from occupational therapists, physiotherapists or reflexologists must be considered being staff support, or as part of ordinary company health and safety efforts.

A much used type of company subsidy to the employees' society activities is subsidy to inter- nal art societies. However, this can be discussed, whether is considered as being staff support, as the activity usually contributes to common artistic decoration of the building, which the company to some extent normally had to fund.

A more direct staff support is company subsidy to establishment of child care centres close to the workplace. Accordingly are subsidies, so that the employees can rent holiday homes at favourable conditions.

The type and amount of staff support depends strongly at the company's culture, and also a certain state of the market conditions. Hence staff support can be an important way of attracting new and sustain existing employees at situations with strain on the labour market. As such periods normally are booms with fine earnings for the companies, there will often be possibilities to allocate money for investments in staff support.

The distinction between fringe benefits and staff support can be difficult to define. Hence the tax authorities' rules are decisive for the type and amount of staff support, if the staff will be subjects to taxation as a fringe benefit. 


\section{References}

\section{Literature}

$\underline{D F M}$ : Nogletal for ejendomsdrift til brug for Benchmarking. (Key indicators for property operation for the use of benchmarking). Copenhagen, 1995.

DFM-benchmarking: Vejledning til spørgeskema - Nøgletal for ejendomsdrift og services.

(Guidance for questionnaire - Key indicators for property operation and services). Second edition, 1998.

Bernard Williams Associates: Facilities Economics. Building Economics Bureau Limited. Kent, revision $1,1996$.

\section{Homepages}

DFM.

www.dfm-net.dk

DFM-benchmarking www.dfm-key.dk 


\begin{tabular}{|c|c|}
\hline \multicolumn{2}{|c|}{ Figures } \\
\hline 8.1 & $\begin{array}{l}\text { The coupling between CAD and } \\
\text { A/N data bases in a CAFM system. . . . 155 }\end{array}$ \\
\hline 8.2 & $\begin{array}{l}\text { Stairway built up by } 4 \text { objects } \\
\text { or } 64 \text { lines } \ldots \ldots \ldots \ldots \ldots \ldots\end{array}$ \\
\hline 8.3 & $\begin{array}{l}\text { Example of digital storey plan for the } \\
\text { use of moving to a new tenancy } \ldots \ldots 160\end{array}$ \\
\hline 8.4 & $\begin{array}{l}\text { Example of a CAFM print for the use } \\
\text { of procurement of cleaning. .........160 }\end{array}$ \\
\hline 8.5 & $\begin{array}{l}\text { Example of a digital storey plan for } \\
\text { the use of internal rent } \ldots \ldots \ldots \ldots 161\end{array}$ \\
\hline 8.6 & $\begin{array}{l}\text { Example of CAFM print for the use } \\
\text { of internal rent. . . . . . . }\end{array}$ \\
\hline 8.7 & The principles of digiral handover . . . . . 162 \\
\hline 8.8 & Building automation system . ........165 \\
\hline \multicolumn{2}{|c|}{ Checklists: } \\
\hline 8.A & Move of IT Equipment . \\
\hline 8.B & Acquisition of a CAFM system . . . . . . . 158 \\
\hline
\end{tabular}

ICT as a Field within FM $\ldots \ldots \ldots \ldots \ldots \ldots 154$

IT based FM Tools.................... 155

CAFM based systems . . . . . . . . . . . . . . . . . . . . . . . . . . . . . . . . . . . . . 155

Digital handover . . . . . . . . . . . . . . . . . . . . . . 161

O\&M systems . . . . . . . . . . . . . . . . . . . . . . . . . . . . . . . . . . . . . 162

Other FM tools. . . . . . . . . . . . . . . . . . . . . 163

Intelligent Buildings................ 164

References...................... 166 
One of the most important technological breakthroughs which we see at present is that the information technology (IT) spreads and increasingly converges with technologies within telecommunication and media. The development of the computer technology for multi media systems with possibilities of playing music from $\mathrm{CD}^{\prime}$ s, mini discs and I-pods, movies from DVD's and to communicate through e-mail, are good examples of this development.

The internet is another significant example of this, where IT networks are connected through telecommunication to a coherent, worldwide data communication network. With on-line news, advertising and streaming of radio and television the media have also become an integrated part of the internet as a communication network. The development of mobile phones with possibilities for text messages (sms), multimedia messages (mms) and link to laptops is a third typical example of the convergence of IT and communication technology.

ICT is as a common joint term for information and communication technology and it will be used as a general term for IT and communication technology in this chapter, and when needed specific technologies will be mentioned with a special term.

As shown in section 1.1 the IT development is one of the most significant factors of importance to the development of FM. This importance is in evidence in various areas and levels. One of these is naturally the changes of office work and other work, which FM must support, cf. the discussion of new ways of working in section 5.3. This chapter will focus on the following three areas, in which the IT development has a great importance to FM:

- ICT as a field within FM

- IT based FM tools

- Intelligent buildings

In FM circles it is much discussed whether or to which extent handling of ICT functions are or ought to be a part of the work area of FM. This question is discussed in section 8.1.

The use of IT based tools is today an irreplaceable part of FM practice. This concerns for instance use of CAFM tools for Space Management et cetera. This is along with other IT based FM tools further discussed in section 8.2 .

A special kind of IT use is intelligent buildings, in which building automation is increasingly built in as a part of the building itself - first and foremost for operation and supervision of the technical systems and installations, but increasingly also into common building sections such as windows and constructions. This development is further discussed in section 8.3.

\subsection{ICT as a Field within FM}

As mentioned in the introduction it is much discussed within FM circles whether or to which extent handling of ICT functions are or ought to be a part of the work area for FM. However, it is common to consider the permanent building parts of the ICT systems as belonging to FM. This mainly includes infrastructure such as cabling and plugs/outlets for connection of computers, printers, telephones, fax machines et cetera in the building. The services connected to this are further discussed in sections 7.4 and 7.6.

Other IT functions which in some cases are handled under FM, are provision and mounting of new computers, printers, permanent telephones, mobile phones and fax machines, acquisition and installation of software and hardware and software support. These services can both include workplaces within the company premises, teleworkplaces and virtual workplaces, $\mathrm{cf}$. section 6.4.1. In other cases these functions are a part of the company's IT department, which also handles the operation of central IT systems. However, there has been a strong tendency to outsource the operation of the company's central IT system. Among IT providers they speak of IT FM in relation to outsourcing the operation of IT systems. Correspondingly there is an increasingly tendency to lease computers and other IT equipment.

In the childhood of the computer age data processing was normally made by special electronic data processing bureaus or centre, as the investments - not at the least for hardware were too high to each user company. There is apparently at present a similar tendency, but now in relation to software, so that the companies pay according to the use of software from an IT provider, a so-called Application Service 
Provider (ASP). The ASP has the software installed on central servers and manages the operation, support and development of the systems as well as education of the users, who can be located in the user company or in the ASP.

With ASP the user companies does not have to pay for a large number of software licenses of which some are only used minimally. The company does not need to have specialised employees to supervise and further develop the systems, just as the responsibility that the system at any time function is with the IT company. With the increasing speed of change in many companies these considerations are becoming more and more important.

A special kind of service in relation to IT is moving of the equipment. In relation to move of ordinary furniture, archives et cetera, which are discussed in section 5.2, there are special demands related to move of the IT equipment. This is due to the following factors:

- Employees who must be moved cannot do their work from the time when the IT equipment is disconnected until it is reconnected and operating in the new location - the employees may do without some bookcases and moving boxes, if only worktable, office chair and IT equipment is into place and operating.

- The IT equipment is rather expensive and vulnerable; hence it must be packed down and transported with care.

- Parts of the IT equipment demand special qualified staff to manage connection and to ensure that it operates as intended.

In checklist 8 . A is shown a number of items which must be met or considered before, during and after move of IT equipment to a new location.

\subsection{IT based FM Tools}

\section{CAFM based systems}

Of course the development of IT based FM tools has taken place parallel to the general development in the IT area. One of the essential results of this development is CAFM systems (Computer Aided Facilities Management). The spread of such systems is still rather modest in Denmark, which is primarily due to fact that it is most very large and dynamic companies with considerable spaces and frequent organisational changes, which has a need of such systems.

The core in a CAFM system is the coupling of a CAD system with a related CAD data base with drawings and an alpha numeric $(\mathrm{A} / \mathrm{N})$ data base containing various information about the buildings, including not at the least the utilisation of each room on each storey in each building. The coupling between the $\mathrm{CAD}$ system and the $\mathrm{A} / \mathrm{N}$ data base is dynamical; hence changes in drafts will automatically lead to consequence changes in the $\mathrm{A} / \mathrm{N}$ data base, and reverse. This correlation between $\mathrm{CAD}$ data base and $\mathrm{A} / \mathrm{N}$ data base is shown in figure 8.1.

The field of application to CAFM systems is first and foremost Space Management. Before the introduction of CAFM systems, this work had to be done on the basis of paper prints of ordinary architect drafts and various lists of rooms with information of their present utilisation and spaces calculated on the basis of hand measurements on storey plans. At calculation of proposals for churns it was usual practice to draw the changes of the space allocation by hand with different colours at storey plans supplemented by arrows and text to indicate from where to where various units must be moved.

In major companies with many employees it was from approx. 1980 common with computer
$C A D+F M=C A F M$

Space Management

Move of IT

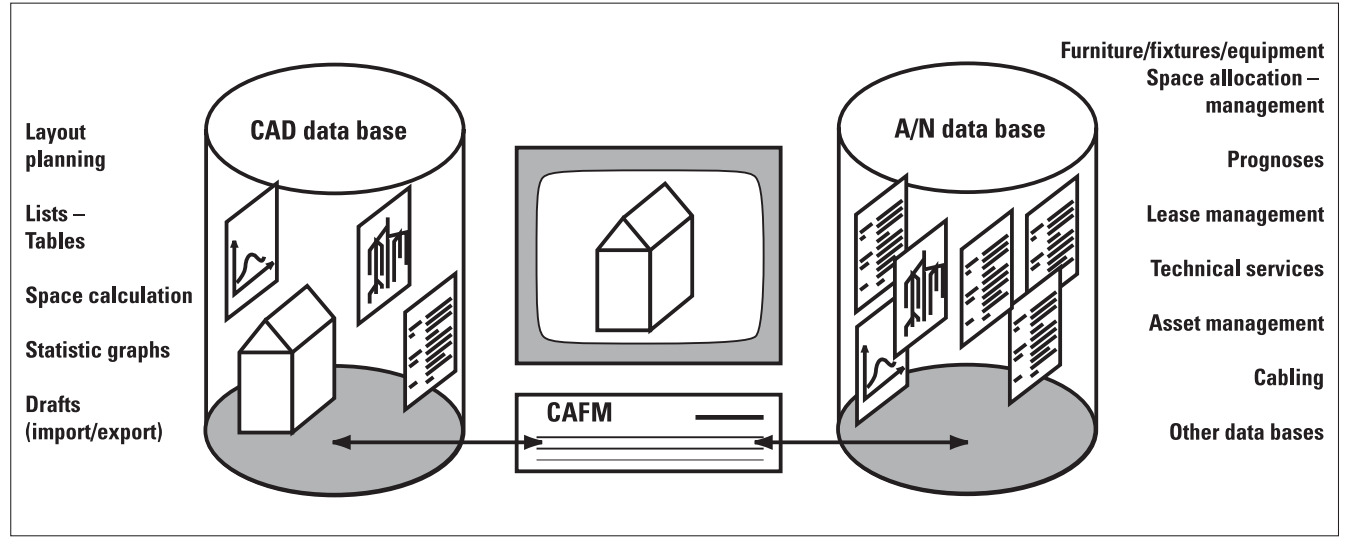

Figure 8.1

The coupling between $C A D$ and $A / N$ data bases in a CAFM system 


\title{
Checklist 8.A: Move of IT Equipment
}

\author{
(source: Partly based on Pathal, 2000)
}

The checklist is based on moves in connection with relocation of the company. At internal moves many of the items of the checklist are also relevant, but some of the items can be ignored.

\section{Before the move}

- Ensure that the space planning includes the necessary space for central IT equipment, including future-proofing

- Ensure establishment of enough routes to and from the central IT equipment and in the premises for all the workplaces and printers et cetera

- Consider type of cabling and location of sockets. Data transmission speed and future connection possibilities depend on this

- Ensure that all external connections are established, i.e. all sorts of telephone and data connections et cetera

- Check with the internet operator that internet connections can function on the new location

- If the company has more locations, check that the changed data connections between the locations are functioning

- Examine if the computers must have changed network cards et cetera

- Plan the move of the equipment, including who attend labelling, separation and later on assembly of equipment, packing away, and later on unpacking, and also the move itself of the equipment

- Arrange with the person in charge of IT and the moving company how the packing away must be done, for instance in moving boxes, wrapped in blankets et cetera

- Ensure that all employees are informed of their tasks in connection with the relocation. Use de-central relocation coordinators and written relocation instructions

- Check that the moving company has a reasonable insurance coverage

\section{The move itself}

- Ensure that everything is labelled

- Ensure that cables and other loose parts are fixed to the equipment

- The physical move is made by professional moving men with experience in relocation of IT equipment

- Move the most important equipment at first, for instance servers and network printers

- Ensure qualified employees to connect and plug in the equipment

- Ensure to have extra extension cords, sockets et cetera so that all equipment can be immediately connected

- Ensure to have IT employees both at the old location and at the new location

- Ensure the presence of or possibility for summon technical experts, for instance in relation to electricity, telephone, the company's central IT systems, internet operator

- After connection of the IT equipment check the most important connections, for instance central systems, printers, e-mail and internet

\section{After the move}

- Ensure that the employees have contacts in case of complaints in connection with move of the IT equipment

- Ensure to have a directory of key persons with responsibility for the various IT and telecommunication connections to be used for follow-up 
based data bases containing the above mentioned information about the space allocation. With the development of CAD systems and the spread in architect practices and in engineering companies during the 1980 'ies it was also common with digital drafts and in the CAD systems space calculations could be made automatically.

At coupling of a CAD system and a room data bank in a CAFM system a very improved system is achieved for the use of Space Management, where updating of the space information are fully optimised. It is also possible to have relevant room information and markings based on the information in the data bank shown on storey plans after needs.

The first CAFM systems were made as supplementary software for specific CAD systems with a matching relation data base. The development has moved towards the CAFM systems becoming open, independent applications based on a relation data base with possibility of coupling of a CAFM system with various CAD systems. The possibilities of coupling and exchange of data with other IT systems has also been enhanced.

Among the advantages at CAFM as a FM tool can be mentioned:

- Overview of the needed information

- The combination of drafts with targeted information and extract of reports gives an optimal overview

- Simulation of churns

- Suggested solutions can quickly be prepared

- Solutions can be evaluated graphically

- Space related consequences are automatically calculated

- Analyses of space allocation

- Status of space per employee can be calculated, for instance per building, per department or per staff category

- At classification of rooms and spaces various key figures can be calculated of space allocation, for instance gross space per employee or office space per workplace

Besides being work tools for FM, CAFM systems are also powerful presentation tools:

- Tool for presentation of draft related information

- Drafts can be formatted according to needs

- Only the necessary information is shown, for instance space information at various levels
- Possibility to use of colours and 3D

- Presentations can be targeted various users

- Can be used to impress management and customers

- Can be made easily understandable to "draft blind" employees

- Can include many and complex information for experts

- Reports can be extracted crosswise and further processed graphically

In checklist 8.B is listed a number of items, which ought to be met or considered before acquisition and at implementation of a CAFM system.

The applications of CAFM are multiple and are expanded concurrently with the systems getting more and more developed with larger possibilities of integration with other IT systems. Most CAFM systems are constructed in modules, so one can acquire the parts of the system, which are needed immediately with possibilities to expand with further modules.

Among the most frequent applications of

CAFM can be mentioned:

- Updating of digital drafts and room information as general data basis

- Space planning (churns, demand analyses, simulation)

- Procurement of cleaning

- Administration of internal rent

- Preparation of design proposals (rebuilding, layout planning et cetera)

- Recording of IT equipment

- Recording of information about building technical systems

- Data base of general property and building information

\section{Digital draft base}

The precondition to achieve the functionality in a CAFM system is, that the drafts are "intelligent", i.e. object oriented. The principle of object orientation is that the CAD system can handle certain elements as identifiable units, and not just as "stupid" lines. This principle is illustrated in figure 8.2, where a stairway is built of four objects in the shape of building parts or by 64 lines. However, in CAFM systems the most important elements are the rooms, and the room number normally makes the unique link between rooms in the $\mathrm{CAD}$ data base and room based information in the $\mathrm{A} / \mathrm{N}$ data base.

In connection with acquisition of a CAFM system you must, as mentioned in checklist 8.B
Acquisition of CAFM

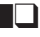

Advantages at $C A F M$

Object orientation 


\section{Checklist 8.B: Acquisition of a CAFM system}

The checklist below is based on own experiences and also various contributions at conferences et cetera.

\section{Before the acquisition}

- Collect experiences from other companies and have relevant providers to demonstrate their products

- Consider whether own competence in the company's FM and IT functions are sufficient, or if impartial consultants should be involved in connection with the acquirement process

- Make a mapping of present procedures and systems, and implement a demand analysis of which functions are important to be handled by a new system

- Decide whether changes must be done of how the company's data are structured, for instance terms for building sections, technical systems, storeys and rooms, and how you want data recorded and maintained

- Estimate what the system must be able to perform from the very start, and what are the long-term needs: Think big, but start in the small

- To have full use-value of data it is the best to start with a few data, which are used optimally and communicated to all partners, than to have many data for only a few

- Clarify which other IT systems in the company with which the CAFM system must be able to communicate

- Decide who must be admitted to the system - as operators and as users

- Decide how drafts and other data can be installed in the system - are they already in a digital form, which makes a direct transfer possible, or must drafts be digitalised if so, by whom and at which price

- Prepare a specification requirement which clearly describe which functions must be fulfilled, and which are desirable, and also demands for data structure, user interface, report generation (standard/user defined), uptimes, response time and expansion possibilities

- Select 3-5 providers to make bids of provision of the system, including software with user adaptations, necessary licenses, possibly special hardware, implementation, function test, possible data input, education and support to the specified extent - on the basis of standard delivery terms for IT and a timetable, if possible with sanctioned deadlines

- After evaluation of the bids with weighing of functionality and economy, a contract is made with the provider, who has given the most beneficial bid

\section{Implementation}

- Only make the necessary data input, which you are prepared to maintain continuously

- Ensure that all relevant employees get the necessary education or introduction to the system

- Ensure thorough education of the operators of the system, so they besides being able to operate the system also have sufficient knowledge to and understanding of the system's structure

- Ensure to have a system administrator, preferably a "fiery soul," with a good IT background, who continuously can supervise the system and make the necessary adaptation and further development of the system

- Ensure continuous support of hardware and software from the IT function and/or provider

- Ensure automatic security backup

- After running-in it can be relevant to make internal marketing of the system, so a wide circle in the company will know the possibilities of the system 


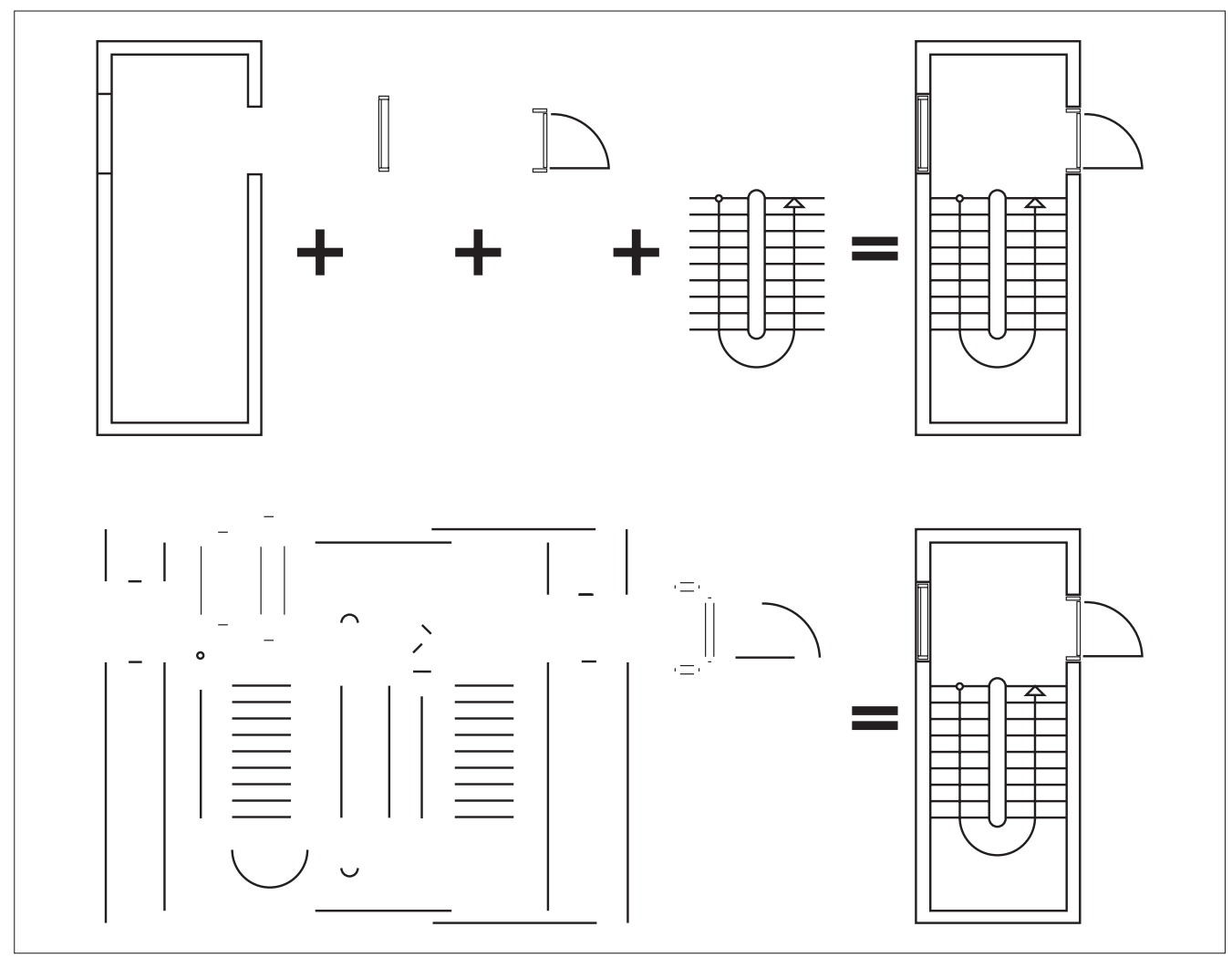

Figure 8.2

Stairway built up by 4

objects or 64 lines

(source: The Danish

Ministry of Housing

and Urban Affairs,

2000)

decide, how to put in drafts and other data to the system. Unless it concerns new buildings there will often not be digital drafts, but only paper drafts from the construction. At first it must be considered whether such paper drafts are sufficient correct to be able to make the basis of digital drafts, or whether the building as a whole must be measured. A few checks of the main measurements of the building compared with the drafts will be able to make basis for such a decision.

There are two methods to produce digital drafts from paper drafts. One method is digitalisation of paper drafts, which is a rather time consuming manual drawing method, but it enables possibilities to make the drawings object oriented in the same process and only to include the necessary information. Another method is scanning, which is a digital "photo" of the paper draft, where everything in the draft is included. To be able to use the draft it is necessary to make a not insignificant manual after-processing to make the drafts entirely or partly object oriented. However, the technologies in this area is improving rapidly to make the process easier and better, so it is recommended to examine the possibilities, when one must make a decision.

It is also important to decide what degree of detail one want the drafts to have. Below is some examples shown of digital drafts, which can give an impression of a relevant degree of detail. In general it can be recommended, that bearing walls are drawn so they visually differ from non-bearing walls, that staircases and lifts are indicated, that windows and glass sections are marked, and also that doors are indicated with punches. It must be further decided whether fixtures, sanitary, hose reels et cetera must be indicated.

\section{Examples of CAFM drafts and prints}

In figure 8.3 is shown an example of a print of a digital draft with a storey plan. The draft in question was made in connection with entering of a new lease as shown in case 5.b. The lessor did not have digital drafts of the lease. Soon after the making of the lease contract the storey plan was digitalised in the tenant company's CAFM system.

At first the draft was used as an ordinary CAD drawing in connection with planning of layout and furnishing. Alternative furnishing proposals were drawn up in drawings with colours for the use of the dialogue with the users. On the draft shown in figure 8.3 is for the use of both lessor's and tenant's installation works indicated the location of the workplace installations, which would be established before moving in.

After determining the layout and furnishing the remaining room related information were installed into the data base, including organisational unit, function, person names, rent catego- 


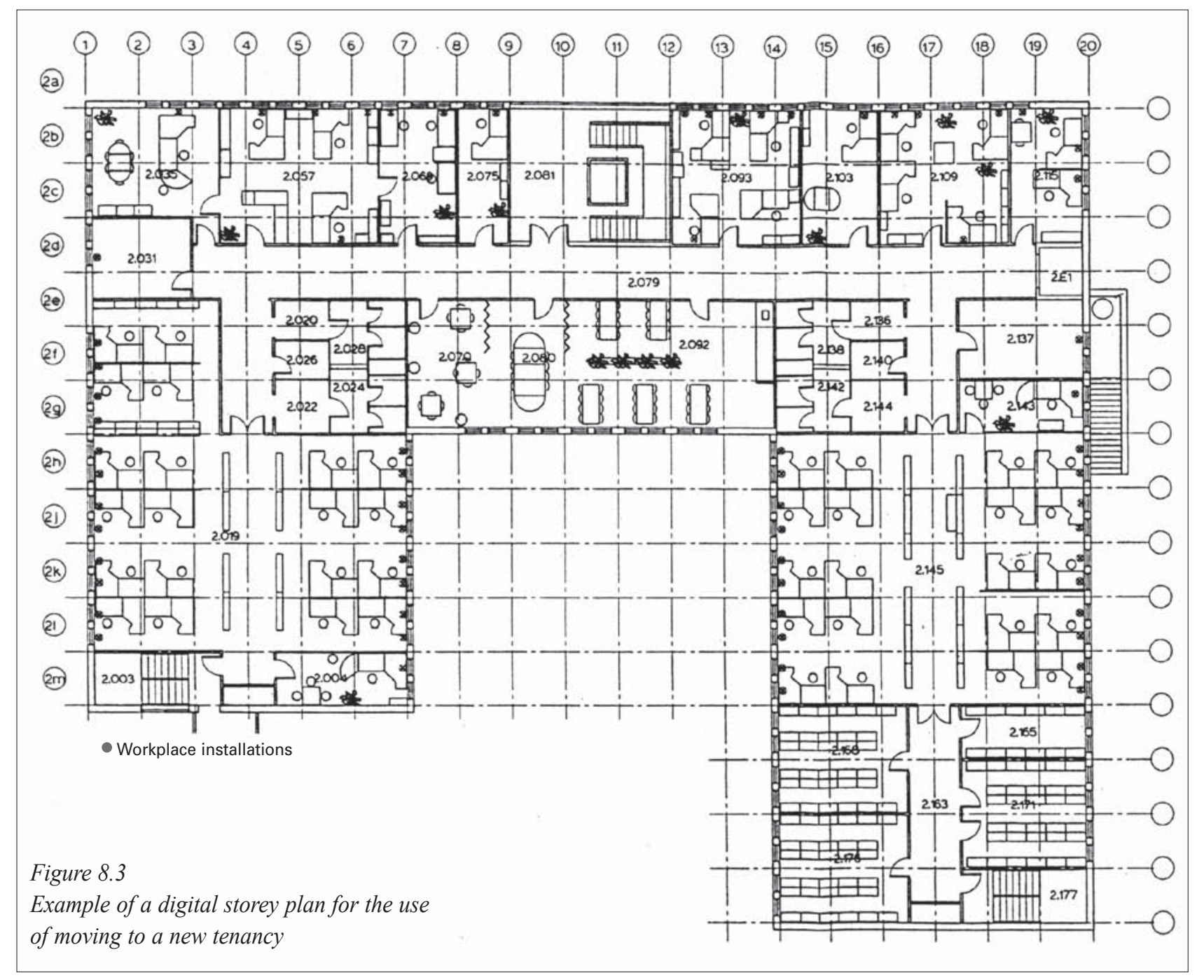

ry, flooring and cleaning frequency to each room.

In figure 8.4 is shown a print from a CAFM system with information for the use of procure- ment of cleaning with indication of space, function, cleaning frequency and flooring for each room. The information can also be printed with the information for each room on digital drawings.
Figure 8.4

Example of a CAFM print for the use of procurement of cleaning

\begin{tabular}{|l|l|l|r|l|l|l|}
\hline Property & Building & Room & \multicolumn{1}{|c|}{ Area $\mathrm{m}^{2}$} & Function & Frequency & Flooring \\
\hline 215 & 1 & 2.102 & 17,9 & Office & 511 & Carpet \\
\hline 215 & 1 & 2.109 & 26,7 & Office & 511 & Carpet \\
\hline 215 & 1 & 2.110 & 8,8 & Office & 511 & Carpet \\
\hline 215 & 1 & 2.114 & 8,8 & Office & 511 & Carpet \\
\hline 215 & 1 & 2.118 & 14,0 & Education & 521 & Carpet \\
\hline 215 & 1 & 2.121 & 21,3 & Office & 511 & Carpet \\
\hline 215 & 1 & 2.124 & 12,8 & Office & 511 & Carpet \\
\hline 215 & 1 & 2.130 & 30,4 & Office & 511 & Carpet \\
\hline 215 & 1 & 2.286 & 60,5 & Corridor & 521 & Hard floor \\
\hline 215 & 1 & $2 . E$ & 20,6 & Staircase & 521 & Hard floor \\
\hline 215 & 1 & $2 . E E$ & 1,8 & Lift & 551 & \\
\hline 215 & 1 & K.001 & 11,8 & Bathroom & 551 & Hard floor \\
\hline 215 & 1 & K.002 & 23,9 & Cloak room & 521 & Hard floor \\
\hline 215 & 1 & K.009 & 8,4 & Corridor & 521 & Hard floor \\
\hline 215 & 1 & K.010 & 9,6 & Toilet & 551 & Hard floor \\
\hline 215 & 1 & K.014 & 50,2 & Workshop & 1 x month & Hard floor \\
\hline
\end{tabular}




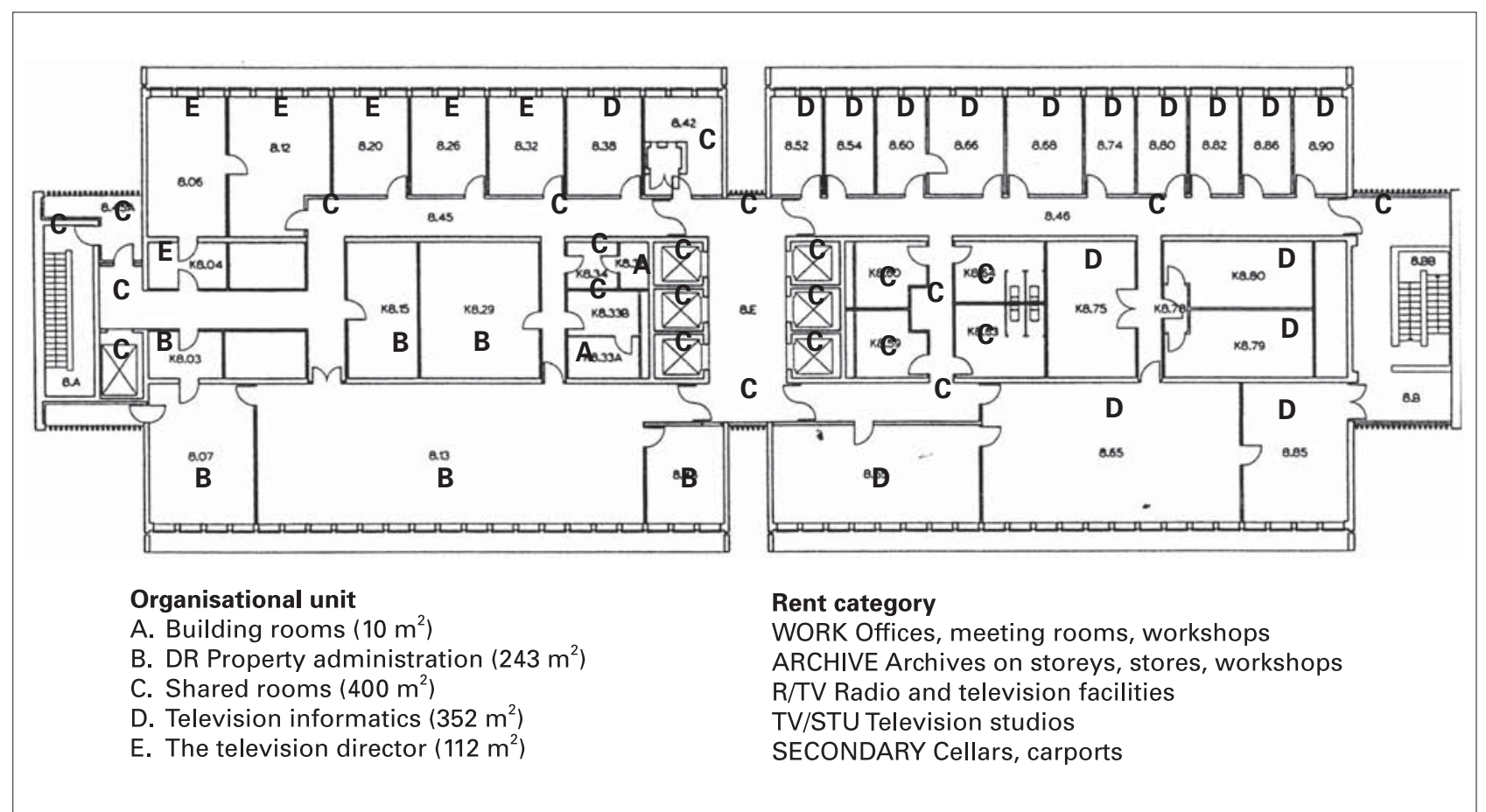

In figure 8.5 is shown an example of a digital storey plan for the use of internal rent with indication of space allocation for each unit and specification of rent categories, cf. case 3.a.

Correspondingly is in figure 8.6 shown an example of a print with calculation of internal rent for a section, cf. figure 8.5 and case 3.a.

\section{Digital handover}

At new building there are special possibilities to create an optimal digital data basis for the property operation. It is today normal procedure that building design is accomplished digitally on CAD systems. Most descriptions, including material and construction descriptions and operational and maintenance instructions are accomplished as digital text documents. So it is obvious to transfer data from the building process digitally to be used in property operation

However, there are some fundamental problems to consider in connection with reuse of digital building data as a digital basis for the property operation. It concerns the following:
- The volume of data which are produced during the design and construction phase is considerable, and it is only a small part of these data which it would be relevant to continuously maintain in a CAFM system or the like. Detailed data about the finished building "as built" can be stored passively and found again later on if needed in connection with rebuilding et cetera.

- The design drawings of buildings are not always object orientated, whereas handling in a CAFM system presume that drafts are object orientated.

- The formats of the digital data may vary among architect and engineering companies involved in the building design, and only in cases where the building client make demands of it at the beginning of the design, there can be attained certainty that data formats for drafts and text are in accordance with the property owner's operational IT systems. The possibilities to this of course are the best, where the building client and the facilities manager belong to the same organisation.
Figure 8.5

Example of a digital storey plan for the use of internal rent

Digital design

\begin{tabular}{|l|l|l|l|l|r|r|r|r|}
\hline Unit & Property & Building & Room & Category & Space & $€ / \mathrm{m}^{2}$ & Factor & In total \\
\hline DR-EA & 216 & 12 & 8.05 & WORK & 32,8 & 2.057 & 1,00 & 67.470 \\
\hline DR-EA & 216 & 12 & 8.13 & WORK & 126,5 & 2.057 & 1,00 & 260.210 \\
\hline DR-EA & 216 & 12 & 8.43 & WORK & 17,3 & 2.057 & 1,00 & 35.586 \\
\hline DR-EA & 216 & 12 & K8.03 & ARCHIVE & 7,7 & 2.057 & 0,75 & 11.879 \\
\hline DR-EA & 216 & 12 & K8.15 & ARCHIVE & 21,8 & 2.057 & 0,75 & 33.632 \\
\hline DR-EA & 216 & 12 & K8.29 & ARCHIVE & 36,8 & 2.057 & 0,75 & 56.773 \\
\hline Sum & & & & & 242,9 & & & 465.551 \\
\hline
\end{tabular}

Figure 8.6

Example of a CAFM print for the use of internal rent 
Figure 8.7

The principles of digital handover

\section{口}

Digital Construction

Data formats

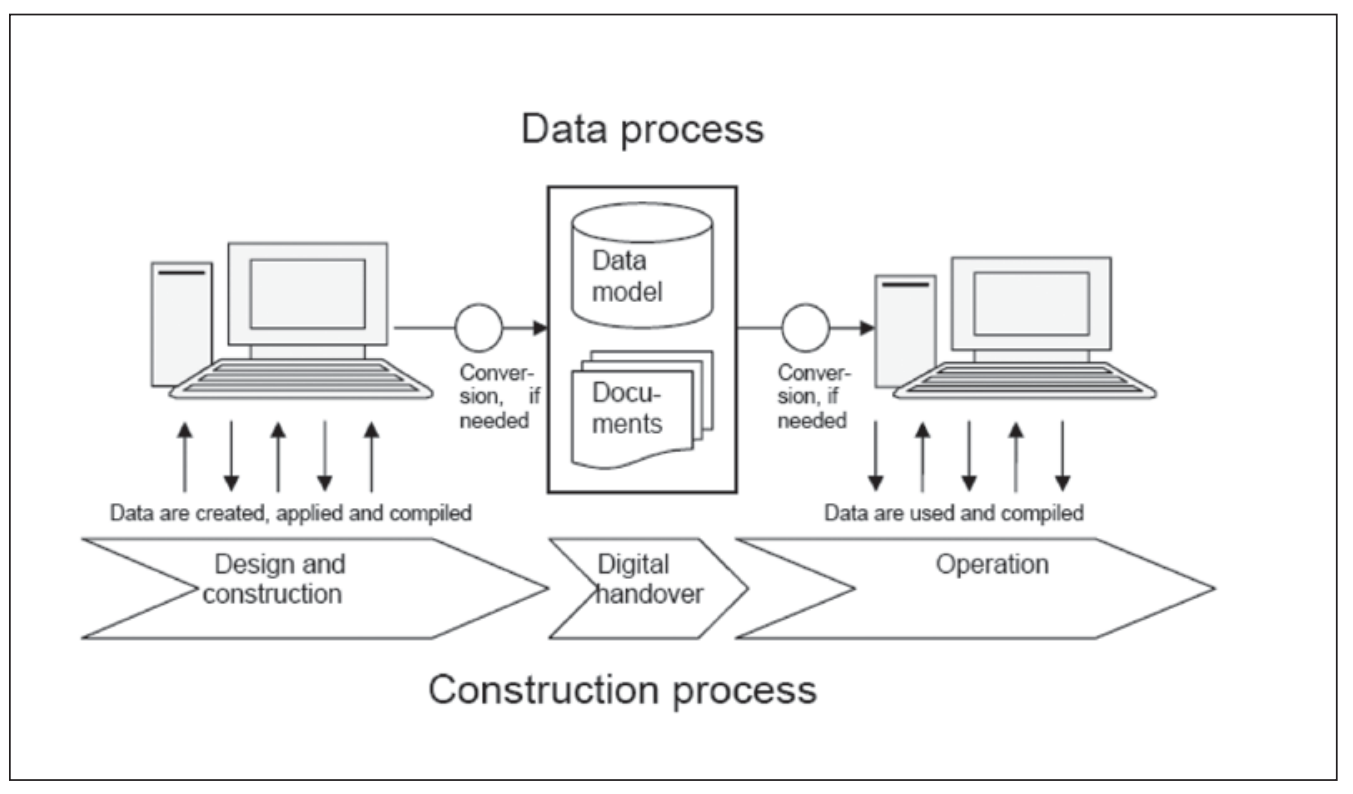

In Denmark the National Agency for Enterprise and Construction in 2003 inittiated a development program called Digital Construction. Behind the program was a vision of a construction process, where all processes from design to building operation are supported by ICT, where all data are digital and where all agents work rationally with the data in the relevant process. The aim of the program wre to develop standards to facilitate the exchange and integration of data in IT systems. The result was that it became mandatory for all state building clients from $1^{\text {st }}$ January 2007 to make requirements to designers and contractors on new building projects over a certain budget threshold to implement digital construction including digital tendering, project web, 3D design and digital handover.

The overall principles in digital handover are shown in figure 8.7. Data can either be directly related to objects in a data model or be included in separate documents. The data model should ideally be concordant with the BIM (Building Information Model) used in the 3D design of the building. The transfer of digital data should take place by use of an open standard and can takes place by use of XML-formats, but also by use of the international IFC-standard (Industrial Foundation Classes), which is an open standard developed by the association IAI (International Alliance for Interoperability).

The requirements to implement digital construction in Denmark was from $1^{\text {st }}$ January 2008 extended to also include refurbishment projects undertaken by state building clients and from $1^{\text {st }}$ January 2009 all social housing project in
Denmark will be included. It is expected that municipalities and regions also will be included, and the intention is that the digital construction will also be implemented in private building projects as a de-facto national standard.

\section{O\&M systems}

Operation and maintenance systems include a wide range of IT tools for the use at both the strategic maintenance planning, which is discussed in section 4.4, and the operation of maintenance tasks, which are discussed in section 6.1. The systems can further be used at budgeting and management of other operational tasks.

Where CAFM systems particularly are based on rooms and spaces, O\&M systems are primarily based on building parts and cost. Many O\&M systems are independent IT tools, which can be built up as modules. This has been most common in Denmark, where many consultant engineering companies have developed and marketed their own O\&M system in connection with their consultancy. Some O\&M systems are modules in connection with a CAFM system. This is normally the case in internationally marketed systems.

The advantages at coupling between O\&M systems and CAFM systems are at first, that many basic data about the buildings are the same and secondly improved possibilities to compare drawing related information with text based information. O\&M systems have furthermore often couplings to BMS systems, cf. section 8.3, and to the company's financial systems. Coupling with helpdesk systems is also possible. In the following is described the most important 
aspects of O\&M systems in relation to the main functions with support of strategic planning and tactical management. In relation to both functions it is important that the system can be built up with a flexible structure according to building parts with varying detail level.

In connection with planning it is important that O\&M systems can handle the following functions:

- Storage of operational and maintenance instructions, for instance in the shape of references within certain areas

- Storage of condition data for building parts from recurring evaluation reports, possibly supplemented with digital photos

- Storage of history of finished maintenance activities and the attached expenses

- Storage of key indicators of typical maintenance activities

- Estimation of expenses from quantities and indexed key indicators

- Possibilities of multi-annual planning of maintenance activities with varying detail level

- Possibilities of classification and prioritising building parts and maintenance activities, for instance in relation to a risk evaluation

- Possibilities of simulation and storage of alternative plans with varying expense levels and distribution on years

- Possibilities of graphical presentation of plans, including graphs of the expenses and timetables

In relation to management the basis is in the approved plan of the current and maybe also the following year. With this basis it is important that the O\&M system can handle the following functions:

- Recording of normally used providers

- Print of task orders for standardised maintenance activities

- Financial management of the expenses in the approved plan and the disposed, implemented and not disposed expenses

- Possibilities of simulation and storage of alternative plans in preparation of adaptation of activities to the budget

- Recording and supervision of company and product guarantees

- Simple updating of the system with information of implemented evaluations reports and maintenance activities
The term FMIS (Facilities Management Information Systems) is sometimes used as a general term for information systems for the use in FM.

FMIS for instance includes the following systems in a more or less integrated form:

- CAFM systems, cf. above in this section

- O\&M systems, cf. above in this section

- Helpdesk systems, cf. below in this section

- Building automation systems, cf. section 8.3

Helpdesk systems are IT tools for support of a centre for error messages and other user approaches to the FM organisation. The importance of such a helpdesk is discussed in section 2.4. The helpdesk system must contribute to a systematic collection of approaches with the possibility that the user can follow what happens with the approach, and with possibility that the FM organisation in a simple and visible way can handle the approaches and make statistical processing and assess performance indicators of various types of approaches.

It is appropriate that helpdesk systems are connected with O\&M systems in relation to user approaches which are related to errors, deficits and quality problems concerning the state of the building and its performance. Correspondingly is it appropriate that helpdesk systems are connected with procurement systems in relation to handle purchase orders.

The IT tools for the use of FM are of course very influenced of the new possibilities which the internet has provided, for instance:

- The internet and e-mails in general allows a more easy and fast change of data, both internally in companies, and among companies, including draft related information

- The possibilities to search for information on companies', institutions', authorities' and associations' homepages, in data bases and in public registers have inconceivably increased

- At major building projects it has becoming normal procedure to establish a project web, where the project documentations are available to project parties after agreed criteria, and this support the possibilities that the property owner can become a more active player in the process than it formerly was standard procedure

- Correspondingly it is possible to establish an operational web where all relevant documentation about the property are available to
FMIS

Planning

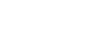


everyone connected to the company's FM organisation, including external consultants, workmen and service providers

- Establishment of websites and portals with markets for products and services is developing fast at the expense of wholesalers and traditional distributors

- Electronic supply and procurement is under heavy development, and it will without doubt influence FM even more in the future

\subsection{Intelligent Buildings}

The term intelligent building has in Denmark been defined by DFM in the following way:

"The intelligence of a building is the integration of technology for the provision of efficient surroundings, which fulfil today's demands and can be adapted to tomorrow's changes and unknown demands, both as to business development and technological development"
Hence it is the integration of technology in the building which is the core function of the intelligent building, especially automated technologies for operation, regulation and supervision of the technical installations in the building. Such a technology is today mainly IT based, where it earlier primarily included electro mechanic control technology.

Comparisons between buildings and cars are popular - why is it as expensive to produce buildings as cars per $\mathrm{m}^{2}$, and why can you not adjust the indoor climate as efficient as a workplace in a building as at a seat in a car with air condition? Space Management primarily works with buildings as a relatively passive physical frame. The term intelligent buildings however bring focus on the building's dynamic performances as an active "machine".

The automation technology in buildings is to a great extent taken from modern production plants. In principle it is the same mechanic, hydraulic, pneumatic, electric and electronic components which are included, both at operation of a modern factory plant, and at the operation of buildings' ventilation, cooling, heating and back-up power units et cetera. And it is not a coincidence, that it traditionally was machine engineers who handled the daily operation of buildings with complex installations. The professional qualifications which are requested to operate a factory plant, a large ship and a com- plex building have many similarities.

Like a ship, a power station and an automated production system has a control room to handle caretaking, monitoring and supervision, a complex building has its control centre (in Danish the term CTS is used for Central Condition and Control), where the state of the technical installations continuously can be followed up and adjusted according to needs, like all alarms in various control systems (fire, security et cetera) are gathered here. Concurrently with the fact that the BMS systems have become IT based, the operation of the various technical installations has been more and more integrated. The physical size of the BMS centre has become smaller and smaller, so all functions can gradually be operated by one person from a computer - with the possibility of signal transfer to a laptop and remote control from it.

The purpose of BMS (Building Management System) is at first to create a more efficient building to the users through a better supervision and faster and more efficient monitoring and regulation. Secondly the purpose is to ensure an energy optimal operation, for instance at minimising necessary operation times to each system, and optimising of temperatures and flow rates. Thirdly the purpose is to reduce the expenses for operation and maintenance, for instance at coupling with a O\&M system, for instance at transfer of date from the BMS system of operation times at each system and limit values for component functions.

BMS systems traditionally primarily included the operation of the central HVAC systems, but gradually power and low power installations have been included in BMS. In recent years it has become common to speak of IBI (Intelligent Building Installations). IBI for instance includes operation of lighting and various alarm and control systems in relation to fire surveillance and security.

However there is an increasing tendency that also common building units such as windows, sunshades and automatic doors are connected with BMS. The increased use of natural ventilation for instance makes increased demands to automatic control of opening and closing of windows. In the future it will probably also be common to supervise passive building parts such as roofs, external walls, bases and basement floors for instance in connection with measurement of the development of damp in 
structures and insulating materials, and localising leakages in membranes. In figure 8.8 is shown examples of a number of the functions, which IBI and BMS can monitor and control.

BMS represents an increased integration among the various building technical control functions and the development of these systems implies a continuous increased integration. Correspondingly one of the most important technological achievements, which we experience during these years, is the increased integration in the IT area with convergence of data, tele and media technologies. There is a concurrent increased integration between building automation systems and general IT systems.
The integration for instance reflects itself in the fact, that BMS starts to function in the same networks as other data communication internally in the companies, hence with possibilities to the same external connections. With that arises new possibilities of de-central management of buildings. For instance, it is possible to each employee to change the indoor climate conditions in an office, or for that matter at a workplace in an open environment, provided that the technical installations are provided with the necessary zone division and control systems.
Figure 8.8

Building automation system (Source: Birch \& Krogboe, shown with permission)

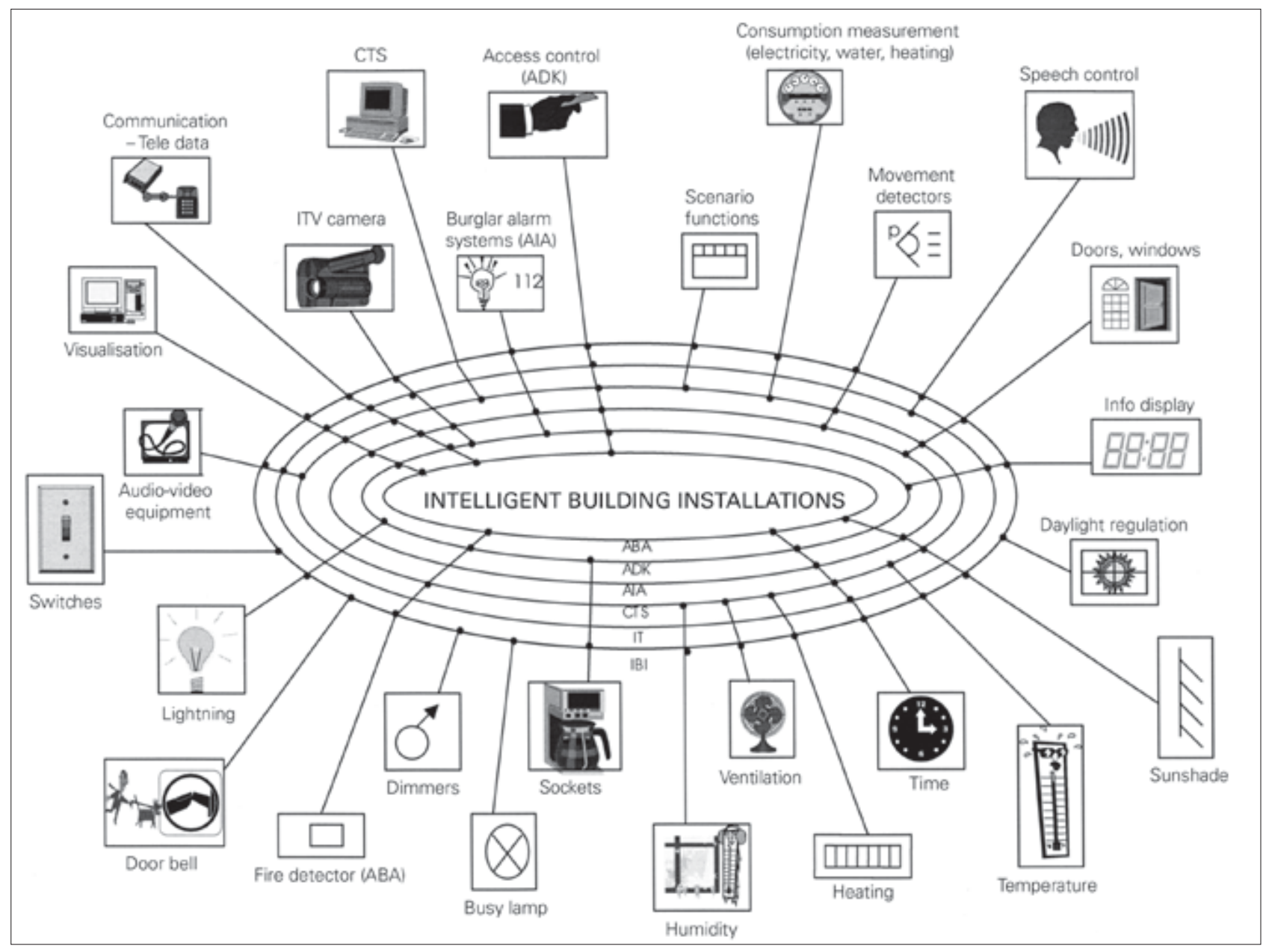




\section{References}

\section{Literature}

Bernard Drion: FMIS is much more than a glorified card index - At least it should be... Article in The European Facility Manager. Number 2, 2000.

Bruce Kenneth Forbes, Archibus Inc.: Mastering the Web: Extending the CIFMTM Enterprise Solution to World Wide Web. Proceeding from EuroFM/IFMA conference, 2000.

Michael P. Gallaher, Allan O'Connor, John L. Dettbarn,Linda \& Gilday: Cost Analysis of Inadequate Interoperability in the U.S. Capital Facilities Industry. NISR GCR 04-867. Published by National Institute of Standards and Technology, USA. 2004 (http://www.bfrl.nist.gov/oae/publications/gcrs.html.)

Andrew Harrison: Converging technologies for virtual companies. Article in Wortington, 1997.

Ian Jones, : Facilities Information Management Systems. Centre for Facilities Management, Glasgow, 1996.

Michael May (ed.): IT im Facility Management erfolgreich einsetzen - Das CAFM-Handbuch. Springer. 2004

National Agency for Enterprise and Construction: Digital Construction. Brochure. March 2005. (http://www.ebst.dk/file/3095/digitalconstruction_intro.)

Bobby Pathal: Plugged in for Business. Article in The Relocation Directory, Volume II. Premises and Facilities Management, 2000.

Websites

DFM

www.dfm-net.dk

DFM-benchmarking

www.dfm-key.dk 


\section{Environment and Health \& Safety Chapter 9}

\begin{tabular}{|c|c|}
\hline \multicolumn{2}{|c|}{ Figures } \\
\hline 9.1 & $\begin{array}{l}\text { Mapping of environmental influence } \\
\text { at new building . . . . . . . . . . . . . }\end{array}$ \\
\hline 9.2 & $\begin{array}{l}\text { The environmental management } \\
\text { process } \ldots \ldots \ldots \ldots \ldots \ldots \ldots \ldots \ldots 170\end{array}$ \\
\hline 9.3. & $\begin{array}{l}\text { The main elements of a green } \\
\text { account } \ldots \ldots \ldots \ldots \ldots \ldots \ldots \ldots \ldots 171\end{array}$ \\
\hline 9.4 & $\begin{array}{l}\text { Environmental influences and system } \\
\text { for environment statement (EMAS) . . . 171 }\end{array}$ \\
\hline 9.5 & $\begin{array}{l}\text { Danish system for environmental } \\
\text { declaration with DR City as example . . . } 176\end{array}$ \\
\hline 9.6 & $\begin{array}{l}\text { Demands at sitting work } \\
\text { seen from above . . . . . . . . . 181 }\end{array}$ \\
\hline \multicolumn{2}{|c|}{ Case } \\
\hline 9.a & $\begin{array}{l}\text { Example of the Energy Part of } \\
\text { a Green Account for a Private } \\
\text { Housing Estate } \ldots \ldots \ldots \ldots \ldots \ldots \ldots 174\end{array}$ \\
\hline \multicolumn{2}{|c|}{ Checklists } \\
\hline 9.A & $\begin{array}{l}\text { External Environment and Material and } \\
\text { Resource Consumption. . . . . . . . . 172 }\end{array}$ \\
\hline $9 . \mathrm{B}$ & The Healthy Indoor Climate. . . . . . . . . . 178 \\
\hline
\end{tabular}

Construction and Environment . . . . . . . . . 168

Environmental and Energy Management . . . . . . 170

Green accounts and environmental certification . . . . . . . . . 171

Energy management and labelling. . . . . . . . . . . . . . . . 173

Environmental classification. . . . . . . . . . . . . . 173

Indoor Climate ..................... 176

Indoor climate factors . . . . . . . . . . . . . . . 176

Indoor climate symptoms and diseases . . . . . . . . . . 177

How to ensure a healthy indoor climate . . . . . . . . . . . 177

Work Involving Computer Screens. . . . . . . 180

References.......................... 182 


\section{Legislation}

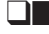

Resource consumption
Environment and health \& safety are areas with an increasing importance to FM. This is caused by the generally increased consciousness about environment and health, which is in evidence in the entire society. Both areas are attitudinal, and this for instance implies that there is a substantial image factor to many companies to be able to show that they work for the environment and the staff. Furthermore there are more direct advantages to the companies in the shape of financial savings through consumption of less energy and raw materials, and through less sickness leave and increased productivity.

A common feature at environment and health \& safety is that both areas to a great extent are under regulatory requirements. To health \& safety there are many years of tradition to this in relation to safety at work. The size of the public regulation is however essentially increased in Denmark after the new health \& safety at work act in the 1970'ies, which was a framework legislation with continuous supplementing, and furthermore concurrently with the Danish membership and increasing harmonising within the EU.

In the environmental area it was at first the industrial pollution and the energy consumption which were objects to legislative intervention in the energy area for instance through demands of heat insulation in buildings, demands on energy and heating planning, and taxes on the energy consumption following the energy crisis in the 1970 'ies. Later on more wide areas of the environment has been included, for instance through implementation of green taxes, and to polluting companies demand on delivery of green accounts.

Using the word environment normally means the external environment, i.e. consumption of resources and pollution et cetera. Health \& safety expresses correspondingly the "internal environment" or the "indoor environment" in a company, which the staff experience and are subject to, when they are at work. However, it is becoming normal to treat environment and health \& safety as a whole, as the experiences show that the problems in connection with environment and health \& safety are interconnected.

If environment and health \& safety are considered separately, one can when dealing with external environmental problems run the risk to move the problems to internal health $\&$ safety problems. An obvious example is the energy area, where one easily can achieve large savings in turning down on heating and ventilation systems, but this will immediately cause comfort related consequences to the staff. Therefore the health $\&$ safety must be an integrated part of the environmental work.

Environment and health \& safety are both comprehensive areas. In this chapter will only be mentioned those aspects which are considered to be especially relevant to FM. In section 9.1 environment in relation to new buildings is discussed, as the basis of environmental friendly FM to a great extent is determined in the planning phase of building projects and in section 9.2 environment and energy management are discussed as some general tools for handling the environmental work in a company.

In connection with health \& safety the focus is on office buildings and office work. In section 9.3 indoor climate is discussed, which is an obvious aspect to FM, and in section 9.4 health $\&$ safety conditions in relation to work with computer screens is discussed.

As in the other chapters, this chapter is concluded with references.

\subsection{Construction and Environment}

Construction and buildings demand considerable resources around the world. Constructional activities imply a high consumption of raw materials for the use as construction materials. This concerns gravel, sand, clay and lime for production of cement, concrete, bricks, glass and mineral wool, and also wood, iron and various artefacts. Furthermore, considerable amounts of energy are used for production of construction materials and for heating of the finished buildings. Buildings are also the frame of most people's activities, and so of substantial importance to health and well-being.

In relation to environment there are good reasons to focus on the way in which we design and construct our buildings. It is not only important to the amount of resources which are used before and during the construction, but also to the energy consumption and other environmental influences during the period of use, and also the possibilities to demolish and reuse 
the materials after the end of the building's period of use. It is therefore crucial to consider the construction's environmental influences throughout the entire life circle, from raw material recovery to demolish - also termed from the cradle to the grave.

To meet such considerations a number of organisations in the Danish construction sector, with subsidy from the Ministry of the Environment, have developed a tool termed environmentally friendly design. The tool consists of a comprehensive material consisting of two ring binders (BPS, 1997). A property owner's instruction has been published, and also an inspiration guide (BPS, 1999 and 2000).

The main principle of environmentally friendly design is that environmental considerations are included as an integrated element in connection with briefing and design of buildings. The amount of the efforts is decided by the building client, and the basis is determined in an environmental brief, which is prepared concurrently with and as part of the building design brief itself. Environmentally friendly design does not ensure an environmentally friendly building unless certain environmentally goals are laid down in the environmental brief, which the building must meet.

Environmentally friendly design is primarily a tool which gives the design team a systematic method to work with and prioritise the environmental work in the design process. During the initial phases a systematic mapping is made of the most important environmental influences, which the construction is expected to meet. An example of such a mapping is shown in figure 9.1. On the basis of the mapping, proposals for environmentally measures during the initial phases are prepared.

During the design the choice of alternative materials and technical solutions can be environmentally examined. In connection with the detailed environmental investigation it is recommended to use Life Cycle Assessment (LCA). Such assessments can be rather comprehensive and difficult to make, and it will always be nec-
Environmentally friendly design

\section{Life Cycle}

Assessments

\begin{tabular}{|c|c|c|c|c|c|c|c|}
\hline $\begin{array}{l}\text { Life cycle phase } \\
\text { Environmental } \\
\text { influence }\end{array}$ & $\begin{array}{l}\text { Raw } \\
\text { materials, } \\
\text { recovery }\end{array}$ & $\begin{array}{l}\text { Production } \\
\text { of materials } \\
\text { and products }\end{array}$ & $\begin{array}{l}\text { Con- } \\
\text { struction }\end{array}$ & $\begin{array}{l}\text { Opera- } \\
\text { tion }\end{array}$ & $\begin{array}{l}\text { Mainte- } \\
\text { nance }\end{array}$ & $\begin{array}{l}\text { Demo- } \\
\text { lish }\end{array}$ & $\begin{array}{l}\text { Removal/ } \\
\text { repro- } \\
\text { cessing }\end{array}$ \\
\hline $\begin{array}{l}\text { Landscape, flora, } \\
\text { fauna }\end{array}$ & E & & L & & & & L \\
\hline $\begin{array}{l}\text { Consumption of } \\
\text { materials }\end{array}$ & $E$ & E & L & & L & & \\
\hline $\begin{array}{l}\text { Consumption of } \\
\text { energy }\end{array}$ & $\mathbf{L}$ & E & L & $E$ & & & \\
\hline $\begin{array}{l}\text { Consumption of } \\
\text { water }\end{array}$ & & & & E & & & \\
\hline $\begin{array}{l}\text { Noise, dust, } \\
\text { vibrations }\end{array}$ & $\mathbf{L}$ & $\mathbf{L}$ & E & & L & $E$ & $\mathbf{L}$ \\
\hline Air pollution & $\mathbf{L}$ & E & L & $E$ & & & \\
\hline Ground pollution & $\mathbf{L}$ & $\mathbf{L}$ & $\mathbf{L}$ & $\mathbf{L}$ & L & L & $\mathbf{L}$ \\
\hline Ground water & L & & $E$ & $\mathbf{E}$ & & & \\
\hline Surface water & & & $\mathbf{L}$ & $\mathbf{L}$ & & & \\
\hline Waste water & & & & $\mathbf{L}$ & & & \\
\hline Waste & $\mathbf{L}$ & $\mathbf{L}$ & $\mathbf{L}$ & E & $\mathbf{L}$ & E & $\mathbf{E}$ \\
\hline $\begin{array}{l}\text { Indoor } \\
\text { environment }\end{array}$ & & & & $E$ & & & \\
\hline Health \& safety & E & E & E & $E$ & E & $E$ & E \\
\hline
\end{tabular}

$E=$ Essential environmental influence $L=$ Less essential environmental influence

Figure 9.1

Mapping of environmental influences at new building 
Environmental policy

Staff contribution
Figure 9.2

The environmental management process essary to make a specific delimitation and prioritisation of the extent of the investigation.

However, there are many possibilities to reuse results of former assessments of similar materials and building parts. Hence, the Danish Building Research Institute has developed a comprehensive catalogue with environmental data to building parts (Petersen et al, 1998), and have also published a number of reports and a computer programme about life cycle based building design (i.a. Petersen, 1998).

Use of environmentally friendly design is voluntary, and even though there at the least among architects is some scepticism to the tool, for instance due to its complexity, it must be recommended to building clients to make requirements to use environmentally friendly design and actively to participate in the preparation of an environmental brief in connection with planning of new building.

However, it is a problem that many architects only to a limited extent are interested in environmental conditions. Therefore such aspects are often not included sufficiently in the early outlining phases, where the building concept is being determined. This for instance concerns consideration to the local climate in relation to the shape and orientation of the building. However, there is internationally a development towards increasing integration of architecture and environment during the concept phase, which for instance is expressed by new terms such as "Integrated building design" and "Architectural engineering".

\subsection{Environmental and Energy Management}

Environmental management is a general term of a number of activities, which aim at gaining overview of the company's environmental con-

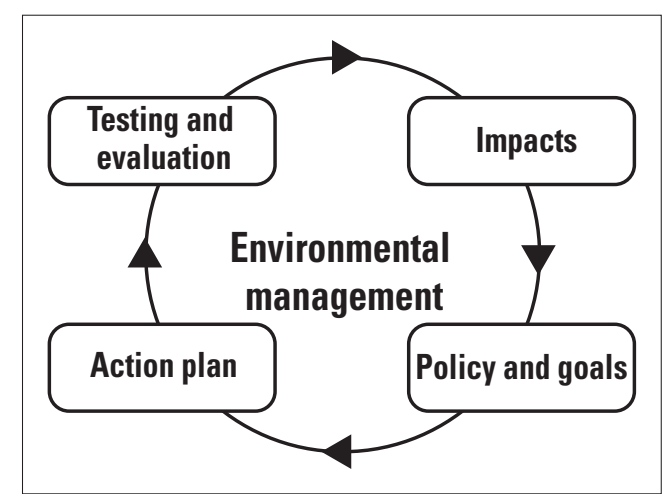

ditions, to define an environmental policy to the company, and to create continuous environmental improvements. Environmental management can be divided into the following four phases, which is also shown in figure 9.2.

- Investigation of the company's environmental impacts

- Determination of policy and the goals to the environmental improvements

- Implementation of action plans which ensure that the goals are attained

- Testing and evaluation of the work (audit)

With the term environmental management the managerial aspect at the environmental work is emphasised. Support by the top management of the company and an efficient administration is crucial to effective environmental efforts. On the other hand it is also important that the company's employees are involved in the environmental work. In many ways it is necessary with changes of behaviour to achieve environmentally positive results, hence the employees' contribution is crucial.

Therefore, environmental management should be management directed but staff driven. It is important that the environmental efforts are made in such a way that the attitudes with both the management and the staff is affected to achieve a wide understanding of the need for the efforts.

In large companies it can be appropriate to initiate the environmental management process in a limited part of the company, which is not too atypical. Considering the data collection it is appropriate to have a property related limitation of the pilot project. After the pilot project the environmental management is gradually expanded to include the entire company.

It is naturally different for each company which environmental impacts are the most important. In general the following external environmental impacts are the most important:

- Greenhouse effect

- Ozone layer destruction

- Smog / photo chemical oxidation

- Food substance strain

- Acidification

- Use of and spread of environmental dangerous and unhealthy material

- Use of and impact on resources

In checklist 9.A is shown a number of possible environmental improvements in relation to the 
external environment and material and resource consumption.

\section{Green accounts and environmental certification}

A main element of environmental management is to document the results. It can of course be done internally, but considering the image effect externally and the motivation effect internally, the results should be published in some way or another; it can be done on the company's website and/or as a leaflet. Another method of documentation, which is widespread, is publication of an annual green account. Green accounts were introduced in Denmark in 1995 as a modification of the Environmental Protection Act (act number 403 from June 14th 1995). The main elements of a green account are shown in figure 9.3.

It is only a few companies which as provided by the Danish Ministry of the Environment order number 975 from December $13^{\text {th }} 1998$ are under obligation to make a green account. In Denmark there are approx. 7.000 specific polluting companies, but it is only the approx. 2.000 of the most polluting companies which are accountable for delivering a green account to the environmental authorities. For that reason the provisions for green accounts are basically made with an eye to industrial companies and the like.

Nevertheless there are many companies which voluntarily have chosen to prepare annual green accounts as documentation of their environmental work. This is without any doubts due to the considerable image effect, and it is also a rather accessible way of documentation, which do not demand external audit.

Danish Broadcasting Corporation for instance decided in 1998 to implement environmental

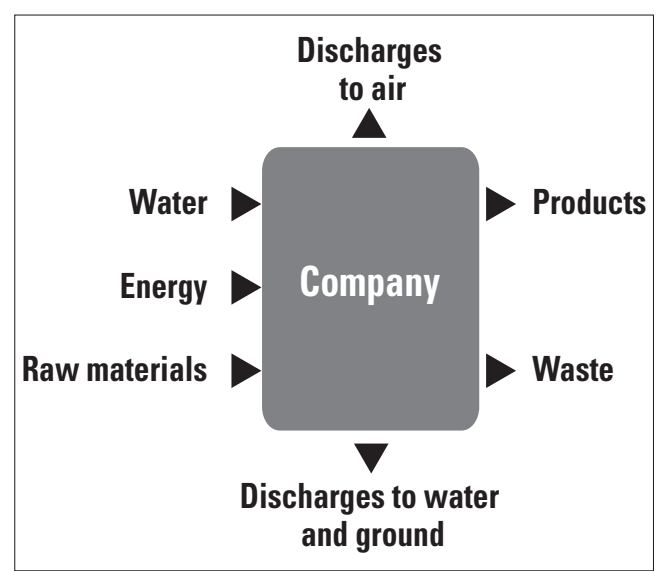

management, and after having prepared internal green accounts during two years DR for the first time published the green account for 1999.

Besides green accounts for companies there are also examples of green accounts for housing estate. In case 9.a is shown an extract of a green account for a private Danish housing estate.

A green account can be the first step which later on can be extended with an environmental certification or an extended green account in the shape of an environmental statement.

The most widespread environmental quality standard is ISO 14001. The principle in this standard to a certain degree matches the widespread quality standard ISO 9001, and approx. $70 \%$ of the contents are shared. In relation to the general elements of environmental management, which were discussed earlier, the most important demands are that observation of the standard must be authorised at internal audit by a certifying body, for instance Danish Standard, and that you must pay for it.

EU has issued a board regulation termed EMAS (Eco Management and Audit Scheme), which is mainly constructed as ISO 14001, but with the characteristic variation, that EMAS recording demands preparation of an environmental state-
Figure 9.3

The main elements of

a green account

\section{Environmental \\ statement}

ISO 14001

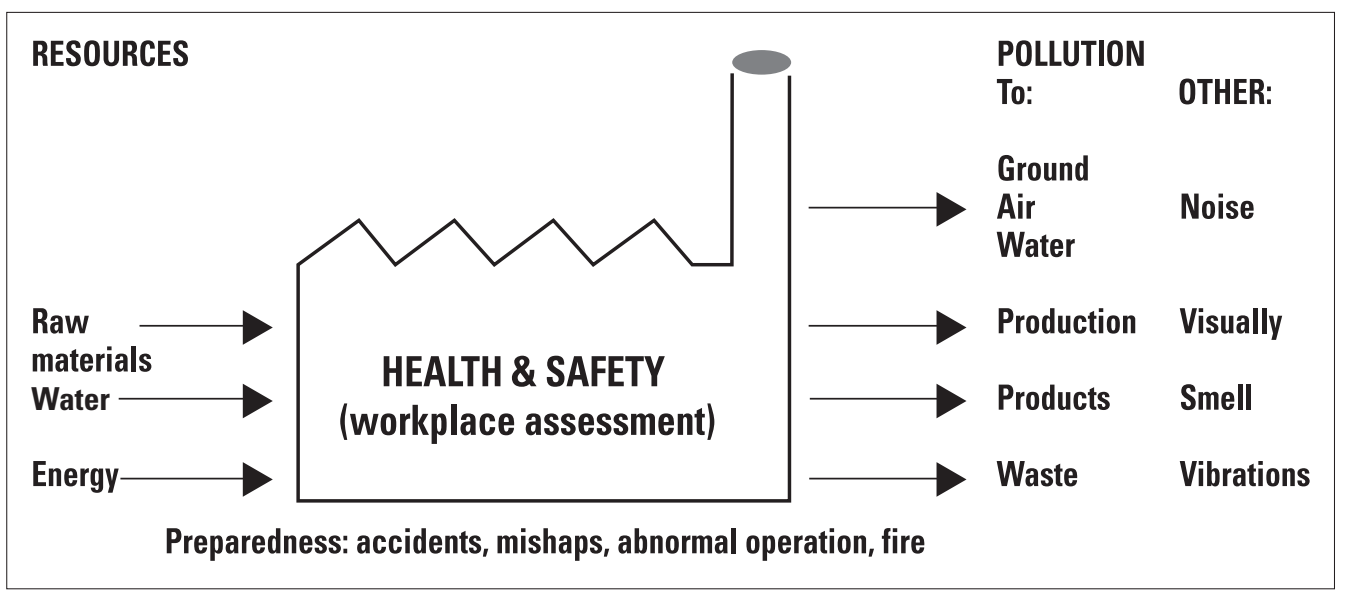

\section{EMAS}

Figure 9.4

Environmental influences and system for environmental statement (EMAS) 


\section{Checklist 9.A: External Environment and Material and Resource Consumption}

(source: Based on Nielsen, 1992)

\section{Energy and water consumption}

- Reduce the electricity consumption at the most, for instance by stopping pumps, compressors, data machinery, light et cetera

- Reduce the heating consumption (thermostat operation et cetera)

- Reduce the water consumption

- Demands to providers of the lowest possible energy and water consumption

- Make internal recording of the electricity, heating and water consumption. If possible record the costs for energy and water in each building section and at each production process

- Establish a work group made up by staff and management within a building section or area of the company to plan energy and water savings

- What are the financial frames to possible investments?

- Install reduction valves on taps

- Check water pipes and consumption places to leakages and if necessary repair

- Check or mount insulation on hot water pipes

- If possible divide the water supply from quality needs (drinking water, washing, cleaning et cetera), to prevent use of a higher water quality than necessary for the purpose

- Ensure that the hot water supply is not more hot than necessary

- Prepare information, set goals and prioritise:

- Immediate initiatives

- Long-term initiatives

- Organisational initiatives

- Deadlines/actions (who, what, when)

- Continuously inform the staff

Purchase and store

- Take stock of the environmental effects:

- Do we use the proper products

- Are there alternatives

- Determine which effects the articles have on the surroundings

- Give precedence to environmental interests in the evaluation of purchase and stock article

- Prepare internal papers of the company's environmentally conscious investigations of all materials

- Replace environmentally dangerous articles in the production

- Avoid to use environmentally dangerous materials for wrapping, storage et cetera

- Purchase products which do not attack the environment, for instance at cleaning

- Do not purchase chlorine bleached paper napkins, paper towels, filter bags, toilet paper et cetera

- Avoid to purchase office supplies, ring binders, plastic pockets made of plastic with PVC

- Purchase energy saving lighting (high-frequency neon tubes, low-energy bulbs et cetera)

- Purchase glue, paint et cetera without contents of solvents or heavy metals
- Replace disposable plates with multiple use plates

- Obtain information from providers and ask them of the production process

- Ask manufacturers to gain information of alternative products

- Consult other information sources to gain information of possible alternative products

- Define the demands which must be made for the product and find the current information

- Ask the environmental department, the occupational health service or environmental authorities of technical data, possible replacements et cetera

- As a main rule you must ask more providers before you decide to purchase

- Examine if the manufacturer is ready to account for the environmental qualities of his products

- Be aware of the will to use reusable materials

- Determine the responsibility conditions to handling of waste

- State the possibilities of disposal

- Collaborate with trade organisations and experts within the product area in question

\section{Waste and reuse}

- Analyse what is a part of the waste as to materials, energy et cetera

- Specify the materials, for instance paper, textiles, plastic, oil, rubber, metal

- Define possible compounds and state which is the main product

- Define compounds of materials - size, physical, biological and chemical compositions, including acute poisonous under long-term influence et cetera

- Examine if changes of the production process can minimise the waste

- Examine the possibility to transform water with dangerous waste into harmless waste, for instance by using physical or chemical processes

- Are there possibilities to reuse the waste or part of the waste in own or external production

- Avoid spread of waste

- Examine possible public or private collection systems

- Systematise collection containers, barrels, reuse salvers

- Inform everybody thoroughly

- Check follow-up systems

- Establish a management system to coordinate all disposal and reuse activities

- Make providers to return possible disposable packaging

- Check the companies which handle waste, authorisations et cetera

- Record and keep records of the materials which are returned as waste 


\section{The vehicle fleet}

- Purchase cars provided with three-way catalyst

- Use non-lead petrol or environmental diesel

- At purchase consider how much the car pollutes, how much it consumes, and how noisy it is

- Use environmentally friendly tyres

- Use brake linings and clutch linings which do not contain asbestos

- $\quad$ Cars must have a system which shut off the fuel supply if the driver reduces speed

- Mount an automatic system which turn off the engine, when the car is at idle speed

- Have the cars regularly checked

- Check the tyre pressure regularly

- Reduce the number of carwashes

- Discard the used oil environmentally properly

- Avoid to drive fast and aggressively

- Adapt the speed to synchronised traffic lights

- Use the choke carefully

- Turn off the car's ventilation in queues or jams

- Plan trips from an environmental point of view

- Use errand boys on bikes, if possible

\section{Buildings and rebuilding}

- Make an analysis and prepare an environmental brief before the design

- Make demands for environmentally friendly design

- Use consultants with experience in environmentally friendly buildings

- Involve the users

- Examine the basis of negative factors

- Ensure that the building or the rebuilding does not affect another workplace negatively, for instance with noise, dust, smoke or shadow
- Dimension in relation to accessibility, expansion possibilities, disposal of waste, reuse et cetera

- Ensure space for external and internal green areas

- Use building materials which pollute least possible throughout their life time

- Ensure maximum heat insulation

- Ensure that all workplaces have daylight

- Possibilities of view must be ensured - use window glass which allows for a natural view

- Use external sunshade

- Avoid electric installations which can be dangerous

- $\quad$ Plan the heating, airconditioning and ventilation with a view to save energy and keep good health

- Ensure that all windows can be opened

- Limit airconditioning to as little as possible

- Use thermostats on radiators

- Prefer ray heating instead of ventilation

- Use all possibilities to reuse the heat

- Plan water installations so there can be saved as mush as possible of the drinking water

- Avoid the use of drinking water in the production - instead use seawater, rain water or purified waste water

- Use rainwater in the toilets, for cleaning, for garden sprinkling, grounds et cetera

- $\quad$ Equip toilets, showers, wash basins et cetera with water savers ment. Compared to an ordinary green account the environmental statement is more comprehensive with demands of more data and also status of the environmental management system. The demands to the data reporting in EMAS are shown in figure 9.4.

The EMAS arrangement at first only applies to production companies, but the arrangement is expected to be expanded to apply for other companies. The environmental statement is however a fine communication tool which appropriately can be used no matter formal recording.

\section{Energy management and labelling}

Energy management is considered being an element of environmental management, but where environmental management has basis in the company, energy management has basis in a property.

In Denmark a mandatory system for energy management was introduced in 1997 for build- ings over $1.500 \mathrm{~m}^{2}$ involving an annual evaluation of the energy performance by an authorised energy consultant. This system was from 1. January 2007 replaced with a new system of energy labelling. Where the former energy management system was based on measuring and inspection the energy labelling includes a calculation of the buildings energy consumption based on the buildings technical properties. It does not take the behaviour of the people using the building or the way the building is operated into account. The energy labelling is mandatory for buildings over $1.000 \mathrm{~m}^{2}$, but only every 5 year or when the building is sold.

\section{Environmental classification}

The world's first and probably most used system for environmental classification is the British BREEAM, which was developed in Great Britain by BRE (Building Research Establishment) as a method for environmental assessment (Environmental Assessment Method) around
Energy labelling 


\section{Case 9.a: Example of the Energy Part of a Green Account for a Private Housing Estate}

(source: Kuben A/S)

The building's consumption of energy in the period May 1st 1997 to April $30^{\text {th }} 1998$

\begin{tabular}{lrrr} 
& For the building & per dwelling & \multicolumn{1}{c}{ per $\mathbf{~ m}^{\mathbf{2}}$} \\
& & & \\
District heating & $136.318 \mathrm{kWh}$ & $6.815 \mathrm{kWh}$ & $90.2 \mathrm{kWh}$ \\
Solar heat & $15.800 \mathrm{kWh}$ & $790 \mathrm{kWh}$ & $10.5 \mathrm{kWh}$ \\
Electricity - shared & $6.993 \mathrm{kWh}$ & $350 \mathrm{kWh}$ & $4.6 \mathrm{kWh}$ \\
Electricity - dwellings & $39.204 \mathrm{kWh}$ & $1.960 \mathrm{kWh}$ & $25.9 \mathrm{kWh}$ \\
Total energy supply: & $\mathbf{1 9 8 . 3 1 5} \mathbf{~ k W h}$ & $\mathbf{9 . 9 1 5} \mathbf{~ k W h}$ & $\mathbf{1 2 1 . 2} \mathbf{~ k W h}$
\end{tabular}

As comparison to normal consumption the district heating consumption is corrected for 1997-1998 from degree days. Degree day figures for a normal year: 2906. Degree day figures 1997-1998: 2730.

Corrected consumption of district heating $\quad 145.106 \mathrm{kWh} \quad 7.255 \mathrm{kWh} \quad 96.0 \mathrm{kWh}$ 1997-1998:

Total energy supply degree day corrected concerning consumption of district hearing 1997-1998:

207.103 kWh $\quad 10.355 \mathrm{kWh} \quad 137.0 \mathrm{kWh}$

The "normal" consumption for a building

of the same size:

$213.400 \mathrm{kWh} \quad 10.670 \mathrm{kWh} \quad 141.1 \mathrm{kWh}$

Savings in relation to the normal

$\begin{array}{lll}6.297 \mathrm{kWh} & 315 \mathrm{kWh} & 4.1 \mathrm{kWh}\end{array}$

consumption up to $\mathbf{3 . 0} \%$.

Consumption 1996-1997:

$183.786 \mathrm{kWh}$

$9.189 \mathrm{kWh}$

$121.6 \mathrm{kWh}$

Increase in relation to 1996-1997:

up to $7.9 \%$.

$\begin{array}{lll}14.529 \mathrm{kWh} & 726 \mathrm{kWh} & 9.6 \mathrm{kWh}\end{array}$

The district heating consumption 1996-1997: $140.902 \mathrm{kWh}$

$7.045 \mathrm{kWh}$

$93.2 \mathrm{kWh}$

During the period there was a small drop in the consumption of district heating. The drop was primarily caused by warmer weather in the period of 1997-1998 than in 1996-1997. If one considers the degree day corrected consumption of district heating there is an increase of $8.482 \mathrm{kWh}$ in 1997-1998 compared to 1996-1997. Hence the consumption has increased during the period.

The increase of supplied energy units from the solar cell is caused by the figures of degree days, as there were more sunshine hours than during the period 1996-1997. It was not possible to use the high quantity of supplied energy units from the solar cell panels, as the energy from this is only used for heating of hot domestic water, and the consumption of hot water is rather low in the building.

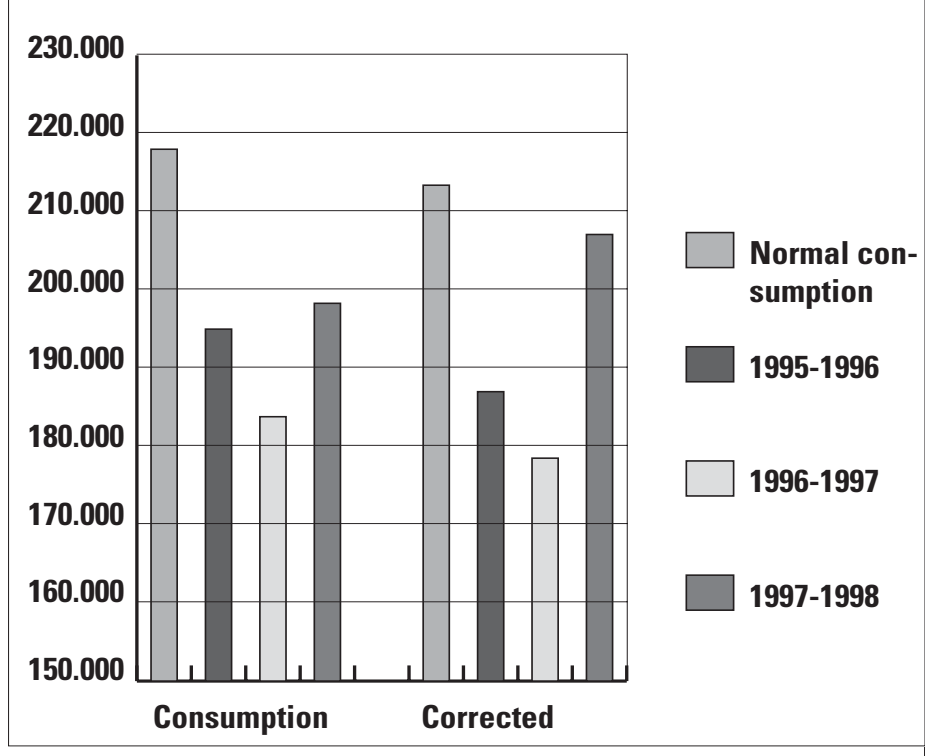


1990. Since 1991 approx. $25 \%$ of all new office buildings in Great Britain have been environmentally certified with the use of BREEAM (Edwards, 1998).

The assessment includes environmental influences on global, regional, local and indoor level divided in more than 100 factors. The result of the environmental assessment is summarised in an environment grade (excellent, very good, good, plain) and an index for environmental performances (Environmental Performance Index).

The environmental assessment includes the following main areas:

- Environmental management (overall policy and procedures)

- Health and comfort (indoor and external conditions)

- Energy (energy consumption and $\mathrm{CO}_{2}$ )

- Transport (transport related $\mathrm{CO}_{2}$ and location conditions)

- Water (consumption and drainage)

- Materials (environmental implications of choice of materials)

- Space usage (change of natural basis)

- Ground conditions (ecological conditions in relation to the site)

- Pollution (air and water pollution besides $\mathrm{CO}_{2}$ )

BREEAM is a system which is under continuous development, for instance in 1998 a new version was introduced for environmental assessment of office buildings. Besides environmental classification of constructed buildings, which is the core of BREEAM, the system can also be used for quality assessment of the design and tendering process in connection with building projects and quality assessment of procedures for property operation. Finally the system can be used as a support tool during the design of new buildings.

In Norway a committee for development of a national proposal for environment assessment of buildings in 1996 presented at proposal for a socalled Eco Profile for buildings. This was later on further developed to an environmental classification system - still with the term Eco Profile. The environmental assessment includes 70-90 parameters divided in three main areas: External environment, resources and indoor climate.

Each parameter is graded 1, 2 or 3, and to each main area the assessment results in a total grade at a scale from 1 to 3 up to the environmental classes less, medium and major environmental strain. Over time is furthermore expected an environmental class 0, which will represent a sustainable level.

20 Norwegian business properties were classified from the Eco Profile method in 2000.

Besides to act as an independent environmental classification system the Eco Profile is also an element of a total Norwegian construction classification system, cf. section 4.7.

In the late 1990'ies, by Canadian initiative, a rather comprehensive international project was carried out to develop of a common method for environmental assessment of buildings with the title GBC `98 (Green Building Challenge 1998). The project was finished with a conference in 1998. Denmark was represented in the project by the Danish Building Research Institute and a test on a building.

The environmental assessment in GBC '98 included a large number of parameters, which to the Danish construction consisted of the following 6 main areas: Use of resources, environmental strain, quality of indoor environment, longlife durability, process and conditions of surroundings. The grading was done from a scale from -2 to +5 .

In continuation of - and partly inspired from GBC '98 - the Danish Building Research Institute have further developed the basis for a Danish system to environmental declaration of buildings. The system includes the following five environmental indicators, which can be estimated quantitatively: energy consumption, material consumption, waste (construction waste), climate influence and air pollution (acidification). Furthermore indoor climate was included as well as a group of other factors, which partly could be decided especially for the each building, and these factors could not be estimated exactly but were based on expert evaluations. Three environmental classes were defined: A, B and C with A as the highest. The reference was the demands in the Danish building codes.

\section{Eco Profile}

The system was tested in two pilot building projects in 2002 (Dinesen \& Hansen, 1999 and 2003). One of the pilot building projects was a part of DR City based on the design phase. The overall results are shown in figure 9.5. DR City was in general evaluated as a class B building except for waste, where it was class $\mathrm{C}$.

Danish Environmenal Declaration

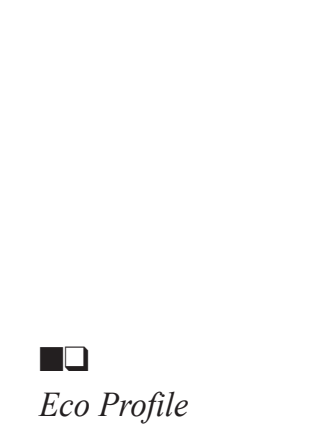


Figure 9.5.

Danish system for environmental declaration with DR City as example (source: Dinesen \& Hansen, 2003)

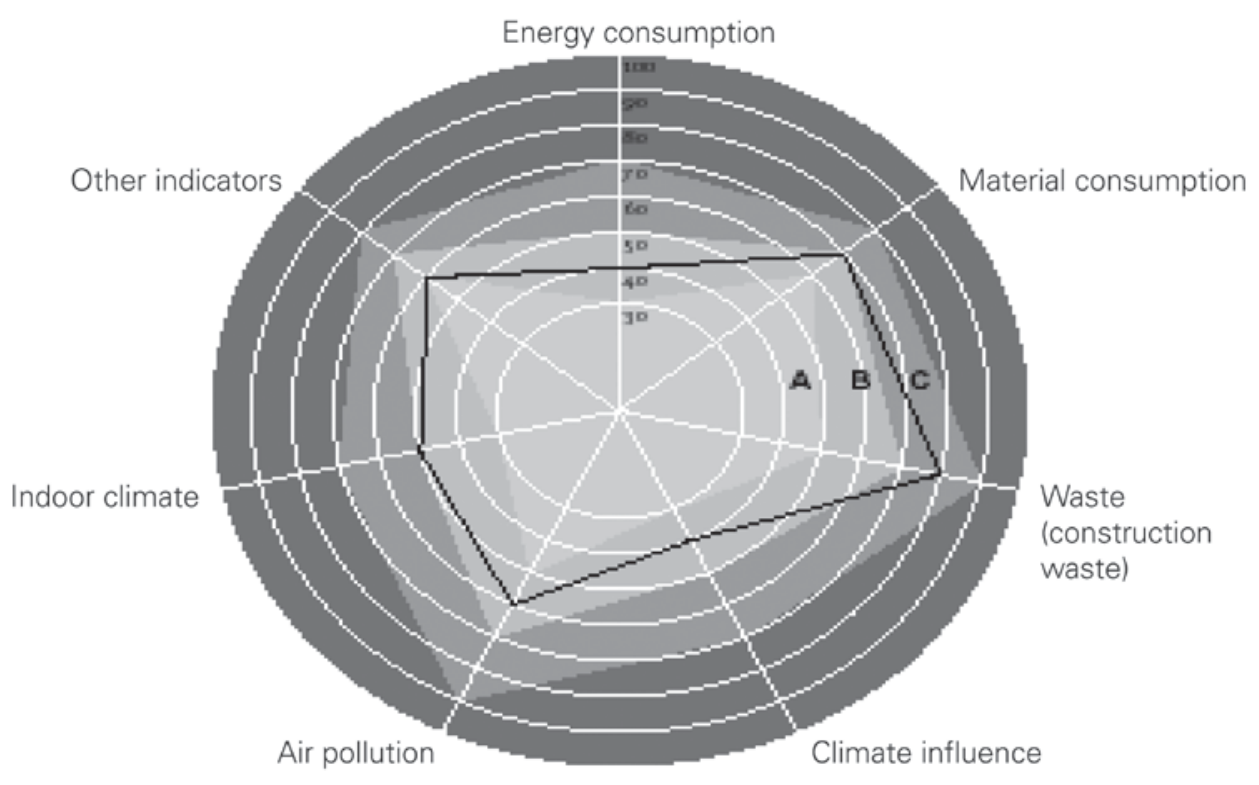

_ Enviromental profile for DR City

\section{Indoor climate}

\section{Indoor climate factors}

Indoor climate is a compound field, which is highly depending on both the shape and the operation of the building and the activities within the building. The indoor climate is also important to both the physical and the psychical health \& safety. Even if there are many possibilities to measure various aspects of the indoor climate, it is also a field, in which health related and psychological conditions are of substantial importance, and the influences from the indoor climate is seen different by different persons. So it is a strongly multidisciplinary field, in which are included professional aspects related to architecture, engineering and medical fields.

The indoor climate can be divided into the following six subareas:

- Thermal conditions, including air temperatures, radiation temperatures, air velocity and air humidity

- Air quality, including the content of pollutions such as dust, air humidity, gasses, vapours and uncomfortable smell

- Static electricity, including charging of persons
9.3 - Light conditions, including luminosity, luminous colour, contrasts and reflexes

- Sound conditions, including volume and spread of frequency

- Ionizing radiation, including the radon concentration

There is a comprehensive specialized knowledge within all these fields. There is no FM function which in own organisation is able to have enough competence to seriously handle indoor climate problems. However, it is important that the FM employees with tasks of importance to other employees' indoor climate have sufficient knowledge about the indoor climate, so they in their daily work can take reasonable considerations to ensure a good indoor climate in the buildings, which they handle, and know when they need to involve experts. It is outside the scope of this book to communicate knowledge about indoor climate which is sufficient to fulfil this. The following pages will only serve as an introduction to the field.

The Danish Health \& Safety Authority has published a number of notifications and other publications about indoor climate and has a special website about indoor climate, cf. references. The Danish Building Research Institute has also 
published many publications about indoor climate, including an Indoor Climate Handbook, which is a very comprehensive and widely covering work of reference (Valbjørn et al., 2000).

Even if there is comprehensive literature et cetera, it is important that you in connection with indoor climate problems include experts to a suitable extent. Especially in cases where an extraordinary extent of indoor climate symptoms is seen, you must immediately seek help from experts. As further described in the following, indoor climate symptoms can be a sign of health threatening conditions, and there are fatal indoor climate related diseases. In particular due to the health related importance of the indoor climate problems one must in some cases not only involve technical expertise, but medical expertise as well.

\section{Indoor climate symptoms and diseases}

Some typical indoor climate symptoms are:

- Irritation of eyes, nose, throat (mucosa irritation)

- Redden and dryness of the skin and unspecified allergic reactions

- Headache or feeling af heaviness in the head

- Unnatural tiredness or trouble with the concentration

- Nausea and dizziness

Such symptoms do not in themselves point in a certain direction and may be caused by others things than the indoor climate. When a larger group of persons, who are in the same building, show identical symptoms, it is however probably that factors of the indoor climate can be an important reason. The probability is much increased if the symptoms disappear for many of the persons, when they for shorter or longer time are outside the building.

In 1983 the World Health Organisation defined at pathological picture termed Sick Building Syndrome (SBS) or the indoor climate disease. The pathological picture is defined by an increased frequency of the above mentioned symptoms among the persons, who are in a certain building (Skov et al., 1989).

There are many inconclusive questions in relation to the origin and which influences can cause which symptoms. Even in buildings in which many persons show symptoms, the cause is rarely that the measured influences are above demands and standards. Therefore the symptoms must be caused by a series of influences which in themselves are acceptable, but which in a whole cause the observed symptoms. Hence it must be aspired to reduce each unwanted influence as much as possible.

Another more definitely defined disease is the legionnaire's disease. It is a lunge disease caused by infection by the bacteria legionella. Usually the infection is spread from building technical installations through the indoor climate. As such one can consider the legionnaire's disease as an indoor climate related disease. In spite of its name, which can give associations to old days and exotic places, it is a new disease, which at first were seen in 1976 during the American Veteran Organisation's congress (American Legion - hence the name), where 29 persons died. The bacteria grew in a cooling tower close to the air intake for the building's airconditioning system, and it was spread through the ventilation air (Valbjørn et al., 2000).

In Denmark are annually recorded approx. 100 cases of the legionaire's disease, of which 10-20 $\%$ terminal. One of the most publically known examples was a number of deaths at the Danish National Hospital (Rigshospitalet), where the infection was spread through the water in showers. The fatal consequences were enhanced by the fact, that the persons in question were sick beforehand and had a weakened immune response. Succeeding examinations of the hot water system at the municipality Hvidovre in the outskirts of Copenhagen have shown that 22 of 24 systems were infected by legionella - and of those 13 were above the danger line.

Besides the above mentioned a number of other diseases may be related to or be aggravated by the indoor climate. It is especially bronchial infections and diseases such as asthma, bronchitis and sinusitis.

\section{How to ensure a healthy indoor climate}

It cannot be determined in general which demands you must make for a good indoor climate. It depends to a great extent to the activities which will take place in a building or part of a building. The healthy indoor climate must not only be defined negatively, as demands of minimising influences which are experienced to be unpleasant, or which can be pathogenic, but also that the indoor climate contributes to positive sense impressions, for instance in connection with light conditions and acoustics.

In checklist 9.B is shown a number of conditions which must be taken under considerations

Legionnaire's disease

sease 


\section{Checklist 9.B:The Healthy Indoor Climate}

(source: Valbjørn et al., 2000)

The location of the buildings and external influences

- Suitable location in relation to traffic (noise and pollution)

- Ground without pollutions or ensure seal against ground

- Special considerations to traffic noise (noise proof windows, noise insulating external air valves)

- Draining of ground and secure removal of rainwater

- No garage or polluting activity in the building

\section{Shape of the building and arrangement}

- High ceilings and high room volume per person

- 1-3 person rooms in office buildings

- Efficient soundproofing between rooms

- Suitable reverberation period

- Polluting processes in separate rooms

- Separate smoking rooms

- Windows which can be and may be opened

- Sufficient daylight admittance and view to all workplaces

- Efficient and easy operation of sunshade

- Individual and adjustable lighting

- Lighting without blind and reflexes, adapted to screen work

- No lowered ceilings (lowered ceilings collect dust)

- A few open shelves and stores for papers

- Furnishing and space of floors and other surfaces can be cleaned

- Good space to maintain technical installations

Building construction and materials

- Dry materials and cleaning of the building during the construction

- Large eaves with gutters outside the boundaries of the outer wall

- Sufficient ventilation of constructions (attics, roof slope and cellars)

- A high degree of heat accumulation

- Durable and hard-wearing materials with a low degassing and smell

- Indoor climate marked materials

- A few furry materials

- Cleaning friendly materials

- Antistatic floorings

- Floorings adapted to the use strain

- Semi hard floors in education and day care institutions

- Surface protected mineral wool products

\section{Ventilation systems and installations}

- Natural ventilation (with a number of preconditions)
- Mechanical ventilation separated from heating

- Sufficient ventilation at least corresponding to the Construction Regulations' demands and the Nordic Committee to Construction Regulations' instruction

- Individual control of temperature and air quality

- Low background noise level

- Clean ventilation components with a low degassing

- Ventilation systems which are simple to adjust and regulate to the operational staff

- Point exhaust of processes, for instance photocopying and cooker hoods in kitchens

- Air intakes situated where the air is pure and without risk of intake of air from return

- No air moistening with open water surfaces

- No recirculation of air from other rooms

- No short circuit in the rooms of the injected air for the exhaust air

- External air valves with good spread and mixing of the air

\section{Heating systems}

- Individual regulation of the temperature

- Radiators or convectors situated so cold air downfall is prevented

- Radiators or convectors situated so they are easy to clean

\section{Devices}

- Frequently used laser printers situated outside rooms with workplaces

- Exhaust at photocopying machines

- No combustion without exhaust to free air

- No evaporators

\section{Operation and maintenance}

- Fast reaction and follow-up on complaints of building and indoor climate

- Fast and efficient remedy of water damages

- Maintenance of building fabric (especially roofs, gutters and downpipes)

- Education of operational staff in servicing of buildings and systems

- Maintenance plan to ventilation system with emphasis on cleaning

- Operational strategy to ventilation adapted to the building's present use

- Forced ventilation after occupation and during and after renovation

- Efficient cleaning programme with periodic comprehensive cleaning 
to ensure a healthy indoor climate. It must be noted that not all conditions in the checklist are relevant to all buildings, and that there can be others considerations which in each case must be considered important.

A main part of the preconditions to a good indoor climate are determined during briefing and design of new buildings. In section 9.1 about construction and environment is discussed how environmental considerations can be included in the planning of new building for instance with the use of environmentally friendly design. The Danish Health \& Safety Authority has further developed a similar method termed health \& safety correct design which is described on the authority's website, and in which indoor climate is also included as an important element.

The indoor climate correct good building ensures (Valbjørn et al., 2000):

- that the indoor climate can be adapted to the activities in the building

- that the adaptation and the adjustment of the indoor climate is simple, easy and intelligible

- that there is possibility to individual regulation of the indoor climate

- that minor interruptions and inconvenient use do not imply a reduction in the quality of the indoor climate

- that the indoor climate can be kept within health secure and comfortable limits during the life time of the building

In relation to building materials there are in Denmark and Norway established arrangements to indoor climate marking based on uniform principles. It is a volunteer arrangement, which in Denmark is handled by Danish Indoor Climate Marking. The marking is based on controlling degassing of gasses and vapours and particle liberation from building materials. Approval is determined in relation to product standards, and there are such for ceiling and wall systems, internal doors and mobile walls, and also a number of floorings.

In relation with existing buildings three elements to ensure a healthy indoor climate are pointed out:

1. Well planned and efficient implemented operation and maintenance of the building throughout the entire life time of the building

2. A well-functioning environment and health \& safety work which continuously aim at improving health \& safety and indoor climate.

3. Fast implementation and professional accomplishment of indoor climate investigations when there is suspicion of acute indoor climate problems.

In connection with operation and maintenance is referred to this in checklist 9.B and the discussion of this topic in other chapters. However, it must be pointed out that many indoor climate problems are owed to lack of maintenance. For instance, leakages of roofs can lead to very unpleasant indoor climate problems derived from fungal attacks et cetera. Many municipalities have throughout the years been forced to close down and renovate badly maintained schools due to attack from mould fungus.

In relation with the environment and security work it is important that the company has a well-functioning system to capture and react on the possible complaints of the indoor climate from the staff. Furthermore can be mentioned that implementation of mandatory workplace assessments can be an important a tool to improve the working environment, including the indoor climate conditions. All companies with employees are under obligations to implement workplace assessments based on a EU directions from 1989.

The contents of workplace assessment depend on the company's character, and there is in principle freedom of method. As a minimum a workplace assessment must include the following four elements:

- Mapping

- Assessment

- Prioritised plan of action

- Follow-up

There are demands of written documentation of workplace assessment. Furthermore a continuous updating at changes of the work of importance to the health \& safety must take place, including in case of rearrangement of the production or the organisation of the work, or if new knowledge or experiences arise, for instance from a work accident. Anyhow the workplace assessment must as a minimum be updated every third year.

With basis in the former experiences in Denmark there is rather wide agreement that workplace assessment has initiated several activities in the workplaces than any other tool as to the
Health \& safety correct design

Workplace assessment

Indoor climate marking 


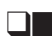

Typical symptoms

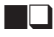

Indoor climate investigations

Desks health \& safety work. It has contributed to make the health \& safety organisation more visible, because it has something concrete to work with. A number of companies have had a number of problems solved, which had been known in the company for a long time. However, many companies also had difficulties to tackle the heavy problems, including problems which demands large investments in technology (Hasle \& Thoft, 2000).

According to an investigation from the Danish Health \& Safety Authority including approx. 800 health $\&$ safety representatives a workplace assessment was in approx. $80 \%$ of the cases drawn up, and indoor climate is one of the topics which have been considered. However, in many cases it is not binding results, as many companies have not prepared or initiated plans of action to solve the problems in connection with a poor indoor climate.

As to indoor climate investigations it is as mentioned on the previous page crucial to include the proper expertise. An indoor climate investigation is often implemented in phases, which in the simple form can include the following four phases:

1. Awareness phase, in which symptoms with the employees attached are recorded, for instance through interviews and questionnaires

2. Measurement phase, in which measurings are made which are analysed, documented and estimated

3. Action phase, in which the necessary improvements of the indoor climate are made based on the conclusions from the previous phases and as agreed with the employees affected

4. Evaluation phase, in which the employees' experiences of changes of the indoor climate are collected and evaluated

In the Indoor Climate Handbook the process is described of a gradual mapping of indoor climate problems divided in nine steps (Valbjørn et al., 2000).

\subsection{Work Involving Computer Screens}

The IT development and the fast spread of computers to almost all office workplaces has implied considerable changes of the demands to office design and the design of workplaces. A number of new work related symptoms have arisen and also diseases due to the work with computer screens and the use of computer mouse et cetera.

The typical symptoms are motor apparatus trouble in the upper part of the body (especially the shoulders, the back of the neck, elbows and wrists), eye trouble, headache, tiredness, nausea and various psychical diseases. In an investigation of the CAD workers' work impacts and health there were reported of trouble with the wrist, shoulder and back of the neck at the same level as it is known from slaughterhouse workers and sewers (Jensen, 1997).

The major problems are in case of long time with monotonous work, where the body is exposed to the same strains almost the entire work day, day after day. This is often the case to CAD workers. So the organisation of the work is very important, as variation and possibility to breaks during the work day to a great extent contribute to limit the extent of monotonous strains.

The design of the equipment is also important, and the possibility to easily and quickly be able to change work position, for instance from sitting to standing position, is an important part to limit monotonous influences. The development with new ways of working, where each workplace is increasingly used by several employees also makes increased demands to the furniture. It must easily and quickly be adjusted so it fits the various employees' height and preferences.

Tables and chairs with adjustable height and good adaptation possibilities have become common equipment in many office workplaces. The size of desks is also an important factor, to achieve the most optimal visual distance to computer screens, and that the employees are not bothered by a table legs or a table frame under the tabletop. The demands to room for the legs are seen in figure 9.6.

The placing of desks and computer screens are important, both in connection with avoiding dimming and reflexes, but also in relation to the communication with colleagues. The design of the room lighting and the possibilities to control the daylight with sunshade or the like has also importance to the arrangement possibilities.

The regulations to the shape and design of workplaces with computer screens are under detailed rules and regulations in Denmark deter- 


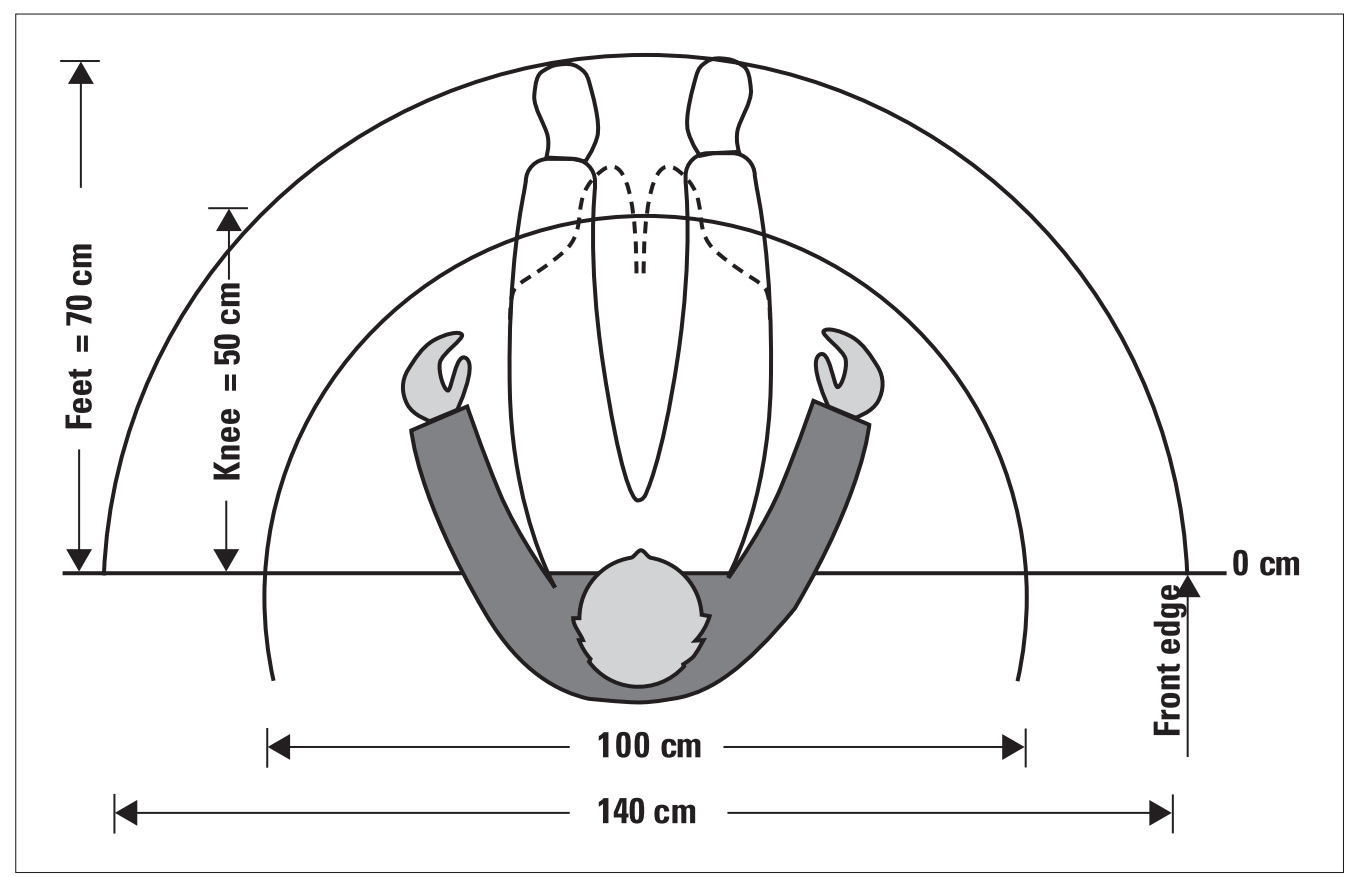

Figure 9.6

Demands at sitting

work - seen from

above (source: The

Danish Health \&

Safety Authority,

1998b)

mined by The Danish Health \& Safety Authority - mostly with the basis in EU directions. Even if the basis is the same in each EU country, it is the impression that the regulations are carried out and enforced quite differently in various countries and more strictly in the Nordic countries compared to some other EU countries.

The continued development within the IT field still implies changes of the conditions to the work with computer screens. The use of computer mouse as supplement to the keyboard at first meant a more efficient way of working, but it also implied health \& safety problems which are rectified by means of better ergonomic design of the computer mouse and introduction of alternatives such as track-balls and pens. Furthermore are systems with speech recognition under heavy development.

Introduction of wireless keyboard and mouse give more freedom in relation to work positions, and annoying cables are also removed from the desk. The use of flat screen limits the generation of heat and electro magnetic radiation to the advantage of the health \& safety, and the depth of desks can be reduced and through this imply a more efficient space utilisation. 
Literature

The Danish Health \& Safety Authority: Bekendtgørelse om arbejde ved skærmterminaler. (Regulation on work at screen terminals). AT-regulation number 1108 from December $12^{\text {th }}, 1992 \mathrm{a}$.

The Danish Health \& Safety Authority: Bekendtgørelse om faste arbejdssteders indretning. (Regulation on the design of permanent workplaces). AT-regulation number 1163 from December $16^{\text {th }}$, 1992b.

The Danish Health \& Safety Authority: Arbejdsrum på faste arbejdssteder (Work rooms on permanent workplaces). AT-regulation number 1.01. from January $12^{\text {th }}, 1996 \mathrm{a}$.

The Danish Health \& Safety Authority: Planlægning af faste arbejdssteders indretning. (Planning of the design of permanent workplaces). AT-regulation number 1.01 from December $13^{\text {th }}, 1996 \mathrm{~b}$.

The Danish Health \& Safety Authority: Arbejde ved skærmterminaler. (Work at screen terminals). AT-instruction number 4.0.1. from December $1^{\text {st }}, 1996 \mathrm{c}$.

The Danish Health \& Safety Authority: Arbejdspladsvurdering. (Workplace assessment). ATinstruction number 4.00. from November 1 ${ }^{\text {st }}$, 1998a.

The Danish Health \& Safety Authority: Inventar på faste arbejssteder. (Equipment in permanent workplaces). AT-instruction number 1.01. from December 14th $1999 \mathrm{~b}$.

The Danish Health \& Safety Authority: Metoder til sikkerhedsorganisationen - indeklima og arbejdspladsvurdering. (Methods for the security organisation - indoor climate and workplace assessment). Leaflet, 2000.

$\underline{B P S}$ : Håndbog i miljørigtig projektering. (Handbook of environmentally friendly design). Publication 121, binding 1 and 2, 1997.

$\underline{B P S}$ : Miljørigtig projektering - bygherrevejledning. (Environmentally friendly design - building owner guidance). Publication 129, 1999.

$\underline{B P S}$ : Inspirationsguide til miljørigtig projektering. (Inspiration guide for environmentally friendly design). Publication 134, 2000.

Jørn Dinesen \& Klaus Hansen: Vurdering og deklarering af en bygnings miljømæssige egenskaber. (Assessment and declaration of a building's environmental properties). Prepared for the Ministry of Housing and Urban Affairs by the Danish Building Research Institute, 1999.

Brian Edwards (editor): Green Buildings Pay. E \& FN Spon, 1998.

Peter Hasle \& Eva Thoft: Arbejdspladsvurdering i fremtiden - Motivation og kvalitet (Workplace assessment in the future - Motivation and quality). Article in LOKE number 2, May 2000.

Bente Rona Jensen: Redegørelse om risikofaktorer ved skærmarbejde, herunder arbejde med EDB-mus. (Statement on risk factors at screen work, including work with computer mouse). Note. The Danish Health \& Safety Institute, 1997.

O.M. Jensen: Grønt regnskab for boligområder. (Green account for housing areas). SBI-rapport 303. The Danish Building Research Institute, 1999.

E.H. Petersen: Database og opgørelsesværktøj for bygningsdeles og bygningers miljøparametre. (Data base and making up tool for building section's and buildings' environment parameters). SBI-report 275. The Danish Building Research Institute, 1998.

E.H. Petersen, H. Krogh, J. Dinesen: Miljødata for udvalgte bygningsdele. (Environment data for selected building sections). SBI-report 296. The Danish Building Research Institute, 1998.

Peter Skov, Ole Valbjørn, Finn Gyntelberg and DISG: Rådhusundersøgelsen - Indeklima i kontorer. (The town hall investigation - Indoor climate in offices). The Health \& Safety Fund, 1989. 
Ole Valbjørn, Susse Laustsen, John Høwisch, Ove Nielsen and Peter A. Nielsen (ed.): Indeklimahåndbogen. (The Indoor Climate Handbook). SBI-direction 196, $2^{\text {nd }}$ edition. The Danish Building Research Institute, 2000.

The Eco Profile Committee: Økoprofil for bygg. (Eco Profile for Buildings). Final report. GRIP Center. Oslo, 1996.

\section{Websites}

BRE (British Research Establishment)

www.bre.co.uk

Danish Building Research Institute.

www.sbi.dk

Data base on city ecology

www.byokologi.dk

DFM.

www.dfm-net.dk

DFM-benchmarking

www.dfm-key.dk

The Danish Association of Energy and Environment.

www.ffem.dk

The Danish Energy Agency.

www.ens.dk

The Danish Energy Information ...

www.energioplysningen.dk

The Danish Environment Marking Secretary

www.ecolabel.dk

The Danish Health \& Safety Authority.

www.at.dk

The Danish Health \& Safety Authority

"Health \& Safety in Offices"

www.kontor.at.dk

The Danish Health \& Safety Authority

The Danish Health \& Safety Institute.

www.indeklima.at.dk

The Danish National Environmental

Research Institute,

www.ami.dk

www.dmu.dk

The Danish Technological Institute.

www.teknologisk.dk

The Ministry for Environment and Energy.

www.bm.dk

The National Agency of Environmental Protection

www.mst.dk 


\section{FM in Denmark and Internationally Chapter 10}

FM in Denmark. . . . . . . . . . . . . . . 186

DFM .................................... 186

DFM-benchmarking ........................ 187

FM Internationally . . . . . . . . . . . . . . . . . . 188

IFMA. . . . . . . . . . . . . . . . . . . . . . . . . . . 188

EuroFM. . . . . . . . . . . . . . . . . . . . . 188

NordicFM . . . . . . . . . . . . . . . . . . . . . . . . . . 189

Research in FM. . . . . . . . . . . . . . . . . 190

FM in the Future. . . . . . . . . . . . . . . . . . . . . . 191

Financial resources. . . . . . . . . . . . . . . . . . . . . . . . . . 191

Human resources............................... 192

Physical resources . . . . . . . . . . . . . . . . . . . . . . . . . . 192

Knowledge resources . . . . . . . . . . . . . . . . . . . . . . . . 192

The Added Value of FM . . . . . . . . . . . . . . . . . . . . . . 193

References. . . . . . . . . . . . . . . . . . . . . . . 194 
This last chapter discuss the development of FM as it looks at a general level, i.e. in relation to associations and institutions et cetera, who work with promotion of FM in Denmark and internationally. In chapter 1 this topic is introduced in the section of the development of FM as a discipline, but in this chapter the topic is further discussed, and some suggestions to the future to FM are presented.

The chapter starts with a discussion of FM in Denmark in section 10.1 divided on DFM and DFM-benchmark, and after that follows in section 10.2 a presentation of $\mathbf{F M}$ internationally, where the associations IFMA, EuroFM and NordicFM are mentioned. The development of Research in FM is discussed in section 10.3, and in section 10.4 some suggestions to FM in the future are presented. The chapter is concluded with References.

\subsection{FM in Denmark}

\section{DFM}

DFM (Danish Facilities Management Associalished at a first general meeting March $19^{\text {th }}$ 1991. In advance there had been some briefing sessions, in which the topic FM had been presented from international experiences and examples from some Danish companies, just as the interest of establishing the network had been tested.

The purpose of the network is:

- to develop the subject area FM

- to spread knowledge to the subject area by communicating knowledge

- to promote the correlation between practice, education and research

- to be the connecting link to FM internationally

The network was from the beginning open to company memberships and personal members. Later reduced membership fees for students were introduced. The first year DFM had 25 members out of which 24 were companies. In 2000 it had grown to 119 with 106 companies and in 2007 the total number of members was 192 with 132 companies and 61 personal members out of which 25 were students. As it appears company members are the actual basis of the network.
It is characteristic that DFM is open to all sorts of companies. Hence the members include both companies from the demand side and from the supply side of the FM market, including consultants and other providers of consultancy services. The spread is fairly even to the two sides of the FM market. Hence $60 \%$ of the members represent companies who themselves handle and inquire for FM services, whereas $15 \%$ are consultants and yet other $22 \%$ are providers of other services. The remaining $3 \%$ of the members consist of institutions et cetera.

Hence DFM is neither a procurement organisation nor a trade association, which must handle the member companies' commercial interests as demanders and providers. In Norway there is an example of a procurement organisation within FM called NfN (Norsk Nettvært for Næringseiendom). In Great Britain there is a similar trade association of providers - Facilities Management Association (FMA).

In organising members from both demanders and providers DFM appears as a professional oriented association which without consideration to special interests aim a developing FM as a profession. This broadness of the association is of course both a weakness and force. The weakness is primarily a rather weak financial foundation, as the companies cannot use the association to handle their fundamental commercial special interests. The force is on the other hand, that DFM network can appear as a professional and neutral association, which only work for the promotion of the profession, including professionalising the practitioners and the market to FM.

The activities of DFM have mainly been arrangement of member meetings, company visits, seminars, conferences and other information activities. From early on DFM has arranged an annual conference - first 1 day and later typically $1 \frac{1}{2}$ day. Until around 2000 DFM produced a written newsletter to the members, but since then it has been replaced by DFM's web-site and news distributed by e-mail. In 2007 DFM started to produce a printed magazine and in 2008 this has been replaced with the collaboration with a Swedish publisher on a Danish version of the magazine Facilities. 
Since 2003 DFM has collaborated with the private Danish foundation BoligfondenKuben about granting an annual FM award.

\section{DFM-benhcmarking}

The interest to implement a project about key indicators was shown at the very first member meeting in DFM network in November 1991. Hence it was decided to start preparing a project with project programme and further clarification of participants and financing. The project was fully financed by the 26 private and public participating companies.

The purpose of the project was to create a common order with concept definitions and structure for the key figure indicators in relation to FM, and establishment of common systematics of handling of the data to this. On basis of such a common order and systematics it would be possible to make meaningful comparisons across companies - benchmarking.

The project was organised with a steering group, a follow-up group and a number of task groups. Throughout the work in the task groups a cost structure with matching definitions was made up and tested with some of the participating companies and processed several times. The result of this is seen in figure 3.4 and chapters 6 and 7. Furthermore a considerable work of defining space terms was made. The result of this is described in section 5.1. Finally the relevant key indicators were defined and a data collection was made concerning the year 1992 with succeeding processing and analysis of key figures.

The result of the project was the publication "Key indicators to property operation for the use of benchmarking" (DFM, 1995), which besides to document the project to the participants also aimed at spreading the knowledge partly to key indicators and benchmarking, and partly to a general introduction to FM. A report reserved for the participants in the project included the detailed key indicators and analyses.

On basis of the key indicator project it was decided to start a further work with concurrently collecting FM key indicators. To ease data collection and processing and to improve the analyse possibilities this assumed considerable development efforts in connection with IT tools. By financial and legal causes it was decided to establish a special association for this purpose still with close connections to DFM network.
So at a first general meeting on January $31^{\text {st }}$ 1996 an association called DFM key indicators (DFM-nøgletal) was established as an association with limited liability with the following objects clause:

"The purpose of the association is to collect process and publish key figures within property activity and related activities, so that these key figures can form the basis of possible benchmarking et cetera.

The association must be run as a non-profit business to create use-value and added value to members and to the society as a whole. The association furthermore support the work and development of DFM network.

From the further decision of the board the association can also arrange education, seminars and network co-operation within the use of key figures in the property sector".

One of the first tasks of the association was to develop the necessary IT tools. They included at first an electronic questionnaire which was send to the members on a floppy disc prior to the annual data collection. The electronic questionnaire included contextual information of definitions and other guidance on screen. Key indicators were furthermore immediately calculated and shown on the screen after input of the necessary data. The electronic questionnaire furthermore included a number of control and validation facilities to ensure the quality of the typed in data.

Secondly an analysis software programme with a data base was developed with a number of standard reports with different choice of parameters, so that key indicators data could be analysed crosswise. Besides standard reports which can produce diagrams with mean values as shown in section 3.4 and chapters 6 and 7, there are also standard reports for detailed statistical analyses with calculation of median, standard deviation, spread and also minimum and maximum values.

In 2007 the system was changed to a fully webbased system where the members can deliver data on-line, and when a sufficient number of data has been delivered for a year, the system is open for the members to use the analysis tools to extract the data that they are interested in, for instance comparisons of own data with the average of properties from all members that meet
Purpose 
the specified criteria. This has replaced the annual publication of a huge report of more than 300 pages with all the data analyses. In 2008 the association has changed its name to DFMbenchmarking.

DFM-benchmarking has private and public companies as members. All members can deliver data to the annual collection of key indicators. There are no personal members. From the start there were 30 members and this has until 2007 increased to 54. Approximately $20 \mathrm{mem}$ bers deliver data each year and for the year 2006 they delivered data for 1.349 estates covering 6,4 million $\mathrm{m}^{2}$.

\subsection{FM Internationally}

IFMA

IFMA (International Facility Mbanagement Association) was established in USA in 1980 as a professional association for personal members. IFMA has an ambition of representing the FM profession all over the world, and IFMA has at present more than 19.000 members in 60 countries. The members are organised in more than 125 national or regional chapters, of which the main part is in USA and Canada. In Europe IFMA have 11 national chapters, in Austria, Belgium, the Czech Republic, Finland, France, The Netherlands, Italy, Luxembourg, Sweden, Schweiz, and Spain.

To become an ordinary member of IFMA one must work professionally with FM or as instructor of FM with your primary field of responsibility in relation to supervise, provide or teach within at least two of the following activities:

- Long-term planning of facilities (strategic planning)

- Annual planning of facilities (tactical planning)
- Financial planning and budgeting of facilities

- Acquisition and/or sale of property

- Internal space planning, specifying and establishment of workplaces and space management

- Architectural design and planning

- Environment, health and security

- Engineer work

- New building and/or renovation

- Maintenance and operation management of the physical property

- Company related facility functions (for instance obeying legislation, total quality control, benchmarking, telecommunication, acquisition, security, catering, printing works/copying, mail, furniture and equipment recording and maintenance) and administrative facility functions

Employees involved in sales and marketing in consultant companies, producers, distributors, providers and distributors of facility related products and services cannot be ordinary members of IFMA, but they can through their company gain associated membership. Companies can furthermore become a kind of support members (Corporate Sustaining Membership). Students can furthermore become junior members.

IFMA is a comprehensive information company. Each year IFMA accomplish a large conference with a matching exhibition in North America (World Workplace - North America). In Europe IFMA together with EuroFM arrange the annual European FM Conference (EFMC) with more than 500 participants.

IFMA also arranges a number of courses and seminars, publish and sell technical books and publish a newsletter and the periodical FMJ Facility Management Journal. Since 1992 IFMA has had a certification system, where single persons with a certain experience of FM after finishing an exam may achieve certification of being certified FM with the right to name himself CFM (Certified Facilities Manager).

IFMA has furthermore its own research department, which accomplish investigations of FM related topics, including for instance benchmarking and outsourcing. Research and development of more technical kind are accomplished in co-operation with specialised institutes.

\section{EuroFM}

EuroFM is another type of association than IFMA. Unlike IFMA, which organise personal members, EuroFM is a proper network association, who organises national FM associations and also education and research institutions. Hence individual persons cannot be members of EuroFM without representing an association or an institution. Companies can like with IFMA become support members (Corporate Associates).

In 2007 EuroFM had in total 79 members. Of those were 28 national FM associations, 37 were research and educational institutions and 
14 were corporation. Among the members are 11 European IFMA chapters.

As it appears from the member composition education and research institutions are strongly represented, and the co-operation in these fields are a substantial part of EuroFM's activities.

EuroFM was established in 1987, where an informal co-operation was started primarily between associations and individuals in Great Britain and The Netherlands. The formal establishment was in December 1993, where EuroFM was formed with statutes according to Dutch legislation. The founders were Centre for Facilities Management (CFM - UK), a Dutch association (NEFMA - today FMN) and DFM.

EuroFM arranged its own conferences in 1990 and 1992, after which collaboration was started with IFMA. Hence EuroFM and IFMA in cooperation arranged an annual conference with matching exhibition in Europe in the period 1994 to 2000 . After 3 years break the collaboration was started again with the conference in 2004 in Copenhagen. The conference now involves a business conference, a research symposium and a student poster competition, and from 2006 a number of FM awards have been granted at the gala dinner during the conference. In June 2008 EFMC took place in Manchester and in June 2009 EFMC is arranged in Amsterdam.

The continuous cooperation in EuroFM is made in a number of project groups and as concrete cooperation projects. Hence there are accomplished a number of research projects in cooperation between member institutions, including several with subsidies from EU, for instance a comprehensive project about workplaces with a number of industrial companies. Education and health service have been general themes in EuroFM. In 2000 EuroFM established a socalled "Business Forum" in preparation of strengthening the cooperation between EuroFM's members and private companies.

EuroFM is organised with 3 Network Groups for Practice, Education and Research, respectively. One of the association's objectives is to become "the hub of FM research". A high quality of research output will be generated through the close cooperation and interaction between the network groups. Each member organisation is able to belong to any one (or two or three) of the Network Groups, according to their interest and/or resource.
The Practice Network Group plays a leading role in bringing together the national organisations representing practitioners in FM to form a European body of FM professionals. One of the most prominent objectives is to improve the performance of business/companies and help organisations to be more productive, effective and creative as a result of continuous professional developments within the EuroFM network.

The Research Network Group has most members from research organisations and educational institutions, however input and close co-operation with practice are vital for an adequate and high quality research and development work. The members of the Research Network Group collaborate in cross-national research projects within FM. The Research Network Group is also responsible for an annual research symposium organised as part of EFMC in parallel with a business conference. Research and development projects are typically focusing on the integration of all support activities, in time, with the core business. FM Research is about organisational processes (maintenance and operation of the FM service) and about the development and change of facilities as an integrated service.

The Education Network Group consists of educators, students and people with an educational interest in academic tuition as well as training for FM practice. Apart from organising forums which will be held at the annual EuroFM conference, the Education Network Group will develop various projects.

The Corporate Associates form a special category. They are seen as supporters of the EuroFM common interest and they are supposed to play an active role in the activities and projects of the different groups. They represent commercial organisations and are dealing in products for the field of FM and are operating preferably on a national or international level.

In 2006 EuroFM launched European Insight (eFMi), an electronic based magazine, about developments in FM. EuroFM joins forces with 23 publications partners to produce the publication. eFMi is distributed all over Europe, the USA, Australia and Japan four times a year.

\section{NordicFM}

The Nordic FM network, NordicFM, was started as a project with financial support from NICE (Nordic Innovation Centre) under the
Practice

Research

Education

Corporate Associates

Network Groups

NordicFM 
Metamorphose

FM Chalmers
Nordic Council of Ministers from 2003-6 with the purpose to develop the collaboration in relation to FM among the five Nordic countries: Denmark, Norway, Sweden, Finland and Iceland. During this period several working parties were active and the results for instance included a guideline for SLA's and an overview of FM education in the Nordic countries.

After the project period it was decided to continue the collaboration as a network with FM associations in the 5 countries as the central members. The steering board has a member from each of the 5 countries and from the beginning each country became responsible to chair a joint development project concerning one of the following 5 topics:

A. Promote a common understanding of FM, including the need for definitions and measuring tools for services.

B. Implement new standards for Facilities Management in the Nordic countries including certification criteria.

C. Develop a Nordic platform for benchmarking

D. Highlight the added values for the core business provided by Facilities Management

E. Formulate common requirements for FM education and training

\subsection{Research in FM}

The following gives an overview of the general development of FM research in some countries in Northern Europe. The information was collected as part of developing FM research in Denmark.

The most experienced research environment is in the UK where a Centre for FM (CFM-UK) was founded in Glasgow around 1990, but it was moved to Salford University in Manchester around year 2000 by Professor Keith Alexander, who has been heading the centre since the beginning. Keith Alexander is also former chairman of EuroFM. Several other environments for FM research exist in the UK.

In the Netherlands a Centre for FM (CFM-NL) was established in the late 1990's at the University of Wageningen by Professor Andreas (Dries) van Wagenberg, who is a former member of the EuroFM board.

NTNU (Norwegian Technical and Natural Science University) in Trondheim has since the early 1990's undertaken research related to FM at the Faculty of Architecture and Fine Arts. The leading person has been professor Tore Haugen, who is a former chairman of EuroFM's

Research Network Group and today is dean of the faculty at NTNU. From 2002 to 2006 Tore

Haugen was leading the ambitious project Metamorphose aiming at developing a research based education and competence environment in relation to Property and FM, and one result was planned to be the establishment of a Centre for Property and FM. However, the recent development has been instead to establish a Gemini Centre for Sustainable Architecture and Property in collaboration between NTNU and the Norwegian research institution SINTEF, and this centre has research in Property Development and Facilities Management as one of three main fields. NTNU has based on the Metamorphoses project started master educations both as candidate and postgraduate programmes.

In Sweden the main centre for FM research is at Chalmers Technical University in Gotenburg where FM Chalmers was established as a strategic action in 1996 as collaboration between three schools: Architecture, Civil Engineering, and Technology Management and Economics. The leading person is Jan Bröchner, chair professor of organization of construction/facilities management, who is a former board member of EuroFM and present member of EuroFM's research group. Before retiring in 2005, Professor Jan-Åke Granath at the Department of Architecture led FM Chalmers jointly with Jan Bröchner.

In Finland research on FM was started in the early 1990's at Helsinki University of Technology with Professor Kari I. Leväinen at the Institute of Real Estate Studies as the leading person. Later research initiatives have spread also to other research organisations within Helsinki University of Technology, for example Facility Services Research group under the Institute of Construction Economics and Management, as well as in other universities and VTT, National Research Center. Kari I. Leväinen has now retired and a new professor in Real Estate and FM is expected to appointed in 2008.

The Technical University of Denmark (DTU) in 2003 decided to introduce FM as a new subject in research and teaching in the strategy plan for the Civil Engineering department. I was appointed as associate professor in 2005 to develop the subject. From the start of 2008 the FM subject has been part of a new department of Manage- 
ment Engineering at DTU and at the same time a new research centre for FM (CFM-DK) has been established with financial support from the private Danish foundation Realdania over a 5 year period. I am heading the research centre.

\section{FM in the Future}

10.4

Around the change of the millennium there was a lot of discussion in general about what the future would bring. Hence, at EuroFM's and IFMA's conference in Glasgow, June 2000, the future of FM was a prominent topic. It was the theme of the finishing plenum session, and there were several presentations which focused on this topic. There was a surprising consensus that the future to FM is called Resource Management. One of the most interesting presentations was held by Professor Bev Nutt, University College London, and he defined FM in the following way (Nutt, 2000):

"At a national level, the strategic objective of Facilities Management is to provide appropriate infrastructure and logistic support to business public endeavours of all kind and across all sectors. At a local level, its objective is the effective management of facility resources and services to provide shells of support to organisations, their operations, their working groups, project teams and individuals, and to their suppliers and customers. So overall, the primary function of FM is resource management, at both strategic and operational level of support".

In continuation of this Bev Nutt defined the four most important types of resources to FM as:

- Financial resources - business

- Human resources - people

- Physical resources - property

- Information resources - knowledge

In the following is described some important trends, which are expected to influence FM in the future in connection with each of the mentioned resource types. The section is concluded with a discussion of the added value of FM.

\section{Financial resources}

In the UK there was during the 1990 'ies a strong development with private financing of public buildings and infrastructure. A number of legislation initiatives have been accomplished to promote cooperation between the public and private sector in UK, for instance under the term PFI (Private Finance Initiative). More general this type of collaboration is now known as PPP (Public-Private Partnerships). They are often package deals, where private consortiums look after financing, performance and operation of public constructions. The public partner can perhaps after some years take over the building at further agreed financial terms.

In relation to FM one of the most interesting aspects of such models is, that the operational expenses will be heavily included before the start of such projects. Operational considerations and life cycle costs hence are more important than at usual construction projects.

Since the change of the millennium this development of PPP has spread to several other European countries. There are for instance a strong development of PPP in Germany and Italy. In the Nordic countries Iceland has been the forerunner. In Denmark the first building project developed as part of a PPP agreement was a school which opened in 2006. Since a few other PPP projects has been launched in Denmark but this development is only at an early stage.

Alongside the development of PPP there has also been a development of other types of Public-Private partnerships, for instance operational partnerships and service partnerships. The book FM Best Practice in the Nordic Countries (Jensen et al, 2008) includes cases on PPP in Iceland, the first PPP project in Denmark, a Danish example of PPP-light, where the finance element is not included, and an example of operational partnerships from the municipality of Copenhagen.

The market for FM is still under fast development with increasing outsourcing and among the providers a lot of mergers and takeovers are happening. A consequence of this development is that due diligence has become an important activity and a new field of competence development within FM. The national markets are becoming increasingly consolidated with a few dominating providers, which in some countries reduces the competition particular concerning TFM. With the also still increasing globalisation we also see that more and more multinational companies coordinates there FM on the demand side internationally and make cross-border partnerships with providers, who also operate internationally.

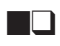

Ressource

Management

Types of resources 


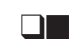

Municipalities

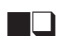

Focus on the employees

Sustainability

The internet

Office = hotel

\section{Human resources}

It must be expected that the companies' efforts of attracting and sustaining employees in the future will be increased. It is not only due to the present situation with descending recruitment to the labour market due to a reduced number of youngsters each year in most European countries. Still more companies are increasingly dependent on the staffs' creative and innovative skills. Hence the competition of attracting and sustaining the best employees with the right qualifications will be intensified.

This development means in relation to FM, that conditions and wellbeing of the employees in the core companies in the future will come even more in focus. It is important to create the best work conditions to the core employees, so they can use their creative and innovative skills most possible. Attractive surroundings must be created and adapted to the specific work culture in each company and each department. The employees will demand involvement in planning and decision processes and possibility to individual influence on the work environment. The FM function must be able to enter into a constructive dialogue with the core employees and ensure the involvement, and at the same time meet an efficient operation of properties and services. In FM research this development is reflected in an increasing interest in the usability of workplaces.

\section{Physical resources}

Compared to the above mentioned development the tendencies are expected to become more teleworking and the use of virtual offices will be increased. This means that the use of the company's properties will be changed. More employees will live far away and will only visit the company's shared facilities periodically. On the other hand the employees will in these periods need to be able to work individually and along with others at any time of the day and the week. Furthermore they will need to be able to stay overnight and to eat close to the workplace

This will imply that the traditional office facilities to a greater extent will become hotel and conference centres with possibilities to work individually, to be coached, to have informal meetings, brainstorming, and project work in teams, seminars, education, lectures and social activities. There must be a high level of services throughout the day. There will be focus on short response times and fast provision of services.
Prices of services will probably become differentiated after needs to the speed of supply.

In Denmark a huge backlog in maintenance of public buildings has been one of the reasons for an increasing interest in FM among municipalities. In connection with a structural reform implementing from the start of 2007, which reduced the number of municipalities from 278 til 97, many of the municipalities has established central property units. DFM in 2006-7 carried out a development project with the participation of 16 of the biggest municipalities in Denmark about how to organise the property related functions in municipalities based on a FM concept. The book FM Best Practice in the Nordic Countries (Jensen et al, 2008) includes cases on the organisation of FM in the municipalities in Copenhagen, Denmark and Malmö, Sweden. In Norway there is a similar focus on the maintenance condition of public buildings.

The topic of sustainability is becoming still more important within FM. Buildings are a major consumer of energy both in the construction phase and during operation, and with the increased awareness of the global climate changes it is necessary to reduce energy consumption and the emission of $\mathrm{CO}^{2}$. The political objectives in this area can only be met with an improved energy performance of buildings.

\section{Knowledge resources}

The most important tendency in relation with use of knowledge will probably attach itself to the possibilities to exchange of knowledge which the IT development and not at least the internet give, including the use of wireless technology. There has been much talk about e-commerce, but so far the use of this in relation to FM has until now been modest. However, in the future it must be expected that the use of e-commerce with FM between companies will be comprehensive with considerable consequences of supplies without mediation between providers and user companies and across borders.

Improved technology for long-range supervision and central coordination of property operation and services across properties will give new possibilities of combinations of economies of scale and local presence. Cheap technology for simultaneous picture and sound communication will also give new possibilities to use of specialists for here and now solutions of operational problems. 
However, the most important development in knowledge resources is the increasing development in education and research in FM. New educations in relation to the field of FM is introduced in more and more European countries on bachelor level and increasingly also on master level in some countries. The research symposium during EFMC2008 in Manchester is the $7^{\text {th }}$ annual EuroFM research symposium and also in June 2008 the CIB W070 arranged an international research symposium on FM and Maintenance in Edinburgh. So the development of new knowledge and the production of candidates specialised in FM is growing very fast. FM is increasingly becoming a professional discipline in its own right with a distinct body of knowledge.

\section{The Added Value of FM}

In chapter 2 the topic of value creation was introduced and the development shows, that the added value of FM is becoming increasingly important, both among practitioners and researchers. As mentioned earlier NordicFM has a project with the title: "Highlight the added values for the core business provided by Facilities Management" as one of its first 5 project and in May $2008 \mathrm{a} \mathrm{PhD}$ project on the Added Value of Real Estate was accepted at the Helsinki University in Finland. This is an expression of an increasing understanding, that FM cannot develop as a profession and industry with main focus on cost reduction. FM has also to provide something which creates positive and qualitative better effects on the core business.

The importance of this development is immense and must not be underrated. While cost reduction can be implemented by general management methods from other fields, adding value needs a much more specific professional knowledge. It cannot either be based on past experiences but it has to build on new knowledge. Research is needed to develop such new knowledge and a strong connection between research and practice is necessary to implement the new knowledge and develop it into practical soluAdded Value tions. 


\section{References}

Literature

$\underline{D F M}$ : Nogletal for ejendomsdrift til brug for Benchmarking. (Key indicators for property operation for the use of Benchmarking). Copenhagen, 1995.

DFM: Facilities Management. Documentation from annual conferences.

EuroFM: Facilities Management - European Practice. Annual publication. Arko Publishers, 1996-2000.

EuroFM/IFMA: Facilities Management. Documentation from annual conferences.

IFMA: Benchmarks 1991. Research Report \#7. International Facility Management Association, 1992.

IFMA: Benchmarks II. Research Report \#13. International Facility Management Association, 1994.

IFMA: Outlook on outsourcing. Press release on the website published December $15^{\text {th }} 1999$.

Per Anker Jensen, Kjeld Nielsen and Susanne Balslev Nielsen: Facilities Management. Best Practice in the Nordic Countries - $\mathbf{3 6}$ cases. Centre for Facilities Management, Technical University of Denmark, 2008.

Bev Nutt \& Peter McLennen: Facilities Management - Risks \& Opportunities. Blackwell Science, 2000.

Websites

CFM-DK

CFM-NL

CFM-UK (Centre of FM, University of Salford)

DFM

DFM key figures

EuroFM

Facility Services Research Group, Helsinki

FM Chalmers

IFMA

NordicFM

NTNU

www.cfm.dtu.dk

www.fmn-vereniging.nl/CFM

intranet.scpm.salford.ac.uk/cfm

www.dfm-net.dk

www.dfm-key.dk

www.eurofm.org

www.cem.tkk.fi/fsr

www.fm.chalmers.se

www.ifma.org

www.nordicfm.org

www.metamorfose.ntnu.no 


\section{Terms and Definitions}

The terms and definitions below include the words, which are emphasised with bold letters in the index. For those words, which are further discussed in the book, a reference to the chapter/section in question is also indicated. In the index there are references to the page, where the words are used - except for the generally used abbreviation FM.

AB92 Abbreviation of the Danish General Conditions for Building and Civil Engineering Works from 1992.

ABC Abbreviation of Activity Based Costing. See section 3.1.

Activity Based Costing (ABC) Term for financial analysis method cf. activity based financial control. See section 3.1.

Activity based financial management

Activity based office

Annual costs

APV

Base rent

BBR

BDA

Benchmarking

Best Practice

BMS

BPR

Building area

Building block
Financial management based on activities instead of organisational structure. See section 3.1.

Office environment designed with facilities for at various activities so that the employees can move around among the facilities depending on the present needs. See section 5.3.

Includes the annual costs calculated from the total life cycle costs in the service life for a building or a building parts. See section 4.3.

Danish abbreviation of workplace assessment. See section 9.3.

The part of the lease which includes the fixed settlement to the lessor. See section 3.2.

Abbreviation of the Danish Building and Housing Register (Bygnings- og boligregistret).

benchmarking. See section 5.1.

Method for achieving improvements in an organisation through systematic comparison with performances in one or several other organisations. At benchmarking you aim to measure yourself to the company, which represents Best Practice. See section 3.4.

Term for the best practice within a field. See section 3.4.

Abbreviation of for Building Management System. See section 8.3.

Abbreviation for Business Process Reengineering. See section 2.4.

Total building area is cf. the Danish Building and Housing Register (BBR) the sum of the area of each storey and area of possible mansard storey, but exclusive area of basements and roof storey. As basis of the size of the storeys is used built-up area. In the area is included areas of gates, air locks et cetera. Areas of open covered terraces, open balconies and open entrances are not included. See section 5.1.

Term for design component which can be used in connection with planning of new ways of working. See section 5.3. 
Building client Term for the legal person who has the responsibility of implementing a construction project. Is for instance used in AB92. Companies who accomplish construction projects in the shape of new building or refurbishment hence act as building client. In FM the function as building operator is often more prevalent than the function as building client. See section 4.4 .

Building installations Includes all installations exclusive installations in ground. DFM-benchmarking divides maintenance expenses for building installations in preventive, corrective and replacement maintenance. See section 6.1.

Building maintenance

Includes maintenance/replacement of each building's building parts (structures, fabric, fit-out, installations, fixtures et cetera). DFM-benchmarking divides building maintenance in external building, internal building and building installations. See section 6.1 .

Building Management System (BMS)

Building operational space (BDA)

Building operator

Built-up area

Business Process Reengineering (BPR)

CAD

CAFM

Capital expenses

Caretaking, monitoring and supervision
Integrated system to control and monitor both the technical supply systems (CTS in Danish) and IBI. See section 8.3.

Space term defined by DFM-benchmarking. To owned and rented out properties defined as the amount of total building space, used roof space and total basement space, all cf. the Danish Building and Housing Register (BBR). To leases the building operation space is defined as lease space with operational obligations. See section 5.1.

Term for the legal person who has the responsibility of the continuous operation of a company or part of a company, which to FM include property operation and services. In FM is included, besides the function as building operator, usually also the function as building client. See section 4.4.

Built-up area is recorded as the ground floor area measured to the outer side of the outer walls. To buildings in which the storeys in relation to area deviate from each other, the area is stated by the largest storey. The area of open, covered terraces, open balconies, and open entrances are not included. On the contrary areas of gates, air locks et cetera are included to the limit, which the building's outer walls states. The area of corridors, carports or annexes, which is a part of the building (outside the building's outer walls and under the same roof) are also included.

Method for implementing thorough changes in a company for instance by change from function orientation to process orientation. See section 2.4.

Abbreviation for Computer Aided Design. See section 8.2.

Abbreviation for Computer Aided Facilities Management. See section 8.2 .

Includes expenses for business and depreciation of property investments.

Caretaking are simple activities, often maintenance related, which are performed then and there, for instance adjustment, oiling and cleaning, and which must ensure that the use of the property is not harmed besides from tear and wear. Monitoring is activities which aim at adaptation of the supply of for instance heating, ventilation and cooling for various uses related needs. Supervision are activities which consist in keeping an eye with the maintenance of the normal situation and to observe and react on deviations, for instance by means of CTS systems and alarm signals. DFMbenchmarking divides caretaking, monitoring and supervision in wages for operational staff, materials, tools and machinery costs, and also service contracts on technical installations like lifts. See section 6.4. 
Cell office Term for an office for one or a few employees. See section 5.3.

Change In relation to buildings, change means rebuilding and/or improvement of a building and is from a financial point of view regarded as an investment.

Churn Moving of employees and functions to other locations internally in a company's properties. See section 5.2.

Churn rate Is defined by DFM-benchmarking as number of internal moves of staff during a year compared to the total number of employees. See section 5.2.

Circulation area

The floor area in corridors, lobbies, stairways, lifts et cetera. To stairways the entire room is included, inclusive horizontal projection of the staircase, to each storey, and to lifts the floor area is included to each storey. See section 5.1.

Cleaning Includes activities and services which aim at maintaining an acceptable hygienic quality level. DFM-benchmarking divides cleaning into external, internal, window polishing, mat and linen service and service articles. Expenses for cleaning are including wages for own cleaning staff, costs for materials and machinery, but are exclusive own work management and administration. See section 6.3.

Cleaning area Amount of floor area, which are included in cleaning minimum every second week to all buildings on the property or to share of a lease. See section 5.1.

Competitive bidding

Computer Aided Design (CAD)

Computer Aided Facilities Management (CAFM)

Construction

Contracting-out

Core function

\section{Corporate Real Estate Management} (CREM)

\section{Corrective maintenance}

Cosourcing
Term from the construction trade for the action in during which bids from a number of competing contractors is send in concurrently, and bidding prices et cetera is read out in the presence of the bidders. Competitive bidding must be accomplished in accordance with the Danish act of competitive bidding for public building and civil engineering works, if bids are obtained from more than three bidders. EU's directive for public procurement stipulates special resolutions to EU tender at fixed threshold values. See section 2.2.

IT system for preparation and handling of drafts. See section 8.2.

IT system primarily for handling of draft related information in connection with FM. See section 8.2.

Includes establishment of property at new building or changes.

Total outsourcing of services - often all operative FM functions - in a contract with one provider. See section 2.2.

A function in a company which opposite to support functions is estimated as primary in relation to the company's earnings. See section 1.1.

Management of Real Estate owned and used by an organisation. See section 4.1 .

Maintenance which is made to remedy acute damage or failure. See section 6.1.

Cooperation types, in which a strategic alliance is made in relation to handling and development of services. The responsibility of services is kept in the company, but the performance of the operative functions is handled by service providers based on agreed ways of settlement and goals for mutual development. See section 2.2. 
CTS Danish abbreviation for Central Condition Control and Monitoring of technical supply systems in a building. See section 8.3.

Discounting Reversed calculation of interest, which is used in connection with calclation of NPV. See section 4.3.

Downsizing/rightsizing Organisational adaptation process where a company analyses work processes and functions in order to clarify which functions they want to be kept in-house and which should be outsourced. See section 2.2.

Drainage According to DFM-benchmarking expenses for waste disposal and drainage are included in utilities. Drainage expenses typically include drainage taxes. See section 6.2.

Energy management Activities aiming at reducing energy and water consumption in buildings. See section 9.2.

Energy Energy supply is divided in heating, electricity and water. DFM-benchmarking operates with energy expenses inclusive non-refundable energy expenses. See section 6.2 .

Environmental management

General term for a number of activities, which aim at achieving overview of the company's environmentally conditions, to define an environment policy to the company and to create continuous environmental improvements. See section 9.2.

EU procurement Public procurement, which is open for providers from the entire EU according to EU directive, with advertising in the EU tidings. See section 2.2 .

External building The part of a building which especially is influenced by climate conditions, i.e. at least on of the factors direct sunlight, large temperature variations, temperature passages through 0 degrees or direct ground contact. DFM-benchmarking divides the maintenance expenses for external building in preventive, corrective and replacement maintenance. See section 6.1 .

External cleaning DFM-benchmarking divides external cleaning in ground and external building. See section 6.3 .

Facilities Management (FM)

The integration of processes within an organisation to maintain and develop the agreed services, which support and improve the effectiveness of the primary processes" (EN15221-1, 2006). See section 1.1.

Facilities Management Information System (FMIS)

Facility Management (FM)

Fixed property expenses
A general term for various IT systems to be used in FM. See section 8.2.

Synonym to Facilities Management. See section 1.1.

Includes expenses that are independent of the operation and mostly mandatory. DFM-benchmarking divides fixed property expenses into taxes and building insurance. In accordance with DFM-benchmarking's definition these property expenses does not include capital expenses. See section 6.5 .

FM Abbreviation for Facilities Management (mainly an English spelling) or Facility Management (mainly an American spelling).

FMIS Abbreviation for Facilities Management Information System. See section 8.2 . 
Focus group Groups consisting of selected customer representatives, who are used as sparring partners in development of services. See section 2.4.

Furniture maintenance

General operation

Green accounts

Gross/net ratio

Gross area

Gross storey area

Ground maintenance

Ground operational area

Ground Includes the part of a property which is not covered by buildings. Ground

Group divided office

Heated area

Helpdesk

Home office

IBI

ICT

Improvement can include covered spaces, planted spaces and natural resort.

According to DFM-benchmarking this includes maintenance/replacement of building furniture and equipment and lock systems. See section 6.1.

Includes the parts of the property operation which are not naturally included in maintenance, utilities, cleaning and fixed property expenses. DFM benchmarking divides common operation in caretaking, monitoring and supervision, movable insurance, external consultants and management and administration. To expenses which cover more properties, only the relative part of the expense is included in key indicator calculations. See section 6.4.

Documentation method in connection with environmental management. Much polluting companies are in Denmark bound to send in green accounts to the environmental authorities, but many companies voluntarily make out a green account. See section 9.2.

Measure for space efficiency. See section 5.1.

The area measured from and until outer sides of outer walls of a storey. The amount of the gross area for all storeys in a building gives the building's gross storey area. See section 5.1.

The gross storey area is defined as the total area of a storey in a building including outer walls. See section 5.1.

Includes maintenance / replacement of small buildings, building parts, ground surfaces, planting, and installations in ground and on / above terrain and terrain equipment on ground and installations. See section 6.1.

Term defined by DFM-benchmarking. Includes the total area of the site deducted the built-up area. See section 5.1.

Office environment designed with an eye on supporting the cooperation in groups. See section 5.3.

By DFM-benchmarking defined as the areas directly or indirectly heated to a minimum of $18^{\circ}$ centigrade to all buildings on the property or to share of a lease. See section 5.1.

Contacts centre for inquiries from customers to a FM function. See section 2.4 .

Office workplace in a private home. See section 5.3.

Abbreviation for Intelligent Building Installations. See section 8.3.

Abbreviation for Information and Communication Technology. See chapter 8 .

A change of state which brings a property (or part of a property) to a new "quality level as built". Improvement can be done through modernisation, refurbishment and extension. Improvements can be caused by changed function demands due to user/owner change or implementation of new technology in the building. New authority demands can also be a reason for improvements. See section 3.3. 
Indoor climate Term for the environment in a building of importance for the staff comfort. See chapter 9 .

Information and Communication Technology (ICT)

Information Technology (IT)

In-house Means company internal. Usually in connection with handling of services by own employees instead of external provider. See section 2.2 .

Insourcing Internal reorganisation and rationalisation of services with the basis in the company's own employees, where it usually concerns a process, where external consultants implement an analysis of the functions in question and participate as process consultants in implementation of changes inhouse. See section 2.2 .

Intelligent building The intelligence in a building is the intelligence of technology to supply of efficient surroundings, which fulfil the present demands and can be adapted to the future changes and the not known demands, both to business related and technological development. See section 8.3.

Intelligent Building Installations (IBI)

Internal building The part of a building which is not chosen af external building, and which is especially influenced by use factors in relation to the use of the building. DFM-benchmarking divides maintenance expenses for internal building in preventive, corrective and replacement maintenance. See section 6.1 .

Internal cleaning Includes cleaning of internal building. DFM-benchmarking divides internal cleaning in daily/periodical cleaning, which is done daily or is planned with certain intervals, major cleaning, which includes a more thorough cleaning than the daily/periodically, and extra/specific cleaning, which includes carpet cleaning, ceiling cleaning, curtain washing, cleaning after arrangements, telephone and computer cleaning et cetera. See section 6.3.

Internal rent Settlement of expenses for lease internally in a company or a group. See section 3.2 .

IT Abbreviation for Information Technology. See chapter 8.

IT-FM A special field of FM with relation to IT. Usually used in connection with outsourcing of the operation of a company's computer systems. See section 8.1 .

Key indicator A key indicator is a relative figure expressed as a fraction or a proportional, which can be used as indicator for performance or similar. A key indicator must in all cases be seen in relation to another figure. Key indicators should focus the attention on the essentially and give real signals of change. Are we doing the right things? And are we doing them well? See section 3.4.

Indicator for the use of performance measurement in connection with services. See section 2.3.

KPI Abbreviation for Key Performance Indicator. See section 2.3. 
LCA Abbreviation for Life Cycle Assessment. See section 9.1.

LCC Abbreviation for Life Cycle Costing. See section 4.3.

Learning organisation An organisation which encourage to new ways of thinking, where the employees learn by own and others experiences, and learn how to learn together. See section 2.4.

Life Cycle Assessment (LCA)

Assessment of environmental influences from raw material extraction to demolition and deposit of a product, a building or a building part. Also named "from cradle to grave". See section 9.1.

Life Cycle Costing (LCC)

The total sum of expenses during the Service life of a building or a building part, including the initial investment and the operational cost. Normally LCC are calculated as net present value. LCC can also be recalculated to annual costs. See section 4.3.

Maintenance Maintenance is the part of the property operation which aims at maintenance of the property's performance. From "quality level as built" cf. new building, the quality level is determined "maintenance as planned". This quality level is politically decided and is normally declining throughout the building's service life. DFM-benchmarking divides maintenance in preventive, corrective and replacement maintenance. See section 6.1 .

Maintenance expenses According to DFM-benchmarking expenses for maintenance include cost to workmen and materials, but excluding planning, management and supervision. Maintenance expenses are divided in ground, building external, building internal, installations and furniture. See section 6.1.

Management and administration

Corresponding to DFM-benchmarking expenses for management and administration include wages, office expenses, travel expenses et cetera, but not rent. See section 6.4.

Mat and linen service

Part of cleaning according to DFM-benchmarking. Includes washing of towels and dish towels for use where wash basins are installed, folding sinks and kitchen sinks, cleaning of floor mats and washing or cleaning of curtains, wall textiles and shower curtains. See section 6.3.

Move Physical transfer of employees and functions in a company or relocation of the entire company. See section 5.2.

Net area Space term specific parts of a storey of building are not included compared to gross area. See section 5.1.

Net Present Value (NPV) Value of future expenses recalculated to present-day level through a discounting with a fixed interest rate. Is used at calculation of LCC. See section 4.3.

New building Establishment of a building at a property. When a property's buildings and ground is made and handed over, "quality level as built" is determined.

New office Another term for new ways of working. See chapter 5.

New Ways of Working Common term for the new developments in office work influenced by implementation of new types of ICT particular in relation to knowledge work, including larger mobility in relation to the workplace, partly as teleworking, partly as activity based office environments and shared workplaces. See chapter 5.3.

NPV (Net Present Value) Abbreviation for Net Present Value. See section 4.3. 
Abbreviation for operation and maintenance primarily in relation with properties and buildings. In principle a rather untimely term, as maintenance is included as a part of property operation, cf. section 3.3.

Open-plan office Office environment for many employees with a few partitions. See section 5.3.

Operation Includes in this connection primarily operational tasks. Financially is distinguished between operational cost and investments, where operational costs are day to day, whereas investments are long-term investments with possibilities annual depreciation.

Operational tasks The daily operation of properties and support functions aiming at providing the best possible fulfilment of the company's needs in accordance with agreed service levels. See section 1.1.

Outsourcing Term for the process by which a service is changes from being handled inhouse to being handled by external provider company. See section 2.2.

Outtasking As outsourcing with the variation that outtasking relates to a single service, for instance cleaning, whereas outsourcing also can relate to a group of bundled services. See section 2.2.

Owner/user categories

Term in DFM-benchmarking' investigations, in which there is distinguished among three different owner/user categories: Properties which are owned and used by the same company, properties which are owned and rented out, and properties which are leased. See section 3.3.

Partnering/partnership Way of cooperation where a strategic alliance is entered in relation to handling and development of services. The responsibility to services is kept inside the company, whereas the performance of the operational functions is handled by service providers based on agreed ways of settlement and development goals. See section 2.2.

Portfolio In this book a term for the total amount of property and space, which a company own and/or has to its disposal. See section 4.1.

Preventive maintenance

Maintenance which is made before the property's quality is on unsatisfactory level in relation to use, or to prevent consequential damages. See section 6.1.

Property Term for an administrative/financial unit including one or more buildings and the matching grounds.

Property operation Includes all services which are needed so that a property can function satisfactory in the use phase. DFM-benchmarking divides property operation in maintenance, utilities, cleaning, general operation and fixed property expenses. See chapter 6.

Property strategy Term used in this book for handling of a company's long-term interests in relation to its property and space portfolio. See section 4.1 .

Relocation Relocation of a company, or part of a company, from one locality to another locality; often in connection with move to a new building.

Rentable area Term for the space on a storey or a building which can be rented out. What is included in rentable area varies from country to country. See section 5.1. 
Replacement Maintenance which implies a major change in quality, which brings a building (or part of it) up to "quality level as built" cf. new building. The term covers the change of major building parts, for instance the entire roofing, all windows and installation system or substantial parts of it. See section 6.1.

Resource Management

Resourcing

Rightsizing/downsizing

Risk Management

Self managed groups

Service articles

Service Level Agreement (SLA)

Service life

Service Management

Services

Shared area

SLA Abbreviation for Service Level Agreement. See section 2.3.

Space briefing Needs analysis of the necessary net space to hold an organisational unit or a company, and the functional demands for the use of the space in connection with rebuilding projects, internal churns and relocation to leases or as part of the building brief at new building. Results in a space brief. See section 5.1.

Space efficiency Term for the efficiency of space use in a building, typically measured by space key indicators. See section 5.1. 
Space Management

Space standards

Strategic tasks

Structural area

Support function

Tactical tasks

Technical service area

Telework centre

Teleworking

Tender

TFM

Total Facilities Management (TFM)

Total Quality Management (TOM)

TQM

Usable area

User profile
A work field within FM which correlates to analyses of space needs, adaptation and disposal of space, planning and implementation of churns and relocations, and also layout of workplaces. See chapter 5 .

Standard figures - primarily company internal - to space use per function for the use of space allocation. See section 5.1.

Long-term tasks concerning policies and strategies for development of the property portfolio and the support functions in relation to the company's overall strategies and goals and structural changes in the outside world. See section 1.1.

The floor area of the base of walls and not mountable shafts. See section 5.1 .

Function in a company which opposite to the company's core functions, is not estimated to be of importance to the company's earnings, but is seen a support function to the core functions. See section 1.1.

Planning of concrete changes of the property portfolio and support functions, partly with an eye to meet the company's long-term policies and strategies, and partly with an eye to adaptation to other changes in the company, for instance the state of the current market. See section 1.1.

The floor space in various building technical rooms, for instance ventilation rooms, cleaning rooms and shaft rooms. See section 5.1.

A commercial run centre or a satellite office, from where the staff can perform telework. See section 5.3.

Work with the use of modern ICT, where the work is done outside the office where the organisation, to which the employee is attached, has its base. See section 5.3.

Term for the process by which a service is procured to external providers - normally through tender invitations from several competing providers. To public companies EU's directive for public procurement determines regulations to in which cases and how invitation of tenders can be done cf. EU procurement. To Danish state organisations the Ministry of Finance has determined supplementary regulations about invitation of tenders. See section 2.2.

Abbreviation for Total Facilities Management. See section 2.2.

Is used in connection with contracting-out in cases where not just the operational FM functions, but also the tactical and strategic FM functions to some degree are included. See section 2.2.

A management philosophy about continuous improvements of products, processes and services by means of activities which involve the entire company in an integrated effort with the purpose to satisfy customer demands and expectations. See section 2.4.

English abbreviation for Total Quality Management. See section 2.4.

Is by DFM network defines as area space in rooms which are not limited to a certain use. See section 5.1.

Characteristic of types of employees in a company for the use of planning new ways of working. See section 5.3. 
Utilities According to DFM-benchmarking a term, which includes the necessary supply of energy divided in heating, electricity and water, and waste divided in waste disposal and drainage. See section 6.2.

Value analysis Method for quantitative assessment and comparison of projects et cetera, so that both financial and qualitative factors af included in a total assessment. Grading and weighed calculations are typically used. See section 4.7.

Virtual office Term for work which is done "in the field" away from the organisation's office building with mobile equipment. See section 5.3.

Waste disposal According to DFM-benchmarking expenses for waste disposal and drainage are included in utilities. Waste disposal expenses include taxes for waste disposal, wages for own staff, costs for materials, and also chimney sweeping and pest control. See section 6.2.

Window polishing DFM-benchmarking divides window polishing in internal and external window cleaning. See section 6.3 .

Workplace assessment (APV) Tool for improvement of work environment and indoor climate at workplaces. Mandatory in Denmark for companies with a minimum number of employed staff. See section 9.3. 
In the index below is mentioned the page numbers where each entry word can be found in the text. Entry words shown with bold types are also included in the previous Terms and Definitions. Where an entire chapter or section concerns the entry word, and where the entry word can be found on a number of pages one after another, the page interval is shown with hyphen between first and last page number in the series.

A

AB92: $109,195-196$

ABC (Activity Based Costing): 20, 50, 195

Acoustics: 177

Activity Based Costing (ABC): 20, 50, 195

Activity based office: 122, 195, 201

Added value: 45-46, 187, 191, 193

Air quality: 176, 178

Annual costs: 71, 77, 79, 195, 201

Applications Service Provider (ASP): 154-155

APV (Workplace assessment): 179-180, 182, 195, 205

Art: 150

ASP (Applications Service Provider): 154-155

Audit: 32, 170-171

Authorisation: 16, 74, 78

Authority: 34, 105, 113, 123, 176, 179-183, 199

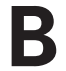

Base Rent: 53, 195

BBR (The Danish Building and Housing Register): 95, 195-196

BDA (Building operational area): 95, 126, 129-134, 137-139, 195-196

Behaviour: 17, 39-40, 51, 53, 59, 117, 121, 133, 170, 173

Benchmarking: 5-7, 20, 22, 32, 35, 38, 42, 44, 49-50, 55-61, 63-70, 85, 91, 95-96, 111, 126-128, 130-132, 134-140, 147, 151, 166, 183, 185, 187-188, 190, 194-203, 205

Best in Class: 22

Best Practice: 5, 7, 22, 24, 46, 47, 58-59, 70, 86, 91, 119 , 123, 191-192, 194-195

BIFM: 17, 38, 40, 47

BMS (Building Management System): 162, 164-165,

195-196

BPR (Building Process Reengineering): 15, 27-29, 38, 43, 79, 81, 94, 195-196

BQA (Building Quality Assessment): 71, 86, 88-89

BRE: $86,91,173,183$

BREEAM: 173,175

Building area: 195

Building block: 122, 195

Building client: 28, 72, 79, 81-82, 109-110, 161, 169, 196

Building codes: 23, 133, 175

Building fabric: 76, 84, 107, 129, 178

Building installations: $84,126,131,196$

Building investment: 83
Building maintenance: 12, 21, 28, 42, 125-127, 129-131, 196

Building Management System (BMS): 162, 164-165, 195-196

Building operational area (BDA): 95, 126, 129-134, 137-139, 195-196

Building operator: 79, 196

Building Quality Assessment (BQA): 71, 86, 88-89

Built-up area: 95, 195-196, 199

Business Process Reengineering (BPR): 15, 27-29, 38, 43, 79, 81, 94, 195-196

C

Cabling: 154, 156

CAD (Computer Aided Design): 153, 155, 157, 159, 161, 180, 196, 197

CAFM (Computer Aided Facilities Management): 17, 20-21, 52, 103, 138, 153-155, 157-163, 166, 196-197

Call Centre: 44, 144

Canteen: 51, 95, 132, 146-147, 203

Capital: 15, 20, 34, 41, 53, 73, 126, 139, 143, 166, 196, 198

Capital expenses: 53, 126, 139, 196, 198

Capitalisation: 77

Caretaking, monitoring and supervision: 51, 125,

137-138, 164, 196, 199

Catering: 45, 141-142, 146-147, 150, 188

Cell office: 114, 122, 197

Centre for Facilities Management (CFM): 5, 7, 17, 24, 47, 70, 91, 123, 166, 188-191, 194

Certification: 17, 88, 91, 167, 171, 188, 190

CFM (Centre for Facilities Management): 5, 7, 17, 24, 47, 70, 91, 123, 166, 188-191, 194

Change: $24,28,31-32,34,39,43,51,60,73,101,104$, $111,113-114,117-121,123,129,139,143-144,146,149$, 155, 163, 165, 175, 180, 189, 191, 196-197, 199-200, 203 Child care centres: 150

Charts of account: 55-56

Churn: 93, 101, 103-108, 111, 197

Churn rate: 111,197

Circulation area: 197

Cleaning: 12 , 14, 20-21, 25, 29, 32, 35-37, 45, 49, 51-52, $55,60,62,66-69,76,78,82,95,102,104-105,109$, $125-128,131,134-138,140,153,157,159,160,172-173$, $178,196-205$

Cleaning area: 95, 197

Cleaning programme: 135,178 
Code of Conduct: 59

Code of Ethics: 9, 18-19

Collective agreement: 32

Competence: 25, 38-40, 51, 81, 158, 176, 190-191

Competitive bidding: 29, 197

Computer: 12, 15, 17, 23, 77, 113, 136, 146, 154-155, 164, 167-168, 170, 180-182, 196-197, 200

Computer Aided Design (CAD): 153, 155, 157, 159, 161, 180, 196-197

Computer Aided Facilities Management (CAFM): 17, 20-21, 52, 103, 138, 153-155, 157-163, 166, 196-197

Construction: $14-15,20,29,32,34-35,44-45,53,56,61$, 71-74, 77, 79-83, 85-86, 88-91, 94, 96, 107, 109-111, 129, 159, 161-162, 166-169, 175, 178-179, 190-192, 196-197 Contract: $12,25,28-32,36,41,52-53,67,71,75,78,90$, 105, 107, 109-110, 112, 127, 135, 137, 139, 158-159, 197

Contracting-out: 25, 29, 31, 197, 204

Copying service: 148

Core business: 9-12, 15, 26, 28, 35, 40, 45-46, 83, 189-190, 193

Core function: 12, 45, 59, 148-149, 164, 197

Corporate Real Estate Management (CREM): 72, 91, 197

Corrective maintenance: 83, 127, 129-131, 197

Cosourcing: 29, 31, 33, 197

Creativity: 114-115, 117

CREM (Corporate Real Estate Management): 72, 91, 197

CTS: 164, 196, 198

Culture: 7, 23, 32, 35, 37, 40-41, 72, 117, 121, 150, 192

Customer/provider relations: 25

\section{D}

Danish Facilities Management Association (DFM): 5-6, 17, 20, 23-24, 47, 49, 57, 60, 62, 65, 67, 70, 76, 85, 93, 95-96, $111-112,120,123,126-128,130-132,134-140,142$, 146-147, 151, 164, 166, 183, 185-189, 192, 194-205 Danish Indoor Climate Marking (DIM): 179

Danish Property Index: 85

Danish Standard: 140, 171

Data base: 155, 157, 159, 182-183, 187

Data communication: $113,154,165$

Data infrastructure: 142, 146-147, 203

Data structure: 68,158

Daylight: 23, 54, 78, 96, 102, 173, 178, 180

Deadlines: 158,172

Delegation: 20, 26, 39

Demand: 10, 20-21, 36, 51, 59, 83, 101, 103, 106, 121, $155,157-158,168,171,186,191-192$

Demolition: 74, 80, 201

Design: 15, 22-23, 33, 40-41, 44, 57, 72, 77, 81, 89, 93-94, 98-99, 101, 107, 109, 111, 113-118, 120-123, 129, 157, 161-162, 168-170, 173, 175, 179-182, 188, 195-197
DFM: 5-6, 17, 20, 23-24, 47, 49, 57, 60, 62, 65, 67, 70, 76, $85,93,95-96,111-112,120,123,126-128,130-132$, 134-140, 142, 146-147, 151, 164, 166, 183, 185-189, 192, 194-205

DFM-benchmarking: 5-6, 20, 49, 57, 60, 65, 67, 70, 85, 95, $111,126-128,130-132,134-140,147,151,166,183,185$, 188, 195-203, 205

Digital: 28, 45, 75, 91, 153, 157-163, 166, 200

Digital drafts: $75,157,159$

Digitalisation: 159

DIM (Danish Indoor Climate Marking): 179

Discounting: 20, 77, 198, 201

Downsizing: 29, 198, 203

Draft: 76, 101, 123, 157, 159, 163, 197

Drainage: 76, 125, 127, 129, 131-134, 175, 198, 205

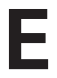

Eco profile: 175,183

Education: 5-7, 14, 16-17, 20, 32, 39, 116, 143, 145, 148, 155, 158, 178, 186-190, 192

Elderly care: 34

Electricity: 54, 76, 84, 105, 109, 117, 131-133, 137, 156, 172, 174, 176, 198, 205

E-mail: 5, 113, 154, 156, 186

EMAS: $167,171,173$

Employment: 20, 32-34

Energy: 9, 12, 15, 21, 23, 41, 61, 76, 81, 83, 85, 125, $132-133,138,140,142,164,167-168,170,172-175,183$, 192, 198, 205

Energy management: 15, 41, 133, 138, 167-168, 173, 198 Engagement: 42-43

Environmentally friendly design: 15, 169-170, 173, 179, 182

Environmental management: 15, 167, 170-171, 173, 175, 198-199

Ergonomics: 16, 180-181

Ethical rules: 17, 50, 59

EU: 14, 23, 25, 29, 33-34, 36, 47, 111, 149, 168, 171, 179, 181, 189, 197-198, 204

EU procurement: 29, 36, 111, 198, 204

EuroFM: 5, 17, 24, 38, 47, 70, 91, 123, 166, 185-186, 188-190, 193-194

Europe: 10, 12, 15, 17, 22, 30, 70, 73, 86, 118, 188-190

External building: 107, 125-127, 129-131, 134-135, 196, 198, 200

External cleaning: 125, 134, 198

Extra space: 106

$\mathbf{F}$

Facilities Management (FM): 1-2, 5-7, 10-24, 26-47, 50-70, 72-123, 126-140, 142-151, 154-166, 168-183, 186-205

Facilities Management Information System (FMIS): 21, $163,166,198$ 
Facility Management (FM): 5-7, 9-33, 36-41, 43-47, 49, 70, 72-73, 75, 79, 81-83, 86, 94-95, 113, 119, 123, 142, 146-148, 153-155, 157-158, 163-164, 166, 168, 176, 185-200, 203-204

Financial control: 50-52, 55-56, 59-61, 88, 195

Fixed property expenses: $63-64,125-126,137,139$, 198-199, 202

FMIS (Facilities Management Information System): 21, 163, 166, 198

Focus group: 44, 199

Form of cooperation: 30

Fringe benefit: 150

Functional demands: 37, 203

Functionality: 11, 86, 157, 158

Furniture: 33, 46, 51, 54, 101, 105, 111-113, 115-116, 119, $121,125-127,132,134-135,138,148-149,155,180,188$, 199,201

Furniture maintenance: 57, 132, 149, 199

Gardener: 42, 127, 135

GBC (Green Building Challenge): 175

General operation: 63, 125-126, 137, 199, 202

Generalist:

Global: 9, 13, 15, 118, 175, 192

Green accounts: 15, 21, 167-168, 171, 199

Green Building Challenge (GBC): 175

Gross area: 54, 98, 199, 201

Gross/net ratio: 21, 54, 96, 98, 102, 199

Gross storey area: 95, 199

Ground: 60, 75, 90, 95, 98, 101, 114, 120, 125-127, 131,

133-135, 139, 175, 178, 196, 198-199, 201

Ground maintenance: 125, 127, 135, 199

Ground operational area: 95, 199

Group divided office: 122,199

Guarding: 88, 141-143

\section{H}

Hardware: 148, 154, 158

Health: 9, 14, 16, 20-21, 23, 84, 89, 110, 150, 168-183, 188-189

Health \& safety: 9, 21, 23, 110, 168, 176, 179-181

Health \& safety organisation: 180

Heated area: 95, 199

Heating: 45, 54, 61, 76, 78, 84, 95, 105, 109, 131-133, 137, 164, 168, 172-174, 178, 196, 198, 205

Heat insulation: 15, 66, 132, 133, 168, 173

Helpdesk: 44, 45, 138, 144, 148, 162, 163, 199

Home office: 15, 199

Hospital: 45, 177

Hotel: 52, 73, 149, 150, 192
IBI (Intelligent Building Installations): 164-165, 196, 199-200

ICT (Information and Communication Technology): 5, 20, 76, 78, 94, 153-154, 162, 199- 201, 204

IFMA: 9, 11, 17-19, 24, 33, 47, 70, 91, 96, 111, 123, 166 , 185-186, 188-189, 194

Image: $21,37,72,81,130,144,168,171$

Improvement: 40, 44, 58-59, 197, 199, 205

Indoor climate investigations: 179,180

Indoor climate marking: 179

Indoor climate: $16,38,46,81,86,98,123,137,164-165$, 167-168, 175-180, 182, 200, 205

Information and Communication Technology (ICT): 5, 20, 76, 78, 94, 153-154, 162, 199- 201, 204

Information Technology (IT): 7, 9-10, 15-16, 21, 38, 41, 43-46, 53, 60, 75, 78, 82-83, 90, 99, 102, 111-114, 116-117, 119, 121-122, 131, 133, 138, 146-149, 153-166, 180-181, $187,192,197-198,200$

In-house: 20, 25, 29, 31, 34-35, 42, 107, 110-111, 126, 131, 142, 144, 146-148, 150, 198, 200, 202-203

Insourcing: 29, 31, 33, 36, 200

INSTA 800: 136

Institutionalisation: $16-17$

Insurance: 39, 71-72, 75, 85, 88-90, 94, 109, 111-112, 125, $137-139,143,149,156,198-199$

Integrated workplace strategy: 117

Intelligent building: 164, 200

Intelligent Client Function: 35

Intelligent Building Installations (IBI): 164-165, 196, 199-200

Interaction: 10, 39, 93, 115, 117, 120-122, 189

Internal building: 125-126, 130-131, 135, 196, 200

Internal cleaning: 125, 134-136, 140, 200

Internal market: $15,20,29,35,45,50-51$

Internal rent: 20, 46, 49-55, 101, 153, 157, 160-161, 200

Internet: 15, 59, 113, 149-150, 154, 156, 163, 192

Investment analysis: 72, 79

ISO 9001: 37,171

ISO 14001: 171

IT (Information Technology): 7, 9-10, 15-16, 21, 38, 41, 43-46, 53, 60, 75, 78, 82-83, 90, 99, 102, 111-114, 116-117, $119,121-122,131,133,138,146-149,153-166,180-181$, 187, 192, 197-198, 200

IT-FM: 200

IT tools: 9, 45, 162, 163, 187

\section{K}

Key indicator: 60, 66-68, 98, 187, 199, 200

Key Performance Indicators (KPI): 20, 37, 200

Knowledge sharing: 17, 58, 60, 115, 119, 121

Knowledge work: 113, 117, 201

KPI (Key Performance Indicators): 20, 37, 200 
$\mathbf{L}$

LCA (Life Cycle Assessment): 169, 201

LCC (Life Cycle Costing): 20, 77, 79, 80, 91, 201, 203

Learning organisation: 43, 201

Lease: 71-78, 80, 85, 90, 93-94, 98, 101-102, 105, 116, $126,139,148-149,154,159,195-197,199-200$

Legal: 25-26, 33-34, 59, 75, 83, 85, 95, 98, 105, 109, 187, 196

Legionnaire's disease: 177

Legislation: 14, 21, 33, 34, 40, 41, 50, 75, 84, 88-89, 94, 99, 133, 168, 188, 189, 191

Lessor: 52, 64, 65, 74, 78, 95, 105, 159, 195

Library: 122, 148

Life Cycle Assessment (LCA): 169, 201

Life Cycle Costing (LCC): 20, 77, 79, 80, 91, 201, 203

Light: 78, 90, 129, 131, 134-135, 142, 172, 176-177, 191

Lighting: 20, 127, 131, 133-136, 164, 172, 178, 180

Line organisation: $12,26,27,50,51$

Localisation: 72

Loyalty: 35

\section{M}

Maintenance: 12, 21, 28, 32-33, 40-42, 44, 49-54, 56, 61-69, 71-73, 76-79, 82-86, 88, 93-94, 101, 107, 109, $125-138,140,143,146,149,161-164,178-179,188-189$, 192-193, 196-203

Maintenance expenses: 49, 61, 63-64, 68, 69, 85, 125-127, 129, 130, 131, 143, 196, 198, 200-201

Maintenance system: 44

Management and administration: 125, 134, 137-139, 197, 199, 201

Management discipline: 16, 20, 27, 38

Management philosophy: 20, 26, 43, 203-204

Marketing: 14, 26, 47, 158, 188

Mat and linen service: 125, 134, 137, 197, 201

Media: 5, 14, 28, 45, 91, 117, 148, 154, 165

Mobile equipment: 115, 116, 117, 121, 205

Mobile phone: 112

Monopoly: 34

Motivate: 40

Move: 28, 81, 98, 101, 103-104, 107, 111-113, 115, 118, 145, 153, 155-156, 168, 195, 201-202

Municipal: 34, 76, 78, 132-134

\section{$\mathbf{N}$}

Net area: $54,95,100,201$

Net Present Value (NPV): 77, 198, 201, 202

New building: 15, 54, 74, 77, 79, 80-83, 85-86, 95, 98-99, $118,133,143,161-162,167,169-170,179,188,196-197$, 201-203

New Office: 94, 98, 114, 123, 175

New Ways of Working: 15, 27, 40, 81, 93-94, 114-123, 154, 180, 195, 201, 204

Non-discrimination: 34
NordicFM: 5, 185, 186, 189, 193, 194

NPV (Net Present Value): 77, 198, 201, 202

O\&M (Operation \& Maintenance): 153, 162, 163, 164, 202

Object orientation: 157

Office environment: 9, 16, 114-115, 119, 122, 195, 199, 202

Office hotel: 52

Office work: 14-15, 94, 111, 113-115, 118, 154, 168, 201 Office workplace: 9, 16, 93, 96, 113, 120, 199

Open-plan office: 114,202

Operation: $5-7,10-12,14-15,18,20-23,30,34,51-52$, $55-57,62-63,65,67-68,74,76-77,82-83,85-86,88,90$, $95,110-113,125-140,142-144,146-148,151,154-155$, $161-162,164,172,175-176,178-179,187-189,191-192$, 194, 196, 198-203

Operational staff: 76, 137-138, 178, 196

Operational tasks: 11, 27, 82, 138, 162, 202

Organisational tools: 9,20

Outsourcing: 9, 11-14, 20-21, 24-31, 33-36, 42, 45, 47, 55, $70,73,79,144,154,188,191,194,197,200,202-203$

Outtasking: 27, 29, 33, 202

Owner/user categories: 202

Own production: 34,133

Parking: 74-76, 78, 95, 127

Partnering/partnership: 31-33, 202

Periodical: 130, 135, 136, 188, 200

Personnel management: 38

Plants: 127, 133, 164

Portfolio: 11, 20, 40, 46, 71-73, 75, 139, 202, 204

Post: 12, 20, 38, 45, 51, 56, 102, 141-142, 144-145, 203

Post service: 38, 56, 144-146, 203

Prequalification: 34

Preventive maintenance: $82,127,129-131,202$

Proactive: 38

Productivity: 37, 45, 46, 116, 120, 168

Professionalisation: 17

Profitability: 42, 43, 50

Profit centre: 27,51

Project management: 50, 81

Property: 5-7, 11, 14, 20-21, 26, 28, 33, 40, 46, 49-54, 56-58, 60-64, 66-68, 71-80, 82-86, 90, 94-95, 99, 101, 107, $117,119-120,125-144,151,157,161,163,169-170,173$, $175,187-188,190-192,194,196-199$, 201-204

Property administration: 51-53, 62, 117

Property operation: 5, 14, 56, 77, 83, 85-86, 125-126, 137-140, 142-143, 151, 161, 175, 187, 192, 194, 196, 199, 201-203

Property owner: 90, 163

Property strategy: $73,84,202$

Purchase: 44, 50, 163, 172-173 
Qualifications: 14, 17, 19, 25-26, 37-39, 138, 164, 192

Quality control: 26, 37-38, 43, 47, 82, 188

$\mathbf{R}$

Radiation: 16, 176, 181

Rationalisation: 28, 36, 45, 63, 102, 200, 203

Reactive: 38

Real estate: 51, 73-75, 79, 85, 94, 119

Rearrangement: 81, 179

Reception: 14, 51, 56, 102, 112, 132, 141-144, 148, 203

Relocation: 28, 44, 72, 74, 79, 81, 93, 102-104, 106-107, $111,113,146,156,166,201-203$

Rentable area: 96, 202

Renting out: 96, 101

Replacement: 15, 62-63, 83, 85, 90, 107, 127, 129-132, 196, 198-201, 203

Research: 5-6, 17, 24, 44, 70, 77, 86, 91, 98, 115, 123, 170, 173, 175-176, 182-183, 185-186, 188-194

Resource Management: 191, 203

Resourcing: 29, 31, 36, 203

Rightsizing/downsizing: 29

Risk analysis: 41, 81, 143

Risk Management: 20, 41, 71-72, 88, 138, 139, 143, 203

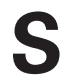

Salary: 16, 34

Sale and lease back: 73

SBS (Sick Building Syndrome): 177

Scanning: 102, 145, 148, 159

Security: 12, 32, 35, 51, 56, 72, 88, 131, 138, 141-143,

146, 158, 164, 179, 182, 188, 200, 203

Selection: 7, 34, 36, 39, 53, 59, 67, 86, 102, 112-113, 146-147

Self managed groups: 20, 42-43, 203

Service articles: 197, 203

Service Level Agreement (SLA): 20, 30, 36, 41, 190, 203

Service level: 32, 35-38, 51, 66, 143-145, 147, 203

Service life: 77, 91, 195, 201, 203

Service Management: 20, 25-26, 38-39, 47, 203

Serviceability Tools Methods (STM): 88

Services: 5-7, 10-12, 16, 19-22, 25-26, 29-36, 40-41, 43, 45, 47, 49-52, 56-58, 60-61, 64, 68, 81, 86, 126, 134, 139, $140-151,154,164,186,188,190-192,194,196-200$, 202-204

Shared area: 203

Sick Building Syndrome (SBS): 177

Sickness: 46, 127, 143, 168

Sickness leave: 168

SLA (Service Level Agreement): 20, 30, 36, 41, 190, 203

Sociological: 16

Software: 21, 26, 77, 147-148, 154-155, 157-158, 187

Sound: 84, 176, 192

Space allocation: 12, 20, 41, 53, 55, 72, 98-100, 103-104, $121,155,157,161,204$
Space brief: 99, 101-103, 106-107, 110, 120, 203

Space briefing: 93, 99, 103, 121, 203

Space efficiency: 96, 199, 203

Space Management: 5, 9, 20-21, 41, 53, 72, 93-123, 138, 154-155, 157, 164, 188, 204

Space standards: $21,52,55,99-101,118,204$

Space use: 41, 96, 98, 203-204

Space utilisation: 20-21, 96, 103, 181

Specification: 83, 99, 110, 142, 158, 161

Sport facilities: 16,150

Sprinkler system: 89, 131

Static electricity: 176

STM (Serviceability Tools Methods): 88

Strategic planning: 5, 9, 20, 28, 72, 94, 138, 162, 188

Strategic tasks: 11, 27, 204

Structural area: 204

Subject area: $17,38,45,186$

Sunshade: 129, 132, 173, 178, 180

Supply chain: 45

Support function: 26, 45, 148, 204

Sustainable development: 15

Symptoms: 167, 177, 180

T

Tactical tasks: 11, 13, 27, 51, 204

Tax: 14, 41, 50, 94, 133, 146, 150

Team: 38, 39-40, 43, 115, 118, 122, 169

Technical conditions: 88

Technical service area: 204

Telecommunication: 113-116, 144, 146-148, 153-166, 188, 200

Telephone exchange: 12, 14, 45, 51, 56, 141-144, 148, 203

Telework centre: 204

Teleworking: 114-116, 192, 201, 204

Tender: 86, 104, 110, 197, 204

Tendering: 29, 34, 36, 82, 109-111, 162, 175

TFM (Total Facilities Management): 24, 29, 31, 191, 204

The Netherlands: 70, 188-189

Threshold value: 34

Top management: 26, 37-38, 51, 53, 60, 73, 79, 81-82, 170

Total Facilities Management (TFM): 24, 29, 31, 191, 204

Total Quality Management (TQM): 25, 38, 43-44, 204

TQM (Total Quality Management): 25, 38, 43-44, 204

Trade: 15, 19, 32, 58, 90, 94, 107, 109-110, 172, 186, 197

Trade association: 186

Training: 42, 189-190

Transfer of Undertakings: 33

Transport: 90, 109, 145, 175

Travel: 90, 138, 149-150, 201 
USA: $6,10,17,22,73,115,118,166,188-189$

Usable space: $95-96,102$

User profile: 122,204

Utilities: 56, 62, 67, 76, 125-126, 132, 137, 198-199, 202,

205

V

Value analysis: $71,86-87,205$

Ventilation: 20, 78, 95, 98-99, 109, 131, 137, 164, 168,

173, 177-178, 196, 204

Virtual office: 115,205

\section{W}

Waste disposal: 33, 76, 125, 128, 132-134, 198, 205

Water: 76, 84, 105, 129, 131-134, 138, 142, 172-175,

177-178, 198, 205

Web: 7, 162-163, 166,186-187

Well-being: 150, 168

Window polishing: 36, 125, 134, 136, 197, 205

Work with computer screens: 168, 180-181

Working environment: 179

Workplace: 9, 14-16, 21, 23-24, 42, 47, 55, 91, 93-94, 96, 98-100, 103, 111, 113-117, 119-123, 150, 157, 159-160,

164-165, 173, 179, 180, 182, 188, 190, 192, 195, 199, 201, 205

Workplace assessment (APV): 179-180, 182, 195, 205

Workplace design: 23, 94, 115, 117, 120 